\title{
DEFINIÇÃO DE UNIDADES DE GERENCIAMENTO DO SOLO POR MEIO DA SUA CONDUTIVIDADE ELÉTRICA E VARIÁVEIS FÍSICO-QUÍMICAS
}

\section{CÉSAR NUNES DE CASTRO}

Dissertação apresentada à Escola Superior de Agricultura "Luiz de Queiroz", Universidade de São Paulo, para obtenção do título de Mestre em Agronomia, Área de Concentração:Máquinas Agrícolas.

P I R A C I C A B A

Estado de São Paulo - Brasil

Junho - 2004 


\title{
DEFINIÇÃO DE UNIDADES DE GERENCIAMENTO DO SOLO POR MEIO DA SUA CONDUTIVIDADE ELÉTRICA E VARIÁVEIS FÍSICO-QUÍMICAS
}

\author{
CÉsar Nunes de CASTRo \\ Engenheiro Agrônomo
}

Orientador: Prof. Dr. JOSÉ PAULO MOLIN

\begin{abstract}
Dissertação apresentada à Escola Superior de Agricultura "Luiz de Queiroz", Universidade de São Paulo, para obtenção do título de Mestre em Agronomia, Área de Concentração: Máquinas Agrícolas.
\end{abstract}

P I R A C I C A B A

Estado de São Paulo - Brasil

Junho -2004 


\section{Dados Internacionais de Catalogação na Publicação (CIP) DIVISÃO DE BIBLIOTECA E DOCUMENTAÇÃO - ESALQ/USP}

\section{Castro, César Nunes de}

Definição de unidades de gerenciamento do solo por meio da sua condutividade elétrica e variáveis físico-químicas / César Nunes de Castro. - - Piracicaba, 2004.

131 p. : il.

Dissertação (mestrado) - - Escola Superior de Agricultura Luiz de Queiroz, 2004. Bibliografia.

1. Agricultura de precisão 2. Condutividade elétrica do solo 3. Cluster (Análise) 4. Fertilidade do solo 5. Geoestatística 6. Mapeamento do solo 7. Variabilidade espacial I. Título

CDD 631.41 


\section{DEDICATÓRIA}

Dedico ao meu pai, Antônio Maria Gomes de Castro, e a minha mãe, Maria Zélia Nunes de Castro, por terem me dado o apoio e as condições necessárias para ser quem hoje sou e superar os desafios que me foram propostos durante a elaboração desse trabalho.

Dedico aos meus irmãos Cristiano Nunes de Castro e Claúdia Nunes de Castro pelos quais eu tenho tanto apreço e que sei que "torcem" por mim tanto quanto eu torço por eles.

Dedico ao meu orientador José Paulo Molin que tão bem me aconselhou durante o curso de mestrado, que me orientou durante a confecção desta dissertação e cujos conselhos foram de grande valia em tornar o caminho, por vezes "tortuoso", do aprendizado científico em algo um pouco mais "retilíneo" para que este inexperiente aprendiz da investigação científica tivesse uma melhor jornada. 


\section{AGRADECIMENTO}

Agradeço ao Eng. Agronômo Leandro Maria Gimenez, pesquisador da Fundação $\mathrm{ABC}$, que tanto auxiliou nas etapas de coleta dos dados que foram utilizados nesta pesquisa e que sem o seu suporte em Castro muito prejudicaria o bom andamento das tarefas requeridas para conclusão deste trabalho.

Agradeço aos demais funcionários da Fundação ABC que auxiliaram nas etapas de coleta de dados deste trabalho.

Agradeço aos funcionários do Departamento de Engenharia Rural da ESALQ-USP que atenciosamente sempre me auxiliaram em preparar os equipamentos que seriam utilizados nas pesquisas de campo. Especial agradecimento para Áureo Santana de Oliveira, Fernanda Barbosa Neves da Silva, Francisco de Oliveira e Juarez Renó do Amaral. Muito obrigado.

Agradeço à Fundação de Amparo à Pesquisa do Estado de São Paulo (FAPESP) pelo financiamento do projeto.

Agradeço aos amigos, colegas, do curso de pós-graduação em máquinas agrícolas (incluindo o "agregado", doutorando do Departamento de Engenharia Florestal), que, as vezes, ajudaram em alguma etapa deste trabalho, na maioria das vezes não, mas que sempre foram bons amigos e isso, geralmente, vale mais do que qualquer ajuda específica.

Agradeço especialmente ao colega de curso, e grande amigo, Rui Marcos Cosentino.

Finalmente, agradeço aos amigos da república Picareta, da Escola Superior de Agricultura “Luiz de Queiroz”: República esta na qual vivi durante meus quatro anos e meio da graduação, e durante o primeiro ano de mestrado, e na qual, durante todos os meus anos em Piracicaba, sempre tive, e espero continuar tendo, bons amigos. 


\section{SUMÁRIO}

Página

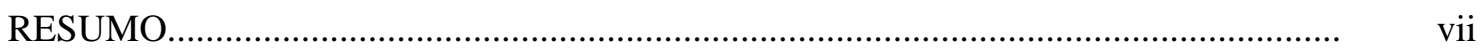

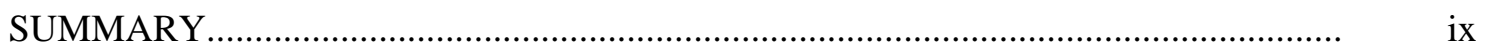

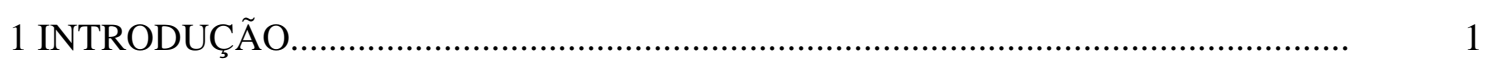

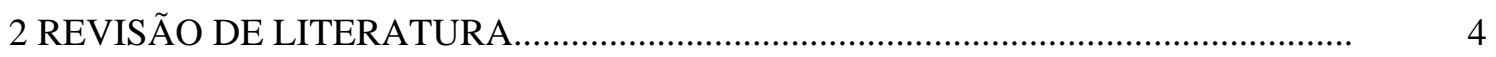

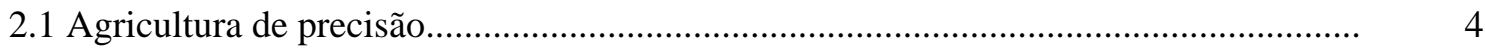

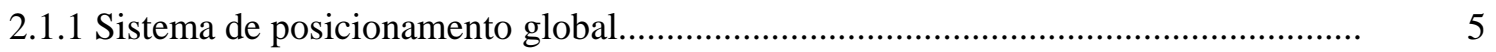

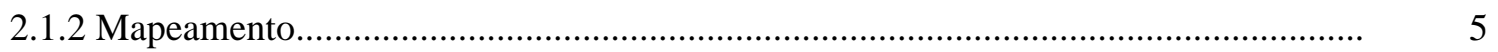

2.2 Condutividade elétrica do solo................................................................................ 5

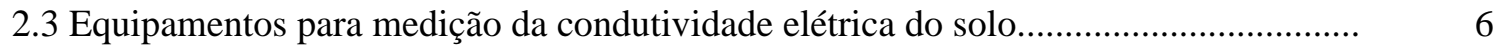

2.4 Fatores que afetam a condutividade elétrica dos solos.................................................. 8

2.5 Aplicações dos sensores de Condutividade Elétrica Aparente (CEa) na agricultura..... 9

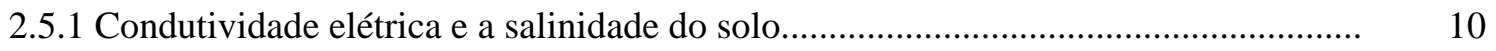

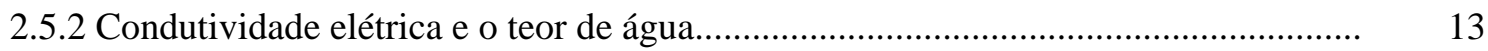

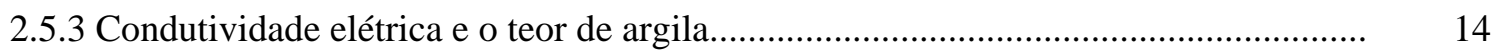

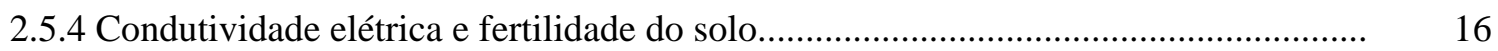

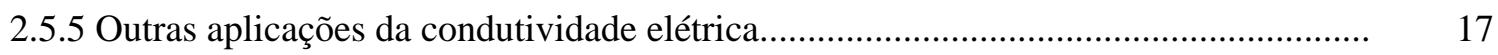

2.6 Unidades de gerenciamento e condutividade elétrica.................................................... 18

2.7 Geoestatística e dependência espacial ........................................................................... 21

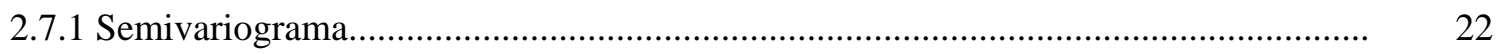

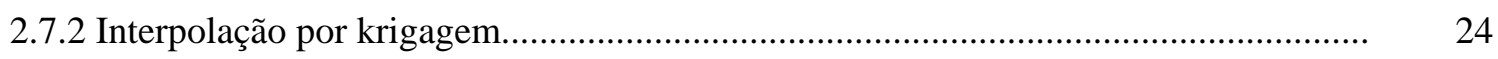

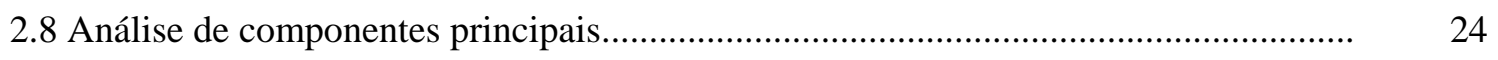

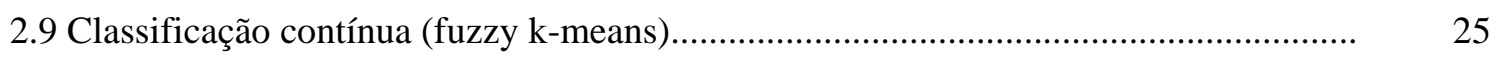

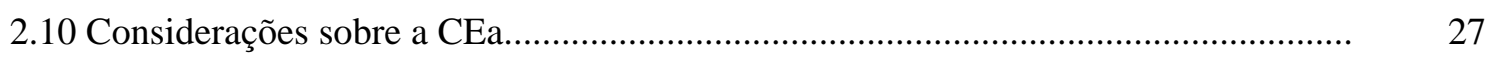

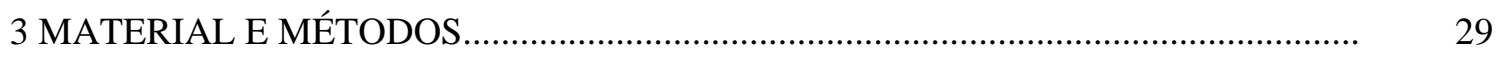

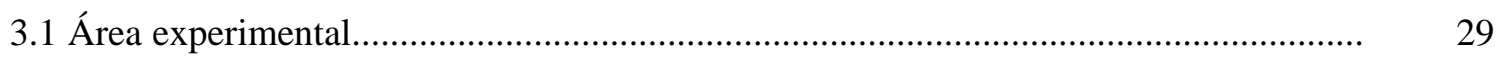


3.2 Caracterização do sensor de CEa por contato direto...................................................... 30

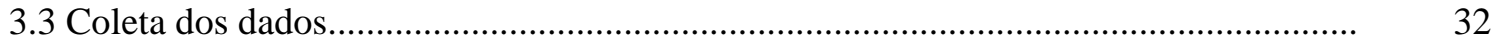

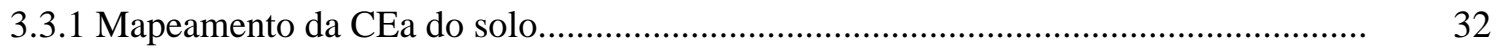

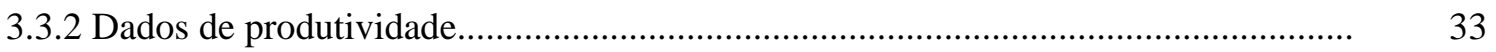

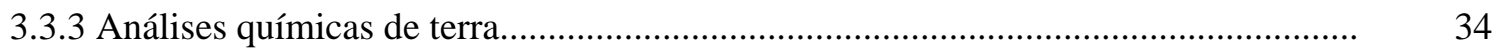

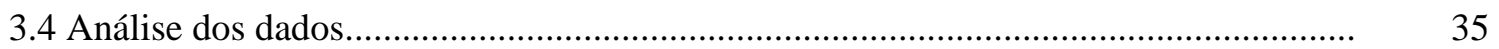

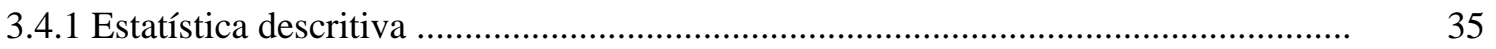

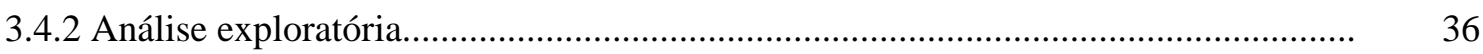

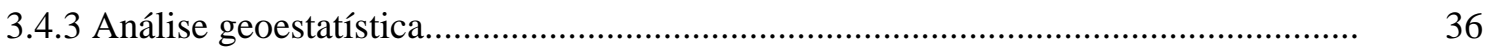

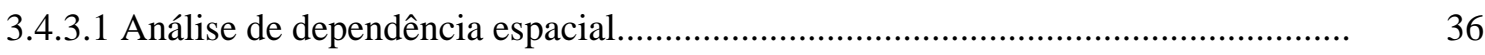

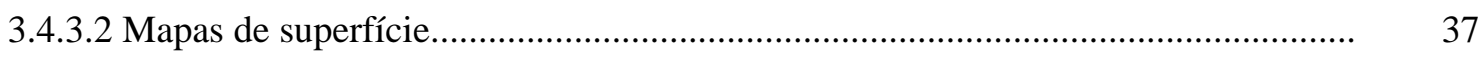

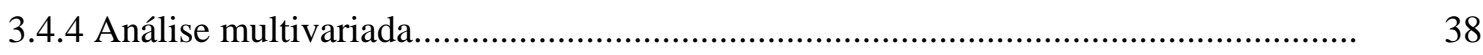

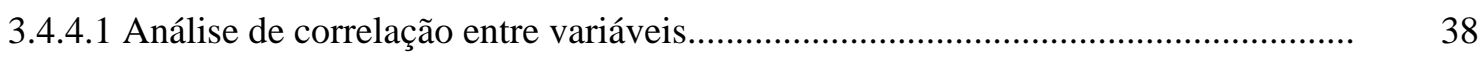

3.4.4.2 Análise de componentes principais.................................................................. 38

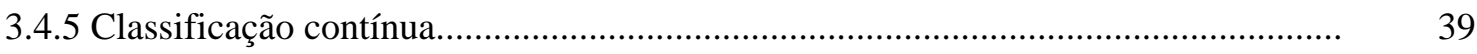

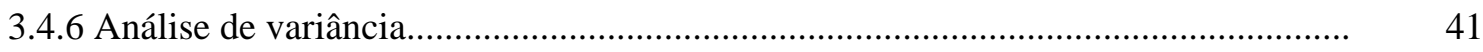

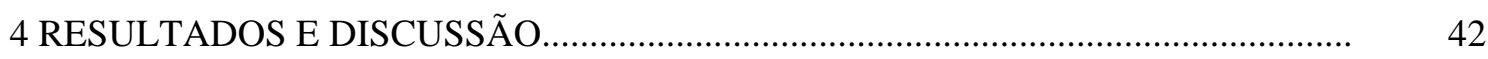

4.1 Estatística descritiva.......................................................................................... 42

4.2 Análise exploratória.............................................................................................. 56

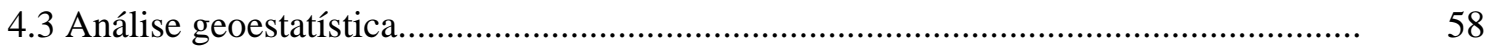

4.3.1 Análise de dependência espacial.................................................................................. 58

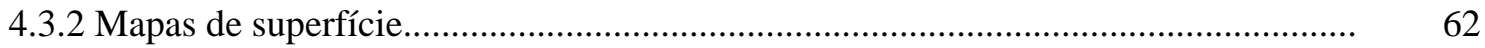

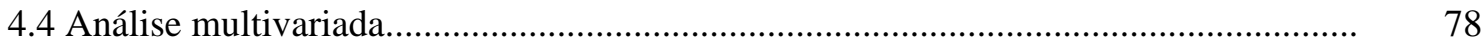

4.4.1 Análise de correlação entre variáveis.......................................................................... 78

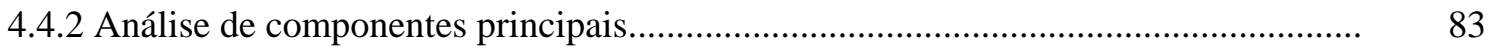

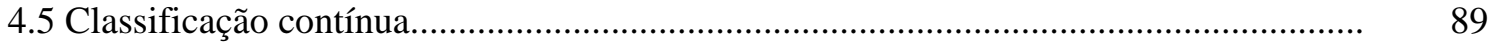

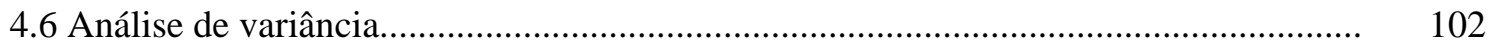

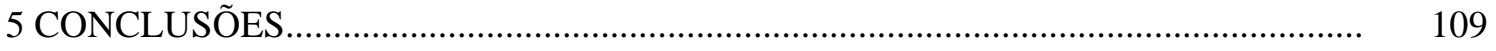

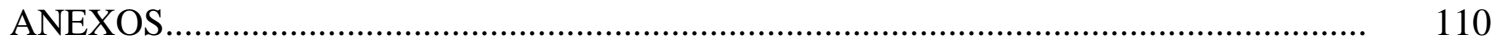

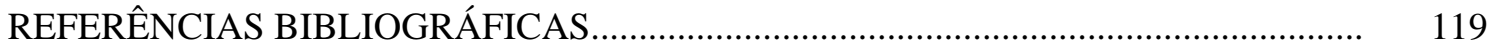




\title{
DEFINIÇÃO DE UNIDADES DE GERENCIAMENTO DO SOLO POR MEIO DA SUA CONDUTIVIDADE ELÉTRICA E VARIÁVEIS FÍSICO-QUÍMICAS
}

\author{
Autor: CÉSAR NUNES DE CASTRO
}

Orientador: Prof. Dr. JOSÉ PAULO MOLIN

\section{RESUMO}

A agricultura de precisão é um ramo de pesquisa relativamente recente na área agrícola e que apresenta perspectivas promissoras na geração de novas técnicas de gerenciamento da lavoura otimizadoras de insumos e que permitam diminuição nos custos de produção. Técnicas como aplicação localizada de fertilizantes, defensivos agrícolas e melhor monitoramento de características dos solos e outros fatores de produção, fornecem informações que permitem um melhor gerenciamento da área a ser cultivada e em última instância resultam num maior rendimento econômico por área cultivada. Para que seja possível otimizar a produção agrícola utilizando essas técnicas algumas informações iniciais são necessárias. Entre essas uma das mais divulgadas é a utilização dos mapas de produtividade na avaliação da variabilidade espacial das lavouras. Pesquisas recentes tem relatado que conjugado a esse mapa outras camadas de informações podem e devem ser incorporadas, possibilitando desvendar os motivos da variabilidade espacial da produtividade em uma lavoura. Entre essas camadas existem os mapas de características físico-químicas do solo. Um conceito de mapeamento de fatores do solo é o monitoramento da condutividade elétrica do mesmo que permite inferir sobre elementos como textura, salinidade, teor de água, entre outros fatores. O presente trabalho estudou a técnica da mensuração desta característica e sua avaliação em solos brasileiros, verificando a correlação das leituras de condutividade elétrica do solo com parâmetros obtidos por análise laboratorial de amostras do mesmo e com a produtividade de culturas instaladas em três áreas experimentais. Além disso verificou-se a possibilidade de definição de unidades de gerenciamento do solo, que consigam com sucesso representar regiões homogêneas quanto a atributos que influenciam o 
desenvolvimento das culturas, utilizando a condutividade elétrica. Para realização desses objetivos técnicas diversas de análises foram utilizadas. Após a análise estatística descritiva dos conjuntos de dados procedeu-se com a análise geoestatística dos mesmos para avaliação do grau de dependência espacial das variáveis e obtenção dos mapas das distribuições espaciais das mesmas. De posse desses mapas foi possível efetuar a análise de correlação linear de Pearson entre as variáveis e em seguida a análise de componentes principais para verificar quais seriam as de maior influência sobre a variação do solo em cada uma das áreas monitoradas. Na última etapa a lógica fuzzy definiu as unidades de gerenciamento do solo e uma análise de variância avaliou a relevância dessas divisões. Os resultados indicaram a utilidade da condutividade elétrica, além de comprovarem a eficácia do procedimento realizado, devido a correlação da mesma com alguns atributos físico-químicos do solo, notadamente a elevada correlação com o conteúdo de argila em uma das áreas experimentais. 


\title{
DELINEATION OF SITE-SPECIFIC MANAGEMENT ZONES USING ELECTRICAL CONDUCTIVITY AND SOIL FERTILITY ATTRIBUTES
}

\author{
Author: CÉSAR NUNES DE CASTRO \\ Adviser: Prof. Dr. JOSÉ PAULO MOLIN
}

\section{SUMMARY}

Precision Agriculture is a line of research relatively recent in the agricultural area and one that presents promising perspectives on the generation of new field management techniques that allow for cost reduction and input optimization. Techniques as variable rate application of fertilizers, agrochemical and better sensing of soil characteristics, and other production factors, give information that enables better management of fields being cultivated and result in greater economic revenue. For it to be possible to optimize agricultural production using these techniques some initial information are necessary. For one, there is the utilization of yield maps to evaluate the spatial variability of fields. Some researches demonstrated that, conjugated to those maps, other levels of information should be incorporated, permitting to reveal factors that explain spatial variability of yield in a field. Among these information there are physicalchemical soil characteristics maps. One of the concepts for mapping soil factors is sensing its electrical conductivity, which is related to soil characteristics such as texture, moisture, salinity and other. This research studied the measurement of the electrical conductivity of some types of Brazilian soils. Then, correlation of the electrical conductivity readings with soil parameters, obtained by laboratory analysis of soil samples, and with crop yields, cultivated on three experimental areas, was obtained. Besides that, it was verified the possibility of definition of soil management zones, using soil electrical conductivity, which can successfully represent homogeneous regions with regards to attributes that influence the development of crops. For accomplishing these objectives, several analysis techniques were used. After the descriptive statistics analysis of the data set, the geostatistical analysis was made for the evaluation of the 
variables' degree of spatial dependence and then obtaining the maps with the spatial distribution of these same variables. In the possession of these maps, it was possible to verify Pearson's linear correlation among all variables, followed by the principal components analysis to infer which of them had greater influence on soil variability in each of the experimental areas. Thenceforth, fuzzy logic was used to define the soil management zones and an analysis of variance evaluated the importance of the zone divisions made. Results showed the usefulness of electrical conductivity, besides corroborating the efficiency of the proceedings used, because of its correlation with some physical-chemical properties of the soil, especially high correlation with clay content in one of the experimental areas. 


\section{INTRODUÇÃO}

A agricultura de precisão é um ramo de pesquisa relativamente recente na área agrícola e é possivelmente a que apresenta as perspectivas mais promissoras na geração de novas tecnologias e propostas de gerenciamento da lavoura otimizadoras de insumos e que permitam diminuição nos custos de produção. Técnicas como aplicação localizada de fertilizantes, defensivos agrícolas e novas formas de monitoramento de características dos solos e outros fatores de produção, fornecem informações que permitem um melhor gerenciamento da área a ser cultivada, e em última instância resultam num maior rendimento econômico por área cultivada.

Novas tecnologias de sensoriamento próximo ou remoto de fatores do meio ambiente, primordiais na produção agrícola, estão constantemente sendo geradas, aperfeiçoadas e difundidas no meio rural. O conceito de gerenciamento localizado defendido pela agricultura de precisão utiliza muitas dessas tecnologias. Nesse contexto poderiam ser citados monitores de colheita, sensoriamento remoto por satélites ou aviões, sensores de monitoramento de plantas daninhas e do teor de água no solo, entre outros.

Dentre esses, os monitores de colheita receberam a maior proporção da atenção destinada à agricultura de precisão nos primeiros anos de pesquisa e de utilização no campo, o que constitui um bom início para a investigação da variabilidade espacial dos fatores numa lavoura: pela variável dependente das demais, a produtividade agrícola, que é o resultado final do processo produtivo o qual se deseja otimizar, seja através da redução na quantidade de insumos aplicados, seja através da maximização da produção, enfim maximizando os lucros.

A partir da informação da variabilidade espacial da produtividade, a próxima etapa no ciclo da agricultura de precisão é então investigar as possíveis causas dessa variabilidade. Uma das causas primárias tem sido atribuída à fertilidade do solo, a qual para ser avaliada necessita de técnicas de amostragem em grande quantidade, especialmente quando da prática do gerenciamento localizado. No entanto, o custo de análise de uma grande quantidade de amostras em laboratório apresenta-se em muitos casos proibitivo, e por isso, na prática, se realiza uma amostragem em número insuficiente para captar, com nível de precisão satisfatório, o modelo da 
variabilidade espacial do solo. Devido a essa necessidade de obtenção de grande número de amostras uma série de idéias de sensores para monitorar o solo tem sido propostas, alguns já em caráter experimental ou para utilização comercial. É o caso dos diferentes modelos de sensores de condutividade elétrica.

Como afirmaram Myers et al. (2000), “A resolução espacial da informação possível de ser obtida com a agricultura de precisão exige métodos rápidos e precisos para mapear a produtividade potencial de uma área. Informações sobre a área devem ser coletadas, com alta resolução, com restrições de tempo para coletar os dados e custo de aquisição dos mesmos, sendo que essa informação coletada deve se relacionar, de alguma forma, com a fisiologia da planta, permitindo retorno previsível do capital e trabalho investido no gerenciamento localizado das culturas proposto pela agricultura de precisão”. Por esses motivos a condutividade elétrica tem recentemente atraído a atenção por ser, segundo alguns autores, como McBride (1990) e Jaynes (1995), um método rápido e custo-efetivo de indicar a produtividade do solo.

Uma etapa subsequente a essa avaliação das condições do solo pode ser a definição de unidades de gerenciamento, que no contexto da agricultura de precisão são referentes a regiões geográficas que possuem atributos de relevo e do solo com menor heterogeneidade. O desenvolvimento de estratégias agronômicas específicas para essas áreas, sujeitas a combinações únicas de fatores limitantes da produtividade das culturas, permitiria um gerenciamento mais preciso das quantidades de insumos a serem aplicadas nelas. No entanto, o desafio de determinar essas áreas é difícil devido aos complexos fatores que afetam a produtividade das culturas.

Com o intuito de determinar essas unidades de gerenciamento vários métodos foram propostos, entre eles: topografia, fotografias aéreas, imagens do dossel das culturas, sensoriamento remoto e mapeamento da produtividade. Uma outra proposta é a utilização de amostras de propriedades físico-químicas do solo.

Entretanto esse método apresenta a desvantagem do grande número de amostras que precisam ser coletadas e analisadas para se obter a representação correta da variabilidade presente. Em anos recentes a condutividade elétrica do solo tem sido proposta como uma, possível, maneira alternativa de se avaliar a variabilidade espacial desse, e a partir dela se definir as unidades de gerenciamento em uma área.

É nesse contexto que se justifica os objetivos desse trabalho: investigar a relação entre a condutividade elétrica, as demais variáveis físico-químicas do solo monitoradas e a produtividade das culturas; avaliar a utilidade da condutividade elétrica do solo na definição de 
unidades de gerenciamento e verificar a validade do procedimento adotado para definir as unidades de gerenciamento. 


\section{REVISÃO DE LITERATURA}

\subsection{Agricultura de precisão}

Balastreire (1998) define a agricultura de precisão como um conjunto de técnicas que permite o gerenciamento localizado de culturas.

A agricultura de precisão é um sistema de gerenciamento da produção agrícola que utiliza tecnologias e procedimentos para que a lavoura e o sistema de produção sejam otimizados, tendo como elemento chave o gerenciamento da variabilidade da produção e dos fatores a ela relacionados (Precision, 1997).

A origem da agricultura de precisão, como é conhecida hoje, tem suas raízes na pressão por uma agricultura menos agressiva ao meio ambiente nos países europeus e logo em seguida nos Estados Unidos. A necessidade da dosagem de insumos que permitam maximizar a produção sem que potenciais excedentes de fertilizantes e defensivos comprometam a qualidade, especialmente da água, foi o que impulsionou essa tecnologia.

\subsubsection{Sistema de posicionamento global}

Um dos requisitos para se praticar a agricultura de precisão é a existência de um sistema de posicionamento que permita a localização georeferenciada com acurácia em todos os pontos da área a ser trabalhada (Queiroz et al., 2000).

A disputa pelo poderio bélico do período da Guerra Fria induziu o desenvolvimento de sistemas de localização mais precisos. Foi assim que surgiram os sistemas de localização por satélite. O “NAVSTAR” (Navegation Satellite Time and Ranging) ou GPS (Global Positioning System) é um sistema de propriedade e operação do Departamento de Defesa dos Estados Unidos. A URSS também criou o seu sistema, hoje propriedade da Rússia, conhecido como GLONASS (Molin, 2001). 
Atualmente, o uso do sistema GPS é amplamente difundido pelas técnicas de agricultura de precisão como: acompanhamento da lavoura; mapeamento da produtividade; amostragem de solos; demarcação de áreas de ocorrência de doenças das culturas, de ataques de pragas ou de plantas daninhas.

\subsubsection{Mapeamento}

Uma das fases iniciais para implantação dos conceitos da agricultura de precisão em uma propriedade, pode ser a do mapeamento de diferentes fatores. A atividade de mapeamento não se aplica somente à produtividade das culturas, mas também a outros fatores como a área coberta por diferentes fases de uma cultura, ao mapeamento de tipos de solos, de ocorrência de plantas daninhas, de pragas ou de doenças (Balastreire, 1998).

Muitos pesquisadores e usuários consideram que o mapa de colheita é a informação mais completa para se visualizar a variabilidade espacial das lavouras. No entanto, várias outras ferramentas tem sido propostas para se identificar a variabilidade espacial existente em uma lavoura. Nesse sentido as fotografias aéreas, as imagens de satélite, a videografia e a condutividade elétrica do solo têm sido testadas (Mulla \& Schepers,1997).

\subsection{Condutividade elétrica do solo}

A condutividade elétrica é a habilidade que um material tem em transmitir (conduzir) corrente elétrica. É uma propriedade intrínseca do material, assim como outras propriedades como densidade ou porosidade. Na opinião de Bohn et al. (1982) o solo pode ser considerado como um recipiente truncado para solução eletrolítica, como um condutor possuindo um percurso tortuoso, ou um grande número de percursos de condução de comprimentos e seções transversais variáveis.

O solo pode conduzir corrente elétrica através da água intersticial que contêm eletrólitos dissolvidos e através dos cátions trocáveis que residem perto da superfície de partículas de solo carregadas e são eletricamente móveis em vários níveis (Nadler \& Frenkel, 1980).

Rhoades et al. (1989a) e Rhoades \& Corwin (1990) apresentam um modelo de condutividade elétrica que descreve a condutância através de três vias atuando em paralelo: (i) condutância através de camadas alternantes de partículas do solo e entre os limites de suas soluções, (ii) condutância através de soluções do solo contínuas, e (iii) condutância através ou 
entre superfícies de partículas do solo em contato direto entre elas. Na ausência de sais dissolvidos na água presente na segunda via, condutividade, textura e umidade se correlacionam muito bem entre si.

\subsection{Equipamentos para medição da condutividade elétrica do solo}

Para medição da condutividade elétrica dos solos os dois principais métodos utilizados são o de indução eletromagnética e o por contato direto (Rhoades \& Corwin, 1984). O primeiro método utiliza um sensor por indução eletromagnética, não penetrante, que mede a condutividade elétrica do solo até uma profundidade de $1,20 \mathrm{~m}$ na configuração vertical e a uma profundidade de até $0,30 \mathrm{~m}$ na configuração horizontal. O segundo método utiliza sensores que penetram no solo medindo a sua condutividade elétrica a profundidades que são função do espaçamento entre sensores em contato com o solo (Fritz et al., 1998).

A tecnologia de indução eletromagnética consiste basicamente de um eletrodo de transmissão que é suspenso próximo à superfície do solo, o qual é energizado com uma corrente alternada numa freqüência de aúdio. Isso estabelece um campo magnético que induz uma fraca corrente elétrica no solo, que por sua vez gera um segundo campo magnético à uma distância específica do eletrodo transmissor. Um segundo eletrodo, receptor suspenso, gera uma corrente alternada em resposta e proporcional àquela gerada pelo eletrodo transmissor, mas modificada pela condutividade elétrica aparente do solo (CEa). Isso pode ser usado para obter uma leitura da condutividade aparente do solo que é linearmente proporcional à razão dos dois campos magnéticos (King et al., 2001).

A indução eletromagnética é um método sem contato e pode ser preferido se na área sendo pesquisada o revolvimento do solo não é desejável por algum motivo, como por exemplo alguma forma de contaminação do solo (Brevik \& Fenton, 2000). A indução eletromagnética é um método de amostragem rápida para a coleta de informações sobre o solo e da distribuição espacial de algumas de suas propriedades (Domsch \& Giebel, 2001).

Outro equipamento comercial utiliza um sensor de contato direto com o solo para medição da CEa possuindo um sistema de discos metálicos lisos que transmitem uma corrente elétrica no solo. 
Freeland (1989) lembra que foi Wenner ${ }^{1}$ o primeiro a apresentar um modelo teórico desse tipo de sensor, que posteriormente seria desenvolvido e originaria alguns modelos de sensores da CEa por contato direto utilizado nos dias de hoje. Esse modelo teórico consistia da utilização de quatro terminais para medir a resistência elétrica do solo, que é o inverso da condutividade elétrica. Quatro eletrodos são dispostos linearmente com distâncias iguais separando eles. A corrente elétrica é transmitida por ambos os eletrodos externos. Teoricamente isso elimina a resistência de contato, o que segundo Freeland (1989) é um dos empecilhos à medição da condutividade elétrica do solo.

O método de corrente direta requer um contato galvânico entre o solo e cada um dos quatro eletrodos, o que é necessário para introduzir a corrente no solo e medir a voltagem resultante. Ao variar o espaçamento entre esses eletrodos, o alcance de profundidade da leitura pode ser alterado. Quanto maior o espaçamento entre os eletrodos, maior é a profundidade da leitura. Diferentes horizontes do solo podem ser avaliados utilizando-se mais de quatro eletrodos. O método de corrente direta fornece valores de resistividade sem nenhuma calibração. Infelizmente a resistência dos eletrodos relativo a superfície do solo pode aumentar sob condições de solo seco, o que resulta em leituras equivocadas durante o mapeamento (Lück \& Eisenreich, 2001).

Um sistema na sua versão comercial utiliza diferentes espaçamentos entre discos para gerar medições da condutividade elétrica do solo à profundidades de 0,33m e 1,00m simultaneamente. O sistema grava as medidas de condutividade elétrica do solo que podem ser georeferenciadas utilizando-se um receptor de GPS (Lund et al., 1998).

Existem vários equipamentos para medição "in-situ” da condutividade elétrica do solo, disponíveis comercialmente, como por exemplo o MuCEP (Dabas et al., 2001), o Veris 3100, o Soil Doctor, o EM 38 e o GEM 300 (Lück \& Eisenreich, 2001). Muitos autores denominam a condutividade elétrica medida diretamente no solo por CEa para diferenciá-la da condutividade elétrica medida em laboratório utilizando extratos de pasta saturada do solo (CEe) (Rhoades, 1981; Rhoades et al., 1989a).

Desse momento do texto em diante a referência a essa variável será feita pela sigla CEa (condutividade elétrica aparente), maneira pela qual ela é comumente designada, nas situações nas quais ela é medida “in-situ” utilizando os sensores descritos.

\footnotetext{
${ }^{1}$ WENNER, F. A method of measuring earth resistivity. Fresno: U. S. Departement of Com. Bur. of Stan. Scien. ,1916. (Papers 258).
} 
Em pesquisa realizada por Fritz et al. (1998) visando comparar as tecnologias de medição da CEa do solo por indução eletromagnética e por contato direto, foi observada a relação dessa característica à topografia do terreno, sendo que nas áreas de menor altitude a condutividade elétrica era maior se comparada com as áreas de maior altitude. Essa diferença foi atribuída aos efeitos combinados do acúmulo de água e sais nas áreas mais baixas. A CEa por indução eletromagnética apresentou maiores valores de leituras nas áreas do terreno mais secas e valores mais baixos nas áreas mais úmidas em relação as leituras do sensor de contato, indicando que esse último, em leituras rasas, tem uma sensibilidade ao teor de umidade diferente daquela da condutividade elétrica por indução eletromagnética. Os autores concluíram que ambos os sistemas com equipamentos comerciais forneceram dados de campo similares. Lück et al. ${ }^{2}$, citados por L:uck \& Eisenreich (2001), também concluíram que ambos os métodos forneciam resultados semelhantes, conclusão esta à qual também chegaram Buchleiter \& Farahani (2002).

\subsection{Fatores que afetam a condutividade elétrica dos solos}

O solo é um sistema trifásico constituído de partículas sólidas, solução e ar. Quando partículas carregadas eletricamente, incluindo colóides e íons, migram sob influência de um campo elétrico aplicado, vários fatores físicos do solo, incluindo textura, estrutura, e conteúdo de água podem afetar a condutividade elétrica interferindo na inter-relação entre as partículas coloidais e os íons (Li, 1997).

A real condutividade elétrica do solo depende do teor de água, da composição química da solução do solo e dos íons trocáveis, da porcentagem de argila no solo e da interação entre os íons não trocáveis e os trocáveis (Nadler \& Frenkel, 1980). Fritz et al. (1998) concordam que a condutividade elétrica é influenciada pelo teor de água, de sais, e pelo material de origem de formação do solo.

\footnotetext{
${ }^{2}$ LÜCK, E.; EISENREICH, M.; DOMSCH, H.; BLUMENSTEIN, O. GEOPHYSIC FÜR LANDWIRTSCHAFT UND BODENKUNDE HERAUSGEBER: arbeitsgruppe stoffdynamik in geosystemen im umweltzentrum der universität Potsdam, 2000. $167 \mathrm{p}$.
} 
Partículas do solo e de rochas, na sua maioria, são isolantes elétricos, mas são capazes de conduzir a eletricidade através dos poros retentores de umidade e de camadas eletricamente carregadas na superfície das partículas do solo (Rhoades, 1993). Portanto, a porosidade do solo, o formato e o tamanho dos poros, a quantidade de água nesses, assim como a distribuição dos poros no solo afetam a condutividade elétrica desse. Entre outros fatores que a afetam é possível citar a concentração dos eletrólitos na água dos poros, a temperatura do solo, a quantidade e a composição dos colóides, a densidade, e o conteúdo de matéria orgânica do solo (Rhoades et al., 1976; Cook et al., 1992).

Mudanças na temperatura influenciam a condutividade elétrica e a solução do solo de uma maneira parecida. Ocorre um aumento de aproximadamente $2 \%$ na condutividade para cada grau de aumento na temperatura, no entanto já foi demonstrado que a temperatura do solo tem influências desprezíveis sobre os valores de leituras dos sensores de CEa do solo se todas as leituras num mesmo campo foram feitas sob condições semelhantes no decorrer de um mesmo dia (Brevik \& Fenton, 2000). Essa mudança devido a temperatura é causada principalmente pelo fato de que com o aumento dessa diminui a viscosidade do líquido, o que aumenta a facilidade com a qual os íons se movimentam (Harstock et al., 2000).

Já foi demonstrado que, enquanto a magnitude de medições temporais da condutividade elétrica varia com a temperatura e a umidade do solo, o padrão espacial dos valores de condutividade elétrica do solo permanece constante (Harstock et al., 2000; Veris Technologies, 2001). Essa constatação é essencial para a utilização do método de mapeamento da CEa do solo como base para identificar unidades de amostragem e gerenciamento desse. Alguns autores atribuem a variação temporal da condutividade elétrica às variações do conteúdo volumétrico de água do solo (Auerswald et al.,2001).

Diversos autores procuraram desenvolver modelos teóricos que explicassem como se comporta a condutividade elétrica dos solos e sua relação com os diversos fatores que a influenciam (Rhoades et al., 1976; Nadler \& Frenkel, 1980; Schainberg et al., 1980; Bohn et al., 1982; Rhoades et al., 1989a; Rhoades et al., 1989b).

\subsection{Aplicações de sensores de condutividade elétrica aparente (CEa) na agricultura}

Métodos de medição da CEa do solo tem sido utilizados por geólogos há muitos anos, particularmente para ajudar na localização de depósitos de minerais metálicos (Brevik \& Fenton, 
2000). Nos últimos vinte anos, cientistas do solo passaram a utilizar esses sensores em estudos aplicados à agricultura (Jaynes, 1996).

Nesse meio os sensores da CEa foram primeiramente utilizados para medição de sais solúveis e da umidade do solo. Outras aplicações agrícolas atualmente incluem a determinação das unidades de mapeamento dos solos (Cupitt \& Whelan, 2001), a estimativa da profundidade do horizonte superficial em solos com acentuado gradiente textural (Kietchen et al., 2000), a profundidade de deposição de areia como conseqüência de enchentes de rios (Kietchen et al., 1996), a estimativa da degradação de herbicidas e a produtividade das culturas (Jaynes et al., 1995).

Para cada uma dessas determinações, uma relação precisa ser estabelecida entre a leitura do sensor da CEa e a variável em estudo. A partir do momento em que essa relação é estabelecida, as leituras e a conseqüente caracterização do processo em estudo podem ser conseguidas rapidamente (Davis et al., 1997).

Já as primeiras aplicações agrícolas do sensor de CEa por contato direto, conhecido como a técnica dos quatro eletrodos, e que se constitui do protótipo do sensor de contato direto utilizado atualmente, foram para medição da salinidade do solo por Rhoades \& Ingvalson (1971) em solos irrigados e por Halvorson \& Rhoades (1976) em áreas de sequeiro e de acúmulo de sais.

A CEa, como forma de monitorar propriedades diversas dos solos tem se mostrado eficiente em áreas onde uma das propriedades que afetam as leituras de CEa é dominante sobre as outras, e diferenças nas leituras podem ser relacionadas às variações da propriedade dominante (Doolittle et al., 1996).

McBride et al. (1990) citam que em solos não salinos essas propriedades do solo são principalmente uma função da textura, umidade e capacidade de troca catiônica. Bons resultados de medições de determinados fatores do solo foram obtidos com as tecnologias de monitoramento da CEa em solos muito revolvidos no centro do estado de Iowa, Estados Unidos. Solos bastante revolvidos possuem a tendência de apresentarem alta variabilidade espacial (Brevik \& Fenton, 2000).

Nehmdahl \& Greve (2001) citam que no ano de 2000, na Dinamarca, vários milhares de hectares de áreas agricultadas foram mapeados pela técnica de mapeamento da CEa por indução eletromagnética e que ela tem o potencial de se tornar uma parte integrante dos sistemas de suporte de decisão para a produção agrícola futura. 


\subsubsection{Condutividade elétrica e a salinidade do solo}

Nas regiões áridas e semi-áridas do mundo, vastas áreas de terras irrigadas estão ameaçadas pelo processo de salinização. No Egito, no Paquistão e na Índia, aproximadamente 0,8, 6,1 e 10,7 milhões de hectares, respectivamente, já foram afetados pela salinidade (Carruthers \& Smith $^{3}$, citados por Hendrickx et al., 1992). Salinidade do solo em excesso afeta a produtividade agrícola e pode, eventualmente, causar a degradação do solo. Por isso, métodos rápidos de levantamento do nível de salinidade dos solos podem minimizar essas perdas (Lesch et al., 1992).

A salinidade do solo é convencionalmente determinada medindo a condutividade elétrica do extrato de pasta saturada do solo (CEe) (Rhoades, 1981). Uma outra maneira de se determinar a salinidade do solo é através da medição da sua CEa, devido a relação dessa com a CEe (Rhoades, 1981; Rhoades et al., 1989a; Lesch et al., 1992), existindo para tanto alguns métodos de calibração da CEe em função da CEa (Rhoades \& Ingvalson, 1971; Rhoades \& Van Schilfgaarde, 1976; Williams \& Hoey, 1987; McKenzie et al., 1989; Rhoades et al., 1989b; Lesch et al., 1992), entre outros. Halvorson et al. (1977) demonstraram que a CEa do solo medida pelo sensor de quatro eletrodos apresenta uma alta correlação com a CEe medida em laboratório, e para as condições do experimento o coeficiente de correlação (r) foi superior a 0,95 .

Devido aos fatores que controlam a condutividade elétrica dos solos (conteúdo de argila, sais solúveis, umidade do solo e temperatura) não é surpresa que muitos dos estudos iniciais utilizando as técnicas de monitoramento da CEa do solo envolvessem a identificação e delineamento de solos salinos (Williams \& Hoey, 1987; Brevik \& Fenton 2000). Brevik \& Fenton (2000) citam que esses estudos continuam a receber atenção considerável.

No começo da década de 1980 Rhoades \& Corwin (1981) já afirmavam, em relação à CEa, que "o estado da arte está agora suficientemente avançado que o uso das medições da CEa do solo podem ser recomendadas para o diagnóstico da salinidade”.

As primeiras determinações da salinidade do solo a partir de medições da CEa foram feitas utilizando técnicas e equipamentos de prospecção geofísica padrões (Rhoades \& Ingvalson, 1971). Shea \& Luthin (1961) foram pioneiros na utilização da técnica dos quatro eletrodos no monitoramento da salinidade do solo. Posteriormente uma sonda de salinidade foi

\footnotetext{
${ }^{3}$ CARRUTHERS, I; SMITH, L. The economics of drainage. In: (SYMPOSIUM ON LAND DRAINAGE FOR SALINITY CONTROL IN ARID AND SEMI-ARID REGIONS). Cairo: Egypt. Drainage Research Institute, 1990. v. 1, p. 151-170.
} 
desenvolvida para obtenção de medições mais localizadas e precisas (Rhoades \& Van Schilfgaarde, 1976). Circuitos elétricos mais apropriados para aplicações em solos foram desenvolvidos (Austin \& Rhoades, 1979). Unidades imóveis de monitoramento foram desenvolvidas para atender as necessidades (Rhoades, 1979) e estruturas fixas foram desenvolvidas para as necessidades de mapeamento e movimentação numa área (Rhoades, 1976).

As medições da salinidade do solo utilizando a CEa apresentam a vantagem de que os dados podem ser coletados numa velocidade elevada (de 10 a $15 \mathrm{~km} / \mathrm{h}$ ), e assim extensas áreas podem ser monitoradas numa fração do tempo que levaria utilizando o método atual por extração de pastas saturadas do solo (Sheets et al., 1994). No entanto, Blackmore (1978) diz que a conversão da CEa do solo medida no campo para um índice do conteúdo de sais dos solos depende de muitos fatores, contendo um pouco o entusiasmo devido a conclusões as quais estudos como o de Halvorson et al. (1977) apresentaram.

Em pesquisa realizada em Falsalabad, Paquistão, em campos irrigados, a CEa do solo foi medida utilizando um sensor por indução eletromagnética. Análise geoestatística dos dados indicou que a salinidade dos campos era principalmente determinada pelo manejo da irrigação. Significativas diferenças de salinidade foram encontradas entre áreas abandonadas, em pousio e cultivadas, mas não entre campos com diferentes culturas. Foi verificada também uma boa correlação entre os dados do sensor eletromagnético com o método de avaliação visual da salinidade (Hendrickx et al., 1992).

A indução eletromagnética tem sido utilizada de diversas maneiras para mapear a salinidade do solo. O método mais simples é tomar uma série de leituras de salinidade com o medidor e utiliza-las para estabelecer regiões distintas quanto ao nível de salinidade. O medidor precisa ser calibrado de uma forma na qual as medidas da CEa possam ser comparadas às medidas da CEe para cada área amostrada (McKenzie et al., 1997).

Mapas da CEa do solo gerados por sensores de contato direto provaram ser úteis como mapas de escala de campo da salinidade do solo, e produziram dados valiosos para avaliação do grau de salinização em diversas áreas estudadas (Mankin et al., 1997).

Em experimentos de campo em Alberta, Canada, o método de indução eletromagnética foi utilizado para avaliar a tolerância à salinidade de 28 espécies de árvores e 28 espécies de gramíneas e forrageiras. Em experimentos similares, no oeste da Austrália, a utilidade do método de monitoramento da CEa do solo por indução eletromagnética foi verificada ajudando a prever a sobrevivência e o crescimento de Eucalyptus globulus e pastagens em solos salinos. Essas 
técnicas estão sendo incorporadas nas estratégias de gerenciamento de áreas agro-florestais com problemas de solos com elevado teor de salinização (McKenzie et al., 1997).

\subsubsection{Condutividade elétrica e o teor de água}

A característica do solo que muitas vezes é determinante na variação da produtividade numa mesma lavoura é sua habilidade em armazenar e fornecer água para o crescimento das plantas, por isso entender os fatores espaciais e temporais da variabilidade da produção causada por essa variável pode ser uma ferramenta importante nas decisões de gerenciamento (Morgan et al., 2000).

Infelizmente, a medição adequada do teor de umidade dos solos em grandes áreas é de difícil avaliação. Métodos convencionalmente utilizados como os métodos gravimétricos, da sonda de nêutrons, e do TDR ("time domain reflectometry"), requerem grande dispêndio de mão-de-obra ou são de natureza destrutiva, não permitindo repetidas medições num mesmo ponto de amostragem (Hendrickx \& Wierenga, 1990).

Devido a relação entre a umidade e a CEa dos solos ter sido observada por diversos pesquisadores (Rhoades et al., 1976; Hendrickx et al., 1992), vários estudos surgiram utilizando o monitoramento desta para avaliar a variabilidade daquela (Edlefsen \& Anderson, 1941; Hendrickx \& Wierenga, 1990; Hendrickx et al., 1992; Sheets \& Hendrickx, 1995; Morgan et al., 2000).

A condutividade elétrica do solo depende em larga escala da solução eletrolítica existente no solo ao invés das partículas sólidas do mesmo. Geralmente, solo secos tem resistência muito alta. Minerais do solo aparecem como isolantes, apesar de que em alguns solos pode existir uma pequena corrente sendo conduzida através da superfície das partículas. Portanto, o nível da condutividade elétrica de um solo é principalmente devido ao seu teor de água e do teor de sais dissolvidos nele. Conforme o solo seca, sua resistência aumenta pois os sais presentes no mesmo precisam ser ionizados para poder conduzir eletricidade. Assim, a resistência aumenta conforme a camada de água envolvente das partículas do solo se torna mais fina, e os espaços porosos são drenados (Freeland, 1989).

Pesquisas recentes constataram que a medição da CEa do solo tem o potencial de realizar medições rápidas da umidade dos solos (Sheets\& Hendrickx, 1995), sendo antigas as aplicações dessa técnica com esse objetivo (Edlefsen \& Anderson, 1941; Kirkham \& Taylor, 1949), todas elas tomando como base os princípios estabelecidos por Wenner $^{1}$, citado por Edlefsen \& 
Anderson (1949). O trabalho de $\mathrm{McNeil}^{4}$, citado por Mankin et al. (1997), enfatiza que a condutividade elétrica do solo e das rochas depende da porosidade e do grau de enchimento dos poros com água.

Morgan et al. (2000), estudando a eficácia da utilização da CEa do solo com o objetivo de servir de parâmetro para inferir sobre o teor de água disponível para as plantas, concluíram que esse método funciona melhor em talhões maiores com uma maior amplitude do intervalo de teores de água através da área. Harstock et al. (2000) obtiveram uma boa correlação entre a CEa medida por um sensor de contato e a umidade do solo.

Bobert et al. (2001) em pesquisa realizada em Wulfen, Alemanha, utilizaram um método que reunia as técnicas de modelagem digital do terreno, uma sonda de capacitância e um sensor por indução eletromagnética para analisar respectivamente a umidade e a textura do solo, visando avaliar a distribuição dessa umidade, permitindo a tomada de decisões sobre o seu correto gerenciamento. O coeficiente de regressão entre os valores da CEa e o parâmetro denominado de índice de molhamento topográfico (IMT) para os doze pontos de amostragem foi de 0,52. Os autores citam que como os valores de CEa são dominados pela textura e pela umidade do solo, o IMT pode ajudar a interpretar o mapa de CEa.

No entanto trabalhos como o de Freeland (1989) alertam para o fato de que, citando palavras do próprio autor, “Ao longo do século XX, uma conclusão geral mantida pelos cientistas do solo foi a de que as variações entre os diferentes tipos de solos são muito grandes para permitir a utilização de métodos de medição da condutividade elétrica do solo “in-situ” (ou CEa) para medir a umidade do solo (as primeiras aplicações desse método foram na segunda metade do século XIX). Essas variações incluem, mas não estão limitadas: ao número de tipos de solos, aos ciclos de temperaturas diurnas e estacionais, às quantidades de sais dos diferentes aditivos químicos aplicados no solo e à alteração do contato solo-sensor”.

\subsubsection{Condutividade elétrica e o teor de argila}

Os íons dentro da dupla camada eletricamente difusa de partículas de argila são capazes de conduzir eletricidade mesmo em baixos níveis de água no solo (Kachanoski et al., 1988). Portanto os minerais de argila contribuem significativamente para a condutividade elétrica do

\footnotetext{
${ }^{4}$ MCNEIL, J. D. Electrical conductivity of soils and rocks. Mississauga: Geonics Ltd., 1980. (Technical Note, TN-5).
} 
solo (Durlesser ${ }^{5}$, citado por Dalgaard et al., 2001). Dessa relação surge a utilidade do monitoramento da CEa do solo para avaliação do teor de argila do mesmo, devido ao fato de que a areia tem baixa condutividade e a argila alta condutividade. Consequentemente, a CEa se correlaciona fortemente à textura (e ao tamanho das partículas) do solo (Lund et al., 1998).

A resposta da CEa à presença de argila tem sido utilizada para estimar a profundidade do horizonte superficial em relação à camada sub-superficial acentuadamente argilosa (Doolittle et al., 1994; Jaynes, 1996; Kietchen et al., 2000).

Depois da grande inundação ocorrida no meio-oeste americano, em 1993, foi conduzida uma pesquisa utilizando uma técnica associando a indução eletromagnética à sondagem laboratorial da condutividade elétrica do solo, atrelada a localização geográfica dos pontos amostrados visando avaliar a quantidade de areia depositada nas áreas de quatro fazendas adjacentes ao leito do rio Missouri. Uma forte relação entre as leituras da CEa e as medidas de profundidade de deposição de areia utilizando métodos convencionais de tradagem foi encontrada, com valores do coeficiente de regressão entre 0,73-0,94. Essa relação foi diferente para cada local de pesquisa, portanto a calibração das leituras da CEa através da análise do solo e análise morfológica do terreno foi necessária para cada local em que foi avaliada o nível de deposição de areia (Kitchen et al., 1996).

A amostragem do solo pode ser reduzida através da leitura da CEa do mesmo e sua conversão em parâmetros de textura. Em pesquisa realizada por Banton et al. (1997) 64\% e 53\% da variação no teor de argila pôde ser explicada através dos dados de resistência elétrica do solo (inverso da CEa), respectivamente para condições de solo seco e úmido. Pesquisa realizada na região de Brandenburgo, Alemanha, demonstrou que a influência do conteúdo de argila nas leituras de CEa, na capacidade de campo, podem ser consideradas de 59\% do seu valor total para solos da região, desde que os horizontes do solo não sejam influenciados pela água.

A relação entre a CEa e o conteúdo de argila é suplantada pelo teor de água nos horizontes saturados pela água (Domsch \& Giebel, 2001). Já em pesquisa realizada em solos da Dinamarca, Dalgaard et al. (2001) concluíram que a CEa do solo explicava 79\% da variabilidade do teor de argila.

A partir dessa relação da CEa do solo com o seu teor de argila, alguns autores pesquisaram em anos mais recentes novas aplicações para a mesma, como por exemplo prever a profundidade até a camada de solo compactada, utilizando para isso o inverso da condutividade

\footnotetext{
${ }^{5}$ DURLESSER, H. Bestimmung der variaiton bodenphysikalischer parameter in raum und zeit mit elektromagnetischen induktiosverfahren. München: Munchen Tech. Univ., 1999.
} 
elétrica (Kitchen et al., 1998). Clark et al. (2000) utilizando um sensor de CEa por contato encontraram resultados que também indicaram a utilização do seu inverso para predição da profundidade da camada compactada do solo, obtendo com esse procedimento uma correlação de aproximadamente 0,6 , entre as duas variáveis, nas regiões da lavoura que sofreram ação do tráfego dos veículos agrícolas.

\subsubsection{Condutividade elétrica e fertilidade do solo}

Li (1997) diz que para solos de carga variável (a maioria dos solos tropicais se enquadram nessa classificação), por causa das diferenças entre fatores físicos de diferentes solos de uma mesma região e diferentes profundidades do perfil do solo não serem grandes, acarreta que geralmente pode ser observado que a condutividade elétrica reflete a condição de fertilidade do solo.

A contribuição relativa de cátions trocáveis para a condutividade elétrica é pequena em altas concentrações da solução do solo (Rhoades et al., 1976). No entanto, em baixas concentrações eles podem ter uma importante contribuição na condutividade elétrica (Nadler \& Frenkel, 1980). Além disso, com uma alta porcentagem de sódio trocável e baixa concentração de eletrólitos, a contribuição relativa da condutividade elétrica da superfície para a condutividade elétrica total do solo vai aumentar (Schainberg \& Kemper $^{6}$, citados por Nadler \& Frenkel, 1980).

A real condutividade elétrica do solo depende da composição química da solução do solo e íons trocáveis e da interação entre os íons trocáveis e a totalidade dos íons (Nadler \& Frenkel, 1980). Por esse motivo a CEa possui relação com a fertilidade do solo, sendo que pesquisas suportam a correlação entre a condutividade elétrica do solo e a CTC devido a relação dessa com aquela (McBride et al., 1990), com o teor de matéria orgânica (Jaynes, 1996) entre outros elementos da fertilidade do solo.

McBride et al. (1990) realizaram o monitoramento da CEa do solo em área de florestamento cultivada com a espécie arbórea Carvalho Vermelho (Quercus Rubra L.) e utilizando simples equações de regressão descobriram as altas correlações da CEa com a CEe medida em laboratório, assim como com o teor de Ca e Mg trocáveis e a capacidade de troca catiônica. Harstock et al. (2000) também encontraram boas correlações entre a CEa e os teores

\footnotetext{
${ }^{6}$ SHAINBERG, I.; KEMPER, W. D. Eletrostatic forces between clay and cations as calculated and inferred from electrical conductivity. Clays and Clay Minerals, v. 14, p. 117-132, 1966.
} 
de Ca e Mg. Banton et al. (1997) encontrou boa correlação da resistência elétrica (inverso da condutividade elétrica) do solo com o teor de matéria orgânica do mesmo ( $r=0,65$ e 0,52, respectivamente, para solo seco e solo úmido).

Em relação à linha de pesquisa de aplicação de insumos por métodos de taxa variada, Jaynes et al. (1995), mostraram correlação substancial entre as doses recomendadas de aplicação de adubos e a CEa do solo em cinco de seis campos pesquisados.

\subsubsection{Outras aplicações da condutividade elétrica}

Ellsbury et al. (2000) monitoraram a CEa do solo com o intuito de tentar inferir sobre áreas mais propícias de ocorrência de infestações da praga do milho larva-alfinete (Diabrotica Speciosa), procurando demonstrar a correlação espacial entre a distribuição dessa praga e de propriedades físico-químicas do solo. Os autores observaram a existência dessa relação, e concluíram da necessidade de maiores investigações desse e de outros métodos de predição da variabilidade espacial da larva-alfinete, de formas que um método mais econômico e eficiente possa ser desenvolvido que combinado com o conhecimento prévio do histórico da área possa ser utilizado como método para gerenciamento localizado no controle dessa praga.

Kravchenko et al. (2001) utilizaram a CEa do solo como variável secundária para auxiliar na construção de mapas de classes de drenagem do solo, utilizando de técnicas como a análise discriminatória ou então a cokrigagem. Por ter sido, juntamente com a declividade e com a distância ao dreno, as variáveis que tiveram maior influência sobre a capacidade de drenagem do solo, serviram para melhorar a precisão da predição da classe de drenagem do mesmo em uma área.

Anderson-Cook et al. (2002) utilizando dados de produtividade e de CEa de uma mesma área classificaram esses dividindo-os para diferentes classes de solos existentes na área. Comparando esses resultados com o mapa de solos existentes os autores observaram que os dados de CEa sozinhos serviram para classificar os solos com uma precisão de $85 \%$, e que quando combinados com os dados de produtividade, esse resultado subiu para $90 \%$.

Inman et al. (2002) compararam a eficácia do método tradicional de classificação dos solos, visando mapear as classes de solo de uma área, com um método não penetrante utilizando técnicas de amostragem geofísica GPR (Ground Penetrating Radar) e indução eletromagnética (EM 38), para medir a CEa do solo. Os autores chegaram a conclusão de que a combinação 
desses dois métodos é uma maneira promissora para se obter informações do solo espacialmente contínuas e de alta intensidade.

\subsection{Unidades de gerenciamento e condutividade elétrica}

Pesquisas recentes em agricultura de precisão tem focado no uso das unidades de gerenciamento como um método para definir regiões de aplicação de insumos a taxas variadas. As unidades de gerenciamento no contexto da agricultura de precisão são referentes a regiões geográficas que possuem atributos de relevo e do solo com menor heterogeneidade (Luchiari Jr. et al., 2000).

Comumente, a determinação dessas unidades de gerenciamento é difícil devido a complexa combinação entre os fatores que podem influenciar a produtividade das culturas. Em alguns casos os fatores afetando a produtividade podem interagir uns com os outros, por isso é importante entender como as unidades de gerenciamento criadas a partir de certos atributos afetam a variabilidade de outros fatores que potencialmente influenciam a produtividade num talhão qualquer. Além disso, quando definidas de forma equivocada podem não trazer nenhuma vantagem em relação ao gerenciamento uniformizado da lavoura (Fridgen et al., 2000).

Diversas metodologias para se definir as unidades de gerenciamento foram propostas, entre elas a utilização da topografia (Franzen et al., 1998; Kravchencko \& Bullock, 2000), fotografias aéreas, imagens do dossel das culturas (Johansen et al., 1999), sensoriamento remoto (Mulla \& Schepers, 1997).

O mapeamento da produtividade é outra maneira de se definir as unidades de gerenciamento (Molin, 2002), sendo das camadas de informações disponíveis, a que tem a maior utilidade no gerenciamento e práticas agrícolas atuais (Cupit \& Whelan, 2001). Lark et al. (1999) consideram que a análise de uma seqüência de mapas de produtividade é uma forma de definir unidades de gerenciamento em um talhão, associando-as às características do solo.

Sete a dez anos de informações sobre a produtividade pode ser necessário para se estabelecer metas de produtividade efetivas, tendo como base apenas essa categoria de informação (Lutticken, 1998).

No entanto, Lund et al. (2000) afirmam que muitos produtores têm dúvidas quanto a estabelecer metas de produtividade localizadas na lavoura (para isso realizando o gerenciamento localizado da área) utilizando somente dados de mapas de produtividade, mesmo com múltiplos anos de monitoramento, por causa da dúvida sobre se dados históricos de produtividade sejam 
provas suficientemente fortes de uma tendência existente na lavoura. Uma alternativa a isso é incluir informações sobre propriedades do solo, juntamente com dados de produtividade, visando incrementar os retornos econômicos da prática de gerenciamento localizado (Lutticken, 1998).

Entre os métodos para se definir unidades de gerenciamento, a utilização da CEa do solo foi um dos mais recentemente propostos e diversos autores já a utilizaram (Fridgen et al., 2000; Lund et al., 2000; Cupit \& Whelan, 2001). Apesar da necessidade de precaução ao interpretar os resultados desse método, devido à extrema sensibilidade do mesmo ao tipo de solo e as condições de manejo, sua facilidade de aplicação o torna uma ferramenta atrativa para aplicações em agricultura de precisão (Lund et al., 1998).

Em estudo realizado por Fraise et al. (1999), os autores consideraram que os atributos mais indicados para definição das unidades de gerenciamento eram a altimetria, a CEa do solo e a declividade em solos com gradiente textural. A inclusão da CEa do solo nesse grupo advém da sua relação com a produtividade das culturas (Kietchen et al., 1996; Lund et al., 2000). A correlação entre a CEa do solo e a produtividade ainda é um assunto para pesquisa, mas os resultados iniciais são promissores, especialmente quando a produtividade é influenciada pela capacidade de retenção de água (Lund et al., 1998). Trabalhos realizados no Missouri (Kitchen et al., 1996) mostraram que medições da CEa ajudaram a explicar a variação da produtividade.

No entanto a relação entre CEa e produtividade não é simplesmente linear. Outros autores também realizaram pesquisas investigando a relação entre a CEa do solo e a produtividade (Fleming et al., 1998). Johnson et al. (2001) observaram correlação negativa entre a produtividade e a CEa do solo.

Luchiari Jr. et al. (2000) realizaram estudo tentando avaliar a eficiência de utilização de técnicas diversas como relevo, fotografias aéreas, monitoramento da CEa e da produtividade na definição das unidades de gerenciamento. Como resultado do estudo os autores concluíram que as variáveis altimetria, coloração do solo, declividade e CEa do solo foram responsáveis por quase 65\% da variabilidade espacial da produtividade, indicando a possibilidade de utilização dessas variáveis na definição das unidades.

Fridgen et al. (2000), procurando determinar a habilidade das unidades de gerenciamento, criadas utilizando dados de elevação do terreno, CEa do solo e declividade, representarem a variabilidade de propriedades do solo (disponibilidade de nutrientes, matéria orgânica...) concluíram que quanto maior a dependência entre os parâmetros utilizados para se criar as 
unidades e os outros fatores com importância em futuros planos gerenciais, maior é a probabilidade de que essas unidades gerenciais criadas serão de utilidade para os produtores.

Cupitt \& Whelan (2001), procurando desenvolver um plano de aplicação de insumos a taxa variada, dividiram um talhão cultivado na Austrália em três unidades de gerenciamento potenciais com base nas diferenças de produtividade, CEa do solo e informações de altimetria.

Johnson et al. (2001) mediram a CEa de um talhão cultivado num sistema de rotação trigo-milho sob plantio direto e a partir desse mapeamento dividiram o talhão em quatro classes distintas de CEa, sendo realizado então a amostragem nas áreas correspondentes a essas quatro classes para alguns parâmetros do solo correlacionadas com a produtividade e com propriedades ecológicas. Parâmetros físicos do solo (densidade, umidade e conteúdo de argila), parâmetros químicos (matéria orgânica, carbono e nitrogênio totais, fósforo extraível, CEe e pH), parâmetros biológicos (biomassa microbiana de carbono e de nitrogênio e nitrogênio potencialmente mineralizável) e resíduo de superfície, foram todos significativamente diferentes entre as diferentes classes de CEa em uma ou em ambas as profundidades de mapeamento da mesma (0-7,5 cm; 7,5-30 cm). Eles observaram ainda que a densidade, o conteúdo de argila, a CEe e o pH foram positivamente correlacionados com a CEa e que todos os outros parâmetros foram correlacionados negativamente. A conclusão final dos autores foi a de que esse método de amostragem do solo efetivamente delimita regiões com diferentes condições do solo, sendo uma alternativa melhor para direcionar a amostragem do solo de formas a captar a heterogeneidade espacial do mesmo, ao contrário da amostragem aleatória.

Como afirmado por Luchiari Jr. et al. (2000): “A utilização de unidades de gerenciamento como um método de aplicação de insumos agrícolas à taxas variáveis, requer maior investigação antes que possa ser um método a ser implementado com sucesso”.

Especificamente, as formas de se definir as unidades de gerenciamento necessitam de maior refinamento, e relações entre elas determinadas. Os esforços em prol desses objetivos irão ampliar nossa capacidade em predizer o desempenho das culturas e o impacto ambiental através dos ambientes agrícolas com sua variabilidade intrínseca (Luchiari Jr. et al., 2000).

Vieira \& Molin (2001) lembram que o conhecimento da variabilidade espacial utilizando as ferramentas estatísticas adequadas é essencial para o mapeamento e determinação das unidades de gerenciamento e, consequentemente, para aplicação das técnicas de agricultura de precisão. 
Quando a correlação espacial existe, a geoestatística fornece as ferramentas adequadas para o mapeamento da variabilidade espacial de variáveis naturais (Oliver, 1999) como atributos do solo e produtividade das culturas.

\subsection{Geoestatística e dependência espacial}

O conhecimento da variabilidade de propriedades do solo é provavelmente tão antigo quanto a classificação do solo. Desde que os cientistas começaram a escolher determinados tipos de solos e começaram a organizar o sistema de classificação dos mesmos, conceitos gerais sobre similaridade ou diferenças nos solos classificados sob o mesmo nome começaram a aparecer na literatura (Vieira et al., 1981).

Segundo Oliver \& Webster (1991) o trabalho mais antigo, do qual eles tem notícia, que procurava identificar essa variabilidade do solo foi o de Mercer \& Hall ${ }^{7}$. Eles examinaram a variação na produtividade das culturas a partir de inúmeras pequenas parcelas do experimento. Descobriram que a variância de parcela para parcela decrescia com o aumento do tamanho dessas até um certo limite, após o qual a variância se estabilizava. Esse limite, em torno de 0,01 ha, passou a ser o tamanho padrão de parcelas em experimentos de campo por muitos anos depois.

Técnicas estatísticas para análise de dados nas ciências agrárias tem sido tradicionalmente guiado pelos esforços pioneiros de R. A. Fisher que assumiu que as observações feitas no campo eram independentes e identicamente distribuídas. Tais técnicas, as quais se provaram úteis no passado e são ainda utilizadas atualmente na comparação dos méritos de diferentes práticas de manejo ou tratamento diferenciado, estão cedendo espaço para métodos que se baseiam em observações que são espacial ou temporalmente correlacionadas. É fisicamente mais sensível se esperar que atributos do solo sejam correlacionados quando eles são medidos em pontos adjacentes no espaço ou no tempo (Nielsen \& Alemi, 1989).

A motivação para estudos mais minuciosos da variabilidade de propriedades do solo revelou limitações das ferramentas estatísticas utilizadas até então para a análise dos dados. Comumente as hipóteses de normalidade e independência dos dados não são testadas e, além

\footnotetext{
7 MERCER, W. B.; HALL, A. D. Experimental error of field trials. Journal of Agricultural Science, v. 4, p. 107-132, 1911.
} 
disto, a independência tem que ser assumida a priori, antes de se amostrar. Toda a variabilidade é atribuída ao resíduo, ou seja, a fatores não controlados.

No entanto, a variação das propriedades do solo no espaço comumente apresenta dois componentes, o sistemático e o aleatório (Gonçalves et al., 2001). Wilding e Drees (1983) descrevem a variabilidade sistemática como sendo as mudanças graduais nos valores da propriedade que ocorrem em função dos fatores de formação ou de processos que atuam dentro da escala de observação. Além disso, parte da variabilidade que se credita ao acaso pode ser devida à dependência espacial.

Por esses motivos Vieira (1995) diz que o estudo da dependência espacial entre amostras requer o uso de um tipo de estatística chamada geoestatística, a qual surgiu na África do Sul, quando Krige, trabalhando com dados de concentração de ouro, concluiu que não conseguia encontrar sentido nas variâncias se não levasse em consideração a distância entre as amostras. Matheron $^{8}$, citado por Vieira (1995), baseado nestas observações, desenvolveu uma teoria, a qual ele chamou de Teoria das Variáveis Regionalizadas, que deu origem ao que atualmente é conhecido como geoestatística.

A geoestatística prega que há uma continuidade espacial entre as amostras, ou seja, a diferença entre dois valores tomados mais próximos no espaço deve ser menor do que entre dois valores tomados mais distantes. Portanto, a dependência espacial entre os valores é uma função da distância entre eles. Cada valor carrega consigo uma forte interferência dos valores de sua vizinhança (Vieira, 2000).

\subsubsection{Semivariograma}

Elemento central para a geoestatística é o semivariograma, que é a função mais comumente utilizada para se descrever como uma propriedade do solo varia sobre a superfície do terreno, pois permite a análise estrutural da dependência espacial a partir de suposições de estacionaridade mais fracas do que são necessárias para a autocorrelação ou a covariância (Trangmar et al., 1985).

O semivariograma expressa matematicamente a maneira pela qual a semivariância (1) da propriedade muda, conforme a distância e a direção de separação entre dois pontos varia. A geoestatística permite que se utilize o semivariograma por toda a região analisada na suposição

\footnotetext{
${ }^{8}$ MATHERON, G. The theory of regionalized variables and its applications. Fontainebleau: École Nationale Supérieux das Mines de Paris. 1971. 211p. (Les Cahiers de Centre de Morphologie Mathématique de Fontainebleau, 5).
} 
de que a função semivariância depende apenas da separação entre dois pontos e não na posição absoluta dos mesmos (Oliver \& Webster, 1991).

Existem diversos estimadores para o semivariograma, entre eles o estimador de Matheron, que é amplamente utilizado em análises de geoestatística, sua expressão é:

$$
\gamma(h)=\frac{1}{2 N(h)} \sum_{i=1}^{N(h)}[z(x+h)-z(x)]^{2}
$$

onde, $\mathrm{N}$ (h) é o número de pares de pontos separados pela distância h; O gráfico dos valores assim calculados em função dos valores de h é denominado semivariograma experimental (Isaaks \& Srivastava, 1989).

O semivariograma experimental pode assumir diversas formas em função dos dados e do intervalo de amostragem utilizado. O semivariograma normalmente começa com um baixo valor de semivariância, denominado efeito pepita, o qual aumenta à medida que h cresce até uma certa distância de separação “a”, chamada de alcance da dependência espacial, que determina a distância até a qual a propriedade se apresenta espacialmente dependente. A partir dessa distância os dados podem ser considerados espacialmente independentes. Para distâncias maiores que o alcance, o semivariograma tende a se estabilizar em torno de um valor da função semivariância, denominado patamar (Trangmar et al., 1985).

O patamar se aproxima da variância dos dados, caso esses sejam estacionários, sendo esse o motivo da independência espacial das amostras pois a semivariância se iguala à variância dos dados, implicando variação aleatória desses. O alcance do semivariograma depende da escala de observação e da interação espacial dos processos do solo afetando cada propriedade na escala de amostragem utilizada (Trangmar et al., 1985; Mallants, 1996).

Devido às propriedades do solo variarem continuamente no espaço os seus semivariogramas são funções contínuas. O semivariograma experimental consiste em alguns pontos estimados ao longo dessa função e portanto sujeitos a erros (Gonçalves, 1997). Por esse motivo Isaaks \& Srivastava (1989) lembram que é necessário ajustar uma função para esses pontos, sendo o ajuste do modelo do semivariograma, segundo Oliver \& Webster (1991), é uma questão de entendimento matemático e de julgamento baseado na experiência.

Diversos métodos para se ajustar um modelo ao semivariograma experimental são descritos na literatura especializada sobre o assunto, entre eles o método da minimização da soma do quadrado dos desvios e o da estimação por máxima vero-semelhança (McBratney \& Webster, 1986). Para escolha do melhor modelo também existe mais de uma opção, como o 
critério de informação de Akaike (McBratney \& Webster, 1986; Webster \& McBratney, 1989) ou a validação cruzada (Isaaks \& Srivastava, 1989).

Webster \& Burgess (1983) citam que a forma do semivariograma nunca pode ser determinada de maneira absoluta. Os semivariogramas resultantes são apenas uma descrição da dependência espacial, e não uma explicação, e existe substancial suporte para que a pesquisa entenda o processo ou processos físicos que geraram um semivariograma qualquer.

\subsubsection{Interpolação por krigagem}

A krigagem é uma técnica de interpolação que providencia uma estimativa de uma variável Z, num local não amostrado, com base na média ponderada de valores adjacentes da mesma variável numa área qualquer (Traintafilis et al., 2001).

A krigagem utiliza um interpolador linear não tendencioso e de variância mínima que assegura a melhor estimativa, tendo como base os dados amostrais da variável regionalizada e as propriedades estruturais do semivariograma obtido a partir desses dados (Yost et al., 1982).

Diversas outras técnicas de interpolação, que não levam em consideração a estrutura de dependência espacial da propriedade realizada pelo semivariograma, estão disponíveis para esse propósito (Isaaks \& Srivastava, 1989). Vários autores descrevem em detalhes o método de krigagem (Journel \& Huijbregts, 1978; Isaaks \& Srivastava, 1989; Webster \& Oliver, 1990).

\subsection{Análise de componentes principais}

Martinho (2001) disse que “é provável que os fatores que limitam a produtividade não se restrinjam a um nutriente apenas ou a um atributo físico do solo, mas seja resultado de uma interação de vários nutrientes e aspectos físicos do solo. A visualização espacial possibilita associar qual deles tem melhor influência nas unidades de gerenciamento”. Por isso, técnicas estatísticas multivariadas, que consigam "extrair" informações de conjuntos de variáveis correlacionadas, auxiliam no melhor entendimento de um fenômeno qualquer.

A análise de componentes principais é uma técnica estatística multivariada que transforma linearmente um conjunto de dados de diversas variáveis. O objetivo dessa técnica é no auxílio a descrição e interpretação de conjuntos de variáveis interdependentes. Essa técnica, na prática, reduz os problemas de dimensionalidade do conjunto de dados das diversas variáveis, e transforma variáveis interdependentes em independentes e significantes. Essa transformação 
linear pode comprimir o conjunto de dados original em um conjunto substancialmente menor de variáveis não correlacionadas, os componentes principais, que representam a maior parte da informação no conjunto de dados originais (Mardia et al., 1989; Manly, 1994).

As variáveis mais importantes, que descrevem a variação total no conjunto de dados, também podem ser selecionadas por essa técnica. Portanto, em vez de substituir os componentes principais pelas variáveis originais, é possível selecionar um conjunto de variáveis que tenham elevada correlação com os componentes principais majoritários (Fraisse et al., 2001), ou então utilizar os próprios componentes principais como novas variáveis (Afifi \& Clark, 1996).

\subsection{Classificação contínua (Fuzzy k-means)}

Embora limites possam ser reconhecidos e freqüentemente utilizados com bom efeito em estudos de solos e geomorfologia, sendo o solo e o relevo fenômenos contínuos, as divisões são meros artifícios (Sa, 2001).

Nos levantamentos convencionais de solos, os perfis são descritos, analisados e classificados segundo parâmetros estabelecidos num sistema taxonômico. Nesse tipo de mapeamento as regras de classificação se definem por critérios específicos que alocam cada ponto georeferenciado a uma única classe. No entanto, os solos apresentam, no geral, uma variabilidade contínua. Na ciência do solo normalmente existe uma noção da definição dos critérios ideais para se determinar classes de aptidão do solo, mas o limite entre o adequado e o não-adequado, entre o pertinente e o não-pertinente nem sempre é precisamente estabelecido. Assim, a ciência do solo se caracteriza por informações substancialmente qualitativas e descritas de forma vaga e imprecisa e de difícil adequação aos procedimentos tradicionais de classificação (Fuks, 1998).

Odeh et al. (1992) lembram que a variação do solo é mais contínua do que discreta e por isso exige um método contínuo para classificar o solo. Burrough (1989) lembra a importância da correta classificação do solo, pois essa é uma etapa essencial no processo de redução de dados, quando conjuntos complexos de observações se tornam compreensíveis. Burrough et al. (1997) apresentam um histórico elucidativo da evolução dos paradigmas da classificação e mapeamento dos solos desde o início de 1960 até a década de 1990.

Um método alternativo para classificação dos atributos do solo surgiu quando Zadeh (1965) apresentou um critério classificatório para lidar com a imprecisão (a teoria não fora originalmente desenvolvida com o objetivo de ser aplicada em qualquer ciência natural, como é 
o caso da ciência dos solos). Esse procedimento é a teoria dos conjuntos fuzzy, método matemático adequado para quantificar a imprecisão inerente à classificação das variáveis relacionadas ao sistema solo.

A característica fuzzy se origina da imprecisão e da incerteza. Sua principal função é o agrupamento de indivíduos em classes que não tem limites bem definidos. Conjuntos Fuzzy são úteis sempre que se precisa descrever a ambigüidade, elementos vagos e a ambivalência em modelos conceituais ou matemáticos de fenômenos empíricos (McBratney \& Odeh, 1997). Na classificação fuzzy o indivíduo pode ter participação total, parcial ou nula em cada uma das diferentes classes.

Entre as diferentes variações da classificação fuzzy uma das mais utilizadas na ciência dos solos é a técnica fuzzy k-means a qual, segundo Burrough et al. (1997), é também conhecida como classificação contínua, devido à continuidade das classes no espaço amostral, e também, como se espera, no espaço geográfico. Diversos trabalhos apresentam a base matemática do grupamento fuzzy k-means e os algoritmos computacionais utilizados na análise dos dados (Burrough, 1989; Odeh et al., 1992; Burrough et al., 1997; McBratney \& Odeh, 1997).

Para descrever de forma resumida a classificação fuzzy k-means, suponha-se que os dados a serem classificados, amostrados em $n$ locais contendo $p$ variáveis, são sumarizados numa matriz Y de tamanho $n$ por $p$. Um local pode pertencer parcialmente a K classes diferentes (ao contrário da classificação booleana) e a taxa de participação do indivíduo $i$ à classe $c$ é quantificada pelo valor de participação $\mathrm{m}_{\mathrm{ic}}$, que pode variar num valor entre 0,0 a 1,0. Considera-se que o somatório dos valores de participação nas K classes de qualquer indivíduo é igual a 1,0, e que classes vazias não existem (Franssen et al., 1997). O grau de participação do indivíduo $i$ a classe $c$ está sujeito a duas restrições:

$$
\begin{gathered}
\sum_{c=1}^{K} m_{i c} \\
0 \leq m_{i c} \leq 1
\end{gathered}
$$

Se $\mathrm{m}_{\mathrm{ic}}=0$, então $i$ não se assemelha de nenhuma forma à classe $c$;

Se $\mathrm{m}_{\mathrm{ic}}=1$, significa semelhança exclusiva do indivíduo $i$ na classe $c$;

Se $0<\mathrm{m}_{\mathrm{ic}}<1$, então $i$ tolera parcial semelhança na classe $c$, como também em pelo menos uma das outras classes (Sa, 2001).

A classificação pode ser realizada procurando pela matriz $M$ de valores de participação que minimize uma função objetiva que caracterize a deficiência da classificação. Na 
classificação fuzzy, cujo expoente fuzzy $\varphi(\varphi \geq 1)$ pode ser escolhido pelo usuário, a função objetiva é uma generalização da soma de quadrados intra-classe da matriz Y, definida por:

$$
J(M)=\min _{c} \Sigma_{i} \Sigma_{c} m_{i c}^{\varphi} d^{2}\left(Y_{i}, Z_{c}\right)
$$

onde, $\mathrm{Y}_{\mathrm{i}}$ é a i-ésima linha da matriz $\mathrm{Y}, \mathrm{Z}_{\mathrm{c}}$ é o elemento de minimização chamado de centróide da classe c e d é a distância entre dois pontos p-dimensionais (Franssen et al., 1997).

O expoente fuzzy $(\varphi)$ controla o grau de “fuzziness” (descontinuidade, incerteza, ambigüidade) da classificação, sendo a escolha de tal expoente subjetiva. Quando o expoente é igual a 1,0 a classificação não produz sobreposição de classes, resultando em classes rígidas. $\mathrm{O}$ aumento do valor desse expoente causa uma maior continuidade ou fuzziness (Franssen et al., 1997). Sa (2001) cita que a maior parte dos estudos de classificação de atributos do solo tem utilizado valores entre 1,1 e 1,5, mesmo intervalo considerado mais indicado para esses atributos por Odeh et al. (1992).

A distância entre dois pontos (d) é uma norma, uma medida da distância entre o objeto $i$ e o centro da classe $c$ no espaço dimensional $p$ definido pelas variáveis medidas. A classificação contínua pode ser obtida utilizando várias normas: a medida métrica (distância) Euclidiana é adequada se as variáveis $p$ não são correlacionadas dentro das classes (variáveis independentes);

a distância Mahalanobis ou a Diagonal são preferidas quando as variáveis mostram correlações mais ou menos homogêneas nas classes (dependências entre as variáveis). O centro da classe $c$ é um vetor dos valores das variáveis $p$ nas quais as classes são definidas e representam o membro típico da classe c (centróide da classe) (Burrough, 1989; Sa, 2001).

Diversos trabalhos surgiram apresentando a possibilidade de utilização da técnica fuzzy na classificação de atributos geográficos como: levantamentos e classificação de solos (Burrough, 1989; Burrough et al., 1997); mapeamento e classificação de elementos da fertilidade do solo (Dobermann \& Oberthur, 1997), de poluentes do solo (Franssen et al., 1997) e inclusive com alguns trabalhos a utilizando na área de agricultura de precisão visando definir unidades de gerenciamento com base em dados de CEa e altitude do solo (Fridgen et al., 2000), ou teor de nutrientes (Sa, 2001), entre outros.

\subsection{Considerações finais}

Por tudo que foi exposto, a grande utilidade da CEa do solo é devido a essa representar uma ferramenta em potencial para auxiliar na investigação da variabilidade espacial de 
propriedades do solo, pois como muitos pesquisadores gostam de dizer: a variabilidade espacial de parâmetros do solo é a chave para a aplicação da agricultura de precisão com sucesso (Pozdnyakova \& Zhang, 1999; Robert, 1999).

Se a CEa vai deixar de ser uma ferramenta em potencial, e passar a integrar o conjunto de práticas adotadas pela agricultura de precisão, isso vai depender de alguns fatores que na opinião de Harstock et al. (2000) são: 1) a CEa tem de ser espacialmente estruturada, 2) o padrão espacial da CEa numa área tem de ser estável temporalmente, e 3) a CEa tem de possuir relação com fatores de importância agronômica. 


\section{MATERIAL E MÉTODOS}

\section{1 Área experimental}

Esse trabalho faz parte de um projeto maior que vem sendo conduzido desde 1998 em áreas localizadas nas propriedades de diversos produtores rurais nos municípios de Castro, Carambeí e Ponta Grossa, no estado do Paraná. Ele é desenvolvido em parceria pela Escola Superior de Agricultura “Luiz de Queiroz”, da Universidade de São Paulo, localizada na cidade de Piracicaba, no estado de São Paulo, e pela Fundação ABC (entidade de pesquisa particular das cooperativas Arapoti, Batavo e Castrolânda), localizada na cidade de Castro, no estado do Paraná.

Para essa etapa do projeto foram coletados dados de CEa do solo, utilizando um sensor por contato direto, em três áreas experimentais, sendo uma das áreas de propriedade da Fundação $\mathrm{ABC}$ e as outras duas pertencentes a dois produtores ligados à Fundação e que participam do projeto de agricultura de precisão dessa instituição juntamente com a Universidade de São Paulo. Na Tabela 1 são apresentadas as informações referentes a essas três áreas, sendo ao lado do nome das mesmas apresentadas as siglas a partir das quais serão feitas referências a elas desse ponto em diante.

Tabela 1. Descrição das três áreas experimentais do projeto

\begin{tabular}{cccc}
\hline Proprietário & Município & Tamanho da área (ha) & Coordenadas \\
\hline Fundação ABC (Fabc) & Castro & 22,2 & $49^{\circ} 55^{\prime}$ O; 2451' S \\
Roberto Buher (RB) & Ponta Grossa & 35,8 & $50^{\circ} 12^{\prime}$ O; 259' S \\
Cornélio Rooy (CR) & Carambeí & 15,9 & $50^{\circ} 13^{\prime}$ O; 2454’ S \\
\hline
\end{tabular}

A altitude média na região é de 1000 metros acima do nível do mar. O clima predominante para esses municípios, aonde foi desenvolvido esse trabalho, segundo a classificação de Köppen, é do tipo Cfb, temperado propriamente dito, com temperatura média no 
mês mais frio abaixo dos $18{ }^{\circ} \mathrm{C}$ (mesotérmico), com verões frescos e temperatura média do mês mais quente abaixo dos $22{ }^{\circ} \mathrm{C}$, sem estação seca definida e com precipitação média anual de $1690 \mathrm{~mm}$.

\subsection{Caracterização do sensor de condutividade elétrica por contato direto}

O equipamento utilizado na medição da CEa dos solos nas áreas experimentais foi o sensor de condutividade elétrica por contato direto Veris $3100^{9} \AA$. Esse equipamento é composto de seis discos de corte: quatro são discos sensores, funcionando como eletrodos que penetram no solo; os outros dois discos servem como eletrodos que injetam uma corrente elétrica no solo. $\mathrm{O}$ implemento, segundo seu fabricante, apresenta largura de 2,35 m, comprimento de 2,44 m e 0,89 m de altura e o implemento requer uma potência de 15,0 kW a 20,0 kW para ser tracionado, dependendo da velocidade, do terreno e das condições do solo. A velocidade de operação é de até $7,0 \mathrm{~m} \mathrm{~s}^{-1}$.

Com o deslocamento no campo, um par de eletrodos ligados aos discos de corte do implemento transmitem uma corrente elétrica ao solo, enquanto que os outros dois pares de eletrodos medem a diferença de potencial que ocorre no campo eletromagnético gerado no solo, devido à corrente elétrica aplicada pelo sensor. Os dois pares de eletrodos de medição são configurados para medir essa diferença de potencial, simultaneamente, até uma profundidade de 0-0,30m (leitura rasa), assim como de 0-0,90m (leitura profunda), sendo a profundidade de leitura função do espaçamento entre esses eletrodos. O programa do coletor de dados do equipamento realiza a conversão da queda de voltagem ocorrida no solo para a condutividade elétrica do mesmo, de acordo com a equação:

$$
\sigma=\frac{I L}{A V}
$$

onde, $\sigma$ é a CEa do solo, em $\mathrm{mS} \mathrm{m}^{-1}$; I é a corrente elétrica aplicada pelo sensor ao solo, em A; $\mathrm{L}$ é o espaçamento entre os pares de eletrodos de medição, em metros; A é a área da seção transversal dos eletrodos de medição (dos discos do implemento) em contato com o solo, em m², e V é a diferença de potencial do campo eletromagnético gerado no solo medida pelos pares de eletrodos de medição, em v.

\footnotetext{
9 a alusão a empresas ou produtos comerciais se deve somente com o objetivo de providenciar informações específicas da condição na qual a pesquisa foi realizada e não como recomendação ou endossamento da Universidade de São Paulo
} 
Os discos penetram aproximadamente entre $0,06 \mathrm{~m}$ a $0,10 \mathrm{~m}$ no solo. O sistema georeferencia as medições da CEa utilizando um receptor de GPS e armazena os dados resultantes em formato digital. Na figura 1 são apresentados lado a lado os cortes esquemáticos transversais do equipamento utilizado e do arranjo de Wenner ${ }^{1}$, que é o modelo teórico de sensor no qual se fundamentou o seu desenvolvimento. Na figura 2a é apresentado uma foto do equipamento.

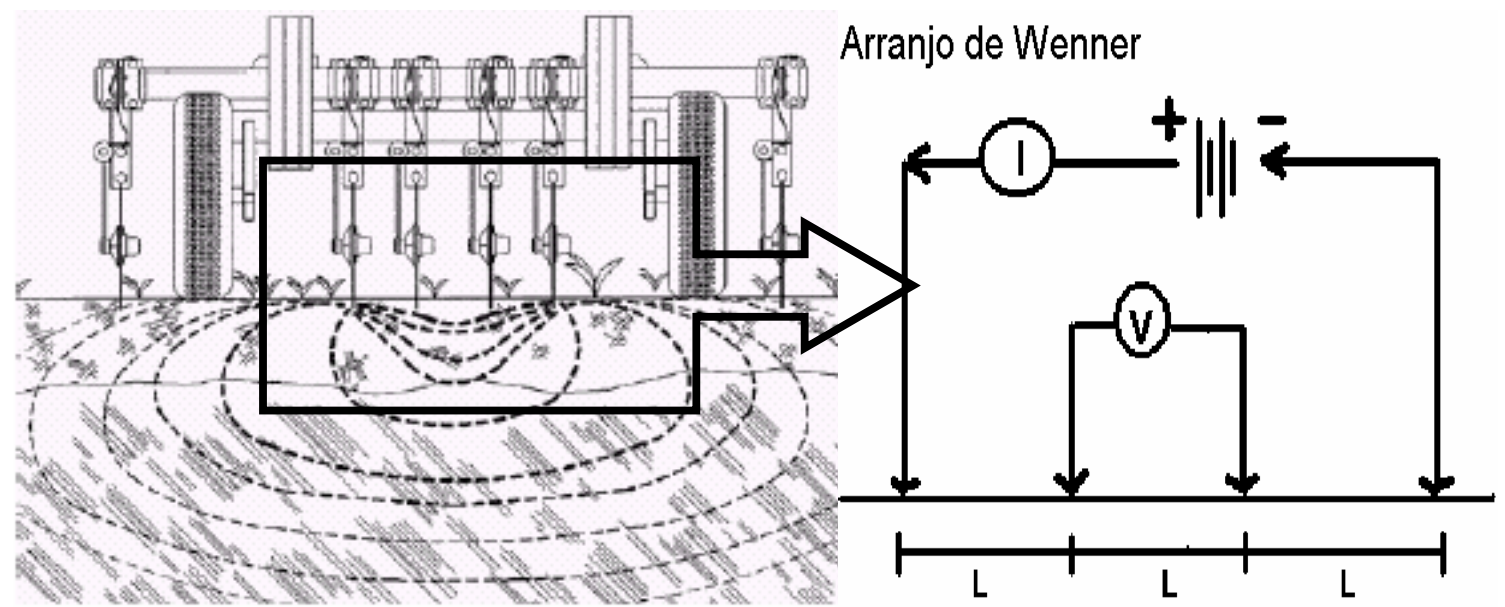

Figura 1 - Corte esquemático transversal do equipamento utilizado; os dois discos mais externos medem a CEa $\left(\mathrm{mS}^{*} \mathrm{~m}^{-1}\right)$ na profundidade de $0-0,90 \mathrm{~m}$, enquanto que os dois discos centrais medem na profundidade de 0-0,30m (Fonte: adaptado de Lund et al., 1999 e de Freeland, 1989)

Para armazenamento das leituras georeferenciadas da CEa do solo o sistema utiliza um equipamento coletor de dados próprio que possui um microprocessador 386SX, com capacidade de leitura contínua de 26 horas de dados obtidos no campo. O coletor de dados grava a latitude, a longitude e os valores da CEa do solo para as leituras rasas $(0-0,30 \mathrm{~m})$ e profunda $(0-0,90 \mathrm{~m})$, cujos valores são expressos em termos de $\mathrm{mS} \mathrm{m}^{-1}$ e são coletados em intervalos de 1 segundo num formato de texto ASCII. Na figura 2b é apresentada uma foto do coletor de dados. 


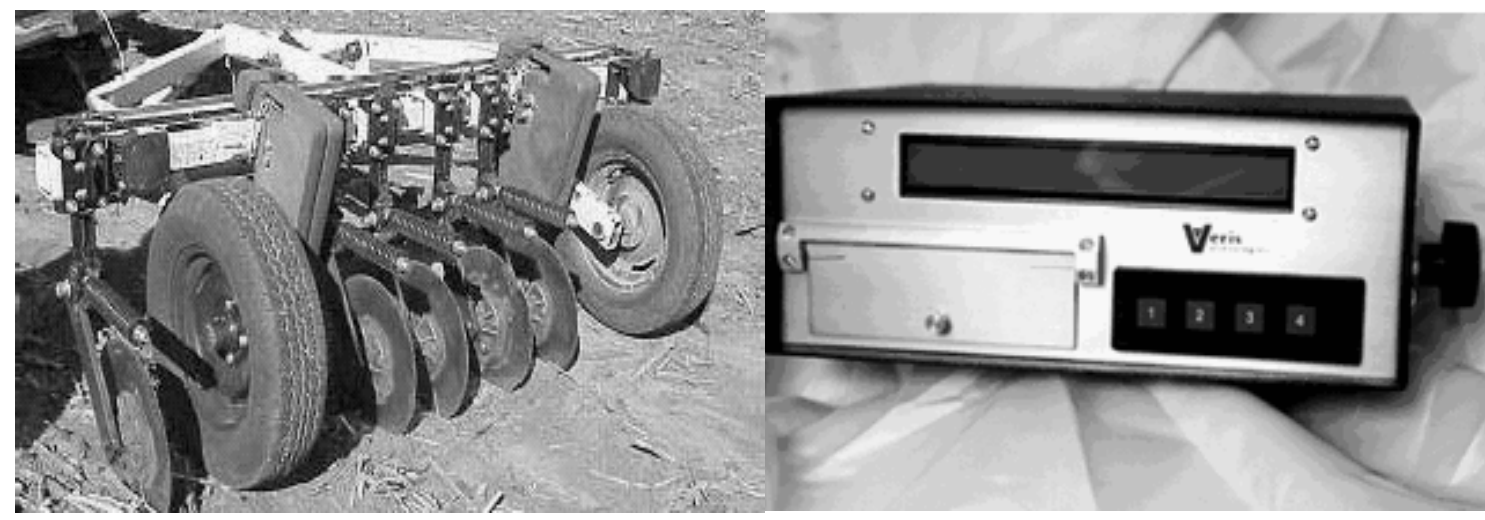

a

b

Figura 2 - Foto do equipamento de CEa do solo utilizado (a) e do seu coletor de dados (b)

\subsection{Coleta dos dados}

\subsubsection{Mapeamento da condutividade elétrica aparente (CEa) do solo}

Cada uma das três áreas avaliadas foram individualmente monitoradas para a CEa do solo, utilizando o equipamento específico apresentado na Figura 2, entre os meses de setembro de 2002 até março de 2003.

A coleta dos dados foi realizada nas áreas cobertas com os resíduos culturais deixados pelas culturas anteriormente cultivadas. O equipamento foi tracionado em cada área por diferentes tratores em transeções paralelas espaçadas em média de 6,0m a 13,0m. Antes da aquisição dos dados em cada área, testes indicados pelo fabricante, foram realizados para certificação do bom funcionamento do equipamento. As informações completas sobre a época e as condições de aquisição dos dados nas três áreas experimentais são apresentadas na Tabela 2.

O coletor de dados do sensor estava ligado a um receptor de sinal de GPS (Sistema de Posicionamento Global) da marca Brunton ${ }^{\circledR}$, nos monitoramentos realizados no ano de 2002, e da marca OmniSTAR (Fugro®), com correção diferencial via satélite geoestacionário (DGPS) da mesma marca, no monitoramento realizado em 2003, para georeferenciamento dos pontos amostrados. Quanto à utilização do receptor de sinal de GPS sem correção diferencial, pesquisas recentes (Molin \& Gimenez, 2002) tem demostrado a boa acurácia de posicionamento obtida por esses equipamentos. 
Tabela 2. Época de coleta dos dados de CEa $\left(\mathrm{mS} \mathrm{m}^{-1}\right)$ do solo, tipo de resíduo cultural presente durante a coleta e número de amostras coletadas em cada uma das áreas estudadas

\begin{tabular}{cccc}
\hline Área & Época da coleta & Resíduo cultural & Número de amostras ha $^{-1}$ \\
\hline Fabc & Setembro/ 2002 & Aveia & 282 \\
& Março/ 2003 & Milho & 323 \\
CR & Outubro/ 2002 & Aveia & 425 \\
RB & Outubro/ 2002 & Aveia & 355 \\
\hline
\end{tabular}

\subsubsection{Dados de produtividade}

Dados de produtividade de grãos $\left(\mathrm{Mg} \mathrm{ha}^{-1}\right)$, em diversas safras, foram coletados nas três áreas utilizando colhedoras comerciais equipadas com monitores de produtividade disponíveis no mercado e receptores dos sinais do sistema de posicionamento global (GPS), com correção diferencial (DGPS). Na Tabela 3 são apresentadas as informações referentes à coleta dos dados de produtividade nas três áreas.

Tabela 3. Safra, cultura, colhedora (marca e modelo) e monitor de produtividade utilizado para coleta dos dados de produtividade em cada área monitorada

\begin{tabular}{cccccc}
\hline Talhão & Safra & Cultura & Colhedora & Modelo & Monitor \\
\hline Fabc & $1998 / 1999$ & Soja & John Deere & 9510 & Greenstar \\
& $1999 / 2000$ & Milho & John Deere & 9510 & Greenstar \\
& $2000 / 2001$ & Soja & John Deere & 9510 & Greenstar \\
& $2001 / 2002$ & Soja & John Deere & 9510 & Greenstar \\
& $2002 / 2003$ & Milho & John Deere & STS 9750 & Greenstar \\
CR & $1999 / 2000$ & Soja & AGCO & MF 34 & Fieldstar \\
& $2000 / 2001$ & Milho & AGCO & MF 34 & Fieldstar \\
& $2001 / 2002$ & Soja & AGCO & MF 34 & Fieldstar \\
& $2002 / 2003$ & Milho & AGCO & MF 34 & Fieldstar \\
RB & $1998 / 1999$ & Soja & John Deere & 9510 & Greenstar \\
& $2000 / 2001$ & Soja & John Deere & 9510 & Greenstar \\
& $2001 / 2002$ & Soja & John Deere & 9510 & Greenstar \\
& $2002 / 2003$ & Milho & John Deere & STS 9750 & Greenstar \\
\hline
\end{tabular}




\subsubsection{Análises químicas do solo}

Para avaliar a relação da CEa com os atributos físico-químicos do solo utilizou-se os resultados das amostragens sistemáticas do solo, nas quais os pontos de amostragem foram localizados em intervalos regulares, realizados nas três áreas experimentais no ano de 2001. Foram coletadas amostras de solo na profundidade de 0 a $0,10 \mathrm{~m}$. As amostras foram coletadas mecanicamente, ou manualmente, com trado holandês (5 cm de diâmetro) obedecendo um arranjo sistemático com 8 a 9 sub-amostras em cada ponto de amostragem, perfazendo número variado de amostras georeferenciadas em cada área.

Nas amostras de solo, determinaram-se os valores de: potencial de hidrogênio $(\mathrm{pH})$, determinado em solução $\mathrm{CaCl}_{2}$; matéria orgânica (MO) $\left(\mathrm{g} \mathrm{dm}^{-3}\right)$, determinada pelo método de Walkley-Black; fósforo (mg dm$\left.{ }^{-3}\right)$, extraído por resina; alumínio (Al) $\left(\mathrm{mmol}_{\mathrm{c}} \mathrm{dm}^{-3}\right)$, extraído por $\mathrm{KCl}$; acidez potencial $(\mathrm{H}+\mathrm{Al})\left(\mathrm{mmol}_{\mathrm{c}} \mathrm{dm}^{-3}\right)$, determinado potenciometricamente após adição da solução tampão (SMP); potássio $(\mathrm{K})\left(\mathrm{mmol}_{\mathrm{c}} \mathrm{dm}^{-3}\right)$, Ca $(\mathrm{Ca})\left(\mathrm{mmol}_{\mathrm{c}} \mathrm{dm}^{-3}\right)$ e magnésio $(\mathrm{Mg})$ $\left(\mathrm{mmol}_{\mathrm{c}} \mathrm{dm}^{-3}\right)$ extraídos por resina e por último argila (\%) e areia (\%) determinados pelo método de dispersão total. Além desses atributos foram calculados os valores da soma de bases (SB) $\left(\mathrm{mmol}_{\mathrm{c}} \mathrm{dm}^{-3}\right)$, da capacidade de troca de cátions (CTC) $\left(\mathrm{mmol}_{\mathrm{c}} \mathrm{dm}^{-3}\right)$, da saturação por bases (V\%) (\%) e da saturação por alumínio (Al\%) (\%). Referências mais completas a todas as metodologias de determinações dos teores desses atributos podem ser encontradas no trabalho de Raij et al. (1987).

As análises químicas das amostras foram realizadas no laboratório da Fundação ABC, localizado na cidade de Castro, PR. Na Tabela 4 são apresentadas as informações sobre as amostragens realizadas nessas três áreas.

Tabela 4. Área onde as amostras de solo foram coletadas, ano de realização e densidade da amostragem

\begin{tabular}{ccc}
\hline Talhão & Ano & Número de amostras ha $^{-1}$ \\
\hline Fabc & 2001 & 10 \\
CR & 2001 & 2 \\
RB & 2001 & 2 \\
\hline
\end{tabular}




\subsection{Análise dos dados}

A análise dos dados foi realizada em seis etapas: (i) estatística descritiva; (ii) análise exploratória (somente para os dados de CEa do solo); (iii) análise geoestatística; (iv) análise multivariada; (v) lógica de agrupamentos fuzzy e (vi) análise de variância.

\subsubsection{Estatística descritiva}

A analise das distribuições da CEa do solo, da produtividade nas diferentes safras e dos atributos físico-químicos do solo nas áreas monitoradas foi inicialmente realizada por meio da estatística descritiva.

Para caracterizar a posição central e a dispersão dos dados calculou-se os momentos estatísticos de ordem até quatro, que também expressam o formato da distribuição, através dos coeficientes de assimetria e curtose. O coeficiente de variação (CV) também foi calculado para se verificar a dispersão dos dados em relação a média de cada distribuição, servindo de parâmetro de comparação da dispersão nas diferentes distribuições. Adotou-se a classificação proposta por Gomes (1984) para qualificar a variação de cada variável em função do seu CV. Segundo essa classificação, uma variável com CV menor que $10 \%$ é considerado de baixa variação; entre 10-20\% média variação; de 20-40\% alta variação e maior do que 40\%, muito alta variação.

A etapa seguinte foi a verificação do ajuste dos dados à distribuição normal, sendo utilizado para isso a avaliação dos coeficientes de assimetria e curtose e em seguida o teste de Kolmogorov-Smirnov (K-S) a diferentes níveis de probabilidade. A hipótese nula, de que a distribuição de uma variável era normal, foi rejeitada sempre que $\mathrm{P} \leq 0,10$.

Para os dados de CEa utilizou-se os quartis e a amplitude interquartílica para verificar se valores extremos podem ser considerados candidatos a discrepantes. Os dados candidatos a discrepantes foram caracterizados, segundo metodologia proposta por Tukey (1977), como todos cujos valores são menores do que o quartil inferior menos 1,5 vezes a amplitude interquartílica e maiores do que o quartil superior mais 1,5 vezes a amplitude interquartílica. Os dados de produtividade sofreram processo de remoção de erros segundo metodologia de Gimenez \& Molin (2000).

Todas as etapas de estatística descritiva foram realizadas no programa STATISTICA (Statsoft Inc., 1999). 


\subsubsection{Análise exploratória}

Os valores dos dados da CEa foram analisados numa nova etapa segundo a análise descritiva espacial, pois, apesar da qualidade da informação a respeito da distribuição do conjunto de dados fornecidos pela estatística descritiva, essa ignora a posição espacial dos dados. Essa etapa de visualização espacial foi realizada para as variáveis CEa, em ambas as profundidades de leitura, utilizando-se o programa Surfer 6.01 (Golden Software Inc. 1995) para gerar um mapa no qual as amostras são representadas georeferenciadas. Esse recurso foi utilizado para auxiliar no processo de decisão sobre a manutenção, ou exclusão, dos pontos de CEa candidatos a discrepantes, assim identificados pelo método de Tukey (1977), através da visualização da distribuição espacial desses mesmos pontos (Issaks \& Srivastava, 1989).

\subsubsection{Análise geoestatística}

\subsubsection{Análise de dependência espacial}

Para realização da análise de dependência espacial das variáveis (CEa, produtividade e atributos físico-químicos do solo) utilizou-se as ferramentas derivadas da teoria das variáveis regionalizadas. Foi necessário adotar algumas hipóteses para as variáveis coletadas, equivalentes àquelas assumidas pela teoria geoestatística (estacionaridade intrínseca).

Utilizando o software VESPER 1.5 (Minasny et al., 2002) foi realizada a construção dos semivariogramas experimentais para as distribuições da CEa, da produtividade nas diferentes safras e das demais variáveis físico-químicas do solo nas três áreas experimentais. Foi utilizado o estimador clássico do semivariograma, ou método dos momentos, ou estimador de Matheron.

A etapa seguinte constituiu do ajuste do modelo aos semivariogramas experimentais obtidos. Os modelos avaliados foram os disponíveis no software VESPER 1.5 (Minasny et al., 2002), sendo eles o exponencial, o gaussiano, o esférico, o função potência e o linear com patamar. Para a escolha dos modelos, e dos parâmetros desses, mais adequados para cada caso, foi utilizado o critério de minimização da soma dos erros quadrados. O grau de dependência espacial foi avaliado segundo critérios propostos por Cambardella et al. (1994). 


\subsubsection{Mapas de superfície}

Após a análise de dependência espacial de todas as variáveis foram realizadas estimativas em locais não amostrados, com o intuito de gerar mapas de superfície, sendo que nos casos em que se identificou dependência espacial de determinada variável a estimativa $\left(Z^{*}\right)$ em determinada posição geográfica $\left(\mathrm{X}_{0}\right)$ pode ser obtida por:

$$
Z *\left(x_{0}\right)=\sum_{i=1}^{N} \lambda_{i} Z\left(x_{i}\right)
$$

onde, $\mathrm{N}$ é o número de vizinhos utilizados na estimativa do valor $\mathrm{Z} *\left(\mathrm{X}_{0}\right)$; $\mathrm{Z}\left(\mathrm{X}_{\mathrm{i}}\right)$ é o valor medido na posição $\mathrm{X}_{\mathrm{i}}$ e $\lambda_{\mathrm{i}}$ é o peso associado ao valor medido na posição $\mathrm{X}_{\mathrm{i}}$ (Isaaks \& Srivastava, 1989; Webster \& Oliver, 1990; Martinho, 2001).

Estabelecendo como critérios para a interpolação de uma variável as características de estimativa sem tendenciosidade e de variância mínima, e submetendo-se a equação (6) a essas condições, obtêm-se o sistema de equações que caracterizam a interpolação conhecida por krigagem:

$$
\begin{gathered}
\sum_{j=1}^{N} \lambda_{j} \gamma\left(x_{i}, x_{j}\right)+\mu=\gamma\left(x_{i}, x_{0}\right), i=1, N \\
\sum_{j=1}^{N} \lambda_{j}=1
\end{gathered}
$$

onde, $\gamma\left(\mathrm{x}_{\mathrm{i}}, \mathrm{x}_{\mathrm{j}}\right)$ é a semivariância fornecida pelo modelo ajustado ao semivariograma experimental, correspondente à distância entre os pontos localizados nas coordenadas $\mathrm{x}_{\mathrm{i}}$ e $\mathrm{x}_{\mathrm{j}}$ e $\gamma\left(\mathrm{x}_{\mathrm{i}}, \mathrm{x}_{0}\right)$ é $\mathrm{a}$ semivariância na distância entre os pontos localizados nas posições $\mathrm{x}_{\mathrm{i}}$ e $\mathrm{x}_{0}$, que é também fornecida pelo semivariograma modelado.

Para digitalização e visualização da distribuição espacial dos atributos estudados utilizouse dos recursos da krigagem ordinária por blocos realizada pelo programa VESPER 1.5 (Minasny et al., 2002). O tamanho da célula do mapa gerado foi estabelecido em 10,0m. O número de amostras a serem utilizadas na estimativa de cada bloco foi estabelecida no intervalo entre o mínimo de 4 e o máximo de 150. Para as variáveis físico-químicas do solo (com exceção da CEa) o raio de busca da krigagem foi estabelecido como sendo igual ao alcance da continuidade espacial da respectiva variável. Já para as variáveis produtividade e CEa o raio de busca foi determinado pelo programa VESPER 1.5 (Minasny et al., 2002). 


\subsubsection{Análise multivariada}

Considerando que, nesse estudo, diversas variáveis físico-químicas do solo foram monitoradas, entre elas a CEa, visando a definição das unidades de gerenciamento do solo, e que essas variáveis são interdependentes umas das outras, uma análise multivariada desse conjunto de dados se fez necessária, não só para se investigar a relação entre elas, mas também para se avaliar qual dessas variáveis físico-químicas do solo são as mais importantes para se definir as unidades de gerenciamento do solo e, durante esse processo, responder a pergunta se a CEa é uma fonte de informação com alguma valia nessa definição.

\subsubsection{Análise de correlação entre variáveis}

Como primeira etapa da análise da relação entre as diferentes variáveis monitoradas nesse estudo realizou-se o cálculo do coeficiente de correlação linear de Pearson, que é uma medida do grau de relação linear entre duas variáveis. Nesse estudo, avaliou-se a correlação entre a CEa medida, com todas as outras variáveis (produtividade e físico-químicas do solo) e entre as de produtividade e as físico-químicas do solo entre si, com o objetivo de verificar possíveis relações entre elas. Essa análise foi realizada no programa STATISTICA (Statsoft Inc., 1999), utilizando como dados de cada variável os resultados de interpolação após a krigagem, com superfícies de células de 10 por 10m, de todas as variáveis envolvidas, célula a célula.

\subsubsection{Análise de componentes principais}

Utilizou-se da técnica de análise de componentes principais para determinar quais variáveis do solo eram as mais importantes na caracterização da variabilidade presente nas três áreas experimentais e através das novas variáveis obtidas nessa análise, os componentes principais, realizar o processo de classificação utilizando a técnica fuzzy k-means (tipo de análise

“cluster”), visando a definição de unidades de gerenciamento do solo. Para realizar a análise de componentes principais foi utilizado o programa STATISTICA (Statsoft Inc, 1999). Os mesmos conjuntos de valores de cada variável, obtidos do processo de krigagem ordinária por blocos, foram utilizados na análise de componentes principais, sendo que, anteriormente à realização da análise, cada propriedade físico-química do solo incluída na mesma foi padronizada segundo a equação: 


$$
Z_{i}=\frac{X_{i}-X_{m}}{S_{i}}
$$

onde, $Z_{\mathrm{i}}$ é a variável padronizada (média igual a zero, variância igual a unidade) e $X_{m}$ e $S_{i}$ são, respectivamente, a média e o desvio padrão da variável i. Essa etapa foi realizada apenas com o intuito de simplificar a análise, não sendo procedimento obrigatório da mesma. A seleção dos componentes principais foi feita após avaliação de diversos critérios apresentados por Afifi \& Clark (1996).

\subsubsection{Classificação contínua}

O principal objetivo numa classificação não supervisionada (clustering) é a identificação de agrupamentos naturais ocorrendo nos dados. Esse processo de classificação foi utilizado como método para agrupamento das novas variáveis (os componentes principais), obtidas pela transformação das variáveis físico-químicas (entre essas está incluído a variável CEa do solo nas duas profundidades na qual ela foi monitorada) do solo pela técnica de análise de componentes principais.

O algoritmo utilizado foi o fuzzy k-means (DeGruijter \& McBratney, 1988). A partir dos valores dos componentes principais selecionados, que foram obtidos na etapa 3.4.4.2, utilizou-se o programa FuzME (Minasny \& McBratney, 2000) para definir as unidades de gerenciamento do solo em cada uma das três áreas avaliadas. Os agrupamentos foram obtidos através de um processo iterativo, começando com um conjunto de valores tomados ao acaso.

O processo começa com médias arbitrárias sendo estabelecidas pelo programa para cada agrupamento, onde cada agrupamento corresponde a uma unidade de gerenciamento. Como dados de entrada indicou-se inicialmente o número mínimo e o máximo de unidades de gerenciamento, 2 e 8 respectivamente, escolha essa requisitada pelo programa FuzMe para iniciar o processo de agrupamento. Essa escolha foi feita de forma arbitrária, assumindo-se que oito unidades de gerenciamento do solo seria o limite máximo que ainda teria alguma aplicabilidade prática na administração de áreas com tamanhos equivalentes às investigadas nesse estudo. Em seguida definiu-se o número máximo de iterações (300), o expoente fuzzy $(1,2)$, o critério de encerramento da análise $(0,0001)$ e o tipo de critério de distância a ser utilizado entre as observações e o centróide de cada classe (euclidiana).

A informação resultante dessa análise, fornecida pelo programa, são os valores da função de participação de cada indivíduo (cada célula do mapa de superfície, gerado pela krigagem, de 
cada variável, é um indivíduo) nas K classes de agrupamento dos dados definidas pelo usuário. Além disso o programa fornece também outras informações que serão utilizadas nesse trabalho, especificamente os índices CI, FPI e MPE.

Para permitir visualização das classes definidas por essa análise utilizou-se de recursos do programa Surfer 6.01 (Golden Software, Inc., 1995).

Para se determinar o número ótimo de unidades de gerenciamento em cada uma das áreas utilizou-se o índice de desempenho fuzzy (FPI: "Fuzziness Perfomance Index”) e a partição da entropia modificada (MPE: “Modified Partition Entropy”), dois índices fornecidos pelo próprio programa FuzMe (Minasny \& McBratney, 2000). O número ótimo de classes de agrupamentos (unidades de gerenciamento) é então definido como aquele no qual esses dois índices atinjam aproximadamente o mínimo (Odeh et al., 1992; Fridgen et al., 2000; Sa, 2001).

De maneira complementar a esses dois índices, e visando auxiliar nessa decisão do número ótimo de unidades de gerenciamento, realizou-se a investigação da redução da variância das variáveis CEa, produtividade das culturas e propriedades físico-químicas do solo em função da divisão da área, apenas para a área CR. A variância dessas variáveis foi ponderada para cada unidade de gerenciamento, em função da área da mesma, segundo a fórmula:

$$
S_{Z}^{2}=\frac{1}{n_{T}} \sum_{i}\left(Y_{i}-Y_{Z}\right)^{2}
$$

onde, $S_{Z}^{2}$ é a variância ponderada para a unidade $\mathrm{Z} ; \mathrm{n}_{\mathrm{T}}$ é o número de observações (células) na unidade $\mathrm{Z} ; \mathrm{Y}_{\mathrm{i}}$ é o valor da variável na célula i; $\mathrm{Y}_{\mathrm{z}}$ é a média da variável na unidade $\mathrm{Z}$ e i varia de 1 até o número de observações na unidade de gerenciamento Z . A variância total da área foi definida como sendo a soma das variâncias ponderadas de cada unidade de gerenciamento, que foi calculada pela seguinte fórmula:

$$
S_{T}^{2}=S_{1}^{2}+S_{2}^{2}+\ldots+S_{Z}^{2}
$$

e essa variância total, para a área dividida em $\mathrm{Z}$ unidades de gerenciamento, foi dividido pela variância original da área inteira como sendo uma única unidade. Observou-se, dessa maneira, o quanto da variância total de um atributo em cada área, pôde ser explicada em função da sua divisão em Z unidades de gerenciamento do solo.

Verificou-se então a existência de concordância, ou não, na definição do número ótimo de unidades de gerenciamento, através dos índices FPI e MPE e da análise da redução da variância das variáveis em função da divisão da área. 


\subsubsection{Análise de variância}

Utilizando o programa STATISTICA (Statsoft, 1999) realizou-se em cada área a análise de variância (ANOVA) para as variáveis CEa, produtividade das culturas e atributos físicoquímicos do solo entre as diferentes unidades de gerenciamento, para verificar se entre elas existiam diferenças significativas entre as médias dessas variáveis. Foi utilizada como variável dependente nesse processo uma contendo a unidade à qual cada indivíduo pertence. Para realizar as comparações entre as unidades de gerenciamento foi utilizado o teste HSD ("Honest Significant Difference”) de Tukey para amostras de diferentes tamanhos. 


\section{RESULTADOS E DISCUSSÃO}

\subsection{Estatística descritiva}

Anteriormente à realização da análise de estatística descritiva dos dados de CEa, tanto rasa quanto profunda, coletadas nas três áreas experimentais, foi realizada um processo de filtragem dos dados para retirada de valores negativos de CEa. Esses valores são erros decorrentes da falta de contato do disco do sensor de condutividade elétrica com o solo durante o monitoramento das áreas. Na Tabela 5 é apresentado o número de leituras negativas da CEa rasa e profunda nos quatro monitoramentos realizados.

Tabela 5. Número de leituras negativas de condutividade elétrica aparente do solo (CEa) nas leituras rasa $(0-0,3 \mathrm{~m})$ e profunda $(0-0,9 \mathrm{~m})$ nas três áreas experimentais

\begin{tabular}{ccccc}
\hline Área & CEa rasa & CEa profunda & $\begin{array}{c}\text { Total de pontos } \\
\text { antes da filtragem }\end{array}$ & $\begin{array}{c}\text { Total de pontos } \\
\text { após filtragem }\end{array}$ \\
\hline Fabc 2002 & 1 & 2 & 6281 & 6278 \\
Fabc 2003 & 45 & 28 & 7190 & 7117 \\
CR & 0 & 0 & 6725 & 6725 \\
RB & 0 & 644 & 13362 & 12718 \\
\hline
\end{tabular}

Todas as leituras negativas foram retiradas do conjunto de dados originais. O número de leituras negativas observadas para a CEa profunda na área RB foi devido ao fato dessa área apresentar uma região com relevo mais ondulado, o que provocou a perda do contato dos discos externos, responsáveis pela leitura profunda, com uma maior freqüência que nas outras áreas.

Na seqüência da análise são apresentadas, nas Tabelas 6 e 7, as estatísticas descritivas para os valores da CEa rasa e profunda nos monitoramentos realizados. 
Tabela 6. Estatística descritiva para os valores de condutividade elétrica aparente do solo $(\mathrm{CEa})(\mathrm{mS} / \mathrm{m})$ nas leituras rasa $(0-0,3 \mathrm{~m})$ e profunda $(0-0,9 \mathrm{~m})$, obtidos na área experimental Fabc nos meses de outubro de 2002 e março de 2003

\begin{tabular}{lcccc}
\hline \multirow{2}{*}{ Estatística } & \multicolumn{2}{c}{ CEa (outubro/2002) } & \multicolumn{2}{c}{ CEa (março/2003) } \\
\cline { 2 - 5 } & rasa & profunda & Rasa & profunda \\
\hline Média & 12,94 & 6,32 & 7,51 & 4,76 \\
Mediana & 12,70 & 6,10 & 7,30 & 4,60 \\
Mínimo & 5,00 & 2,60 & 1,00 & 1,30 \\
Máximo & 31,00 & 34,50 & 29,50 & 28,40 \\
Q. inferior & 11,10 & 5,40 & 5,80 & 3,90 \\
Q. superior & 14,50 & 6,90 & 9,10 & 5,40 \\
L. inferior & 6,00 & 3,15 & 0,85 & 1,65 \\
L. superior & 19,60 & 9,15 & 14,05 & 7,65 \\
Desvio padrão & 2,66 & 1,44 & 2,49 & 1,41 \\
Assimetria & 0,88 & 3,89 & 0,91 & 2,82 \\
Curtose & 2,30 & 46,49 & 3,83 & 25,56 \\
CV & 20,55 & 22,78 & 33,15 & 29,62 \\
D & $0,06^{*}$ & $0,10^{*}$ & $0,04 *$ & $0,08^{*}$ \\
\hline
\end{tabular}

* - distribuição normal a 1\% de probabilidade (Campos, 1983). 
Tabela 7. Estatística descritiva para os valores de condutividade elétrica aparente do solo $(\mathrm{CEa})(\mathrm{mS} / \mathrm{m})$ nas leituras rasa $(0-0,3 \mathrm{~m})$ e profunda $(0-0,9 \mathrm{~m})$, obtidos nas áreas experimentais CR e RB

\begin{tabular}{lcccc}
\hline \multirow{2}{*}{ Estatística } & \multicolumn{2}{c}{ CEa (área CR) } & \multicolumn{2}{c}{ CEa (área RB) } \\
\cline { 2 - 5 } & rasa & profunda & rasa & profunda \\
\hline Média & 9,70 & 6,09 & 4,86 & 2,70 \\
Mediana & 9,50 & 6,70 & 5,00 & 2,70 \\
Mínimo & 4,30 & 2,70 & 0,70 & 0,60 \\
Máximo & 28,00 & 16,00 & 15,00 & 7,80 \\
Q. inferior & 8,40 & 5,30 & 3,70 & 2,30 \\
Q. superior & 10,70 & 6,80 & 5,90 & 3,20 \\
L. inferior & 4,95 & 3,05 & 0,40 & 0,95 \\
L. superior & 14,15 & 9,05 & 8,20 & 4,55 \\
Desvio padrão & 1,99 & 1,21 & 0,62 & 1,64 \\
Assimetria & 1,16 & 1,04 & 0,40 & 0,95 \\
Curtose & 4,38 & 3,75 & 9,20 & 4,55 \\
CV & 20,51 & 19,86 & 12,75 & 60,74 \\
D & $0,06^{*}$ & $0,04 *$ & $0,04^{*}$ & $0,07 *$ \\
\hline
\end{tabular}

* - distribuição normal a 1\% de probabilidade (Campos, 1983).

Observando os resumos estatísticos apresentados nas Tabelas 6 e 7 é importante se destacar a maior magnitude dos valores de CEa rasa em todas as áreas em relação a CEa profunda. Um fator, dentre outros, que podem explicar esse fato é a elevada fertilidade do solo praticada na região onde foi realizada esse estudo. Isso acarretou a existência, na camada superficial do solo $(0-10 \mathrm{~cm})$, de um ambiente com concentração da solução do solo mais elevada, devido as grandes quantidades de nutrientes aplicados ao solo, na forma de adubos químicos e de matéria orgânica. Esta ocorrência de acúmulo superficial de fertilizantes é verificada no sistema plantio direto (Martinho, 2001).

A variabilidade dos valores de CEa, tanto rasa quanto profunda, evidenciada pelo coeficiente de variação, oscilou no intervalo entre 12,75\% (CEa rasa na área RB), que é considerada como variação média (Gomes, 1984), até 60,74\%, uma variação muito alta (CEa profunda na mesma área). Em todas as outras áreas experimentais ela ficou num nível de 20 a $30 \%$, indicando alta variabilidade para essa variável.

Outro fato importante destacado pelo resumo estatístico foi a diferença em valores absolutos entre a CEa medida na área Fabc em outubro de 2002 e março de 2003, evidenciando a 
variabilidade temporal dessa variável, sendo a CEa em média maior na primeira data de monitoramento. Além disso, é interessante observar a maior variabilidade espacial dessa variável na segunda época de monitoramento (março de 2003).

Também é importante ressaltar que as distribuições da CEa em ambas as profundidades em todas as áreas monitoradas foram constatadas como sendo normais ao nível de $1 \%$ de probabilidade após análise de ajuste à distribuição normal pelo teste de Kolgomorov-Smirnov (K-S), descrito por Campos (1983). Isso apesar do alto valor de curtose calculado para algumas dessas variáveis, especificamente para a CEa profunda nos dois monitoramentos realizados na área Fabc. No entanto, a grande quantidade de dados da distribuição e o pequeno número de valores extremos perante o total de dados levaram essas distribuições a serem caracterizadas como normais pelo teste K-S. A proximidade dos valores da média e da mediana para a distribuição da CEa do solo, monitorada nas diversas áreas, foi outro fator que enfatizou ainda mais a normalidade das distribuições.

O ajuste à distribuição normal é uma característica avaliada com rigor para todas as variáveis consideradas nesse estudo, devido à realização da etapa de análise de dependência espacial e interpolação por krigagem, se beneficiar de distribuições mais simétricas em torno da média (Webster \& Oliver, 1990).

Para as variáveis CEa rasa e profunda, em todos os monitoramentos realizados, foi calculado o valor dos limites inferior e superior da distribuição dessas variáveis, segundo metodologia proposta por Tukey (1977). Isso foi feito para se analisar possíveis valores extremos de cada distribuição, os quais após consideração mais cuidadosa são passíveis de serem excluídos do conjunto de dados originais por serem considerados discrepantes.

Os valores dos limites inferior e superior de cada distribuição são apresentados, juntamente com o restante do resumo estatístico, nas Tabelas 6 e 7, sendo que a partir desses valores se verificou, para cada distribuição, o número de dados tanto com valores abaixo quanto acima dos limites estabelecidos pelo método de Tukey (1977). Os resultados dessa análise são apresentados na Tabela 8. 
Tabela 8. Número de pontos candidatos a discrepantes para os valores das variáveis CEa rasa (00,3m) e CEa profunda (0-0,9m) nas três áreas experimentais

\begin{tabular}{cccc}
\hline Área & Variável & \multicolumn{2}{c}{ Número de valores candidatos a discrepantes } \\
\cline { 3 - 4 } & & Abaixo do limite inferior & Acima do limite superior \\
\hline Fabc 2002 & CEa rasa & 10 & 103 \\
& CEa profunda & 13 & 183 \\
Fabc 2003 & CEa rasa & 0 & 76 \\
& CEa profunda & 12 & 165 \\
CR 2002 & CEa rasa & 4 & 193 \\
& CEa profunda & 1 & 119 \\
RB 2002 & CEa rasa & 0 & 227 \\
& CEa profunda & 177 & 286 \\
\hline
\end{tabular}

Observando o resultado da Tabela 8 verifica-se que todas as distribuições apresentaram um maior número de dados acima do limite superior do que abaixo do limite inferior, fato esse de acordo com as assimetrias positivas apresentadas nos resumos estatísticos das Tabelas 6 e 7 .

A decisão de se manter esses dados, ou excluir os mesmos da seqüência desse trabalho, será realizada na etapa de análise exploratória dos dados, onde esses valores, candidatos a discrepantes de cada distribuição, serão visualizados, respeitando suas respectivas posições geográficas, nos mapas representativos das áreas experimentais onde os monitoramentos da CEa foram realizados.

Nas Tabelas 9, 10 e 11 são apresentados os resumos estatísticos para a distribuição dos valores de cada monitoramento de produtividade realizada nas três áreas experimentais. 
Tabela 9. Estatística descritiva para os valores de produtividade $\left(\mathrm{Mg} \mathrm{ha}^{-1}\right)$ nas safras de 1998/1999 até 2002/2003 na área experimental Fabc

\begin{tabular}{|c|c|c|c|c|c|}
\hline \multirow[t]{2}{*}{ Estatística } & \multicolumn{5}{|c|}{ Variável } \\
\hline & $\begin{array}{c}\text { Soja 1998/ } \\
1999 \\
\end{array}$ & $\begin{array}{c}\text { Milho 1999/ } \\
2000 \\
\end{array}$ & $\begin{array}{c}\text { Soja 2000/ } \\
2001 \\
\end{array}$ & $\begin{array}{c}\text { Soja 2001/ } \\
2002 \\
\end{array}$ & $\begin{array}{c}\text { Milho 2002/ } \\
2003 \\
\end{array}$ \\
\hline Média & 3,18 & 9,92 & 3,67 & 3,65 & 10,47 \\
\hline Mediana & 3,18 & 9,92 & 3,70 & 3,66 & 10,40 \\
\hline Mínimo & 1,05 & 3,31 & 1,11 & 1,16 & 3,47 \\
\hline Máximo & 6,22 & 16,79 & 9,91 & 9,83 & 19,74 \\
\hline Des. pad. & 0,68 & 1,67 & 0,79 & 0,79 & 2,01 \\
\hline Assimetria & 0,17 & $-0,91$ & 0,10 & 0,32 & 0,10 \\
\hline Curtose & 1,25 & 1,11 & 2,31 & 2,18 & 0,60 \\
\hline $\mathrm{CV}$ & 21,38 & 16,83 & 21,52 & 21,64 & 19,19 \\
\hline $\mathrm{D}$ & $0,03 *$ & $0,03^{*}$ & $0,04 *$ & $0,02 *$ & $0,02 *$ \\
\hline
\end{tabular}

* - distribuição normal a 1\% de probabilidade (Campos, 1983).

A distribuição da produtividade nas diferentes safras na área Fabc é apresentada na Tabela 9. Todas as distribuições foram consideradas como sendo normais conforme verificado pelo teste K-S a 1\% de probabilidade. Em todas as safras, com exceção da 1999/2000, a assimetria foi positiva. A variabilidade da produtividade nessa área foi no geral menor do que aquela verificada para a CEa do solo. Além disso, apresentando uma certa constância de safra para safra, se enquadrando sempre no limite entre a classificação de média e de alta variação (Gomes, 1984).

Um detalhe interessante é a grande semelhança obtida para as distribuições da produtividade de soja nas safras 2000/2001 e 2001/2002, indicando uma possível baixa variabilidade temporal nessas safras para a variável produtividade de soja.

Na Tabela 10 são apresentados os resumos estatísticos das distribuições de produtividade na área CR. Novamente ocorre a normalidade a 1\% de probabilidade. Ao contrário do observado na área Fabc, em todas as safras ocorreram valores de assimetria negativos, indicando que, possivelmente, determinadas regiões dessa lavoura apresentam a característica de continuamente produzirem abaixo da média.

Outro aspecto a ser considerado são os valores de coeficiente de variação mais baixos verificados nessa área (variando entre médios e até mesmo baixo para a safra de 2000/2001) do que na área Fabc, sendo que a partir desse fato pode-se inferir de que a variabilidade espacial da 
produtividade nessa área é menor do que naquela. Alguns valores médios de produtividade encontrados nessa área, notadamente nas safras de 2000/2001 e 2001/2002, despertam a atenção para a característica de alta (em alguns casos muito alta) produtividade dessas lavouras.

Tabela 10. Estatística descritiva para os valores de produtividade $\left(\mathrm{Mg} \mathrm{ha}^{-1}\right)$ nas safras de 1999/2000 até 2002/2003 na área experimental CR

\begin{tabular}{lcccc}
\hline \multirow{2}{*}{ Estatística } & \multicolumn{4}{c}{ Variável } \\
\cline { 2 - 5 } & Soja 1999/ 2000 & Milho 2000/ 2001 & Soja 2001/2002 & Milho 2002/ 2003 \\
\hline Média & 3,42 & 12,01 & 4,51 & 8,37 \\
Mediana & 3,47 & 12,09 & 4,61 & 8,47 \\
Mínimo & 1,46 & 7,05 & 1,89 & 3,22 \\
Máximo & 4,76 & 16,80 & 6,59 & 11,61 \\
Desvio padrão & 0,44 & 0,69 & 0,66 & 0,98 \\
Assimetria & $-1,02$ & $-1,08$ & $-0,64$ & $-0,98$ \\
Curtose & 2,30 & 5,45 & 0,28 & 2,47 \\
CV & 12,87 & 5,75 & 14,63 & 11,71 \\
D & $0,09 *$ & $0,05^{*}$ & $0,06 *$ & $0,07 *$ \\
\hline
\end{tabular}

* - distribuição normal a 1\% de probabilidade (Campos, 1983).

Na Tabela 11 são apresentados os resumos estatísticos da análise de produtividade para a área RB. Novamente, as distribuições foram constatadas como sendo normais a $1 \%$ de probabilidade. Nenhuma tendência à assimetria foi verificada nessa área quanto às variáveis produtividade das culturas. Os valores do coeficiente de variação nas diferentes safras, no geral, foram maiores do que os encontrados para a área CR, se assemelhando aos valores encontrados na área Fabc e todos eles estão no limite entre média e alta variação. 
Tabela 11. Estatística descritiva para os valores de produtividade $\left(\mathrm{Mg} \mathrm{ha}^{-1}\right)$ nas safras de 1998/1999 até 2002/2003 na área experimental RB

\begin{tabular}{lcccc}
\hline \multirow{2}{*}{ Estatística } & \multicolumn{4}{c}{ Variável } \\
\cline { 2 - 5 } & Soja 1998/1999 & Soja 2000/2001 & Soja 2001/2002 & Milho 2002/2003 \\
\hline Média & 3,58 & 3,87 & 3,68 & 7,90 \\
Mediana & 3,62 & 3,95 & 3,79 & 7,81 \\
Mínimo & 1,10 & 1,27 & 0,67 & 4,21 \\
Máximo & 6,99 & 10,71 & 9,75 & 14,99 \\
Desvio padrão & 0,79 & 0,79 & 0,80 & 1,54 \\
Assimetria & 0,05 & $-0,29$ & $-0,49$ & 0,70 \\
Curtose & 1,20 & 1,86 & 2,07 & 1,38 \\
CV & 22,06 & 20,41 & 21,73 & 19,49 \\
D & $0,04 *$ & $0,05^{*}$ & $0,07^{*}$ & $0,04^{*}$ \\
\hline * - distribuição normal a 1\% de probabilidade (Campos, 1983).
\end{tabular}

Além das observações realizadas sobre a produtividade obtida nessas três áreas experimentais, é importante ressaltar também a característica dessas lavouras de serem, sem exceções, todas lavouras de alta produtividade agrícola, fato constatado através das médias de produtividade obtidas em todas as três áreas nas várias safras, com média de produtividade

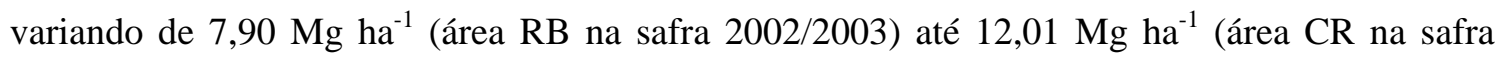
2000/2001) para milho, e de 3,18 $\mathrm{Mg} \mathrm{ha}^{-1}$ (área Fabc na safra 1998/1999) até 4,51 Mg ha-1 (área CR na safra 2001/2002) para soja.

Considerando as médias para o estado do Paraná e para o Brasil de produtividade de milho, respectivamente 3,04 $\mathrm{Mg} \mathrm{ha}^{-1}$ e 2,62 $\mathrm{Mg} \mathrm{ha}^{-1}$ (FNP, 2001), e de soja, respectivamente 2,74 $\mathrm{Mg} \mathrm{ha}^{-1}$ e 2,52 $\mathrm{Mg} \mathrm{ha}^{-1}$ (FNP, 2001), esses valores enfatizam a característica dessas áreas de serem cultivadas sob regime de alta tecnologia de produção agrícola. Ressaltam também a variabilidade da produtividade nas mesmas, favorecendo nesse caso a adoção das técnicas de agricultura de precisão, pois, apesar de nessas áreas as práticas de gerenciamento agrícolas da lavoura terem sido uniformes, a produtividade resultante não o foi.

Mesmo em áreas onde o CV da produtividade foi baixo, como na área CR na safra de 2000/2001 (Tabela 10), equivalente a 5,75\%, ainda assim a produtividade variou de 7,05 $\mathrm{Mg} \mathrm{ha}^{-1}$ até $16,80 \mathrm{Mg} \mathrm{ha}^{-1}$, indicando que, possivelmente, determinadas regiões da lavoura devam ser cultivadas de forma diferenciada do restante da área. 
Quanto aos valores máximos e mínimos apresentados para a produtividade monitorada nas diferentes safras em cada uma das áreas, alguns valores, principalmente máximos, por exemplo, 19,49 $\mathrm{Mg} \mathrm{ha}^{-1}$ na safra de 2002/2003 na área Fabc (Tabela 9), podem causar dúvida quanto à informação contida no mapa de colheita. No entanto esses valores foram aqueles que restaram após o processo de filtragem utilizado (Gimenez \& Molin, 2000), sendo que esse procedimento, assim como qualquer outro processo de filtragem, apesar de comprovadamente melhorarem a qualidade da informação fornecida pelos monitores de colheita, não são infalíveis. De qualquer maneira, esses monitores já atingiram um bom nível de acurácia e em termos de totalização de produto colhido, quando comparado com o resultado da balança, os fabricantes atribuem valores de erros na ordem de 2\% (Molin, 2000), justificando portanto a utilização dessa informação.

Nas Tabelas 12, 13 e 14 são apresentados os resumos estatísticos das variáveis do solo analisadas em laboratório para as áreas experimentais. Os critérios de interpretação utilizados para os níveis dessas variáveis, encontrados nas três áreas, foram os apresentados por Raij et al. (1996). Apesar desses critérios terem sido apresentados por esses autores para o estado de São Paulo, eles também são utilizados para interpretação dos resultados de análise do solo na região dos Campos Gerais no estado do Paraná, aonde foi realizada essa pesquisa.

No entanto, para alguns dos atributos do solo analisados, notadamente a acidez potencial $(\mathrm{H}+\mathrm{Al})$, a soma de bases $(\mathrm{SB}=\mathrm{Ca}+\mathrm{Mg}+\mathrm{K})$ e a capacidade de troca de cátions (CTC), não são fornecidas classes de interpretação no trabalho de Raij et al. (1996). Isso ocorreu devido à falta de um critério lógico, em termos de fertilidade do solo que relacione essas variáveis com produtividade ou necessidade de diferenciar o gerenciamento (Raij, 1991). Para esses atributos, as considerações realizadas no decorrer do trabalho, no intuito de interpretação dos seus teores, foram mais subjetivas e tiveram auxílio, na sua interpretação, de classificações outras, como as apresentadas por Muzilli (1978) e Boarreto ${ }^{10}$.

Na Tabela 12 são apresentados os parâmetros estatísticos das distribuições das quatorze características físico-químicas do solo amostradas na área Fabc.

\footnotetext{
${ }^{10}$ BOARETTO, A. E. (Escola Superior de Agricultura “Luiz de Queiroz” - USP). Material didático de apoio à disciplina Avaliação do estado nutricional e da fertilidade do solo. 2003.
} 
Tabela 12. Estatística descritiva para os valores das variáveis físico-químicas do solo amostradas em laboratório no ano de 2001 na área experimental Fabc

\begin{tabular}{|c|c|c|c|c|c|c|c|}
\hline \multirow[t]{2}{*}{ Variável } & \multicolumn{7}{|c|}{ Estatística } \\
\hline & Média & Mediana & Des. pad. & Assim. & Curtose & $\mathrm{CV}$ & D \\
\hline $\mathrm{P} \dagger$ & 130,04 & 127,00 & 51,32 & 1,03 & 4,49 & 39,47 & $0,05 \S$ \\
\hline $\mathrm{MO}+\dagger$ & 59,76 & 60,00 & 4,88 & 0,67 & 1,77 & 8,17 & $0,10 ¥$ \\
\hline $\mathrm{pH} \dagger \dagger \dagger$ & 5,21 & 5,10 & 0,38 & 0,67 & $-0,25$ & 7,27 & $0,15^{*}$ \\
\hline $\mathrm{H}+\mathrm{Al} \ddagger$ & 48,89 & 47,00 & 16,60 & 0,13 & $-0,57$ & 33,96 & $0,07 \S$ \\
\hline $\mathrm{Al} \neq$ & 0,83 & 0,00 & 1,07 & 1,31 & 1,14 & 129,03 & $0,30 *$ \\
\hline $\mathrm{K} \ddagger$ & 2,72 & 2,60 & 0,86 & 0,67 & 0,56 & 31,61 & $0,10 ¥$ \\
\hline $\mathrm{Ca} \ddagger$ & 57,84 & 55,00 & 14,73 & 1,41 & 4,35 & 25,46 & $0,11^{*}$ \\
\hline $\mathrm{Mg} \ddagger$ & 26,16 & 24,00 & 9,40 & 1,61 & 3,57 & 35,94 & $0,17^{*}$ \\
\hline $\mathrm{SB} \ddagger$ & 86,73 & 82,30 & 23,45 & 1,41 & 3,57 & 27,04 & $0,11^{*}$ \\
\hline CTC $\neq$ & 135,62 & 134,20 & 13,86 & 2,13 & 9,52 & 10,22 & $0,11 ¥$ \\
\hline V\% & 63,48 & 62,00 & 12,61 & 0,11 & $-0,50$ & 19,87 & $0,06 \S$ \\
\hline M\% & 1,23 & 0,00 & 1,76 & 1,86 & 3,52 & 143,62 & $0,27^{*}$ \\
\hline Argila (\%) & 41,08 & 41,90 & 7,59 & $-0,91$ & 0,85 & 18,48 & $0,09 \S$ \\
\hline Areia (\%) & 31,12 & 30,60 & 4,91 & 0,52 & 0,09 & 15,78 & $0,08 \S$ \\
\hline
\end{tabular}

Distribuição normal: * a $1 \%$ de probabilidade; ¥ a $5 \%$ de probabilidade; \& a $10 \%$ de probabilidade; § não significativo a 10\% de probabilidade (Campos, 1983).

$\dagger=\mathrm{mg} / \mathrm{dm}^{3} ; \dagger \dagger=\mathrm{g} / \mathrm{dm}^{3} ; \dagger \dagger \dagger=\mathrm{pH}$ em $\mathrm{cacl}_{2} ; \ddagger=\mathrm{mmol}_{\mathrm{c}} / \mathrm{dm}^{3}$.

Constatou-se que o solo da área Fabc (Tabela 12) apresenta, em média, 41\% de argila, sendo classificado como de textura argilosa (EMBRAPA, 1999), característica essa reforçada pelo conteúdo médio de MO encontrado na área, de aproximadamente $60 \mathrm{~g} \mathrm{dm}^{3}$ típica de solos de textura argilosa (Muzilli, 1978; Raij et al., 1996).

Observando os valores médios dos níveis dos atributos da fertilidade do solo nessa área, verifica-se que os níveis dos elementos $\mathrm{P}, \mathrm{Ca}$ e $\mathrm{Mg}$ foram bastante elevados (respectivamente muito alto, alto e alto, segundo os critérios de interpretação), enquanto que os níveis de K e de V\% se encontraram ambos na faixa de níveis médios.

A SB e a CTC calculados, com valores médios considerados bons, indicaram a característica do solo dessa área de apresentar boas condições de fertilidade e propício para o bom desenvolvimento da soja e do milho.

Quanto à acidez do solo, o valor do pH igual a 5,21 caracterizou esse solo, na época em que foi realizada a amostragem, como apresentando acidez média, sendo o principal elemento responsável por essa acidez o íon hidrogênio presente no solo, com pequena contribuição do Al 
(acidez trocável). Isso pode ser verificado pelo baixo teor encontrado para esse elemento, e consequentemente da saturação por alumínio, enquanto que o teor de $\mathrm{H}+\mathrm{Al}$ se encontrou num nível médio.

Analisando a dispersão dos dados medidos desses atributos em relação às médias calculadas para as suas distribuições, verificou-se as diferenças quanto a homogeneidade entre as diferentes características. Cuidado tem de ser tomado ao se interpretar o coeficiente de variação do $\mathrm{pH}$, pois como o mesmo é medido em escala logarítmica, o valor dessa variável não pode ser diretamente comparado com o das outras variáveis.

Chama a atenção os coeficientes de variação elevados das distribuições de $\mathrm{Al}$ e de M\%, indicando a possível ocorrência de regiões isoladas de maior concentração desse elemento na área.

Quanto ao ajuste à distribuição normal dessas variáveis do solo, verificou-se um bom ajuste, tanto aos níveis de 1\%, 5\% e 10\% de probabilidade, para a maioria das variáveis, sendo que desse ponto em diante elas foram consideradas como apresentando distribuições normais, exceções feitas para as variáveis $\mathrm{P}, \mathrm{H}+\mathrm{Al}, \mathrm{V} \%$ e os teores de argila e areia, que não apresentaram ajuste à distribuição normal num nível de significância adequado. Para essas variáveis foi necessária uma maior atenção na etapa de interpolação pelo processo de krigagem, sendo inclusive considerada a possibilidade de transformação logarítimica das mesmas, procurando melhorar a eficiência do processo de interpolação. Na Tabela 13 são apresentados os resumos estatísticos para as variáveis físico-químicas do solo na área CR. 
Tabela 13. Estatística descritiva para os valores das variáveis físico-químicas do solo amostradas em laboratório no ano de 2001 na área experimental CR

\begin{tabular}{|c|c|c|c|c|c|c|c|}
\hline \multirow[t]{2}{*}{ Variável } & \multicolumn{7}{|c|}{ Estatística } \\
\hline & Média & Mediana & Des. pad. & Assim. & Curtose & $\mathrm{CV}$ & $\mathrm{D}$ \\
\hline $\mathrm{P} \dagger$ & 115,69 & 112,00 & 25,49 & $-0,04$ & 0,22 & 22,03 & $0,14 \S$ \\
\hline $\mathrm{MO}+\dagger$ & 30,61 & 31,00 & 4,80 & $-0,40$ & $-0,84$ & 15,68 & $0,17 \S$ \\
\hline $\mathrm{pH} \dagger+\dagger$ & 4,99 & 5,00 & 0,15 & $-0,09$ & 0,99 & 2,92 & $0,16 \S$ \\
\hline $\mathrm{H}+\mathrm{AL} \neq$ & 45,55 & 47,00 & 5,26 & 0,40 & $-0,61$ & 11,55 & $0,23 ¥$ \\
\hline Al & 1,16 & 1,00 & 1,07 & 0,54 & $-0,13$ & 91,93 & $0,22 థ$ \\
\hline $\mathrm{K} \ddagger$ & 3,01 & 2,90 & 0,53 & 1,09 & 2,29 & 17,52 & $0,16 \S$ \\
\hline $\mathrm{Ca} \ddagger$ & 30,03 & 29,00 & 8,70 & 0,17 & $-0,45$ & 28,98 & $0,12 \S$ \\
\hline $\mathrm{Mg} \ddagger$ & 12,48 & 12,00 & 3,88 & 1,80 & 4,65 & 31,08 & $0,23 \notin$ \\
\hline $\mathrm{SB} \neq$ & 45,52 & 43,70 & 12,36 & 0,57 & 0,53 & 27,15 & $0,14 \S$ \\
\hline CTC $\ddagger$ & 91,07 & 92,60 & 11,41 & 0,18 & 0,33 & 12,52 & $0,10 \S$ \\
\hline V\% & 49,23 & 50,00 & 8,20 & $-0,16$ & $-0,09$ & 16,67 & $0,11 \S$ \\
\hline M\% & 2,95 & 2,40 & 3,25 & 1,88 & 5,94 & 109,94 & $0,18 \S$ \\
\hline Argila (\%) & 22,54 & 22,80 & 4,65 & $-0,31$ & $-0,54$ & 20,63 & $0,09 \S$ \\
\hline Areia (\%) & 68,54 & 66,99 & 6,53 & 0,41 & $-0,47$ & 9,53 & $0,11 \S$ \\
\hline
\end{tabular}

Distribuição normal: ¥ a 5\% de probabilidade; $\$$ a $10 \%$ de probabilidade; $\S$ não significativo a $10 \%$ de probabilidade (Campos, 1983).

$\dagger=\mathrm{mg} / \mathrm{dm}^{3} ; \dagger \dagger=\mathrm{g} / \mathrm{dm}^{3} ; \dagger \dagger \dagger=\mathrm{pH}$ em $\mathrm{cacl}_{2} ; \ddagger=\mathrm{mmol}_{\mathrm{c}} / \mathrm{dm}^{3}$.

A textura do solo nessa área pode ser classificada como sendo de textura média, sendo que o teor de MO ficou num limite entre o encontrado num solo de textura média e um de textura argilosa. O nível de $\mathrm{P}$ foi muito alto, idêntico ao identificado na área Fabc, o que pode estar confirmando o acúmulo de P no sistema plantio direto na camada superficial do solo em função da sua baixa mobilidade. Os níveis de Ca e Mg foram altos e o de $\mathrm{K}$ foi médio. Os bons teores encontrados para esses nutrientes resultaram num nível elevado para a SB e para a CTC nessa área.

Quanto à acidez do solo, o valor encontrado para o pH ficou no limite entre acidez alta e média, enquanto que o valor da acidez trocável pode ser considerado baixo e o do $\mathrm{H}+\mathrm{Al}$ médio. O solo dessa área, assim como o da Fabc, também apresentou baixo M\%. No entanto, ao contrário daquela área, o V\% ficou no limite entre o nível baixo e o médio.

Quanto ao ajuste da distribuição desses atributos à distribuição normal na área CR, a maioria das variáveis não apresentou esse ajuste, ao contrário da área Fabc, com exceção da 
acidez potencial (a 5\% de probabilidade) e da acidez trocável e do teor de $\mathrm{Mg}$ (a 10\% de probabilidade). Essa diferença ocorreu, em grande, parte devido a diferença na densidade no número de pontos amostrais nas duas áreas (10,0 amostras ha ${ }^{-1}$ na área $A B C$ e 2,0 amostras ha-1 na área CR). Esse resultado está de acordo com o resultado obtido por Cambardella et al. (1994), que para a maioria das variáveis do solo utilizadas naquele estudo, constatou uma fuga à distribuição normal. Espera-se, devido a essa falta de normalidade da distribuição, uma menor qualidade da interpolação dessas variáveis nessa área.

Na Tabela 14 são apresentados os resultados dos resumos estatísticos das variáveis físicoquímicas do solo submetidas a análise em laboratório para a área RB.

Analisando os resultados do resumo estatístico para os atributos do solo medidos na área $\mathrm{RB}$, verifica-se que o solo é de textura média, com conteúdo de MO elevado característico de solos de textura argilosa (maior que $31 \mathrm{~g} \mathrm{dm}^{-3}$ ).

O nível encontrado para P, ao contrário das outras duas áreas, nesse caso se encontrou na classe de nível alto, ainda bastante adequado para o cultivo de culturas anuais como soja e milho. O teor, tanto de Ca quanto de Mg, novamente, foi alto e o de $\mathrm{K}$, novamente, foi médio, mostrando semelhanças nas características indicativas da fertilidade do solo nas áreas experimentais aonde foi conduzida essa pesquisa. Também foi verificada essa constância para os níveis encontrados para a SB e para a CTC, cujos teores novamente podem ser considerados adequados.

O solo dessa área apresentou-se com acidez alta (pH em $\mathrm{CaCl}_{2}$ abaixo de 5,0), fato que pode ser explicado pela acidez potencial um pouco mais elevada do que nas outras duas áreas, nesse caso podendo ser considerada alta, enquanto que a acidez trocável se manteve num nível baixo, respeitando o comportamento padrão dos solos da região, de geralmente não apresentarem problemas com elevadas concentrações de $\mathrm{Al}$ no solo. O V\%, assim como na área $\mathrm{CR}$, ficou no limiar entre as classes de nível baixo e médio.

Quanto ao ajuste à distribuição normal, a mesma constatação, que ocorreu na área CR, devido à densidade amostral, se verificou nessa área. Das quatorze variáveis medidas, apenas para os teores da acidez trocável e do $\mathrm{pH}$ (a 1\% de probabilidade), do P e do V\% (a 5\% de probabilidade) e da acidez potencial (a 10\% de probabilidade) apresentaram distribuições que podem ser consideradas normais. Os mesmos possíveis problemas durante a etapa de interpolação descritos para a área CR são esperados nessa situação e os mesmos cuidados para identificá-los, e se possível conseguir evitá-los, devem ser tomados. 
Tabela 14. Estatística descritiva para os valores das variáveis físico-químicas do solo amostradas em laboratório no ano de 2001 na área experimental RB

\begin{tabular}{|c|c|c|c|c|c|c|c|}
\hline \multirow[t]{2}{*}{ Variável } & \multicolumn{7}{|c|}{ Estatística } \\
\hline & Média & Mediana & Des. pad. & Assim. & Curtose & $\mathrm{CV}$ & $\mathrm{d}$ \\
\hline $\mathrm{P} \dagger$ & 50,20 & 40,00 & 30,56 & 1,31 & 1,05 & 60,88 & $0,16 ¥$ \\
\hline $\mathrm{MO} \dagger \dagger$ & 38,17 & 40,50 & 11,00 & $-0,57$ & $-0,16$ & 28,81 & $0,13 \S$ \\
\hline $\mathrm{pH} \dagger \dagger \dagger$ & 4,89 & 4,90 & 0,15 & 0,73 & 1,65 & 3,11 & $0,20 *$ \\
\hline $\mathrm{H}+\mathrm{AL} \ddagger$ & 52,11 & 52,00 & 10,46 & 0,28 & $-0,13$ & 20,07 & 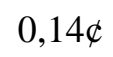 \\
\hline $\mathrm{Al} \neq$ & 1,71 & 2,00 & 1,46 & 1,62 & 3,81 & 84,94 & $0,25^{*}$ \\
\hline $\mathrm{K} \ddagger$ & 2,55 & 2,55 & 1,02 & 0,28 & $-0,35$ & 40,11 & $0,05 \S$ \\
\hline $\mathrm{Ca} \ddagger$ & 29,47 & 29,00 & 8,99 & 0,42 & 0,86 & 30,51 & $0,12 \S$ \\
\hline $\mathrm{Mg} \neq$ & 15,36 & 15,00 & 6,04 & 0,92 & 1,75 & 39,32 & $0,13 \S$ \\
\hline $\mathrm{SB} \ddagger$ & 47,38 & 46,80 & 15,57 & 0,59 & 1,31 & 32,87 & $0,10 \S$ \\
\hline CTC $\neq$ & 99,49 & 103,35 & 19,99 & $-0,34$ & 0,25 & 20,09 & $0,13 \S$ \\
\hline V\% & 46,80 & 46,50 & 8,68 & 0,14 & $-0,33$ & 18,55 & $0,08 \S$ \\
\hline M\% & 3,85 & 3,33 & 3,56 & 1,74 & 3,79 & 92,52 & $0,19 ¥$ \\
\hline Argila (\%) & 28,46 & 29,85 & 10,63 & $-0,40$ & $-0,35$ & 37,35 & $0,12 \S$ \\
\hline Areia (\%) & 59,61 & 58,00 & 15,39 & 0,36 & $-0,55$ & 25,82 & $0,11 \S$ \\
\hline
\end{tabular}

Distribuição normal: * a $1 \%$ de probabilidade; ¥ a $5 \%$ de probabilidade; \& a $10 \%$ de probabilidade; **** não significativo a $10 \%$ de probabilidade (Campos, 1983).

$\dagger=\mathrm{mg} / \mathrm{dm}^{3} ; \dagger \dagger=\mathrm{g} / \mathrm{dm}^{3} ; \dagger \dagger \dagger=\mathrm{pH}$ em $\mathrm{cacl}_{2} ; \ddagger=\mathrm{mmol}_{\mathrm{c}} / \mathrm{dm}^{3}$.

Um fato interessante de se observar, o qual foi verificado nos resultados apresentados para as áreas experimentais Fabc, CR e RB (Tabelas 12, 13 e 14 respectivamente), foi a grande variabilidade do teor de $\mathrm{Al}$ e por conseqüência do M\%, com CVs da ordem de 84,94\% até 129,03\% para o teor de Al nas áreas RB e Fabc respectivamente.

Como os solos da região onde foi realizado esse estudo não apresentam maiores problemas relativos a altas concentrações de $\mathrm{Al}$, ocorrendo essas concentrações mais elevadas em pontos localizados dessas lavouras, a falta de uniformidade da calagem poderia agravar a situação, podendo ser uma das causas dessa variabilidade. Por outro lado, é possível também que parte dessa variabilidade seja devido a problemas de precisão analítica para se detectar baixos teores de $\mathrm{Al}$ no solo, o que explicaria a grande quantidade de amostras identificadas como tendo teor de $\mathrm{Al}$ igual a zero.

Além disso os altos teores encontrados para nutrientes como $\mathrm{P}$, Ca e Mg confirmam a tendência de acúmulo na camada superficial do solo sob sistema de cultivo em plantio direto, 
devido, entre outras coisas, ao maior controle da erosão e conseqüente menor perda de solo. Esse efeito se verifica principalmente para o $\mathrm{P}$, que dos macronutrientes é o que apresenta a menor mobilidade e têm apresentado os maiores acréscimos, com relatos de 4 a 7 vezes o seu conteúdo no plantio direto em relação ao preparo convencional, na camada de 0 a $5 \mathrm{~cm}$ (Schear \& Moschler ${ }^{11}$, citados por Sá, 1995).

\subsection{Análise exploratória}

Essa etapa da análise foi realizada com o intuito de se investigar em maiores detalhes os dados de CEa do solo identificados como candidatos a discrepantes, definidos pela metodologia de Tukey (1977). Com esse intuito esses dados foram visualizados nas suas respectivas posições geográficas para então se decidir qual seria a melhor maneira de tratá-los, sendo os diferentes critérios de tratamento abordados em diversos estudos (Hamlett et al., 1986; Isaaks \& Srivastava, 1989; Libardi et al., 1996).

Nas Figuras de 3 a 5 são apresentados os mapas de valores candidatos a discrepantes para alguns dos monitoramentos realizados nas áreas experimentais analisadas nesse estudo. São apresentados em cada área os mapas com os valores da leitura rasa ou com a leitura profunda, e não ambos, pois as tendências verificadas entre eles para cada área são bastante semelhantes.

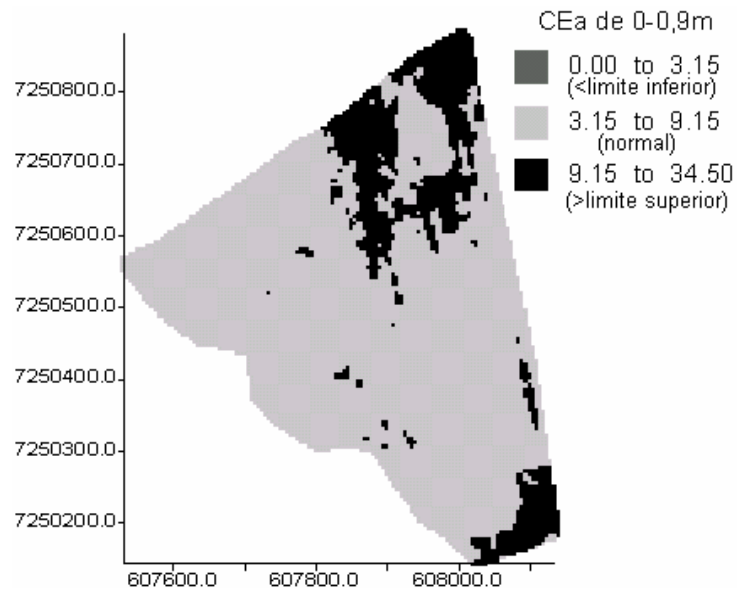

Figura 3 - Candidatos a dados discrepantes para a CEa profunda da área Fabc

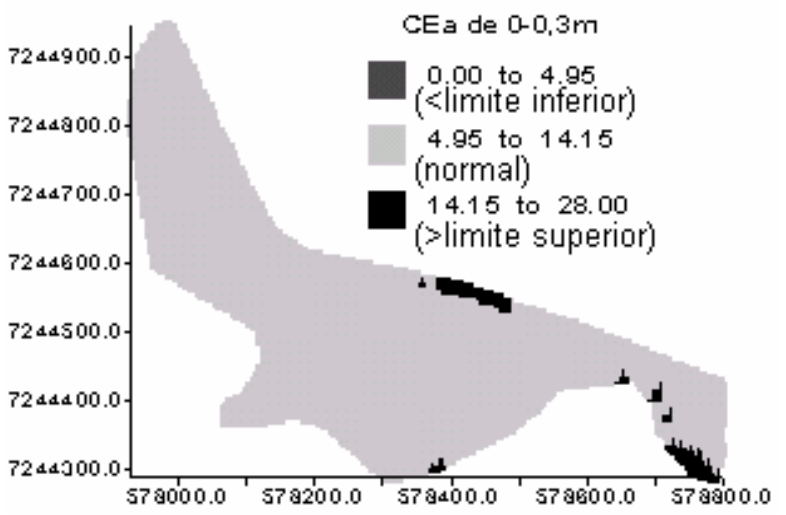

Figura 4 - Candidatos a dados discrepantes para a CEa rasa na área CR

\footnotetext{
${ }^{11}$ SHEAR, G. M.; MOSCHLER, W. W. Continuos corn by the no-tillage and conventional tillage methods: a six year comparison. Agronomy journal., v. 61, p. 524-526, 1969.
} 


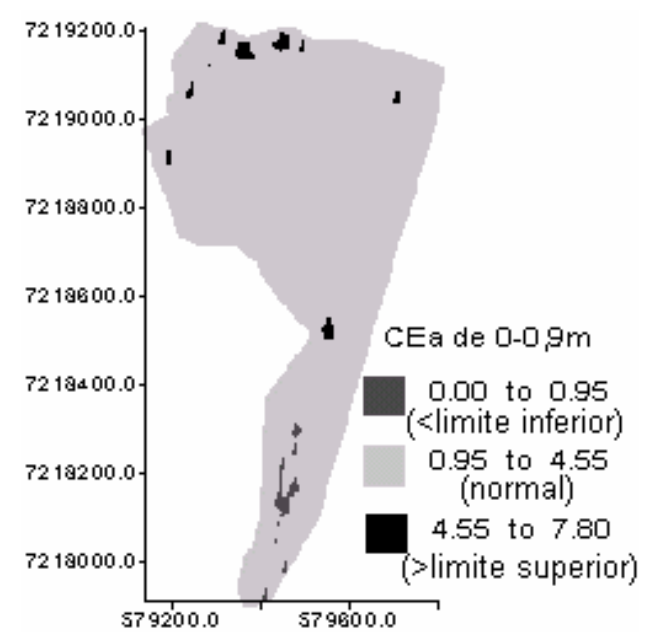

Figura 5 - Candidatos a dados discrepantes para a CEa profunda na área RB

Observando essas figuras é possível se verificar a tendência, em todas as áreas, de concentração de valores de CEa, rasa e profunda, candidatos a discrepantes, tanto abaixo do limite inferior quanto acima do limite superior, próximos uns aos outros. Esse fato indica que esse valores na verdade podem representar regiões das áreas experimentais que, por motivos diversos, apresentaram comportamento anômalo quanto às variáveis CEa rasa e profunda. Essa aglomeração serviu como indício de que eles na verdade podem ser representantes de regiões diferenciadas da área quanto a essas variáveis, não justificando, portanto, a exclusão deles do conjunto de dados. A essas concentrações de valores parecidos, Isaaks \& Srivastava (1989) chamam de sub-regiões.

Apesar de em alguns casos esses valores ocorrerem isolados nas áreas, considerou-se todos eles como pertencentes ao conjunto de dados, sendo descartado desse ponto em diante a hipótese de existência de valores candidatos a discrepantes em todas as distribuições das variáveis CEa rasa e profunda. 


\subsection{Análise geoestatística}

É importante para aplicação da tecnologia de agricultura de precisão, quantificar a estrutura da variabilidade espacial das variáveis monitoradas e identificar na lavoura áreas de ocorrência de valores baixos e elevados das mesmas.

Para se avaliar essa estrutura espacial e poder a partir dela realizar inferências em locais não amostrados é que se utiliza a geoestatística. A ferramenta que capta essa estrutura espacial é o semivariograma, sendo que a partir desses utilizou-se o método da krigagem para interpolação das variáveis e geração dos seus mapas de superfície, técnica essa que os geoestatísticos chamam de método ótimo de interpolação, pois ela resulta na melhor estimativa linear não tendenciosa de uma variável em um ponto qualquer, devido à minimização do erro de variância (Isaaks \& Srivastava, 1989).

É importante lembrar que caso os valores de uma variável aparentem ser distribuídos aleatoriamente numa área, então o melhor estimador para essa variável continua sendo a média amostral ou a mediana.

\subsubsection{Análise da dependência espacial}

Os semivariogramas foram calculados para as variáveis CEa do solo nas duas profundidades, produtividade das culturas e características físico-químicas do solo. Nos Anexos A1 a A3.3 são apresentados os parâmetros efeito pepita, patamar, alcance, modelo dos semivariogramas calculados, além dos valores da soma dos erros quadrados (critério adotado para escolha do melhor ajuste de cada modelo), e do componente estrutural [C1/(C0+C1)], que indica o quanto da variação total dos dados é explicada pela continuidade espacial.

O parâmetro componente estrutural é importante para se avaliar a eficiência da análise geoestatística, sendo um indicador consistente da variância estruturada (C1) na dependência espacial das variáveis monitoradas. Utilizando esse critério, Cambardella et al. (1994) definiram classes distintas de dependência espacial. Se o componente estrutural for maior que 0,75 a variável é considerada de elevada dependência espacial; entre 0,25 e 0,75, média dependência e abaixo de 0,25, baixa dependência espacial.

Para nenhuma das variáveis foi realizado a tentativa de avaliação da anisotropia, realizando-se todas as análises geoestatísticas utilizando-se os semivariogramas omnidirecionais, 
nos quais apenas a distância de separação entre as amostras é importante no cálculo da função semivariância e não o vetor de separação entre as mesmas.

No Anexo A são apresentados os parâmetros dos semivariogramas calculados para a CEa em ambas as profundidades nas áreas Fabc (nos dois monitoramentos realizados), CR e RB .

Com exceção da CEa rasa medida na área Fabc em 2003, todas as outras variáveis indicaram elevada dependência espacial, com valores do componente estrutural elevados. Além disso, com exceção da CEa rasa medida em 2003, todas apresentaram um baixo efeito pepita, indicando que em distâncias de separação pequenas entre as amostras a variabilidade é pequena, o que significa que a distância de amostragem foi adequada.

Outra característica desses semivariogramas que é importante ser destacada são os baixos valores encontrados para o alcance da dependência espacial dessas variáveis. A curta distância de separação entre cada ponto coletado no campo pode ser uma das explicações para esse fato, devido a essa distância ter permitido captar a variabilidade dessas variáveis na curta escala.

Pelas análises de dependência espacial da CEa do solo, pode-se perceber que, quanto a característica de que ela tem de ser espacialmente estruturada para integrar o conjunto de práticas da agricultura de precisão (Harstock et al., 2000), os resultados obtidos dessa etapa enfatizaram a concordância a esse critério.

Espera-se uma boa qualidade de interpolação a partir desses semivariogramas, exceção feita para o semivariograma da CEa rasa medida em 2003 que, devido ao efeito pepita representar cerca de $64 \%$ da semivariância dos dados, espera-se que a suavização da superfície de valores obtida por krigagem seja grande para essa variável, aproximando as estimativas de uma média local.

Na seqüência da análise foi avaliado a variabilidade espacial para os dados de produtividade de soja e de milho, nas áreas experimentais. No Anexo A2 são apresentados os parâmetros dos semivariogramas das produtividades nas diferentes safras nas três áreas experimentais.

O componente estrutural foi, no geral, elevado. As únicas exceções foram no caso da produtividade de milho na safra 2002/2003 nas áreas Fabc e RB, inclusive nesta não se encontrou nenhuma dependência espacial para essa variável.

Foram constatados baixos valores para alcances, o que aliado aos valores elevados dos componentes estruturais calculados, provocam uma diminuição da característica de suavização da técnica de interpolação por krigagem, com muito do total de pesos, atribuídos aos dados ao redor de um ponto sendo estimado, sendo atribuídos para aqueles dados que estejam mais 
próximos, semelhante a um método de interpolação do tipo vizinho mais próximo (ou poligonação). Novamente, a qualidade dos ajustes dos modelos foi boa.

Os parâmetros dos modelos dos semivariogramas para os dados de fertilidade do solo são apresentados no Anexo A3.

Na área Fabc apesar da densidade amostral $\left(10,0\right.$ amostras $\left.h^{-1}\right)$ ser bem inferior à densidade amostral tanto dos dados de CEa do solo (Tabela 3), quanto dos de produtividade, todas as variáveis apresentaram dependência espacial.

No entanto é necessário destacar de que a qualidade dos semivariogramas obtidos não foi a mesma que foi obtida para os dados de CEa e produtividade. Além do que a tolerância da distância de separação entre amostras sucessivas, formadoras de pares durante o cálculo da função semivariância, foi bastante elevada (da ordem de 100\% até 300\%), ao contrário das tolerâncias utilizadas para os dados de CEa e produtividade, que variou de $15 \%$ até 50\%. Assim, cada incremento da distância, nos respectivos semivariogramas calculados dessa maneira, se constituíam de uma média da função semivariância para várias distâncias de separação, entre pontos amostrais, diferentes.

Os alcances da dependência espacial para todas as variáveis de fertilidade do solo na área Fabc são muito superiores aos alcances identificados para as variáveis CEa e produtividade. Isso ocorreu pois o alcance depende da escala de observação, sendo que quanto maior a distância de amostragem, maior será o alcance (Trangmar et al., 1985).

Destaque entre outras coisas para a menor qualidade do ajuste dos modelos aos semivariogramas experimentais, a menor dependência espacial encontrada para algumas variáveis e inclusive a presença de alguns modelos do tipo linear com patamar. Esse modelo linear com patamar surgiu em alguns casos para variáveis nas quais um patamar nítido não pôde ser identificado no semivariograma. Entretanto, optou-se por ajustar esse tipo de modelo ao semivariograma na esperança e confiança, na ferramenta de interpolação geoestatística, de realizar melhores estimativas do que métodos utilizados que não fizessem quaisquer considerações sobre a dependência espacial da variável sendo interpolada.

Observando os resultados apresentados para as áreas CR e RB verifica-se ainda mais o problema da densidade amostral na avaliação da dependência espacial. Nessas áreas, a densidade (2,0 amostras ha $\left.{ }^{-1}\right)$ foi menor do que a utilizada na área Fabc.

Para variáveis como o Mg e o V\%, na área CR, não se captou dependência espacial, fenômeno convencionalmente chamado de efeito pepita puro. Além disso, a diminuição da qualidade dos ajustes dos modelos do semivariograma fica ainda mais nítida comprando-se o 
respectivo valor da soma dos erros quadrados entre os semivariogramas das variáveis físicoquímicas do solo obtidos na área Fabc com aqueles obtidos nas áreas CR e RB.

Quanto ao componente estrutural, também é evidente a diminuição da dependência espacial identificada para essas variáveis nas áreas CR e RB, na maioria dos casos, ficando a dependência no nível intermediário.

Uma característica interessante foi o aparecimento de alguns modelos do tipo função potência para as variáveis referentes a granulometria do solo na área RB. Esse não é um tipo de modelo comumente utilizado na geoestatística; sua característica marcante é a de não possuir um patamar definido, e representar fenômenos que possuem uma capacidade infinita de dispersão.

O seu aparecimento para as variáveis abordadas por esse estudo, especificamente para as duas variáveis de granulometria do solo (teores de argila e areia) da área RB, pode ser explicado pelo comportamento dessas variáveis, nessa área, não respeitarem a característica de estacionaridade intrínseca, devido a essa área possuir regiões bastante distintas quanto à textura do solo.

Vale lembrar o que foi afirmado por Journel \& Huijbregts (1978), que se $E[Z(s)]=m(s)$, ou seja, o valor de m é função da posição s, então a estacionaridade não se confirma. Nesse caso se constata a presença de uma tendência, sendo esta claramente a situação verificada para os teores de argila e areia na área RB. Na opinião de Vieira (1995), caso essa tendência seja verificada, ela deve ser removida dos dados e o semivariograma deve ser ajustado para os resíduos.

No entanto, nesse trabalho optou-se, na interpolação dessas duas variáveis, por restringir o raio da elipse de busca da krigagem. Segundo Deutsch \& Journel (1992), na interpolação de variáveis que apresentam tendência na sua distribuição espacial, essa prática produz resultados similares àqueles obtidos utilizando técnicas de krigagem mais complexas, como a krigagem universal e a krigagem com tendência externa, indicadas, segundo Trangmar et al. (1985), para interpolação de variáveis com tendência.

Uma forma de definir o tamanho do raio da elipse nesses casos é como sendo a distância na qual a função semivariância atinge o valor da variância do conjunto de dados (Trangmar et al., 1985). 


\subsubsection{Mapas de superfície}

A partir dos parâmetros dos modelos ajustados aos semivariogramas experimentais obtidos foi realizada a sequiência da análise de variabilidade espacial de cada um dos atributos a partir da geração dos mapas de superfície de cada um.

É importante lembrar novamente a característica da krigagem ser uma técnica de estimação de valores que tende a gerar uma distribuição mais "suave” da variável sendo estimada, o que diminui a ocorrência de valores extremos, do que a real distribuição da mesma. Esse fato ocasiona que o CV da distribuição estimada de uma variável tende sempre a ser menor do que o CV da real distribuição da mesma. Enfatizado essa característica da técnica, é possível se discutir os resultados obtidos com a precaução necessária.

Na Figura 6 são apresentados os mapas de superfície da CEa do solo obtidos na área Fabc nos dois monitoramentos realizados. É importante serem confrontados esses resultados com aqueles dos resumos estatísticos descritivos obtidos para as respectivas variáveis. Nesses mapas se evidencia novamente a obtenção de maiores valores de CEa nas duas leituras nos monitoramentos realizados em 2002 (Figuras 6A e 6B).

Não foi possível identificar uma semelhança entre os dois monitoramentos realizados para a CEa na leitura rasa (Figura 6A e 6B) e na profunda (Figura 6C e 6D).

Se a variabilidade temporal da CEa do solo é baixa, então a utilização dessa informação na definição de unidades de gerenciamento do solo, e no auxílio à investigação das características físico-químicas desse, de interesse na exploração agrícola, é viabilizada.

Essa característica de estabilidade temporal da informação CEa do solo é uma das características às quais Harstock et al. (2000) definiram como sendo fundamentais na definição de se a CEa do solo será uma ferramenta que efetivamente passará a integrar o conjunto de práticas da agricultura de precisão.

Os resultados obtidos na área Fabc tem de serem considerados com certa parcimônia em função de terem sido realizados apenas dois monitoramentos. Para obtenção de conclusões mais contundentes, um maior número de monitoramentos têm de ser realizados, abrangendo épocas de monitoramentos as mais distintas, que captem um maior intervalo de variações da umidade, densidade e temperatura do solo, preferencialmente em condições controladas.

Quanto à variabilidade espacial da CEa nas diferentes profundidades de leitura para a área Fabc, conforme evidenciado na Figura 6, a semelhança da informação nas duas leituras não foi visualmente detectada, indicando que os fatores influenciando a CEa nas duas profundidades são 
distintos e também que aparentemente a CEa apresentou uma maior variabilidade na leitura rasa do que na profunda. Essa diferença pode acarretar definição de unidades de gerenciamento do solo diferenciadas, quando da utilização da informação CEa rasa ou profunda.

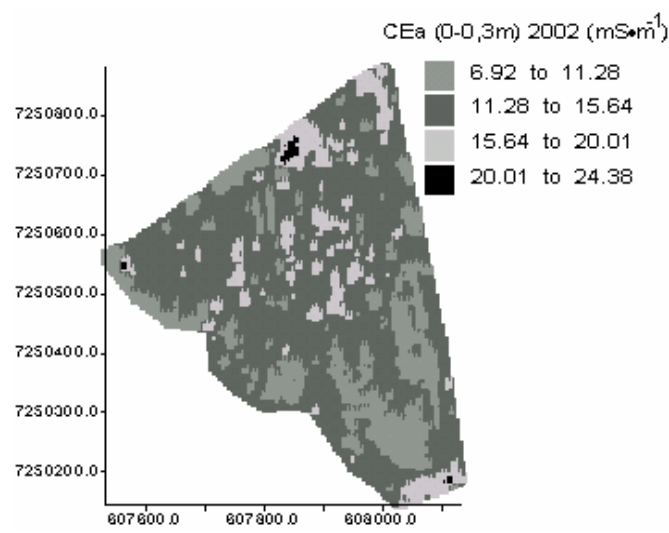

A.

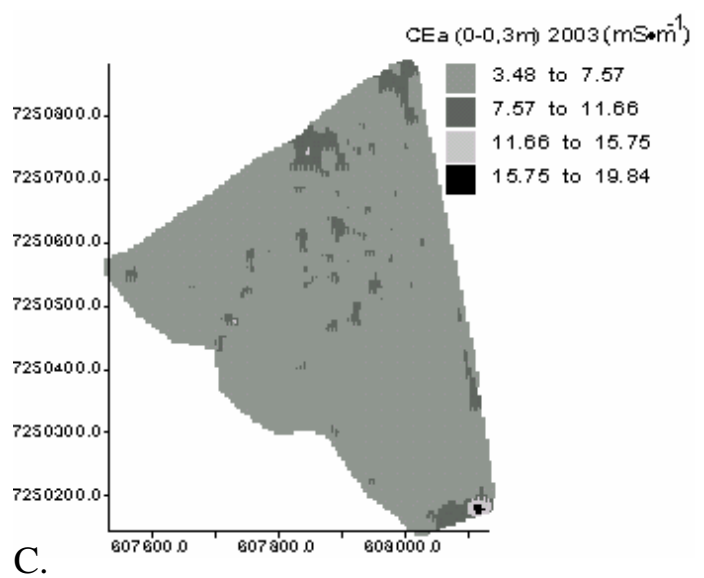

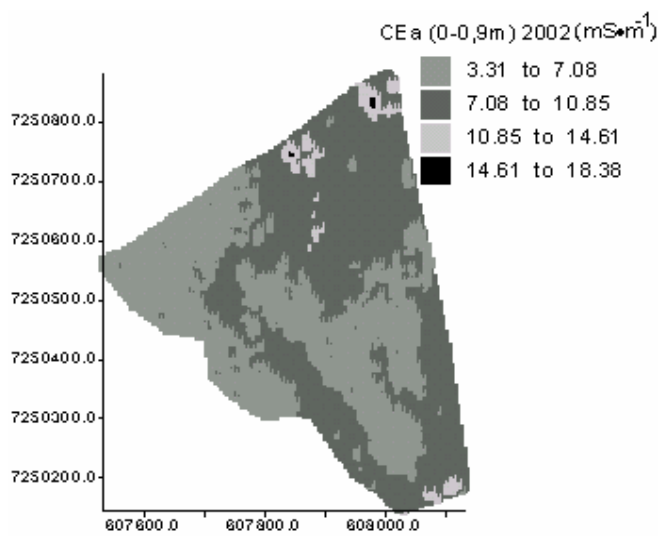

B.

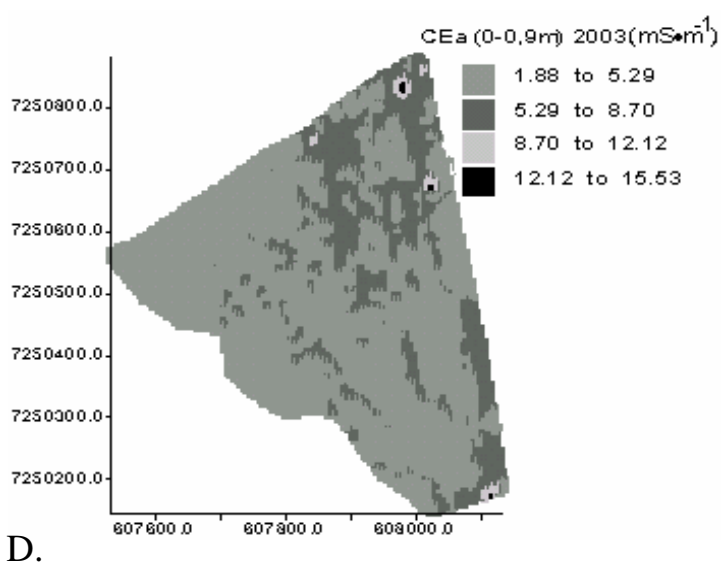

Figura 6 - Mapas da CEa do solo $\left(\mathrm{mS} \mathrm{m}^{-1}\right)$ nas leituras rasa $(0-0,3 \mathrm{~m})$ e profunda $(0-0,9 \mathrm{~m})$ na área Fabc nos anos de 2002 e 2003

Na Figura 7 são apresentados os mapas de distribuição espacial da CEa do solo para a área CR. Quanto ao padrão da variabilidade espacial da CEa nas leituras rasa e profunda nessa área, ao contrário da área Fabc, se verifica uma maior semelhança da informação nas duas profundidades, não considerando a magnitude dos valores. 

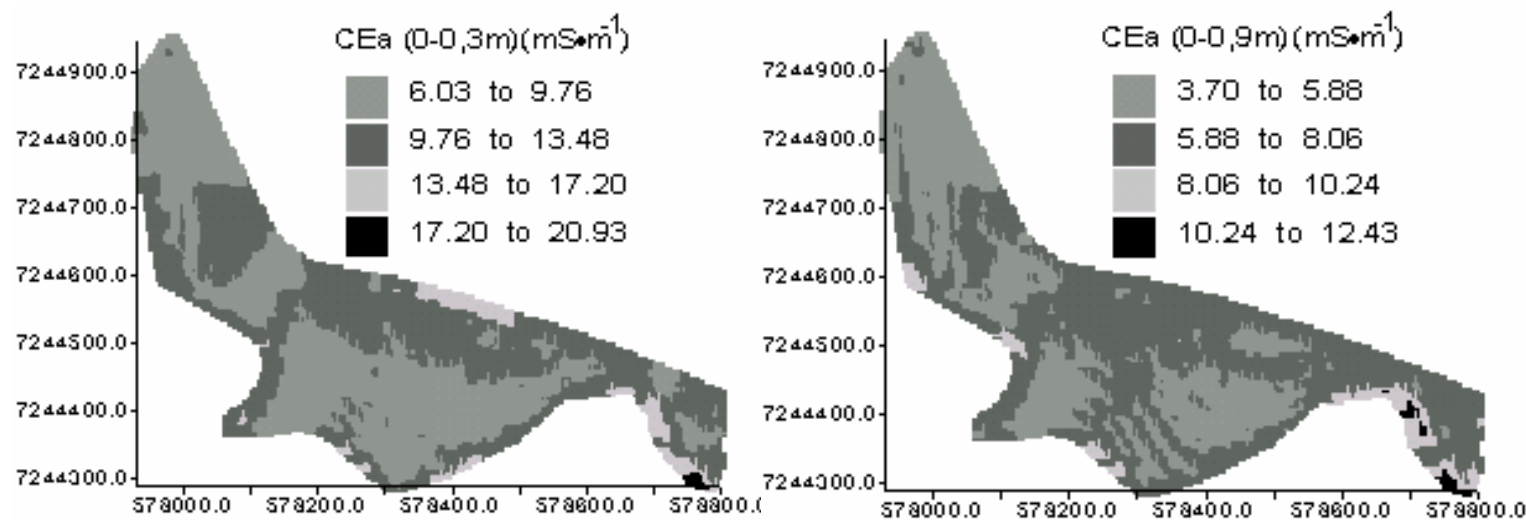

A.

B.

Figura 7 - Mapas da CEa do solo $\left(\mathrm{mS} \mathrm{m}^{-1}\right)$ nas leituras rasa $(0-0,3 \mathrm{~m})$ e profunda $(0-0,9 \mathrm{~m})$ na área CR no ano de 2002

Na Figura 8 são apresentados os dois mapas da CEa espacializada nas duas leituras na área RB. Para a CEa rasa (Figura 8A), o CV de 34,00\%, para a distribuição dos valores estimados, foi maior do que o dos valores amostrados (12,75\%). A não observância da estacionaridade intrínseca nessa área pode ser a explicação para isso. Assim, como na área CR, o padrão espacial da CEa nas duas profundidades é bastante parecido. Além disso é nítida a concentração de valores baixos de CEa do solo na região alongada ao sul do talhão (indício da falta de estacionaridade).

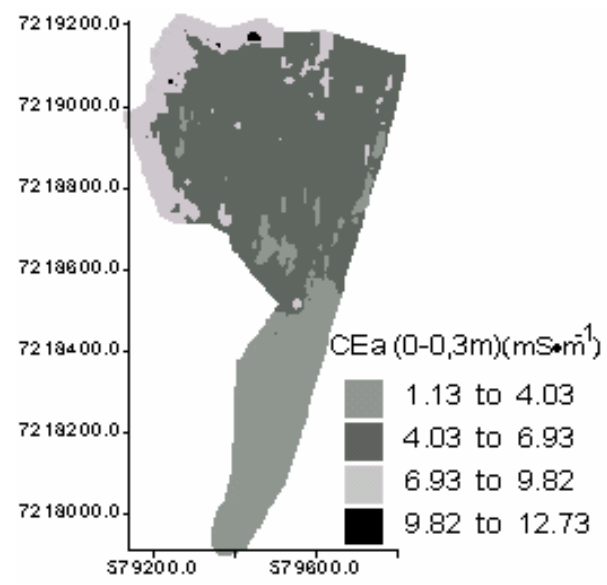

A.

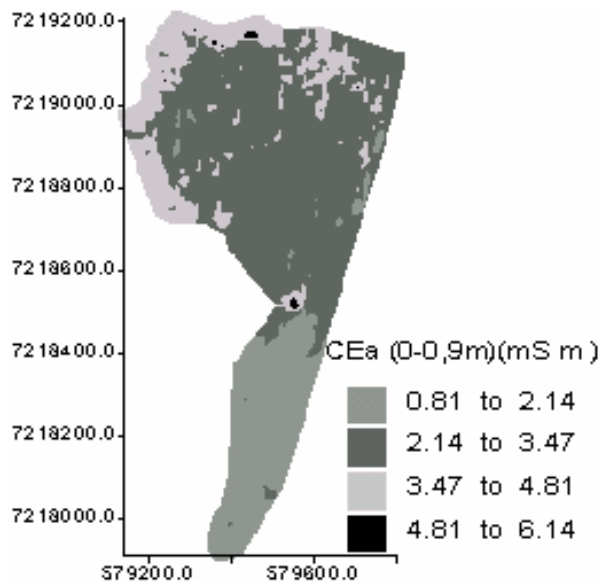

B.

Figura 9 - Mapas da CEa do solo $\left(\mathrm{mS} \mathrm{m}^{-1}\right)$ nas leituras rasa $(0-0,3 \mathrm{~m})$ e profunda $(0-0,9 \mathrm{~m})$ na área RB no ano de 2002 
A variabilidade espacial da produtividade nas diferentes safras na área Fabc pode ser visualizada na Figura 9. A importância de se observar cuidadosamente esses mapas reside na possibilidade de utilização desse procedimento visual como primeira etapa de comparação do padrão espacial da CEa do solo e da produtividade agrícola na área. Fornecendo indícios da viabilidade de utilização da CEa na definição das unidades de gerenciamento na área, caso o padrão da distribuição espacial de ambas camadas de informação sejam parecidos.

Essa concordância da informação CEa com a produtividade nas diferentes safras, como característica a reforçar a utilização da mesma na definição das unidades de gerenciamento, se deve ao fato da produtividade ser a variável dependente, a qual as variáveis independentes, que melhor expliquem a sua variação, são as que efetivamente devem ser trabalhadas para gerenciar localizadamente a produtividade na lavoura.

Na área Fabc a produtividade nas diferentes safras (Figuras 9A a 9E) apresenta alguma semelhança de safra para safra. No entanto essa semelhança não é tão evidente como foi para os dois monitoramentos da CEa realizados nessa mesma área, o que poderia indicar uma maior variabilidade temporal dessa variável, justificando alguns autores terem afirmado que são necessários vários anos de monitoramento da produtividade para se definir unidades de gerenciamento apenas utilizando essa informação (Lutticken, 1998).

Para essa área não foi possível se constatar através da inspeção visual dos mapas relação clara entre a CEa e a produtividade. 


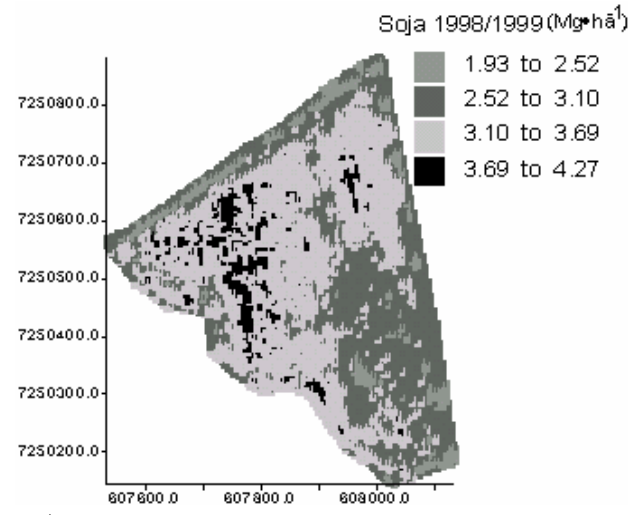

A.

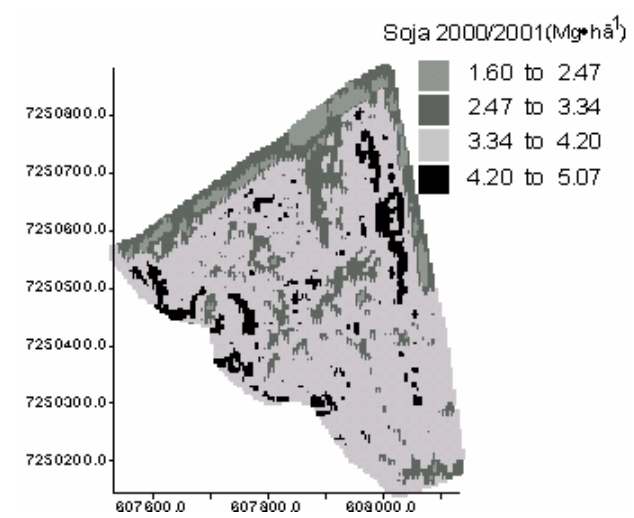

C.

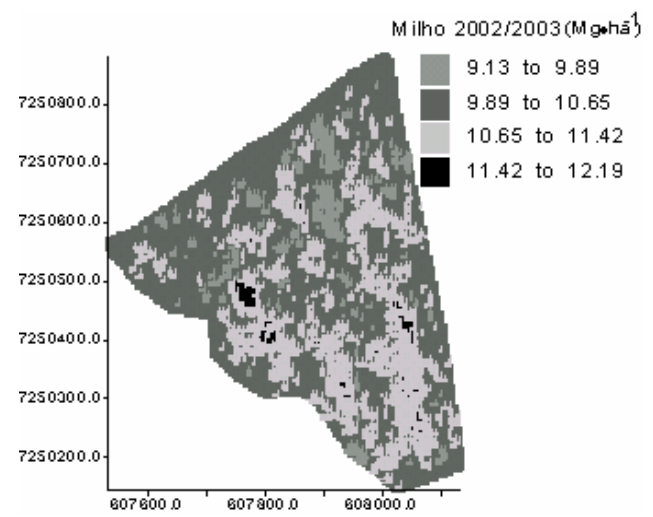

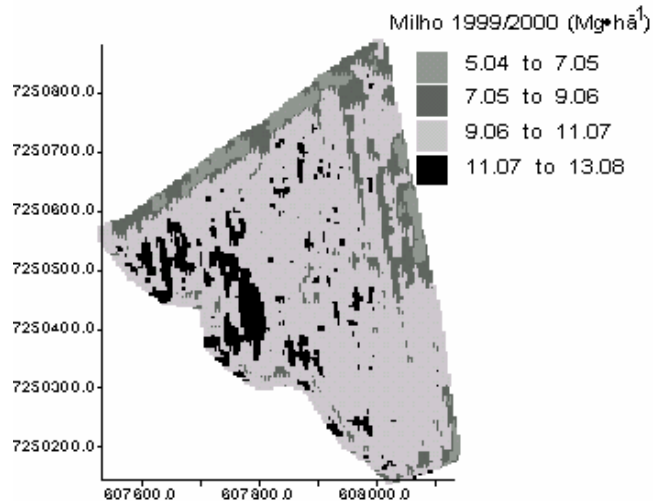

B.

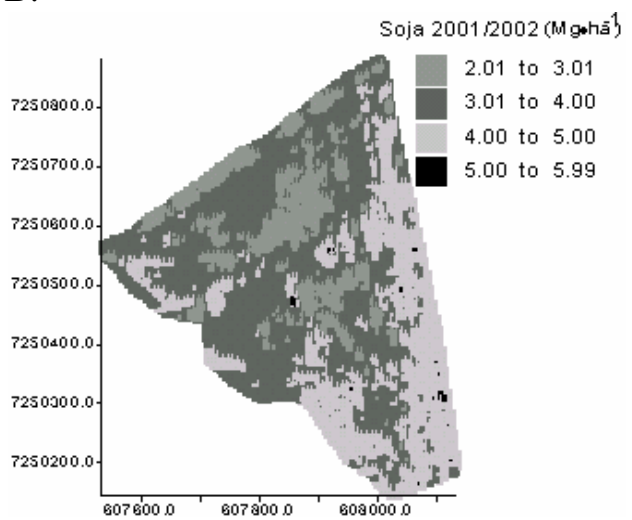

D.

E.

Figura 9 - Mapas da produtividade das culturas $\left(\mathrm{Mg} \mathrm{ha}^{-1}\right)$ nas safras de verão de 1998 /1999 até 2002/2003 na área Fabc

Na Figura 10 são apresentados os mapas de produtividade na área CR nas safras de 1999/2000 até 2002/2003. Assim como na área Fabc, nessa não se constata uma tendência clara na distribuição espacial da produtividade nas diferentes safras.

Na região central dos mapas (Figuras 10C e 10D) é possível se constatar um contraste em algumas safras quanto à produtividade, com a mesma região produzindo acima da média em 
uma safra e abaixo da média em outra. O padrão espacial da produtividade também não apresenta semelhança visual com o da CEa em nenhuma das duas profundidades (Figuras 7A e 7B).

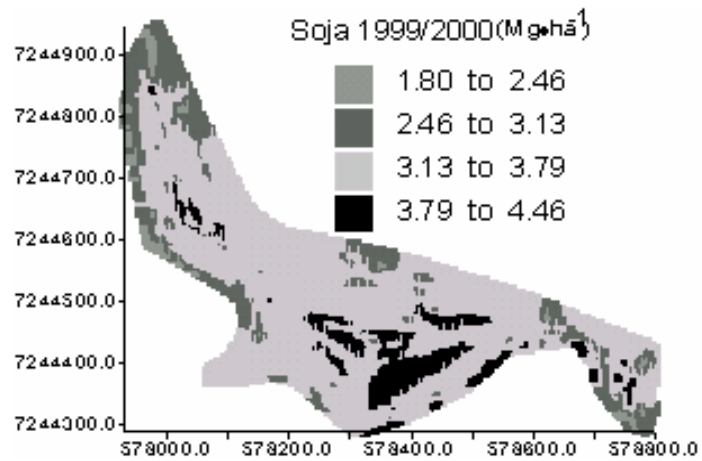

A.

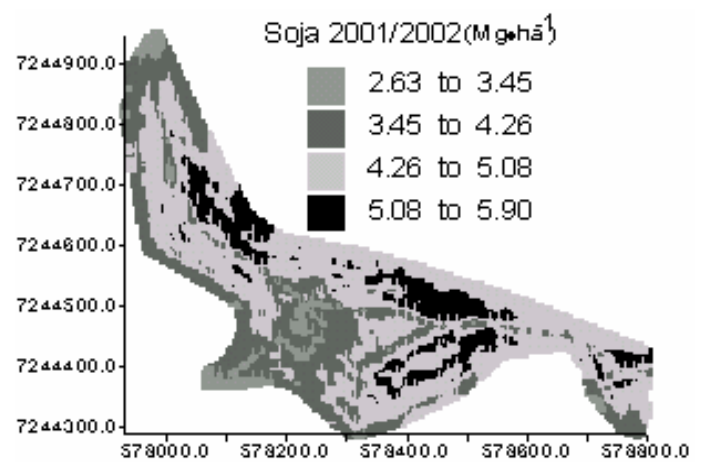

C.

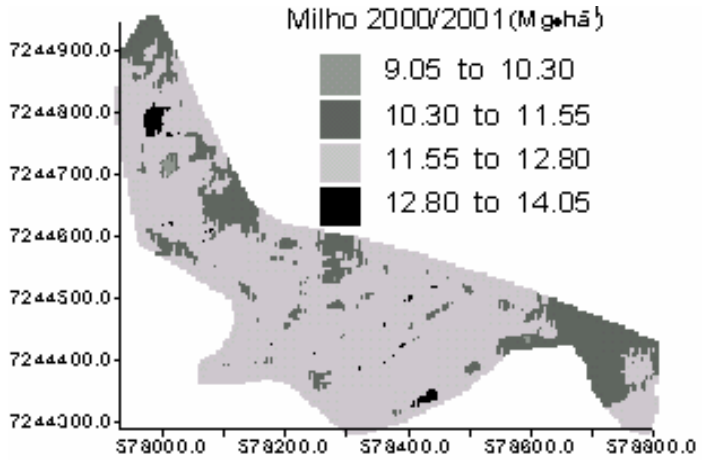

B.

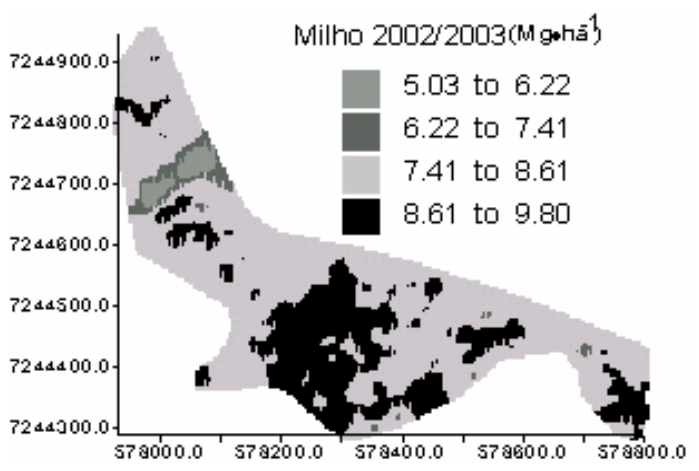

D.

Figura 10 - Mapas da produtividade das culturas (Mg ha ${ }^{-1}$ ) nas safras de verão de 1999 /2000 até 2002/2003 na área CR

A produtividade nas diferentes safras é apresentada para a área RB na Figura 11. Ao contrário das outras duas, nessa a produtividade aparenta uma maior estabilidade temporal, não só pela semelhança do padrão da distribuição espacial nas diferentes safras mas também devido aos intervalos idênticos de variação da produtividade da soja nas safras de 1998/1999 até 2001/2002. Também, ao contrário das outras duas áreas, nessa se verifica uma semelhança do padrão espacial da variação da CEa do solo e da produtividade.

O semivariograma da produtividade na safra 2002/2003 apresentou efeito pepita puro (Anexo A2). Nesse caso a interpolação foi feita utilizando-se a própria técnica de krigagem, onde, para quaisquer distâncias de separação entre as amostras utilizadas no processo de estimação, adotou-se um modelo de semivariograma que fornecia para o sistema de equações da 
krigagem iguais valores da função semivariância, e tendo estabelecido um raio de busca de 40,0 m, o processo de interpolação foi do tipo média móvel, utilizando uma "janela" circular de 40,0 m de raio.

Em casos como esse, o procedimento de interpolação normalmente utilizado seria outro método de estimação que não o geoestatístico (krigagem), como por exemplo o inverso da distância.

No entanto, a escolha por se utilizar um desses métodos, obrigatoriamente atribui maior peso para as amostras mais próximas do ponto sendo estimado, em função do expoente da função inverso da distância, o qual é estabelecido de forma empírica pelo usuário.

Portanto, se a utilização da krigagem na estimação dessa variável (Figura 11D) foge ao convencional, e se o raio de busca foi definido de forma arbitrária, assim também o seriam as decisões necessárias de serem tomadas caso fossem utilizados métodos como o inverso da distância, vizinho mais próximo, triangulação entre outros.

Analisando a distribuição dos valores da produtividade na safra 2002/2003, tanto a dos valores amostrados quanto a dos estimados, observa-se uma semelhança através das suas médias (7,89 $\mathrm{Mg} \mathrm{ha}^{-1}$ para os valores estimados e 7,90 $\mathrm{Mg} \mathrm{ha}^{-1}$ para os valores amostrados) e mediana (7,89 $\mathrm{Mg} \mathrm{ha}^{-1}$ para os valores estimados e 7,81 $\mathrm{Mg} \mathrm{ha}^{-1}$ para os valores amostrados), indicando semelhança entre as duas distribuições, e, consequentemente, a qualidade da interpolação realizada. 

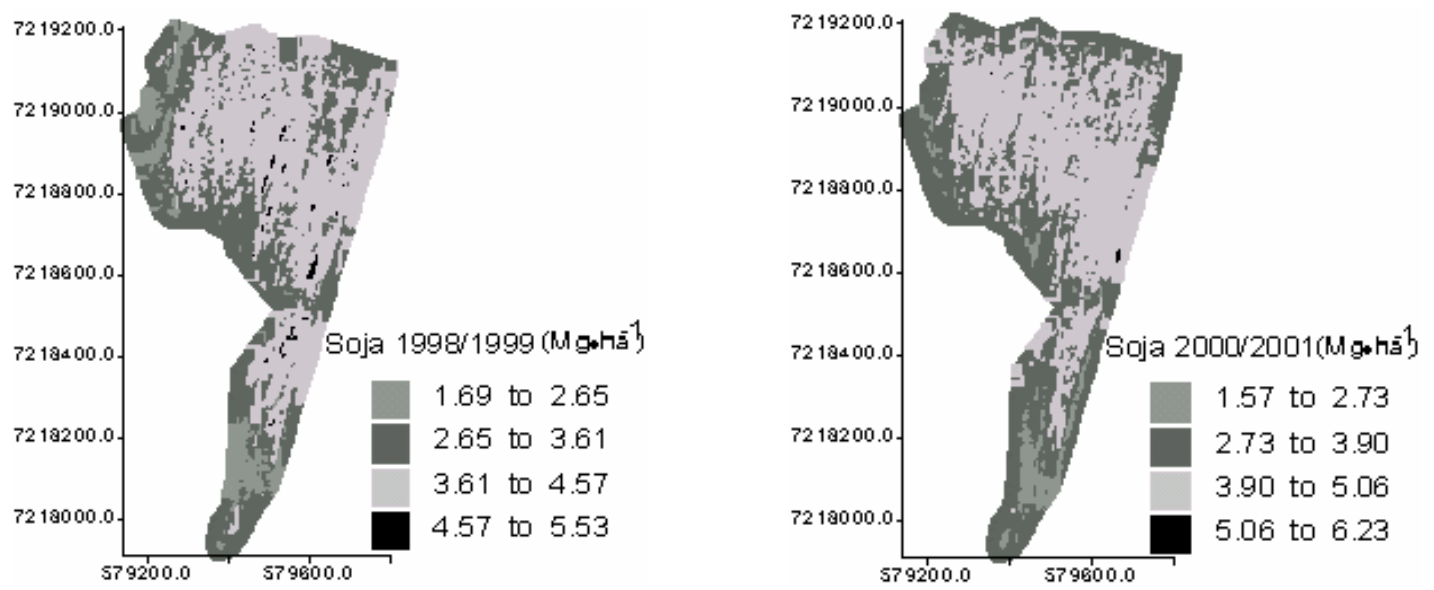

A.

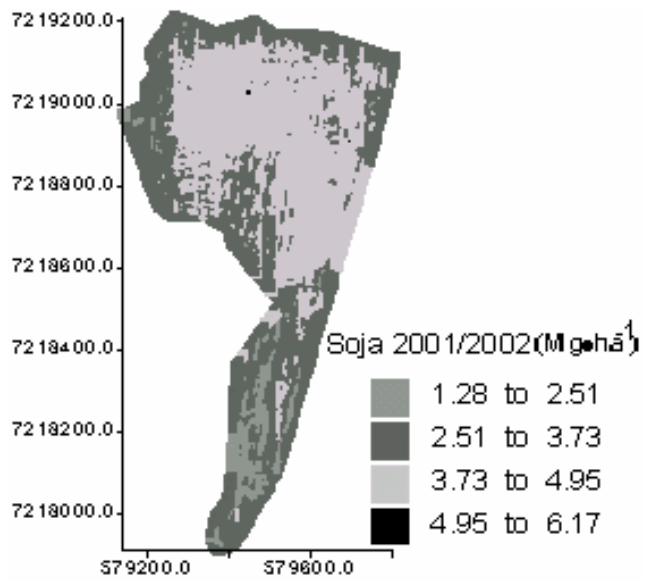

B.

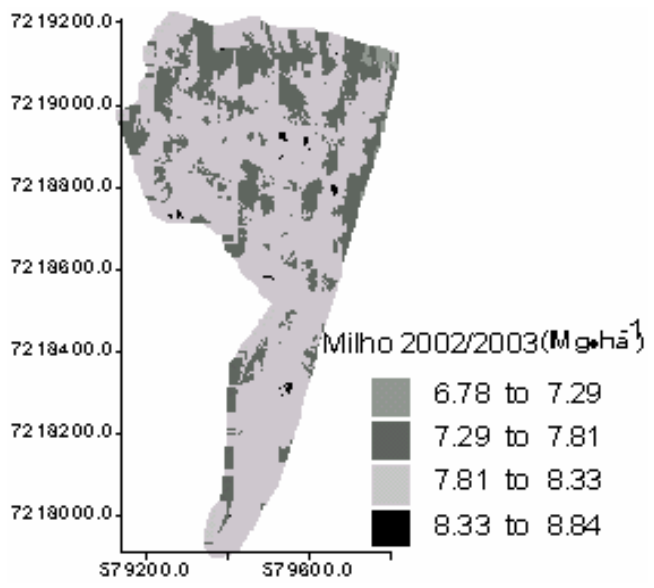

C.

D.

Figura 11 - Mapas da produtividade das culturas (Mg ha ${ }^{-1}$ ) nas safras de verão de 1998/1999 até 2002/ 2003 na área RB

Na Figura 12 são apresentados os mapas dos atributos físico-químicos do solo obtidos pela krigagem para a área Fabc. Além da importância de uma detalhada análise espacializada dessas variáveis visando dar continuidade a exploração das possíveis inter-relações entre as variáveis CEa, produtividade e físico-químicas do solo, especificamente para as últimas, surge a necessidade de se identificar a sua importância na definição das unidades de gerenciamento do solo.

Se a mesma consideração não foi feita durante a análise dos mapas da CEa nas três áreas, primeiramente foi devido a esse plano de informação (CEa) ser o foco maior desse estudo. E, secundariamente, a carência de referências agronômicas na literatura nacional, ou internacional, a respeito de níveis de interpretação para a CEa, resultou na falta de parâmetros para exclusão da 
mesma como sem importância na definição das unidades de gerenciamento. Consequentemente ela foi definida previamente como candidata a integrar todas as etapas desse estudo, buscando diferentes técnicas que pudessem comprovar ou refutar a utilidade dessa informação na definição das unidades de gerenciamento em cada uma das áreas.

Para o teor de P na área Fabc (Figura 12A) observa-se que grande parte da área se encontra acima do limite considerado muito alto $\left(>80,00 \mathrm{mg} \mathrm{dm}^{-3}\right)$ e apenas numa pequena região na parte sul do mapa o nível é alto (de 41,00 até $80,00 \mathrm{mg} \mathrm{dm}^{-3}$ ). Isso indica que provavelmente o teor de $\mathrm{P}$ nessa área não apresentou forte relação com a produtividade das culturas, sendo essa relação avaliada posteriormente.

Para teores elevados como os que se apresentam no mapa da Figura 12A, segundo Raij (1991), nesses casos, geralmente não se espera resposta ao adubo, e as adubações que devem ser feitas são aplicações leves, de manutenção ou de implantação das culturas. O teor de MO (Figura 20B) nessa área é elevado segundo Muzilli (1978), característico de solos com textura argilosa, e como pode ser observado na Figura 20N o solo nessa área é de textura argilosa com pequena variação no teor de argila.

Para avaliar o nível de acidez do solo nessa área, nas Figuras 12C e 12D são apresentados os mapas do $\mathrm{pH}$ e do $\mathrm{H}+\mathrm{Al}$. Para o pH (Figura 12C) verifica-se variação entre uma elevada acidez na região central do talhão até uma baixa acidez na região oeste do talhão. O mapa do $\mathrm{H}+\mathrm{Al}$ (Figura 12D) apresenta uma clara relação inversa com o mapa do $\mathrm{pH}$. Quanto ao teor de Al (Figura 12E) e do M\% (Figura 12M) a situação que se apresenta com nitidez é a da ocorrência de uma baixa concentração no solo desse elemento em toda área, não devendo a presença do mesmo ser um fator limitante à produção agrícola na área.

O teor de K (Figura 12F) variou de médio até elevado na maior parte do talhão. No caso dos teores de Ca (Figura 12G) e Mg (Figura 12H) ambos se encontraram no intervalo de elevada concentração. O valor da SB (Figura 12I) variou de médio na maior parte da área até elevado na região oeste da mesma, enquanto que o valor do V\% (Figura 12L) foi interpretado como estando no limite entre baixo e médio no leste e elevado no oeste da área. 


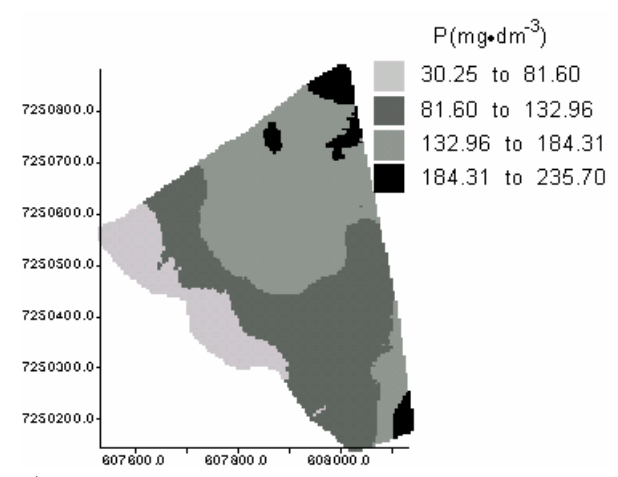

A.

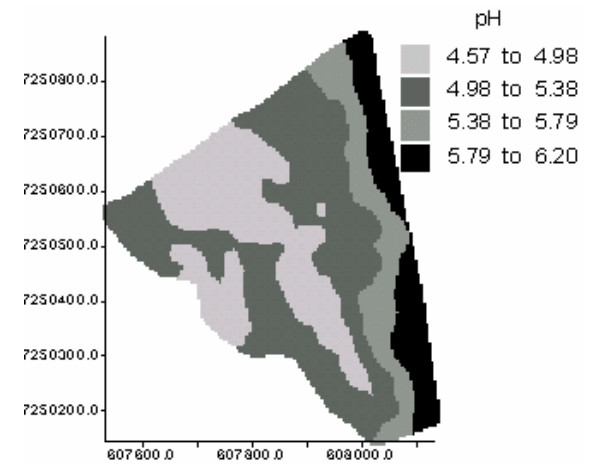

C.

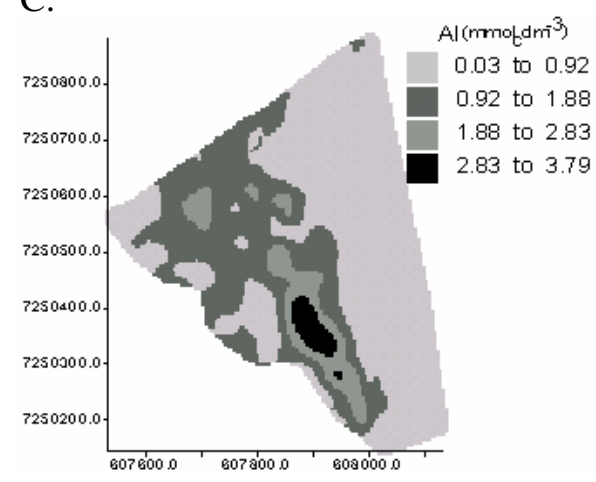

E.

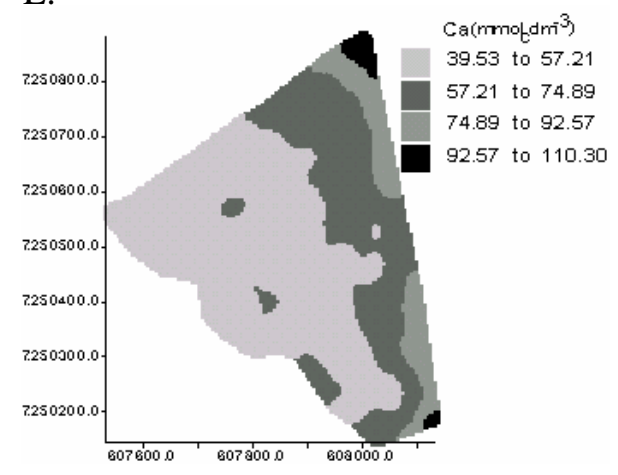

G.

Figura 12 - Mapas das variáveis físico-químicas do solo na área Fabc

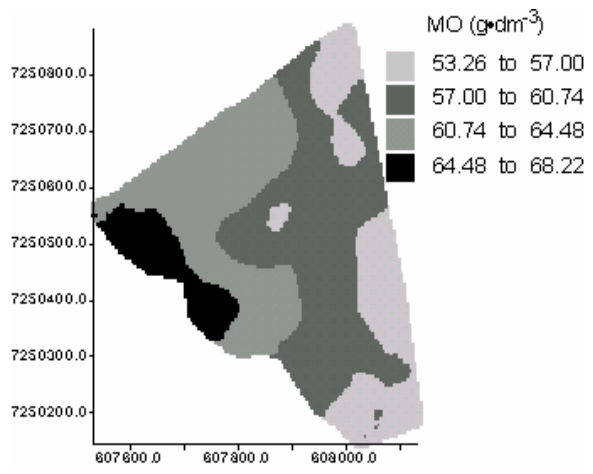

B.

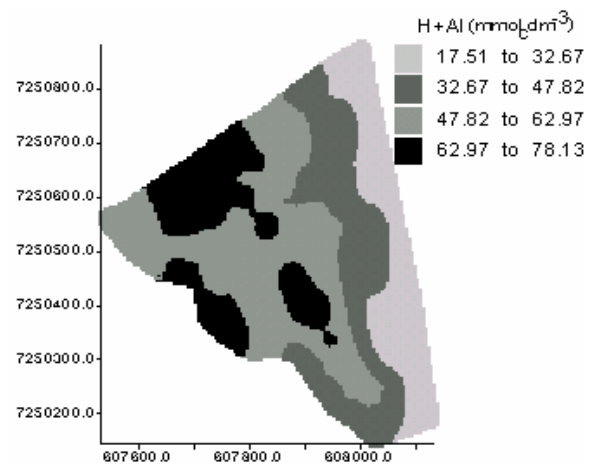

D.

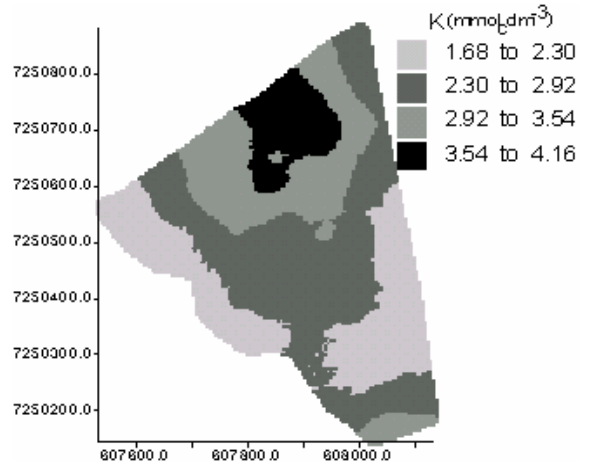

F.

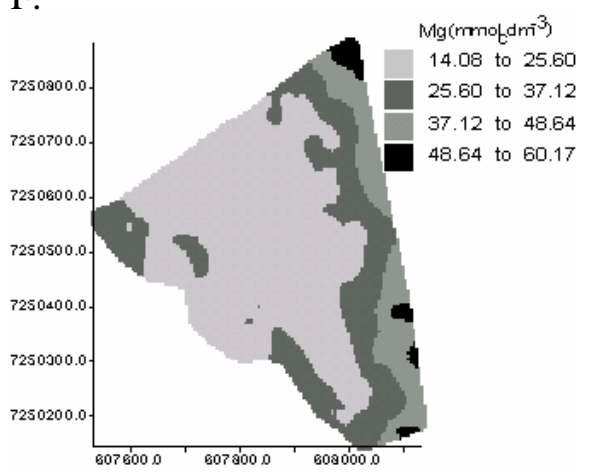

$\mathrm{H}$.

bc 

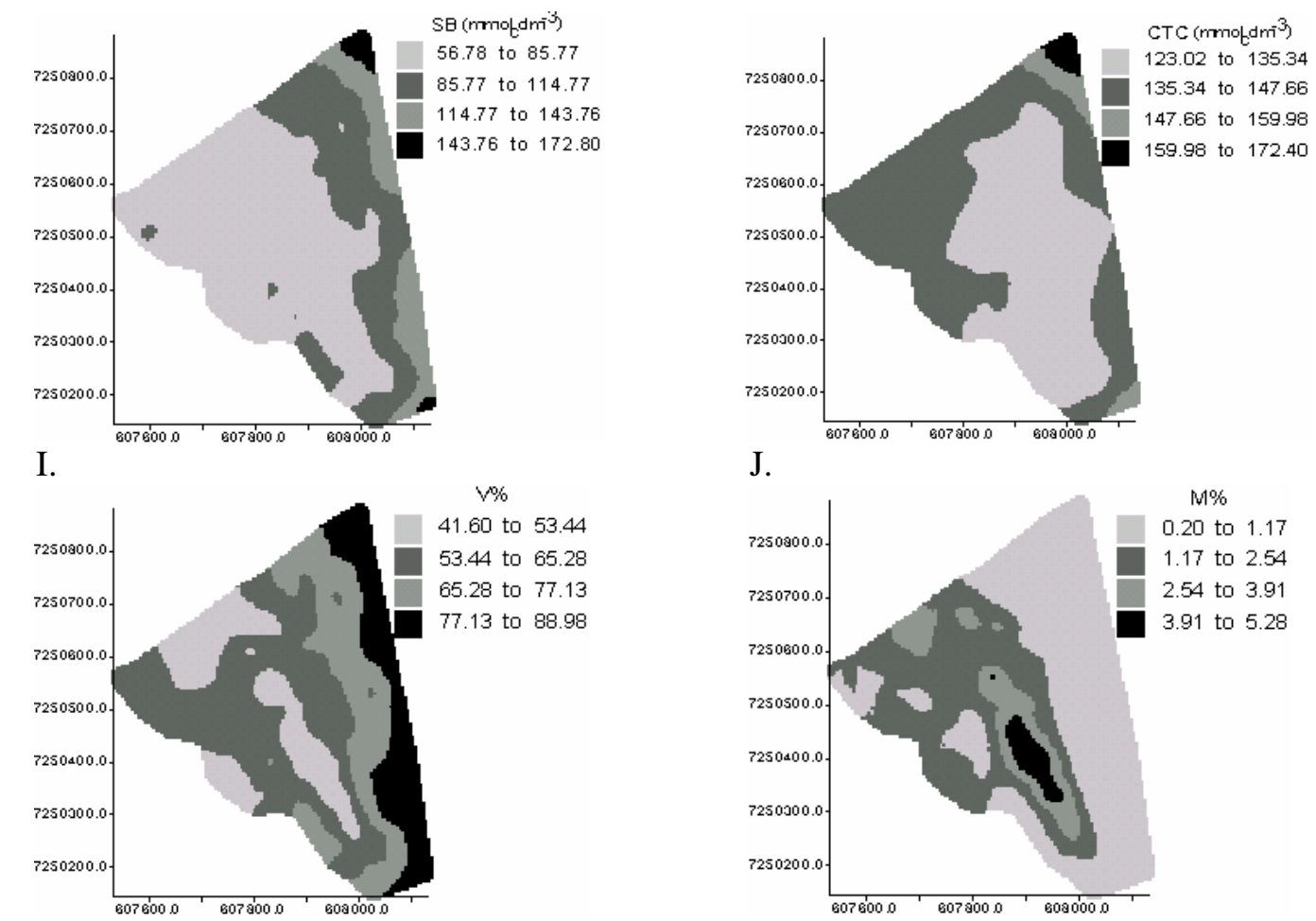

L.

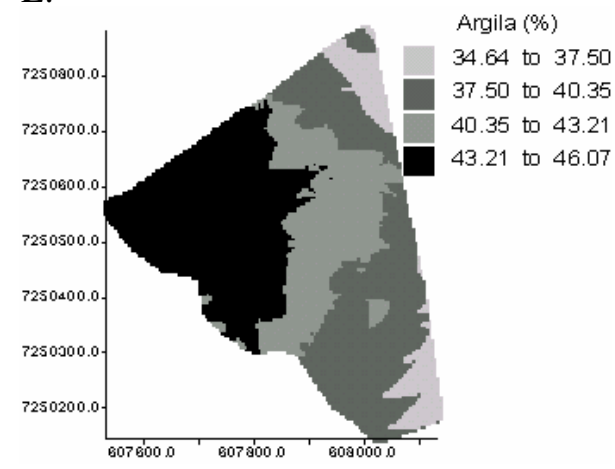

N.
Argila (\%)

34.64 to 37.50

43.21 to 46.07
40.35 to 43.21

Figura 12 - Mapas das variáveis físico-químicas do solo na área Fabc

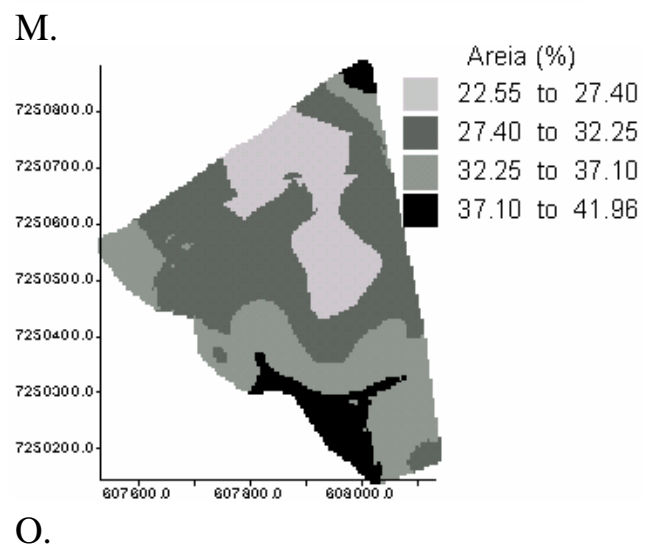

O.

Observando os mapas dos atributos do solo apresentados para a área Fabc (Figuras 12A até 12O) não é possível perceber tendência visual nítida desses com aqueles de CEa nas leituras rasa e profunda (Figura 6).

Na Figura 13 são apresentados os mapas dos atributos físico-químicos do solo na área CR. Uma diferença desses mapas em relação aos mapas apresentados para esses mesmos atributos na área Fabc, é a aparência mais suave destes em relação àqueles, com maior continuidade espacial dos valores dos atributos do solo. Esse fato pode ser explicado devido ao menor número de 
amostras coletados na área CR (2,0 amostras ha $\left.{ }^{-1}\right)$ em relação à Fabc (10,0 amostras ha $\left.{ }^{-1}\right)$, resultando um mapa com transições mais suaves entre os níveis de cada atributo na área CR.

Em seguida analisou-se, caso a caso, os níveis de cada elemento nessa área, começando pelo teor de $\mathrm{P}$ (Figura 13A), onde o teor se manteve em todo o talhão acima do nível interpretado como muito alto.

O teor de MO (Figura 13B) variou na classe característica de solos de textura média $(<31$ $\left.\mathrm{g} \mathrm{dm}^{-3}\right)$, na região noroeste do talhão, e de textura argilosa $\left(>31 \mathrm{~g} \mathrm{dm}^{-3}\right)$ na maior parte da área, podendo ser considerado em toda ela alto (Muzilli, 1978).

Quanto à textura do solo, na maior parte da área se constata a presença de solos com textura média (Figura 13N), e na região no noroeste do talhão ocorre uma área de solo com textura mais arenosa (Figura 13O). O teor de pH do solo (Figura 13C) variou entre alto na maior parte do talhão até médio na região sudeste da área, sendo as regiões de ocorrência de teores de $\mathrm{H}+\mathrm{Al}$ (Figura 13D) maiores ou menores aproximadamente igual ao inverso do $\mathrm{pH}$.

Os teores de $\mathrm{Al}$ e do M\% (Figuras 13E e 13M) foram baixos, indicando novamente a pouca probabilidade desse elemento ser um fator limitante ao desenvolvimento das plantas cultivadas nessa área. O K (Figura 13F) se apresentou com concentração média na maior parte da área e com concentração elevada no sudeste da mesma.

Com referência aos teores de Ca e Mg (Figuras 13G e 13H, respectivamente) ambos foram elevados, com maior variabilidade do primeiro, não devendo ocorrer elevada relação de nenhum deles com a produtividade, devido aos níveis bastante adequados em toda a área. $\mathrm{O}$ valor da CTC (Figura 13J) foi menor do que na área Fabc, entre outras coisas devido ao solo ser mais arenoso, sendo a SB (Figura 13I) também menor e a V\% (Figura 13L) se mantendo em toda a área no limite entre as classes de baixo e médio valores, com apenas uma pequena região no sudeste da área apresentando saturação média.

Assim como o ocorrido para a área Fabc, nessa também não se percebe nenhuma relação visual nítida entre a CEa em ambas as profundidades de leitura (Figuras 7A e 7B) com nenhuma das variáveis físico-químicas do solo analisadas em laboratório. 


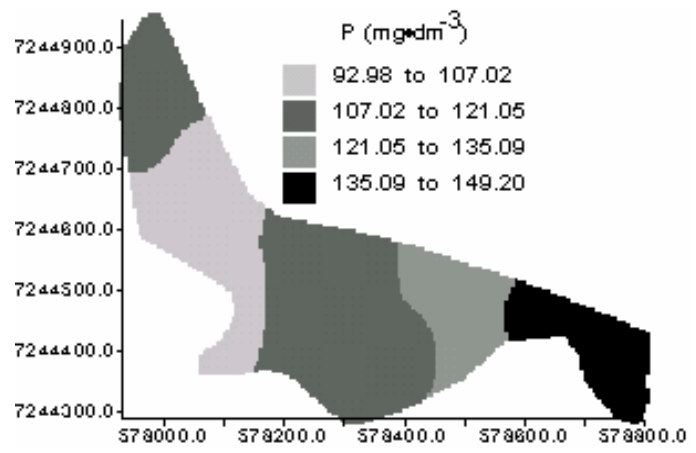

A.

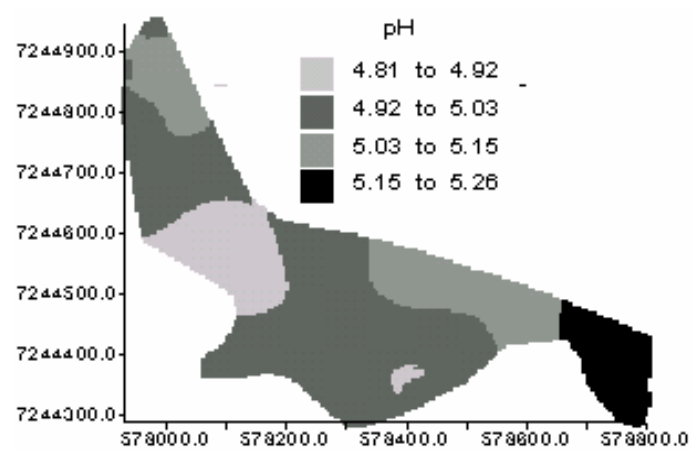

C.

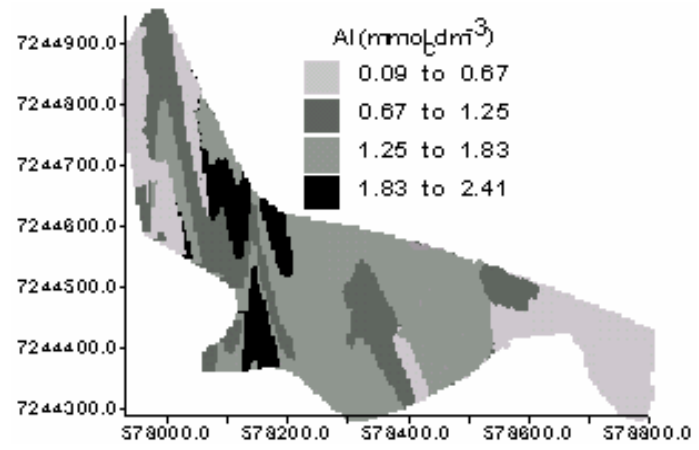

E.

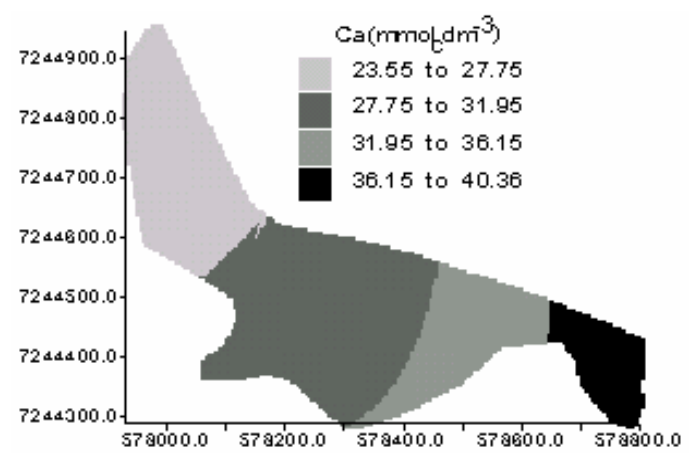

G.

Figura 13 - Mapas das variáveis físico-químicas do solo na área CR

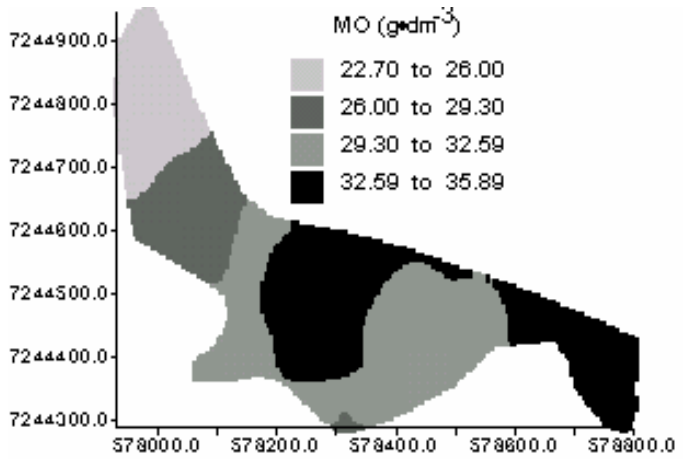

B.

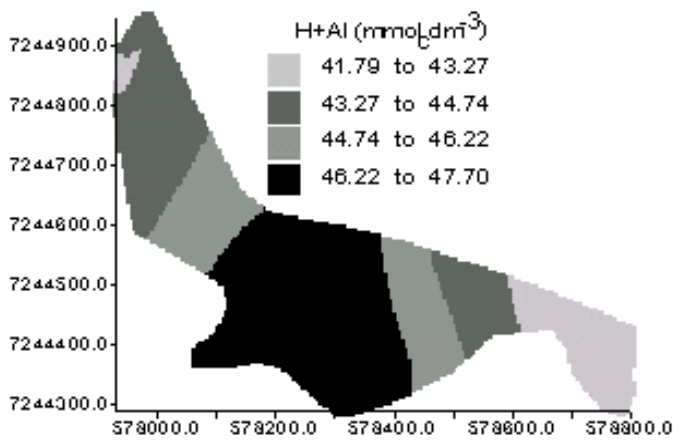

D.

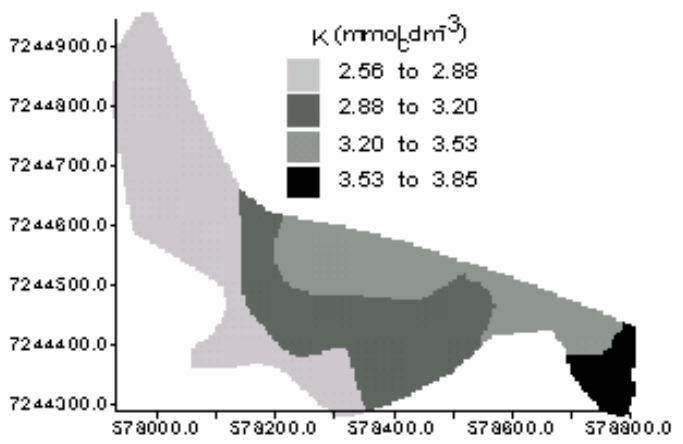

F.

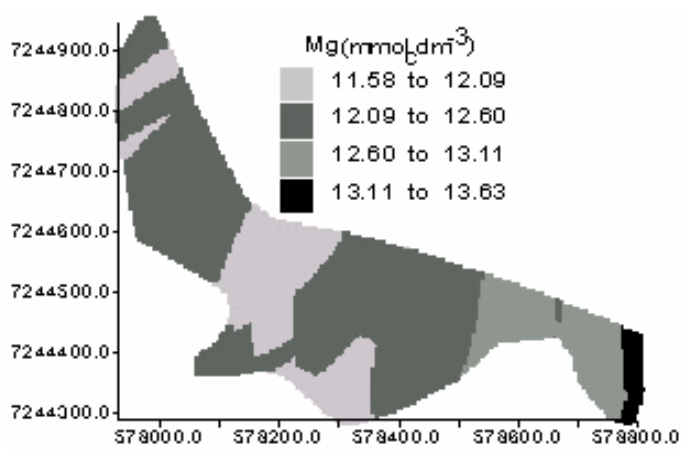

$\mathrm{H}$. 

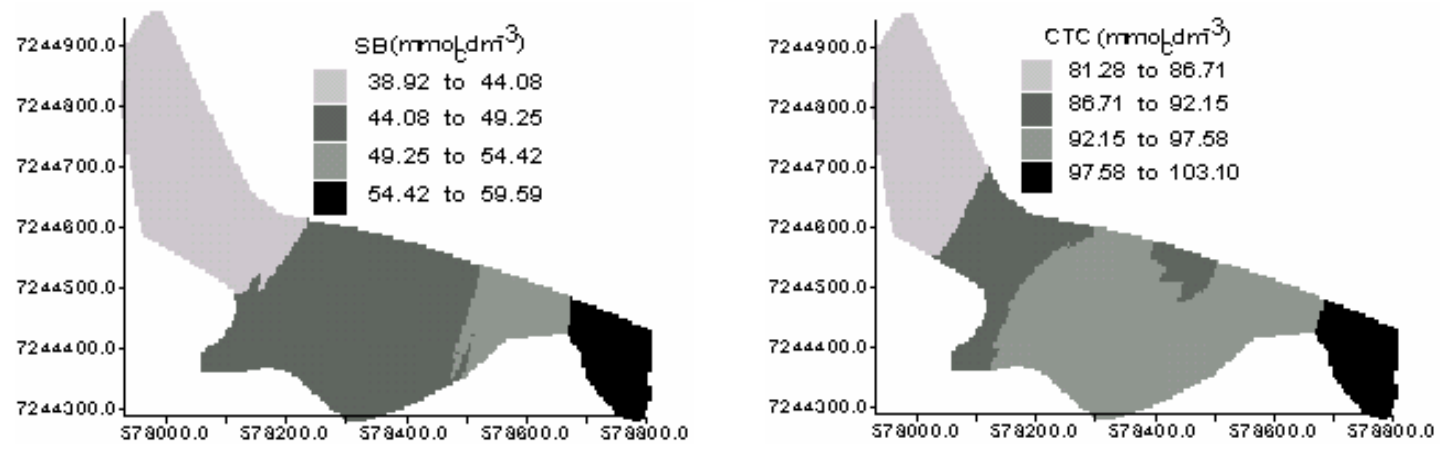

I.

$\mathrm{J}$.
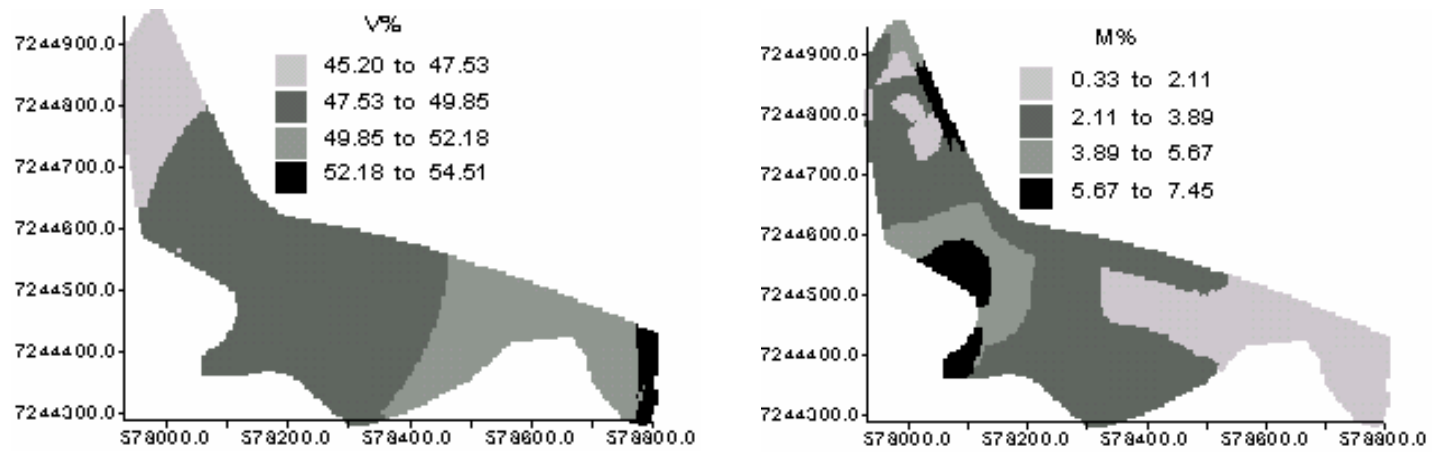

L.

M.
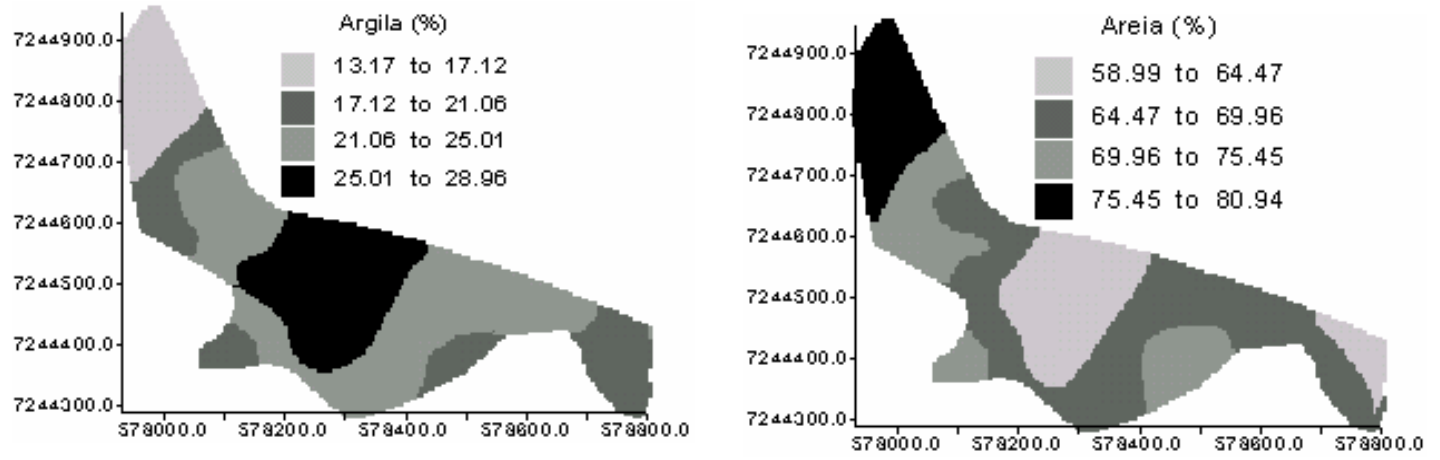

N.

O.

Figura 13 - Mapas das variáveis físico-químicas do solo na área CR

Na Figura 14 são apresentados os mapas dos atributos físico-químicos do solo na área RB. A mesma observação que foi feita para a área CR em relação à aparência de transição, de níveis dos atributos, mais suave para aquela área em relação à aparência abrupta que se verificou na área Fabc, é válida nesta. Quanto aos atributos que não apresentaram dependência espacial, e cujos processos de interpolação se assemelharam a um processo de média móvel, o único caso em que isso ocorreu foi para o M\% (Figura 14M). 
Para o teor de $\mathrm{P}$ uma grande diferença ocorreu em relação às outras duas áreas. Na maior parte da área o teor de P (Figura 14A) ficou no limite, ou um pouco abaixo, do teor considerado alto, ficando na classe de teor médio. Nesse caso, segundo Raij (1991), surge a necessidade de adubações moderadas, visando manter ou elevar o teor de P. Por isso a relação do P com a produtividade nessa área deve ser melhor investigada. A curiosidade é que a região de ocorrência dos maiores teores de P é a mesma da ocorrência do solo mais arenoso (Figura 14O) e com menor CTC (Figura 14J).

Para a textura do solo dessa área é muito claro a existência de duas regiões distintas: uma região na extremidade sul da área de solo muito arenoso (Figura 140) e o restante da área apresentando solo argiloso (Figura 14N), com o teor de MO (Figura 14B) acompanhando a textura do solo.

Quanto à acidez do solo a variabilidade evidenciada para o pH (Figura 14C) foi baixa, e o nível de acidez foi alto para toda a área. Os níveis de Al (Figura 14E) e M\% (Figura 14M) mantiveram as tendências identificadas para as outras duas áreas.

Os teores de K (Figura 14F), Ca (Figura 14G) e Mg (Figura 14H) ficaram abaixo dos níveis verificados para as outras duas áreas, sendo sempre os teores mais baixos observados na extremidade sul do talhão, que possui solo com textura arenosa. Nessa região, o nível de K verificado foi baixo e os níveis de Ca e Mg foram interpretados como sendo médios, enfatizando ainda mais a diferença entre essas duas regiões de solos texturalmente diferentes.

A CTC (Figura 14J), SB (Figura 14I) e V\% (Figura 14L) apresentaram padrão de distribuição espacial pela área bastante semelhante, com regiões de ocorrência de valores mais baixos de CTC apresentando valores mais baixos também da SB, do V\% e vice-versa. Novamente, a região que manifestou os menores teores para esses atributos foi a que possui solo muito arenoso, ao sul do talhão (Figura 14O).

Ao contrário das outras duas áreas, nessa é possível se observar relações entre os mapas da CEa rasa e profunda, da produtividade e dos atributos físico-químicos do solo, relação essa marcante no contraste entre as duas regiões de texturas distintas. A comparação visual entre os mapas da CEa nas duas profundidades (Figuras 8A e 8B), da produtividade de soja (Figuras 11A, 11B e 11C) e dos conteúdos de argila e de areia (Figuras 14N e 14O) mostram claramente essas relações. 


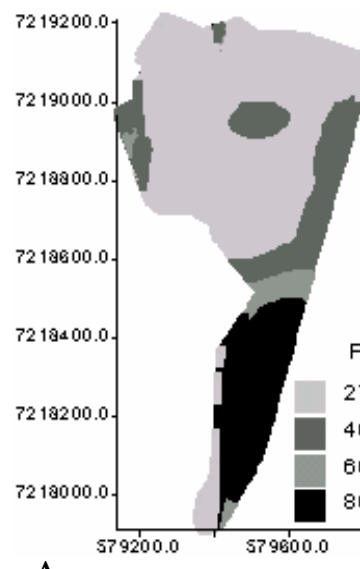

A.

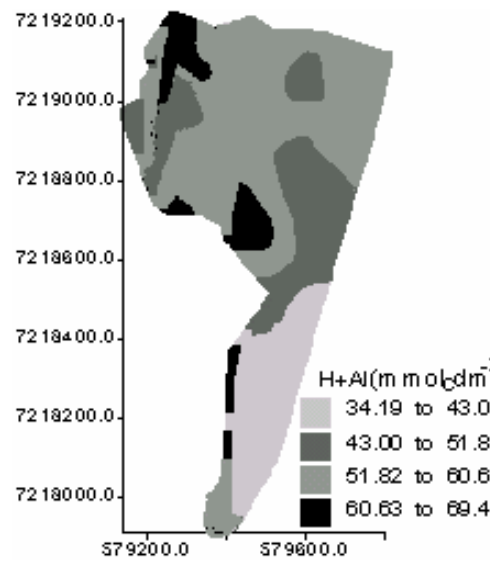

D.

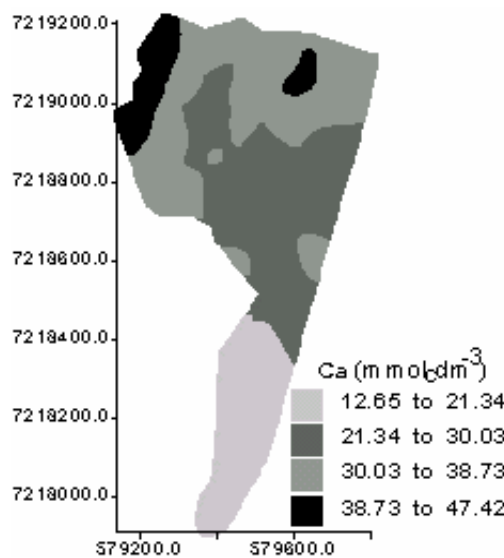

G.

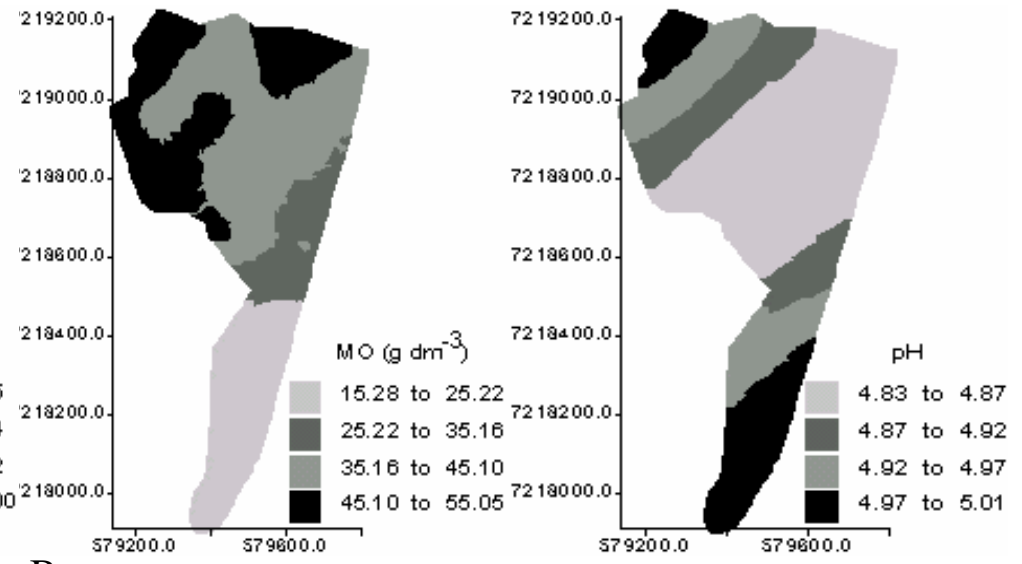

B.

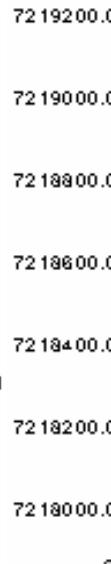

E.

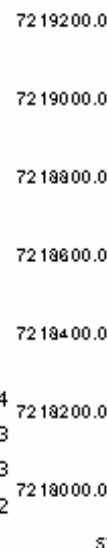

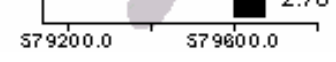

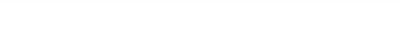

C.

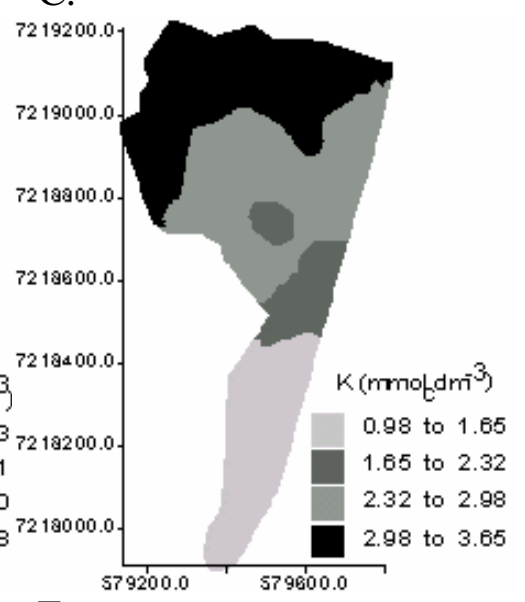

F.

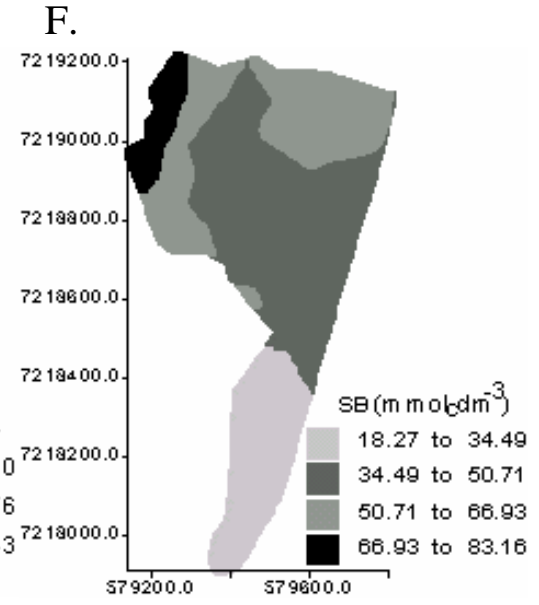

$\mathrm{H}$.

I.

Figura 14 - Mapas das variáveis físico-químicas do solo na área RB 

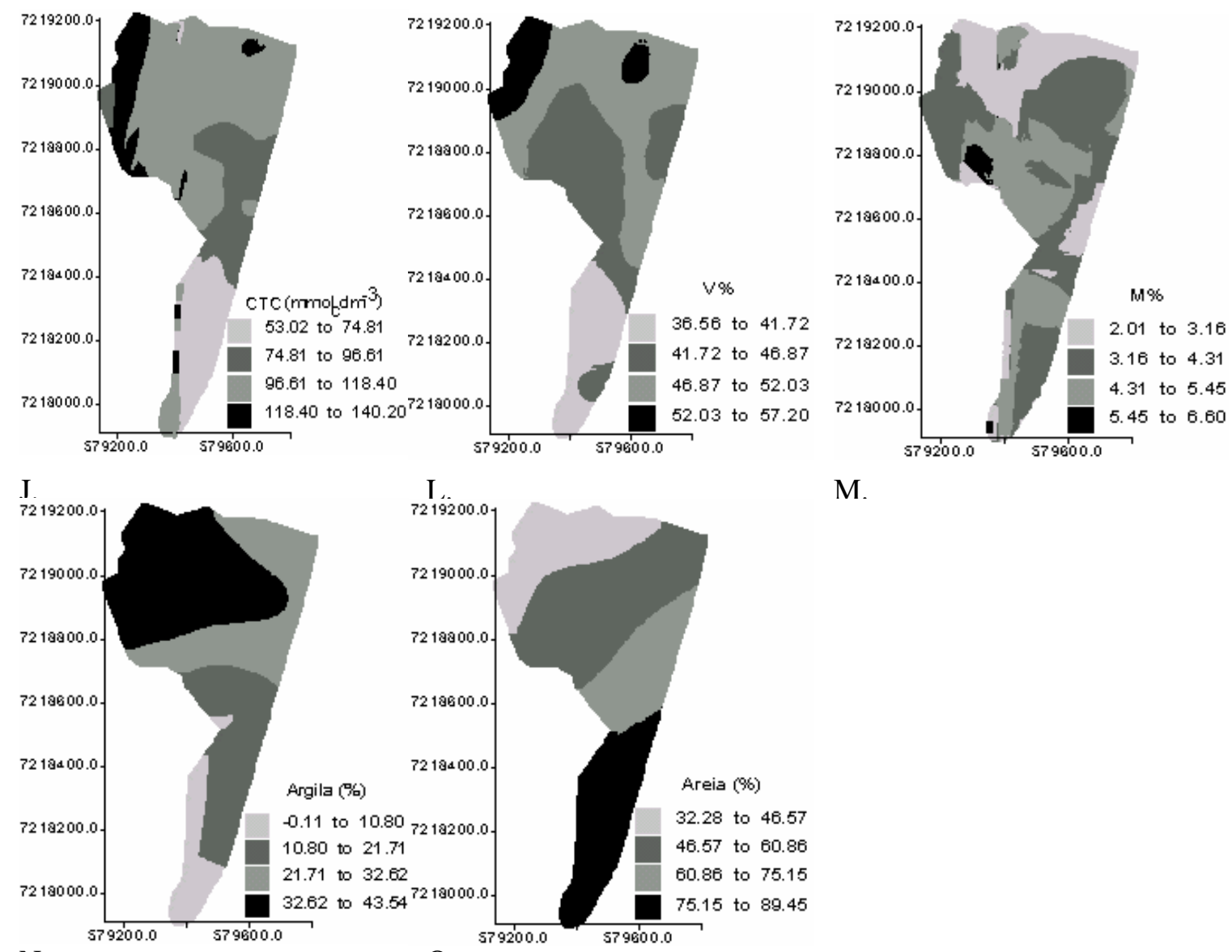

M. N.

O.

Figura 14 - Mapas das variáveis físico-químicas do solo na área RB

\subsection{Análise multivariada}

\subsubsection{Análise de correlação entre variáveis}

A partir dos valores interpolados realizou-se a análise da relação linear entre as variáveis. Para isso calculou-se o coeficiente de correlação linear de Pearson entre todas as variáveis nas três áreas.

Entre as variáveis físico-químicas do solo analisadas em laboratório, aquelas referentes aos teores de $\mathrm{Al}$ e M\% foram excluídas da análise de correlação. Essa decisão é justificada pois, além de nas três áreas ambas terem se manifestado com teores baixos, sem maiores prejuízos ao desenvolvimento das culturas, as correlações obtidas entre as mesmas com as outras variáveis 
foram também baixas (valores não apresentados). Além do que, os elevados teores de Ca nos solos das três áreas (Tabelas 12, 13 e 14), reforçam ainda mais a característica desses solos de não apresentarem acidez elevada. As tabelas de correlações com as relações verificadas entre as distribuições espaciais de todas essas variáveis, são apresentadas nos Anexos B1, B2 e B3 ao final do texto.

Nos estudos que procuram quantificar a variabilidade de atributos do solo, grande parte da atenção tem sido dada à variabilidade espacial destes, como pode ser constatado na extensa bibliografia de trabalhos publicados sobre o assunto, como Franssen et al. (1997), Gonçalves (1997), Martinho (2001), Sa (2001), citando apenas alguns mais recentes; inclusive alguns que se utilizaram dos monitoramentos da CEa do solo para esse fim, como McBride et al., 1990 e Harstock et al., 2000.

No entanto, pouco tem sido abordado sobre outro tipo de variabilidade, a qual os atributos do solo estão sujeitos, que é a variabilidade temporal. Hoskinson et al. (1999) realizaram um trabalho em que procuravam estudar essa variabilidade e chegaram a afirmar que apenas considerando a variabilidade espacial dos atributos do solo, não considerando a variação temporal, na recomendação da adubação, não seria suficiente para gerar ganhos ambientais de produtividade ou qualidade das culturas.

Nesse estudo, as considerações feitas referentes as correlações entre as variáveis do solo analisadas em laboratório (medidas em 2001) e a CEa nas duas profundidades (medidas em 2002 nas três áreas, mais um segundo monitoramento em 2003 na área Fabc) procuraram, apesar da consciência sobre a variabilidade temporal dos atributos, apenas investigar possíveis relações da distribuição espacial das variáveis, na esperança de que o padrão da distribuição espacial delas se mantenham aproximadamente constantes ao longo do tempo.

Nesse sentido, as características do gerenciamento das áreas experimentais contribuem com a esperança dessa manutenção pois, devido ao alto nível da fertilidade do solo, conforme descrito na seção 4.1 (Tabelas 12, 13 e 14), além delas serem cultivadas sob sistema de plantio direto há vários anos (>10), elas demoram mais para terem seu nível de fertilidade alterado pelas culturas (Molin, 2001).

As relações entre as variáveis para a área Fabc são apresentadas no anexo B1. Ao contrário do que foi exposto na seção 4.3.2, a respeito da estabilidade temporal das duas leituras de CEa realizadas na área Fabc, os coeficientes de correlação obtidos ( $r=0,86$ entre as duas leituras rasas e 0,83 entre as profundas) indicam a existência da estabilidade temporal do padrão da distribuição espacial para os dois monitoramentos realizados. 
Esse resultado está de acordo com o postulado por Lund et al. (1999) de que, como em solos não salinos o contribuinte primário para a CEa do solo é a textura, conquanto essa não seja alterada, o padrão de distribuição espacial identificado de um monitoramento para outro tende a ser mantido, mesmo resultado encontrado por Nehmdahl \& Greve (2001).

É interessante perceber também a existência de uma relação entre as leituras rasas e profundas nos dois monitoramentos ( $\mathrm{r}=0,47$ e 0,59 em 2002 e 2003, respectivamente). As correlações encontradas entre a CEa (ambas as leituras nos dois monitoramentos) e a produtividade nas diferentes safras e entre a CEa e os atributos físico-químicos do solo, foram, no geral, baixas. Especificamente a relação da CEa com a produtividade nas diversas safras foram sempre baixas $(\mathrm{r}<0,3)$, ao contrário do que foi relatado por Jaynes et al. (1995).

Entre outros fatores que poderiam explicar esse fato, a grande variabilidade temporal da produtividade nessa área, como evidenciado pelos baixos coeficientes de correlação entre as produtividades das diferentes safras, fornece indícios de que a CEa não é um dos fatores que expliquem prontamente a variação da produtividade.

A CEa rasa medida em 2002 apresentou relação moderada apenas com o K (r=0,41), enquanto que a leitura profunda medida em 2002 apresentou relação com o P (r=0,64); pH $(\mathrm{r}=0,48) ; \mathrm{H}+\mathrm{Al}(\mathrm{r}=-0,51) ; \mathrm{K}(\mathrm{r}=0,50) ; \mathrm{Ca}(\mathrm{r}=0,61) ; \mathrm{Mg}(\mathrm{r}=0,43) ; \mathrm{SB}(\mathrm{r}=0,57) ; \mathrm{V} \%(\mathrm{r}=0,54)$ e teor de argila $(\mathrm{r}=-0,42)$. Para a CEa rasa, medida em 2003, ela só apresentou relação considerada moderada com o P $(\mathrm{r}=0,42)$ e a leitura profunda apresentou relação com o P $(\mathrm{r}=0,51)$; pH $(\mathrm{r}=0,41) ; \mathrm{H}+\mathrm{Al}(\mathrm{r}=-0,44)$; $\mathrm{Ca}(\mathrm{r}=0,53) ; \mathrm{Mg}(\mathrm{r}=0,39)$; $\mathrm{SB}(\mathrm{r}=0,49)$ e V\% $(\mathrm{r}=0,46)$.

Esses resultados mostram, em primeiro lugar, que a CEa profunda apresentou relação com um maior número de parâmetros do solo de interesse agronômico do que a CEa rasa. Assim, caso esses atributos possuam relação com a produtividade (o que não foi evidenciado pelas correlações obtidas), indicaria a viabilidade da utilização da CEa profunda no auxílio a definição de unidades de gerenciamento.

Essas relações da CEa profunda nos dois monitoramentos se verificaram principalmente com elementos relacionados ao complexo de armazenamento, disponibilização e troca de cátions no solo. Isso está de acordo com o relatado por Nadler \& Frenkel (1980) de que quando da ocorrência de baixas concentrações da solução do solo esse tipo de relação poderia ser evidenciado, relação essa também identificada para os teores de Ca e Mg por McBride et al. (1990) e Harstock et al. (2000). Além disso, essa tendência novamente indica uma estabilidade temporal da informação CEa do solo nessa área. 
No anexo B2 são apresentados os resultados das correlações entre todas as variáveis monitoradas na área CR. Ao contrário da área Fabc, a relação entre a CEa rasa e profunda foi mais evidente $(r=0,84)$. Novamente a relação da distribuição espacial da CEa com a da produtividade não é marcante, caracterizada pelos baixos coeficientes de correlação (em todos os casos $r<0,3$ ), e, novamente, a variabilidade temporal da produtividade foi constatada entre as diferentes safras.

Com referência à relação da CEa rasa com os demais atributos físico-químicos do solo essa apresentou média intensidade apenas com o K $(\mathrm{r}=0,41)$ e com a V\% ( $\mathrm{r}=0,39)$. Quanto à CEa profunda, essa apresentou relação com o teor de P (r=0,47); MO (r=0,52); K (r=0,54); Ca $(\mathrm{r}=0,52)$; SB $(\mathrm{r}=0,53)$; CTC $(\mathrm{r}=0,52)$; V\% $(\mathrm{r}=0,50)$ e conteúdo de areia $(\mathrm{r}=-0,46)$.

Esses resultados se assemelham aos obtidos entre a CEa e esses mesmos atributos do solo na área Fabc, indicando para essa área que a informação fornecida pela CEa profunda apresenta uma maior utilidade na definição das unidades de gerenciamento, devido à sua relação com os atributos da fertilidade do solo.

Uma diferença em relação ao que ocorreu na área Fabc foi uma correlação, ainda que modesta, entre a CEa profunda e o conteúdo de areia, dando um indício da relação entre a CEa do solo e a textura do mesmo, comumente citada na literatura ( $\mathrm{Li}, 1997$; Lund et al., 1999; Nehmdahl \& Greve, 2001).

Os mesmos atributos que se correlacionam com a CEa profunda são fortemente interrelacionados, como pode ser verificado pelos coeficientes de correlações entre eles (são citados apenas as correlações cujos coeficientes foram maiores do que 0,80): $\mathrm{P}$ e pH (r=0,83); $\mathrm{P}$ e K $(r=0,85)$; P e Ca $(r=0,88)$; P e SB $(r=0,91)$; P e V\% $(r=0,85)$; MO e K $(r=0,80)$; MO e Ca $(\mathrm{r}=0,80) ; \mathrm{MO}$ e CTC $(\mathrm{r}=0,91) ; \mathrm{MO}$ e conteúdo de areia $(\mathrm{r}=-0,94) ; \mathrm{K}$ e Ca $(\mathrm{r}=0,83) ; \mathrm{K}$ e SB $(\mathrm{r}=0,84)$; K e CTC $(\mathrm{r}=0,83)$; Ca e SB $(\mathrm{r}=0,99)$; Ca e V\% $(\mathrm{r}=0,94)$; SB e CTC $(\mathrm{r}=0,92)$; SB e V\% $(\mathrm{r}=0,95)$ e CTC e V\% $(\mathrm{r}=0,85)$.

Essas inter-relações tornam as análises feitas sobre conjuntos de dados como esse mais complexas, devido à interferência de uma variável sobre as outras, e técnicas estatísticas multivariadas devem ser utilizadas, sendo esse assunto abordado na etapa 4.4.2.

A área que possivelmente obteve os resultados de correlações entre a CEa e as demais variáveis mais interessantes foi a RB, sendo a tabela de correlações apresentada no anexo B3. Nessa área a relação obtida entre a CEa rasa e profunda foi a mais elevada entre as três áreas $(r=0,96)$. Entre a CEa rasa e profunda e a produtividade nas diferentes safras, novamente, os coeficientes de correlação foram baixos (sempre menores do que 0,4 ). 
No entanto, ao contrário das outras duas áreas, correlações de médias a fortes foram identificadas entre a produtividade nas diferentes safras: soja 1998/1999 e soja 2000/2001 ( $\mathrm{r}=0,55)$; soja 1998/1999 e soja 2001/2002 (r=0,52) e soja 2000/2001 e soja 2001/2002 (r=0,72), apenas a safra de milho 2002/2003 não possuindo nenhuma relação com os outros três monitoramentos da produtividade.

Quanto à relação da CEa rasa com os atributos do solo analisados em laboratório, diversas correlações médias e fortes também puderam ser identificadas: $\mathrm{P}(\mathrm{r}=-0,68) ; \mathrm{MO}(\mathrm{r}=0,86) ; \mathrm{pH}$ $(\mathrm{r}=-0,41) ; \mathrm{H}+\mathrm{Al}(\mathrm{r}=0,66) ; \mathrm{K}(\mathrm{r}=0,87) ; \mathrm{Ca}(\mathrm{r}=0,84) ; \mathrm{Mg}(\mathrm{r}=0,63) ; \mathrm{SB}(\mathrm{r}=0,84) ; \mathrm{CTC}(\mathrm{r}=0,77)$; V\% (r=0,76); argila $(\mathrm{r}=0,75)$ e areia $(\mathrm{r}=-0,86)$. Também para a CEa profunda se verificaram várias correlações de média e elevada intensidade com os atributos do solo: $\mathrm{P}(\mathrm{r}=-0,64)$; $\mathrm{MO}$ $(\mathrm{r}=0,82) ; \mathrm{pH}(\mathrm{r}=-0,42) ; \mathrm{H}+\mathrm{Al}(\mathrm{r}=0,62) ; \mathrm{K}(\mathrm{r}=0,81)$; $\mathrm{Ca}(\mathrm{r}=0,81) ; \mathrm{Mg}(\mathrm{r}=0,60)$; $\mathrm{SB}(\mathrm{r}=0,81)$; CTC $(\mathrm{r}=0,74) ; \mathrm{V} \%(\mathrm{r}=0,73)$; argila $(\mathrm{r}=0,66)$ e areia $(\mathrm{r}=-0,79)$.

Entre outros fatos interessantes, que podem ser inferidos dessas correlações, destaque tem de ser dado para a semelhança da intensidade das correlações entre cada variável do solo e a CEa rasa e profunda, indicando uma grande semelhança de ambas camadas de informação (CEa rasa e profunda). Além disso, novamente se identificou forte relação da CEa do solo com teores de nutrientes como P, K, Ca e Mg e aquelas variáveis ligadas à química dos solos que regulam o seu complexo de troca de cátions.

Uma diferença marcante que ocorreu nessa área em relação as outras duas foram as fortes correlações entre a CEa rasa e profunda com a textura do solo (argila e areia). Esse fato ocorreu de forma não tão intensa na área CR entre a CEa profunda e o conteúdo de areia. Essa forte correlação da CEa com parâmetros de textura do solo foi intensamente investigada e vários relatos podem ser encontrados na literatura (Banton et al., 1997; Lund et al., 1998; Dalgaard et al., 2001; Domsch \& Giebel, 2001).

Especificamente para a área RB essa forte relação da CEa com a textura do solo é um indício promissor da utilização da mesma na definição de unidades de gerenciamento do solo nessa área.

Observando novamente os mapas, com os teores dos atributos do solo para a área RB, apresentados na Figura 14, e prestando atenção na diferença dos teores dessas variáveis entre as duas regiões distintas quanto ao teor de areia (Figura 14N) (extremidade oeste da área), e teor de argila (Figura 14O) (restante da área), fica evidente a influência da textura do solo sobre as condições de fertilidade do solo e inclusive sobre a produtividade das culturas (Figuras 12a1 a 
12b2). Como a CEa apresentou forte correlação com a textura, sua utilização como importante informação no gerenciamento dessa área pode ser inferida dos dados.

\subsubsection{Análise de componentes principais}

Observando as correlações obtidas (Anexos B1; B2 e B3) entre as variáveis físicoquímicas e a CEa do solo, nas leituras rasa e profunda, é possível se identificar uma série de correlações de moderada a forte intensidade. Essas interações são fatores limitantes à utilização da análise de correlações simples na interpretação dos dados (Afifi \& Clark, 1996). Tais interrelações entre variáveis requerem a utilização de técnicas de análise que se baseiam no agrupamento das mesmas.

Nesse estudo foi utilizada a técnica conhecida como análise de componentes principais, que serve para identificar as maiores fontes de variação no conjunto de dados observados e a partir dessa identificação e caracterização da variabilidade dos fatores do solo, se proceder com a definição das unidades de gerenciamento deste, para isso utilizando de uma técnica de classificação matemática.

O principal objetivo desse processo foi o de reduzir o número de variáveis sem a perda de informação importante. Também procurou-se avaliar se a CEa (ambas as profundidades) tem alguma utilidade na definição das unidades de gerenciamento do solo, ou se essa definição pode ser feita com sucesso utilizando apenas outras variáveis do solo. Alguns autores se aproveitaram dessa técnica com objetivo semelhante (Fridgen et al., 2000; Fraisse et al., 2001).

Na Tabela 15 são apresentados os resultados dos componentes principais dos atributos do solo amostrados na área Fabc. Entre esses resultados é apresentado a porcentagem da variância total do conjunto dos dados que pode ser explicada por cada componente principal da análise.

O primeiro componente principal sempre explica a maior porção da variação desse conjunto original de dados. O segundo componente explica a segunda maior porção da variância e assim por diante. Quando o número de componentes principais é igual ao número de variáveis originais do estudo, 100\% da variância total dos dados é explicada (Mardia et al., 1989; Fraisse et al., 2001).

O critério utilizado para escolha dos componentes principais, que correspondem a uma nova variável formada pela transformação linear das variáveis originais, os quais serão utilizados na definição das unidades de gerenciamento do solo, foi o de manter aqueles que representassem uma porcentagem acumulada acima de $80 \%$ da variância total dos dados originais. Somente 
esses componentes são apresentados na Tabela 15. Inúmeros outros critérios existem para proceder essa escolha e maiores informações sobre esse assunto podem ser encontradas no trabalho de Afifi \& Clark (1996).

Na Tabela 15 são apresentadas as correlações entre as variáveis originais e as novas variáveis (componentes principais), correlações essas que nos programas computacionais de estatística são chamadas de "factor loadings", e indicam quais variáveis influenciam o modelo da variância dos dados.

Observando os resultados apresentados na Tabela 15 evidencia-se a forte inter-relação entre essas variáveis, devido à variação total das 16 variáveis ter sido explicada em grande parte (81,98\%) por três componentes principais.

A interpretação de cada componente principal ou nova variável é um aspecto importante desse tipo de análise. Para isso é necessário o conhecimento agronômico das causas potenciais para a variação observada e, às vezes, a tomada de decisões subjetivas.

O primeiro componente principal engloba 50,59\% da variação original dos dados (Tabela 15) e as variáveis que apresentam correlações negativas elevadas com ele são a CEa profunda 2002; o pH; o Ca; o Mg; a SB; a V\%, além de elevadas correlações positivas, notadamente o $\mathrm{H}+\mathrm{Al}$ e o teor de argila. Essa nova variável pode ser interpretada como sendo o potencial de fertilidade inerente do solo, representando a contribuição de uma série de propriedades organomineralógicas e físico-químicas do solo, com uma marcada influência da disponibilidade das bases Ca e Mg nesse solo. Dobermann \& Oberthür (1997) também, após análise multivariada dos atributos da fertilidade do solo, definiram uma nova variável sob esse nome.

Uma região dessa área com menores valores desse primeiro componente é uma que possui maiores teores da SB; Ca; Mg e V\% indicando possuir uma maior fertilidade do solo.

O segundo componente principal representa 21,34\% da variação total dos dados. Ele apresenta elevada relação com menor número de variáveis originais do que o primeiro componente principal, que normalmente apresenta correlação elevada com inúmeras variáveis originais (Afifi \& Clark, 1996).

Esse segundo componente apresenta elevada correlação positiva com a CEa rasa 2002 e com o teor de K e elevada correlação negativa com o teor de areia. A contribuição negativa do teor de areia sugere efeito da textura sobre o teor de K. Essa nova variável pode ser caracterizada como a disponibilidade de $\mathrm{K}$ no solo, indicando maiores teores de K existente no solo em áreas com maiores valores dessa nova variável. 
Tabela 15. Análise de componentes principais para as variáveis físico-químicas do solo na área Fabc

\begin{tabular}{|c|c|c|c|}
\hline \multirow[t]{2}{*}{ Componentes de variância } & \multicolumn{3}{|c|}{ Componentes principais } \\
\hline & 1 & 2 & 3 \\
\hline Variância & 8,09 & 3,41 & 1,61 \\
\hline Proporção (\%) & 50,59 & 21,34 & 10,06 \\
\hline Proporção acumulada (\%) & 50,59 & 71,93 & 81,98 \\
\hline Variáveis & \multicolumn{3}{|c|}{ Correlação com os componentes principaisł } \\
\hline CEa rasa 2002 & $-0,27$ & 0,71 & 0,37 \\
\hline CEa profunda 2002 & $-0,70$ & 0,51 & $-0,01$ \\
\hline CEa rasa 2003 & $-0,42$ & 0,63 & 0,36 \\
\hline CEa profunda 2003 & $-0,63$ & 0,47 & 0,07 \\
\hline $\mathrm{P}$ & $-0,58$ & 0,61 & $-0,36$ \\
\hline MO & 0,69 & 0,13 & 0,56 \\
\hline $\mathrm{PH}$ & $-0,93$ & $-0,27$ & $-0,02$ \\
\hline $\mathrm{H}+\mathrm{AL}$ & 0,92 & 0,24 & 0,20 \\
\hline K & $-0,05$ & 0,85 & $-0,26$ \\
\hline $\mathrm{Ca}$ & $-0,96$ & $-0,06$ & 0,13 \\
\hline Mg & $-0,90$ & $-0,34$ & 0,22 \\
\hline SB & $-0,96$ & $-0,15$ & 0,16 \\
\hline CTC & $-0,52$ & 0,05 & 0,67 \\
\hline V\% & $-0,95$ & $-0,21$ & $-0,06$ \\
\hline Argila (\%) & 0,76 & 0,26 & 0,36 \\
\hline Areia (\%) & $-0,10$ & $-0,72$ & 0,34 \\
\hline
\end{tabular}

‡ Números em negrito visam destacar as variáveis originais com elevadas correlações $(>|0,70|)$ com os componentes principais.

O terceiro, e último, componente principal retido pela análise, explicou 10,06\% da variação dos dados, não apresentando correlações consideradas elevadas $(>|0,70|$, limite arbitrário definido nesse trabalho) com nenhuma das variáveis originais.

No entanto, a CTC apresentou correlação com esse componente próxima a esse limite $(0,67)$, se destacando em relação as demais variáveis, além de uma moderada correlação com a MO $(0,56)$, sugerindo a relação dessa nova variável com fatores ligados à capacidade de armazenamento de bases desse solo. Isso permite caracterizar essa nova variável como a capacidade de retenção de cátions, e áreas com maiores valores da mesma são provavelmente mais férteis e com maior quantidade de bases disponíveis às plantas. 
Esse resultado concorda com a característica da importância da MO sobre a magnitude da capacidade de troca de cátions de solos tropicais, principalmente na camada superficial do solo, visto que a caulinita, principal mineral de argila encontrado em solos de regiões tropicais úmidas (Raij, 1991), possui uma CTC relativamente baixa.

Na Tabela 16 são apresentados os resultados da análise de componentes principais realizada nas variáveis do solo na área CR. Ao contrário da área Fabc, nessa apenas dois componentes principais (dos quatorze existentes) foram mantidos na análise, os quais, suas variâncias, somadas, explicam 81,63\% da variação total dos dados originais.

O primeiro componente é responsável por 57,66\% da variação total dos dados. Novamente, devido à influência de muitas variáveis originais do estudo sobre esse componente, ele pode ser caracterizado como o potencial de fertilidade inerente ao solo. Entretanto algumas diferenças em relação ao que ocorreu na área Fabc devem ser ressaltadas.

Em primeiro lugar, a maioria das correlações das variáveis originais nesta área com esse componente são positivas, ao contrário daquela, indicando que elevados valores dessa nova variável correspondem a solos mais férteis.

Além disso, nessa o atributo textural do solo que apresenta maior influência sobre esse componente é o teor de areia, apresentando correlação negativa com o mesmo, o que concorda mais com a expectativa geral de que solos mais arenosos são menos férteis. Na área Fabc o teor de argila apresentou correlação com o primeiro componente principal de tendência contrária as correlações dos atributos de fertilidade do solo. Uma troca da influência do Mg pelo K também ocorreu, com o segundo, juntamente com o P e a MO, adquirindo uma importância marcante que não ocorrera anteriormente.

A segunda nova variável apresentou elevadas correlações positivas com o teor de areia e negativas com os teores de argila e de $\mathrm{H}+\mathrm{Al}$. Essa variável pode ser qualificada como o potencial de acidificação do solo, e quanto maior o valor da mesma menor o teor de argila e conseqüentemente menor a capacidade de retenção de $\mathrm{H}+\mathrm{Al}$ no solo.

A CEa do solo nessa área apresentou influência apenas moderada sobre o primeiro componente principal e praticamente nenhuma sobre o segundo, o que significa que para as condições do solo existentes não foi possível se comprovar algum indício de utilidade dessa informação na definição de unidades de gerenciamento. 
Tabela 16. Análise de componentes principais para as variáveis do solo coletadas na área CR

\begin{tabular}{ccc}
\hline Componentes de variância & \multicolumn{2}{c}{ Componentes principais } \\
\cline { 2 - 3 } & 1 & 2 \\
\hline Variância & 8,07 & 3,36 \\
Proporção (\%) & 57,66 & 23,97 \\
Proporção acumulada (\%) & Correlação com os componentes principaisł \\
Variáveis & 0,49 & $-0,05$ \\
CEa rasa & 0,65 & $-0,07$ \\
CEa profunda & $\mathbf{0 , 9 0}$ & 0,33 \\
P & $\mathbf{0 , 8 4}$ & $-0,50$ \\
MO & 0,66 & 0,59 \\
PH & $-0,24$ & $\mathbf{0 , 9 3}$ \\
H+AL & $\mathbf{0 , 9 2}$ & $-0,04$ \\
K & $\mathbf{0 , 9 6}$ & 0,00 \\
Ca & 0,65 & 0,63 \\
Mg & $\mathbf{0 , 9 6}$ & 0,12 \\
SB & $\mathbf{0 , 9 3}$ & $-0,24$ \\
CTC & $\mathbf{0 , 9 2}$ & 0,12 \\
V\% & 0,37 & $\mathbf{- 0 , 8 9}$ \\
Argila (\%) & $-0,67$ & $\mathbf{0 , 7 0}$ \\
Areia (\%) & &
\end{tabular}

‡ Números em negrito visam destacar as variáveis originais com elevadas correlações $(>\mid 0,70)$ com os componentes principais.

Na Tabela 17 são apresentados os resultados para a área RB. Nessa área novamente foram selecionados dois componentes principais, os quais somados explicam 83,34\% da variância total dos dados.

O primeiro componente principal (responsável por 75,37\% da variabilidade) é fortemente influenciado por todas as variáveis originais com exceção do pH (que apresenta média influência). Novamente o primeiro componente principal pode ser categorizado como sendo o potencial de fertilidade inerente ao solo, se comportando de maneira similar ao que ocorreu na área CR.

A grande mudança ocorrida foi a maior intensidade da influência da CEa tanto rasa quanto profunda sobre essa nova variável. Além disso, a influência da textura sobre a fertilidade do solo nessa área é mais acentuada, estando esses resultados de acordo com as observações realizadas anteriormente na etapa de análise de correlação linear. Maiores valores desse componente 
sugerem solos mais férteis e mais argilosos, enquanto que o contrário indicam solos mais arenosos e menos férteis.

Tabela 17. Análise de componentes principais para as variáveis do solo coletadas na área RB

\begin{tabular}{ccc}
\hline Componentes de variância & \multicolumn{2}{c}{ Componentes principais } \\
\cline { 2 - 3 } & 10,55 & 2 \\
\hline Variância & 75,37 & 1,12 \\
Proporção (\%) & 75,37 & 7,97 \\
Proporção acumulada (\%) & Correlação com os componentes principaisł \\
Variáveis & $\mathbf{0 , 9 1}$ & $-0,09$ \\
CEa rasa & $\mathbf{0 , 8 7}$ & $-0,08$ \\
CEa profunda & $\mathbf{- 0 , 8 4}$ & $-0,40$ \\
P & $\mathbf{0 , 9 6}$ & 0,10 \\
MO & $-0,51$ & $-0,68$ \\
PH & $\mathbf{0 , 7 7}$ & 0,39 \\
H+AL & $\mathbf{0 , 9 7}$ & $-0,01$ \\
K & $\mathbf{0 , 9 4}$ & $-0,23$ \\
Ca & $\mathbf{0 , 7 6}$ & $-0,15$ \\
Mg & $\mathbf{0 , 9 4}$ & $-0,26$ \\
SB & $\mathbf{0 , 9 1}$ & 0,10 \\
CTC & $\mathbf{0 , 8 5}$ & $-0,39$ \\
V\% & $\mathbf{0 , 8 5}$ & $-0,08$ \\
Argila (\%) & $\mathbf{0 , 9 5}$ & 0,05 \\
Areia (\%) &
\end{tabular}

¥ Números em negrito visam destacar as variáveis originais com elevadas correlações $(>|0,70|)$ com os componentes principais.

O segundo componente principal não apresentou nenhuma correlação considerada forte com as variáveis originais. No entanto, em relação ao $\mathrm{pH}$, apresentou-se próximo de tal limite $(0,68)$, o que, aliado com as duas outras variáveis originais que na seqüência apresentaram maiores correlações com tal componente $(\mathrm{V} \%$ e $\mathrm{H}+\mathrm{Al})$, parecem indicar essa nova variável como sendo uma combinação entre a acidez real $(\mathrm{pH})$ e a potencial $(\mathrm{H}+\mathrm{Al})$, a qual foi nomeada de acidez total do solo, com maiores valores da mesma indicando menor valor para o $\mathrm{pH}$ e possivelmente maior participação do $\mathrm{H}+\mathrm{Al}$ sobre o complexo de troca de cargas dos minerais de argila. 


\subsection{Classificação contínua}

A técnica de classificação fuzzy k-means foi utilizada para se definir as unidades de gerenciamento do solo nas três áreas, a partir das novas variáveis criadas pela análise de componentes principais.

Optou-se por utilizar a medida de distância euclidiana pois, por serem as variáveis utilizadas na definição das unidades de gerenciamento os componentes principais obtidos na etapa anterior, e como os mesmos não apresentam correlação entre si (Afifi \& Clark, 1996), nesses casos de variáveis não correlacionadas, a distância de separação euclidiana funciona adequadamente (Burrough, 1989).

O expoente fuzzy utilizado $(1,2)$ se encontra no intervalo mais comumente adotado para classificação de atributos do solo, conforme proposto por Odeh et al. (1992). Aparentemente ele é adequado, visto a moderada continuidade espacial encontrada para as variáveis físico-químicas do solo avaliadas nesse estudo, com exceção da CEa rasa e profunda, para as quais a dependência espacial encontrada foi elevada.

Iniciando a análise do número ótimo de unidades de gerenciamento do solo, nas Figuras 15, 16 e 17 são apresentados os gráficos com os valores dos índices FPI e MPE (adimensionais) em função do número de classes de agrupamento dos dados, respectivamente para as áreas Fabc, CR e RB.

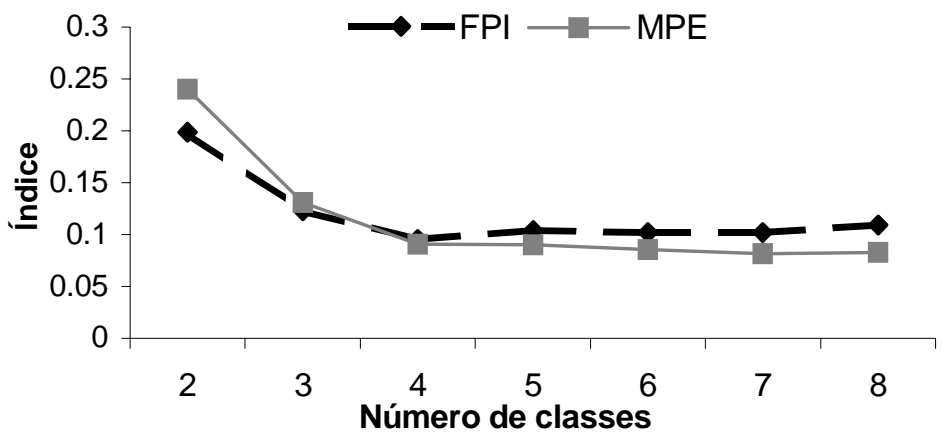

Figura 15 - Gráfico dos valores dos índices FPI e MPE em função do número de classes na área Fabc 


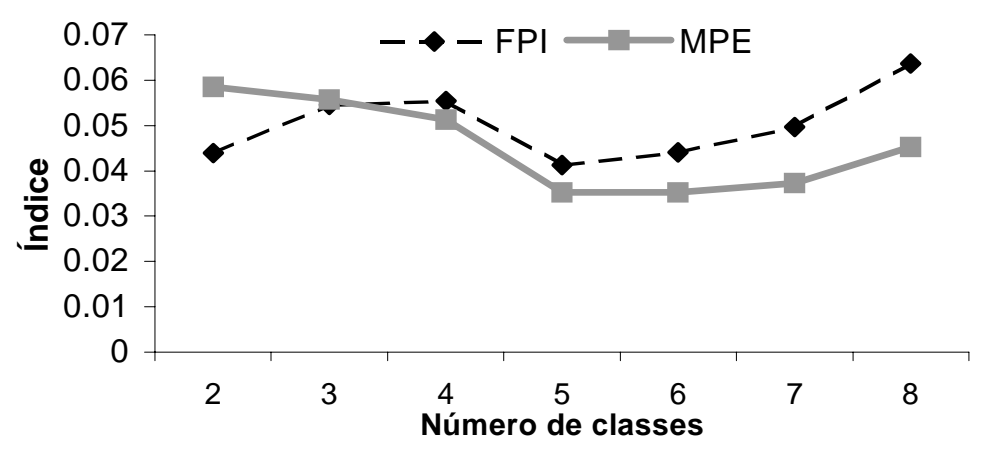

Figura 16 - Gráfico dos valores dos índices FPI e MPE em função do número de classes na área CR

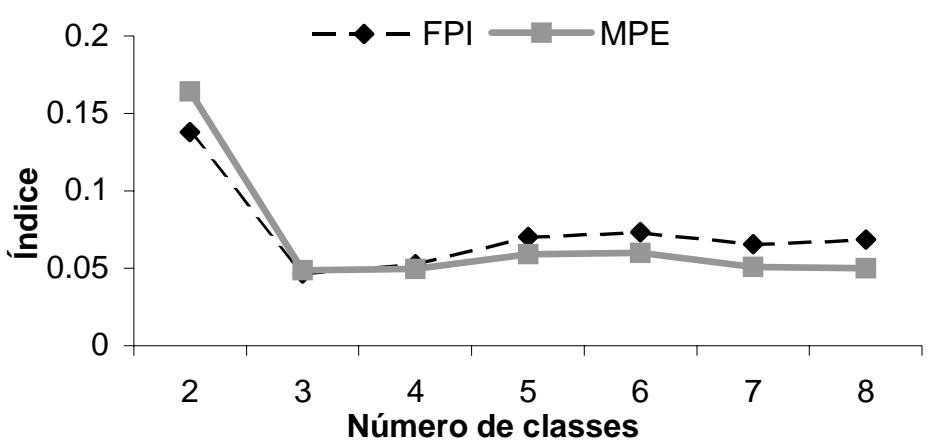

Figura 17 - Gráfico dos valores dos índices FPI e MPE em função do número de classes na área RB

Pelos resultados dos índices FPI e MPE, apresentados nas Figuras 15, 16 e 17, o número ótimo de unidades de gerenciamento seria igual a 4, 5 e 3 para as áreas Fabc, CR e RB, respectivamente. Com exceção da área Fabc, os dois índices indicaram o mesmo número de classes, enquanto que nessa, o índice MPE não atinge seu valor mínimo para o número de classes igual a 4, atingindo-o com a divisão em 8 classes. Apesar disso, o decréscimo no valor desse índice (na área Fabc) é acentuado até a divisão em 4 classes, decaindo proporcionalmente muito pouco a partir desse ponto.

Odeh et al. (1992) lembram de algumas limitações de conformidade de utilização desses índices com o número ótimo de classes a serem geradas pela análise fuzzy. Por isso, as decisões sobre o número ótimo de divisões de cada área em unidades de gerenciamento do solo não foram guiadas unicamente por esses índices, e foram auxiliadas pela análise de redução da variância 
das variáveis em função do número crescente de unidades. Os resultados dessa análise para as variáveis CEa, produtividade das culturas e físico-químicas do solo para a área CR, são apresentados na Figura 18.

Tabelas com essa mesma informação no formato numérico para as áreas Fabc, CR e RB são apresentados respectivamente nos anexos C1, C2 e C3. Os resultados dessa etapa para a área Fabc e RB não serão discutidos, pois como é possível se observar nos respectivos anexos (C1 e C3) eles são semelhantes ao que é discutido relativo à área CR, com resultados comparáveis a essa (anexo C2).

Ao contrário do que foi afirmado por Fridgen et al. (2000), de que a análise da redução da variância da produtividade em função da divisão de uma área em unidades de gerenciamento, seria um bom método de se determinar o número mais adequado de unidades, considerou-se não só a análise de redução da variância dessa, mas também das variáveis do solo coletadas nesse estudo (CEa e demais variáveis físico-químicas). Se, por um lado, isso pode dificultar a decisão a respeito do número de divisões da área, por outro lado, deve-se considerar que o decréscimo da variância dos atributos do solo é uma característica importante e potencial responsável pelo fomento da produtividade. Caso a redução da variância dessa não apresente conformidade com a verificada para os atributos do solo, isso pode ser explicado pela influência de outras variáveis sobre o desenvolvimento fisiológico das culturas (ex: clima), ocultando, mas não dando indícios contrários, a influência dos atributos do solo. 

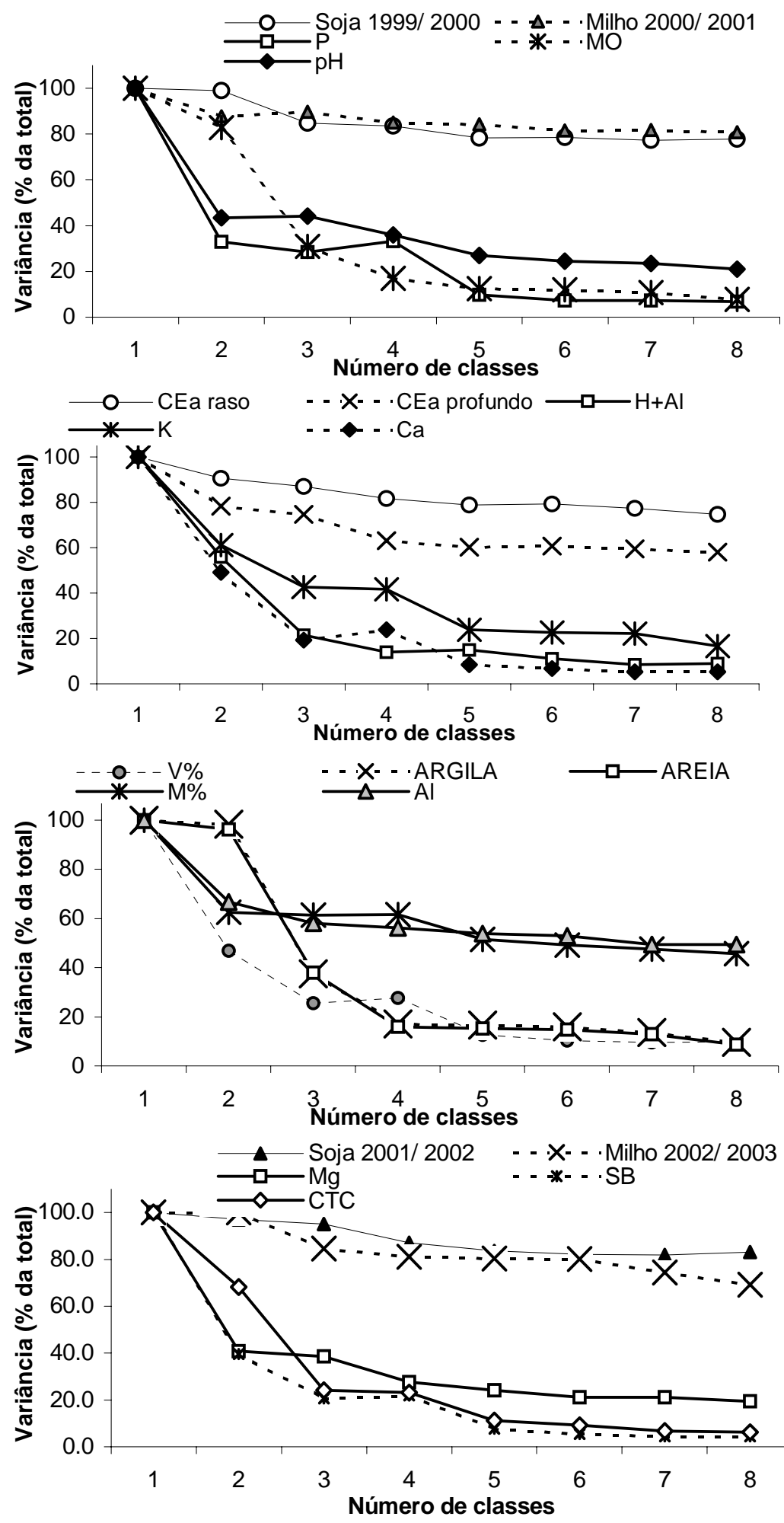

Figura 18 - Decréscimo na variância da CEa rasa e profunda, da produtividade nas diferentes safras e dos atributos físico-químicos do solo na área CR devido à divisão da área em unidades de gerenciamento 
Interpretando os resultados apresentados na Figura 18, pode ser observado uma tendência geral de que a maior amplitude de redução da variância ocorreu até a divisão da área em três classes, o que justificaria a divisão da área em três unidades de gerenciamento. No entanto, até quatro e cinco classes, uma nítida redução ainda ocorreu e a partir daí praticamente se estabilizou. Dessa forma se optou por manter o número de unidades definidos pela análise dos índices FPI e MPE, sendo igual a 5, 4 e 3 para as áreas CR, Fabc e RB, respectivamente.

Pequena redução da variância das variáveis pode indicar que as mesmas são relativamente uniformes ao longo de toda a área, ou então, que importantes causas contribuindo para a sua variabilidade não foram consideradas durante a divisão da área (Fridgen et al., 2000).

Dessa forma utilizou-se critérios subjetivos, visando a organizar a informação passível de ser extraída dessa análise, para classificar as variáveis. Assim, aquelas cuja redução da variância após divisão da área no número de unidades de gerenciamento julgado ideal (5 na área CR) foram menores do que $25 \%$, considerou-se sua variabilidade pouco explicada pela divisão realizada; entre $25 \%$ e $50 \%$ medianamente explicada e maior do que $50 \%$ indicou criação de unidades homogêneas quanto a esses atributos.

As variáveis produtividade de soja, nas safras de 1999/2000 e 2001/2002, e de milho, na safra 2000/2001, sofreram pequena redução nas suas variâncias, indicando que possivelmente os atributos físico-químicos do solo e a CEa utilizados para se definir as unidades de gerenciamento não seriam as variáveis apresentando níveis deficientes nessa área, e portanto, com acentuada influência sobre a produtividade. É importante lembrar, que essa área foi aonde a produtividade apresentou menor variabilidade.

Já para as variáveis CEa rasa e profunda e produtividade do milho na safra 2002/2003, a redução da variância ficou num nível médio (69,1\% da variância total no caso da produtividade do milho). No caso da CEa raso e profundo grande parte da variação dessas pôde ser explicada pela divisão realizada (74,7\% e 58,0\% respectivamente).

As quatorze variáveis físico-químicas do solo dessa área apresentaram reduções da variância que variaram entre o limite com o moderado, como para o $\mathrm{Al}$ e o $\mathrm{M} \%$ (mesmo apesar de ambas terem sido retiradas da análise de componentes principais), até níveis muito acentuados como nos casos da SB e do Ca (95,6\% e 94,7\% da variação podem ser explicadas pela divisão realizada), comprovando a eficiência da classificação realizada.

Após a definição do número ótimo de unidades de gerenciamento do solo em cada área, optou-se por interpolar os dados da função de participação, resultantes em cada uma das classes 
(unidades de gerenciamento do solo), utilizando o método de vizinhos naturais, procedimento esse também adotado por Sa (2001).

Burrough et al. (1997) citam que é possível utilizar a krigagem para esse fim, no entanto, nesse caso, evitou-se esse método de interpolação devido ao fato de que o efeito de suavização da mesma (Isaaks \& Srivastava, 1989; Cressie, 1991) se acumularia em mais de uma etapa de interpolação sofrida por essas variáveis. Isso porque os componentes principais utilizados nessa etapa de classificação são frutos de uma transformação linear de um conjunto de variáveis interpoladas. Isso poderia "mascarar" em demasia a real variabilidade espacial dos atributos dos solos dessas áreas, gerando unidades de gerenciamento do solo que, possivelmente, não seriam um modelo fiel do potencial produtivo do solo dessas áreas.

Na seqüência serão apresentadas as Figuras com os mapas da distribuição espacial dos valores da função de participação de cada indivíduo nas unidades de gerenciamento definidas pela técnica fuzzy k-means nas áreas Fabc, CR e RB respectivamente, nas quais também é apresentado o mapa da distribuição espacial do índice CI (“Confusion Index”), o qual é calculado através da seguinte fórmula:

$$
C I=1-\left[(m \max )-\left(m \max _{2}\right)\right]
$$

onde, mmax representa o máximo grau de participação em uma classe de uma célula qualquer (indivíduo) e $\operatorname{mmax}_{2}$ representa o segundo maior grau de participação em outra classe para essa mesma célula.

Esse índice serve como uma medida da sobreposição entre classes no espaço. Quanto menor o valor desse índice melhor caracterizadas são as classes nas quais uma variável qualquer é dividida. Para melhor entendimento desses mapas é importante explicar que a participação parcial de um indivíduo numa classe qualquer é diferente da probabilidade de participação, apesar de ambos serem expressos no intervalo [0,1]. A probabilidade de um indivíduo $P_{i}$ ser membro de um conjunto $\mathbf{S}$, assume a definição rigorosa de $\mathbf{S}$ e que a participação é baseada numa função de distribuição de probabilidade associada com S. Já a possibilidade de $P_{i}$ ser membro do conjunto fuzzy $\mathbf{F}$ é o reconhecimento do grau no qual $P_{i}$ tem as características do conceito central de $\mathbf{F}$ (Burrough et al., 1997).

Tendo conceituado o significado da possibilidade de participação de um indivíduo $i$ numa classe $c$ é possível se analisar os mapas dos agrupamentos realizados de forma mais criteriosa, a partir da visualização do grau de participação dos indivíduos nas diferentes classes. Na Figura 28 são então apresentadas essas informações para a área Fabc, sendo discutidas na seqüência. 
Percebe-se nos mapas das quatro classes definidas na área Fabc (Figura 19) uma grande contiguidade espacial das classes, com apenas a classe 4 apresentando alguns agrupamentos isolados ao redor da área.

O intervalo de valores, do grau de participação em uma classe, compreendido entre 0,5 e 1,0 representa a classe na qual uma célula tem a maior possibilidade de pertencer, assim, o agrupamento de todas as células que possuírem grau de participação numa classe qualquer maior do que 0,5 constitui uma unidade de gerenciamento.

Na Figura 19E os valores do índice CI são apresentados em dois intervalos distintos: de 0 até 0,30 e de 0,30 até 1,00 . O primeiro intervalo representa indivíduos (células) para as quais existe pequena possibilidade de terem sido classificadas erroneamente. Percebe-se que a maior parte da área se enquadra nesse aspecto, além de novamente se visualizar a contiguidade espacial das classes.

O segundo intervalo do índice CI representa indivíduos cujas possibilidades de pertencerem a duas ou mais classes distintas são maiores. Analisando com cuidado as regiões onde ocorrem valores do índice CI maiores do que 0,30 é possível perceber claramente que são aquelas regiões de fronteira entre duas classes distintas. 


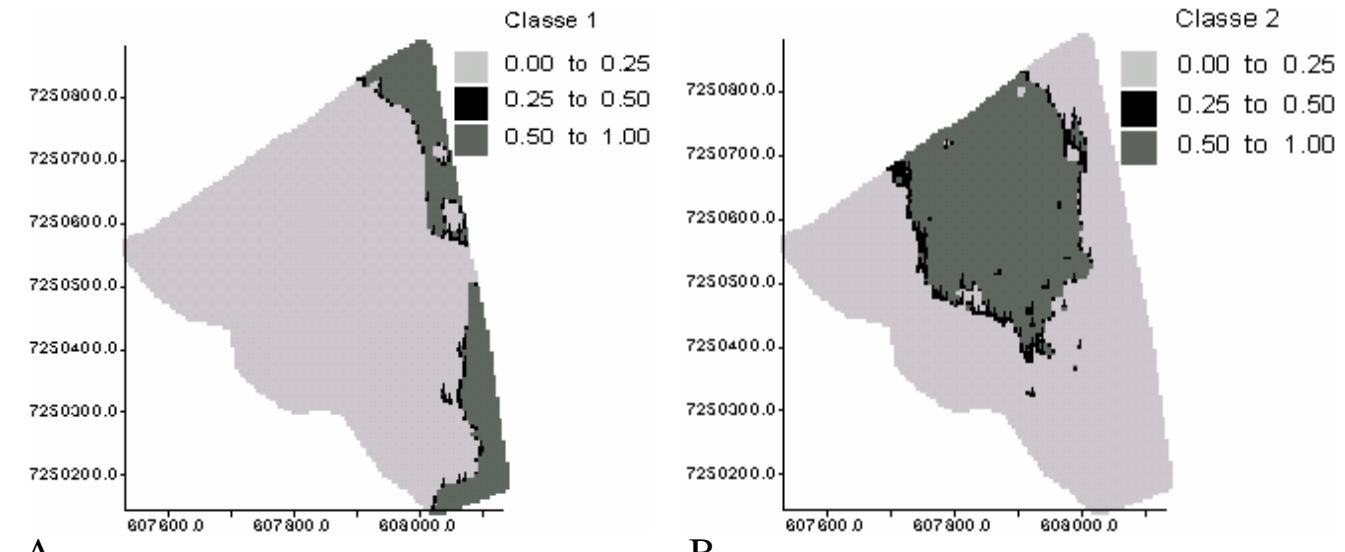

A.

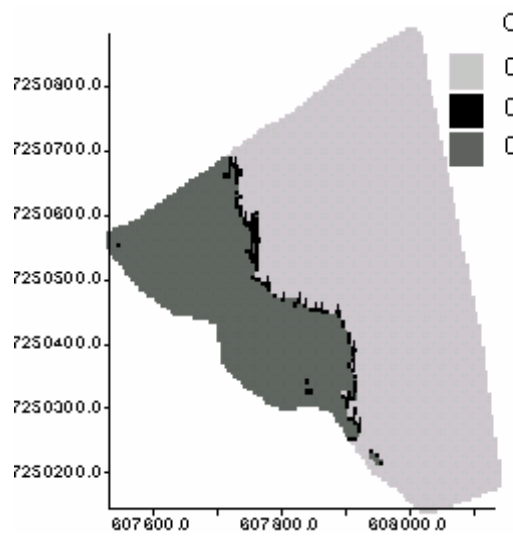

C.

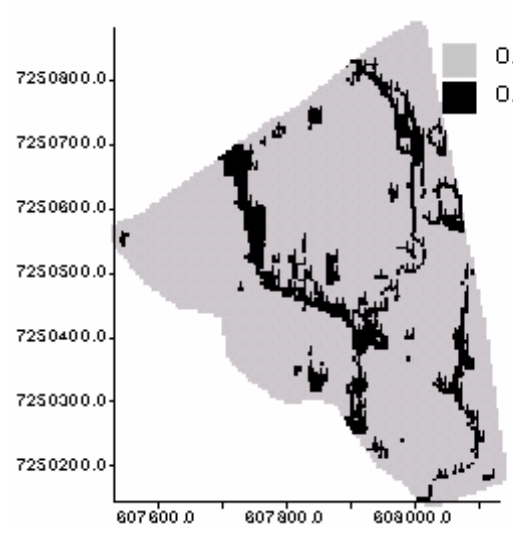

Classe 3

0.00 to 0.25

0.25 to 0.50

0.50 to 1.0072507000

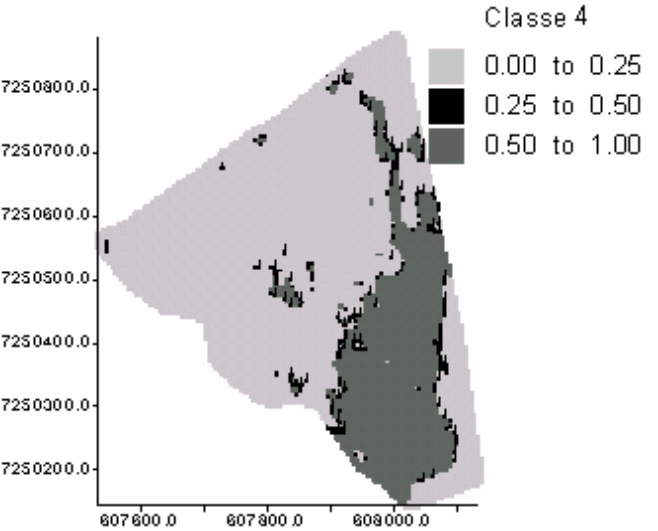

D. cl

0.00 to 0.30

0.30 to 1.00

E.

Figura 19 - Mapas com a distribuição espacial dos valores da função de participação de cada indivíduo nas quatro classes definidas, e do índice CI, obtidos após classificação pelo algoritmo fuzzy-k-means dos três componentes principais selecionados, para a área Fabc 
Na Tabela 18 são apresentados os valores dos centróides (média) para os três primeiros componentes principais utilizados na divisão da área Fabc em cada uma das classes (seção 4.4.2, Tabela 15), além da média da participação dos indivíduos em cada uma das quatro classes.

Tabela 18. Média (centróides) dos componentes principais e dos valores da função de participação em cada uma das quatro classes na área Fabc

\begin{tabular}{cccccccc}
\hline Classe & CP 1 & CP 2 & CP 3 & $\mathrm{~m}_{1}$ & $\mathrm{~m}_{2}$ & $\mathrm{~m}_{3}$ & $\mathrm{~m}_{4}$ \\
\hline 1 & $-1,87$ & $-0,25$ & 0,57 & 0,95 & 0,01 & 0,00 & 0,04 \\
2 & 0,19 & 1,06 & $-0,46$ & 0,00 & 0,95 & 0,02 & 0,03 \\
3 & 0,82 & $-0,34$ & 1,08 & 0,00 & 0,03 & 0,96 & 0,01 \\
4 & $-0,08$ & $-0,84$ & $-0,84$ & 0,02 & 0,03 & 0,01 & 0,94 \\
\hline
\end{tabular}

Os valores médios de participação em cada classe apresentada (Tabela 18) indicam nitidamente que as classes são muito bem separadas: todos os valores médios da função de participação foram maiores do que 0,94. Esse resultado é muito influenciado pelo expoente fuzzy utilizado, e, apesar dele ter sido de moderado a baixo $(1,2)$, ainda assim encontra-se no intervalo freqüentemente utilizado para dados de solo, por isso o sucesso da classificação realizada é evidente.

Procurando avaliar o comportamento que se espera para as condições físico-químicas do solo, nessas quatro unidades de gerenciamento, é necessário se observar os valores médios dos três componentes principais utilizados para se classificar essa área, valendo-se nessa observação do que foi discutido para os resultados apresentados na Tabela 15. Dessa maneira as médias desses componentes parecem indicar que, no geral, a unidade 1 seria aquela de maior fertilidade, sendo difícil se diferenciar entre as outras três.

Na última etapa desse estudo, a diferenciação entre os atributos físico-químicos do solo, nas unidades de gerenciamento, será abordada com maior detalhamento, visando enfatizar a viabilidade, ou não, das divisões realizadas nas três áreas.

Nas Figuras 20A até 20E são apresentados os mapas com a distribuição espacial da participação de cada indivíduo nas unidades de gerenciamento definidas para a área CR. 

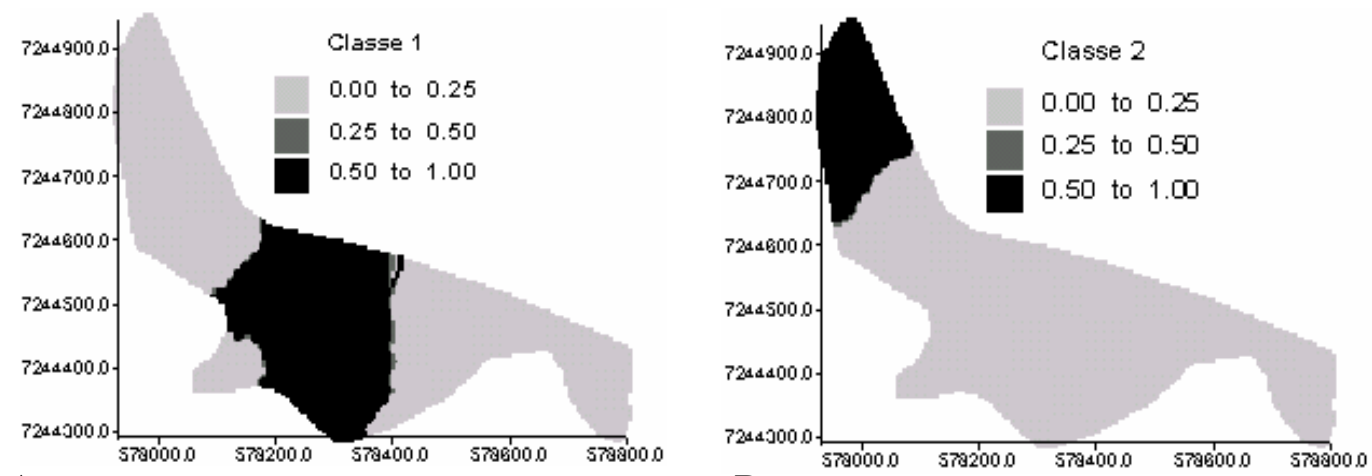

A.

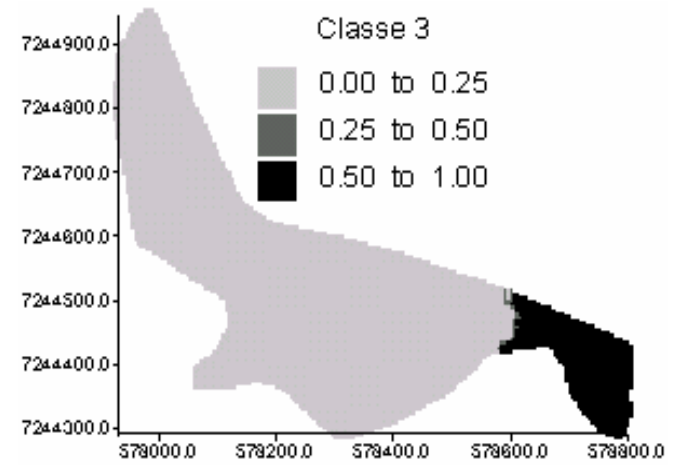

B.

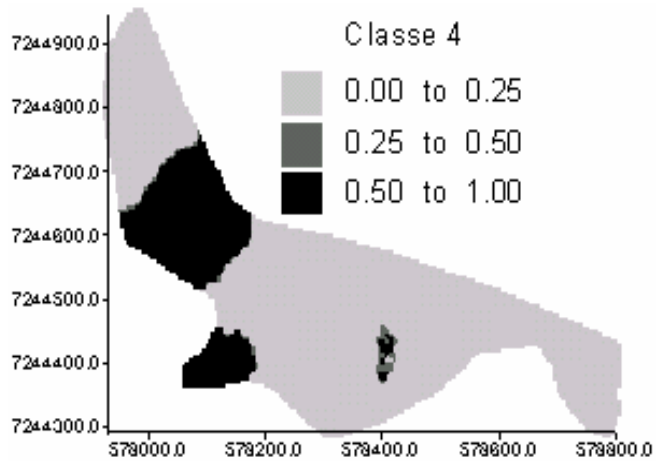

C.

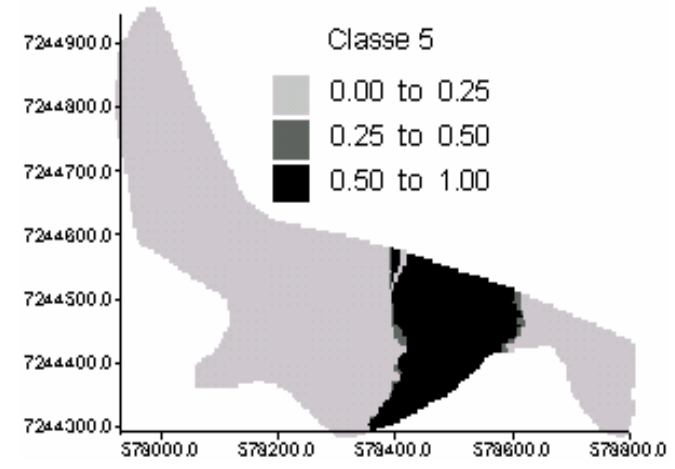

E.

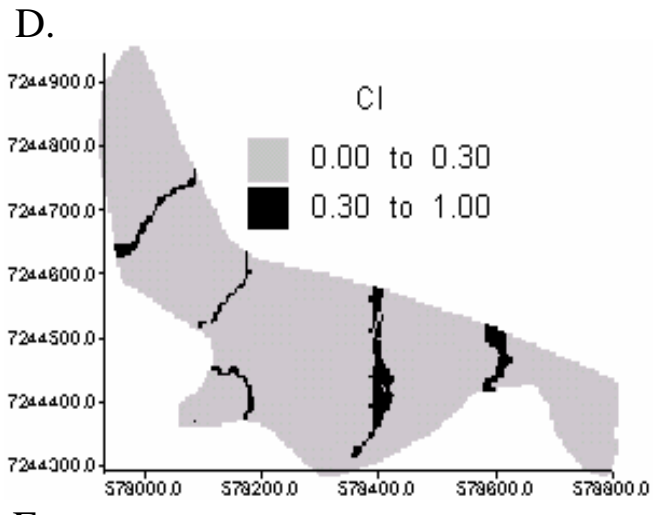

F.

Figura 20 - Mapas com a distribuição espacial dos valores da função de participação de cada indivíduo nas cinco classes definidas, e do índice CI, obtidos após classificação pelo algoritmo fuzzy k-means dos dois componentes principais selecionados, para a área CR

Assim como ocorreu na área Fabc (Figuras 27A até 27D), a contiguidade espacial das cinco unidades de gerenciamento é evidente. Apenas na classe 4 (Figura 28D) ocorrem dois agrupamentos separados do agrupamento maior a noroeste do talhão. Novamente o índice CI indica com eficiência as regiões fronteiriças entre as diferentes unidades de gerenciamento, e, no 
geral, a classificação final gerou classes bastante "rígidas”, se assemelhando a uma classificação booleana.

Confirmando a "rigidez” da classificação final, na Tabela 19 são apresentados os valores médios de participação das classes nas cinco unidades de gerenciamento. Os resultados indicam participação nas classes ainda mais claras do que na área Fabc (Tabela 18), cujos resultados por sua vez já foram bastante enfáticos.

Esse fato pode ser explicado devido a densidade amostral, utilizada para se avaliar os atributos físico-químicos do solo analisados em laboratório, nesta área ter sido menor do que naquela, o que gerou modelos da distribuição espacial dessas variáveis (Figura 13A até 130) com caráter menos errático.

Quanto às médias dos dois componentes principais, utilizados para se classificar essa área nas cinco unidades de gerenciamento, aparentemente a unidade 3 possui melhores condições da fertilidade do solo. Isso indica o fato dessa unidade provavelmente possuir maiores teores de atributos como $\mathrm{P}, \mathrm{Ca}, \mathrm{Mg}, \mathrm{K}, \mathrm{MO}$, além de ser potencialmente menos ácida, ou pelo menos com menor reserva de elementos acidificantes do solo, conforme discutido para os resultados apresentados na Tabela 16, para o primeiro e segundo componentes principais respectivamente. Em contraposição a essa, a unidade 2 deve ser aquela com as piores condições da fertilidade do solo.

Tabela 19. Média (centróides) dos componentes principais e dos valores da função de participação em cada uma das cinco classes na área CR

\begin{tabular}{cccccccc}
\hline Classe & CP 1 & CP 2 & $\mathrm{~m}_{1}$ & $\mathrm{~m}_{2}$ & $\mathrm{~m}_{3}$ & $\mathrm{~m}_{4}$ & $\mathrm{~m}_{5}$ \\
\hline 1 & 0,06 & $-1,08$ & 0,98 & 0,00 & 0,00 & 0,01 & 0,01 \\
2 & $-1,42$ & 1,46 & 0,00 & 0,99 & 0,00 & 0,01 & 0,00 \\
3 & 2,08 & 1,23 & 0,00 & 0,00 & 0,98 & 0,00 & 0,02 \\
4 & $-0,74$ & $-0,08$ & 0,02 & 0,01 & 0,00 & 0,96 & 0,01 \\
5 & 0,52 & 0,30 & 0,01 & 0,00 & 0,01 & 0,01 & 0,97 \\
\hline
\end{tabular}

Por último são apresentados os mapas das três unidades de gerenciamento na área RB (Figuras 21A até 21C), e o respectivo mapa do índice CI (Figura 21D). Para esses mapas as mesmas considerações feitas para as áreas Fabc e CR são válidas aqui. Apenas para a unidade 1 (Figura 21A) observa-se uma menor contiguidade espacial. 
É interessante se confrontar esses mapas das unidades de gerenciamento nessa área com os mapas das distribuições espaciais da argila (Figura 14N) e da areia (Figura 14O), sendo, a partir da comparação dessas camadas de informação, fácil de se perceber a influência da granulometria do solo sobre o seu comportamento físico-químico e, conseqüentemente, sobre as unidades de gerenciamento propostas.

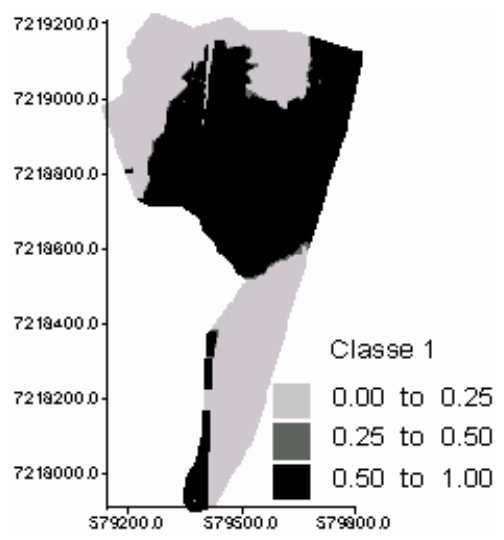

A.

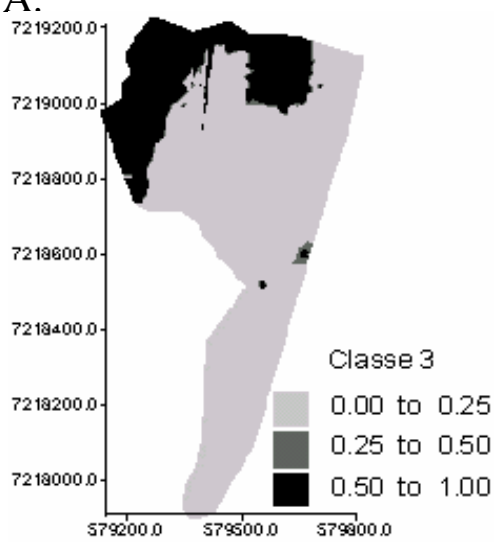

C.

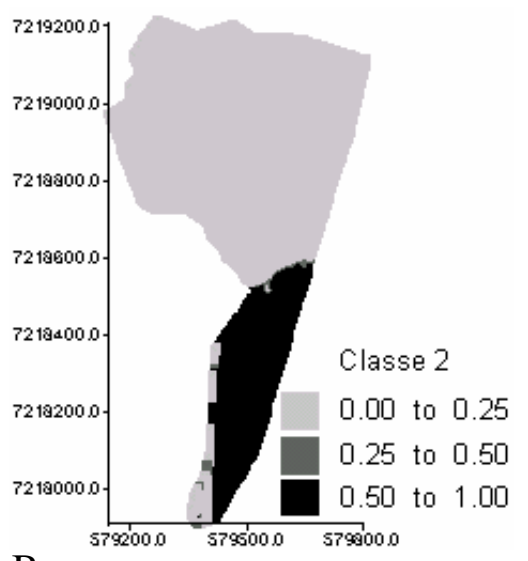

B.

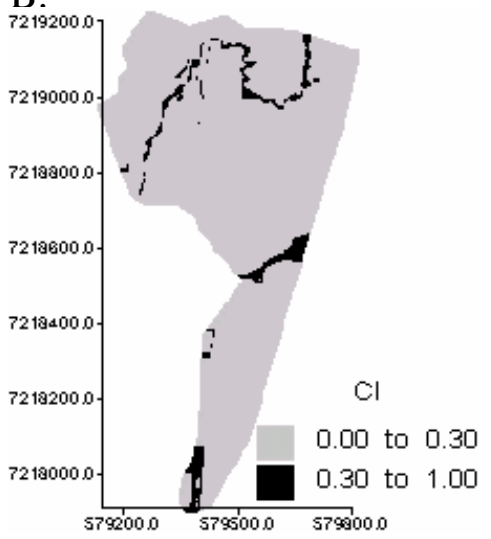

D.

Figura 21 - Mapas com a distribuição espacial dos valores da função de participação de cada indivíduo nas três classes definidas, e do índice CI, obtidos após classificação pelo algoritmo fuzzy k-means dos dois componentes principais selecionados, para a área $\mathrm{RB}$

Os resultados apresentados na Tabela 20, para a área RB, quanto aos valores médios de participação nas três unidades pela qual essa área foi dividida, são muito parecidos com os apresentados para a área CR, novamente produzindo classes “rígidas”. 
As médias dos componentes principais dessas unidades indicam que a unidade 3 é a que apresenta maior fertilidade do solo e, possivelmente, a unidade 2, a de menor fertilidade. A comparação desses mapas com aqueles das variáveis físico-químicas do solo (Figura 15A até Figura 150) confirma isso.

Tabela 20. Média (centróides) dos componentes principais e dos valores da função de participação em cada uma das três classes na área RB

\begin{tabular}{cccccc}
\hline Classe & CP 1 & CP 2 & $\mathrm{~m}_{1}$ & $\mathrm{~m}_{2}$ & $\mathrm{~m}_{3}$ \\
\hline 1 & 0,22 & 0,69 & 0,98 & 0,01 & 0,01 \\
2 & $-1,66$ & $-0,69$ & 0,01 & 0,99 & 0,01 \\
3 & 1,00 & $-1,09$ & 0,03 & 0,00 & 0,97 \\
\hline
\end{tabular}

Após tudo o que foi discutido sobre as divisões das áreas experimentais, para melhor visualizar as unidades de gerenciamento do solo propostas para essas, na Figura 22 elas são apresentadas para as três áreas. Nessas Figuras uma unidade extra, representada pela coloração preta, é apresentada nos três mapas. Essas unidades extras nada mais são do que aquelas regiões onde o índice CI superou o valor de 0,30 (conforme pode ser visualizado nas áreas Fabc, CR e RB respectivamente nas Figuras 19E, 20F e 21D), e assim, indicando existência de dúvidas sobre qual classe melhor representaria esses indivíduos. Os que obedeceram a esse aspecto foram classificados num agrupamento extra, que no geral ocorreu na fronteira entre duas unidades de gerenciamento vizinhas no espaço.

A contiguidade espacial das unidades de gerenciamento é muito acentuada, aspecto muito bom do ponto de vista prático de condução das lavouras que venham a ser implantadas nessas áreas. O sentido agronômico de efetivamente se proceder com essas divisões será abordado na seqüência. 


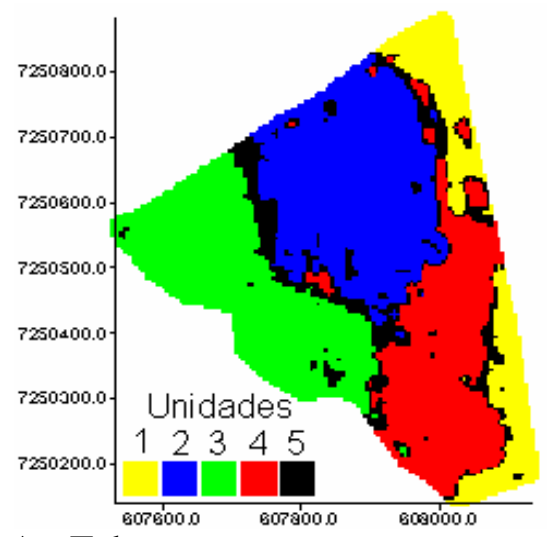

A. Fabc

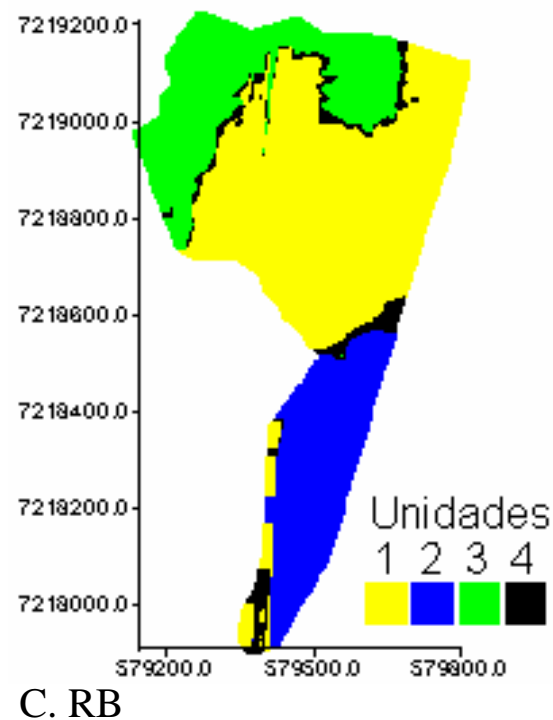

B. CR

Unidades

123456

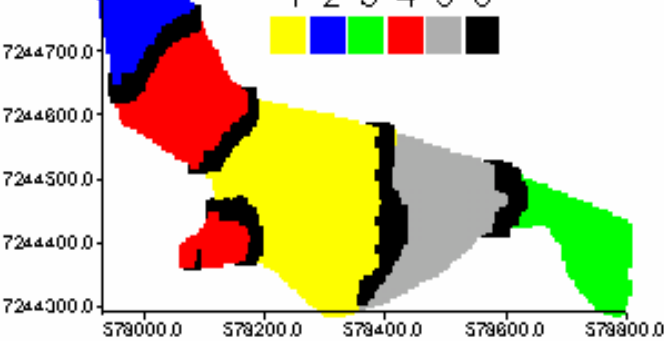

Figura 22 - Unidades de gerenciamento do solo definidas para as áreas experimentais Fabc, CR e RB

\subsection{Análise de variância}

A análise de variância (ANOVA) foi realizada para se verificar se existem diferenças entre as variáveis CEa, produtividade nas diferentes safras e físico-químicas do solo entre as diferentes unidades de gerenciamento criadas pelo algoritmo fuzzy k-means. Assim, diferenças constatadas entre essas para a produtividade podem indicar oportunidades de gerenciamento diferenciado entre elas para algum ou alguns fatores na área.

Quanto maiores as diferenças entre as unidades com relação à CEa e às demais variáveis físico-químicas do solo, mais se confirma a validade da divisão realizada, assim como do processo de redução do número de variáveis, utilizando novas variáveis obtidas após 
transformação linear das existentes, conseguindo expressar de forma adequada o modelo da variabilidade espacial das mesmas.

Antes de apresentar e discutir os resultados dessa etapa da análise é importante destacar que os indivíduos cujas classificações sofreram maiores graus de dubiedade, aqueles que obtiveram valores do índice CI maiores do que 0,30, foram retirados da análise de variância.

Apesar do número de indivíduos que se enquadram nesse critério terem sido poucos, justifica-se a decisão de exclusão deles pois, por comporem regiões divisórias entre duas unidades vizinhas, dúvidas sobre a qual unidade eles pertenceriam resultaram da classificação. Então a retirada dos mesmos elimina quaisquer possíveis interferências de indivíduos erroneamente classificados sobre a análise de variância proposta.

Os resultados da análise de variância (ANOVA) assim descritos, e que serão discutidos na seqüência, são apresentados para as três áreas experimentais nas Tabelas 21, com os resultados da CEa e demais variáveis do solo, e 22, com os resultados da produtividade nas diferentes safras.

Os resultados são bastante favoráveis no sentido de comprovarem a viabilidade das unidades de gerenciamento propostas para essas três áreas. Eles mostram nitidamente que diferenças entre as unidades para as variáveis consideradas ocorreram na grande maioria dos casos. Poucas exceções ocorreram, as quais serão aqui relatadas, sendo dentro dos parênteses apresentado para cada variável entre quais unidades as diferenças encontradas não foram significativas. 
Tabela 21. Média das variáveis físico-químicas do solo nas áreas Fabc, CR e RB por unidade de gerenciamento

\begin{tabular}{|c|c|c|c|c|c|c|c|c|c|c|c|c|}
\hline \multirow[t]{3}{*}{ Variáveis } & \multicolumn{12}{|c|}{ Área* } \\
\hline & \multicolumn{4}{|c|}{ Fabc } & \multicolumn{5}{|c|}{ CR } & \multicolumn{3}{|c|}{$\mathrm{RB}$} \\
\hline & 1 & 2 & 3 & 4 & 1 & 2 & 3 & 4 & 5 & 1 & 2 & 3 \\
\hline CEa r. 2002 & $14,12^{d}$ & $14,00^{\mathrm{C}}$ & $12,76^{\mathrm{b}}$ & $11,48^{\mathrm{a}}$ & $9,79^{b}$ & $8,37^{\mathrm{a}}$ & $11,31^{\mathrm{e}}$ & $10,07^{\mathrm{C}}$ & $10,33^{\mathrm{d}}$ & $5,16^{\mathrm{b}}$ & $2,43^{\mathrm{a}}$ & $6,63^{\mathrm{c}}$ \\
\hline CEa p. 2002 & $9,46^{\mathrm{d}}$ & $8,31^{\mathrm{c}}$ & $6,51^{\mathrm{a}}$ & $6,97^{\mathrm{b}}$ & $6,27^{\mathrm{d}}$ & $5,08^{\mathrm{a}}$ & $7,67^{\mathrm{e}}$ & $5,91^{\mathrm{b}}$ & $6,11^{\mathrm{c}}$ & $2,79^{b}$ & $1,68^{\mathrm{a}}$ & $3,38^{\mathrm{c}}$ \\
\hline CEa r. 2003 & $7,21^{\mathrm{d}}$ & $6,74^{\mathrm{c}}$ & $6,04^{\mathrm{b}}$ & $5,66^{\mathrm{a}}$ & - & - & - & - & - & - & - & - \\
\hline CEa p. 2003 & $6,05^{\mathrm{d}}$ & $5,15^{c}$ & $4,20^{\mathrm{a}}$ & $4,43^{b}$ & - & - & - & - & - & - & - & - \\
\hline $\mathrm{P}$ & $163,59^{\mathrm{d}}$ & $158,62^{c}$ & $83,31^{\mathrm{a}}$ & $114,52^{b}$ & $113,74^{\mathrm{c}}$ & $108,31^{b}$ & $146,12^{\mathrm{e}}$ & $100,66^{\mathrm{a}}$ & $125,95^{\mathrm{d}}$ & $40,22^{b}$ & $93,11^{\mathrm{c}}$ & $38,90^{\mathrm{a}}$ \\
\hline MO & $56,38^{\mathrm{a}}$ & $60,20^{\mathrm{C}}$ & $63,99^{\mathrm{d}}$ & $57,41^{\mathrm{b}}$ & $32,88^{\mathrm{d}}$ & $23,72^{\mathrm{a}}$ & $35,13^{\mathrm{e}}$ & $28,54^{\mathrm{b}}$ & $31,02^{c}$ & $40,46^{\mathrm{b}}$ & $20,13^{\mathrm{a}}$ & $46,72^{\mathrm{C}}$ \\
\hline $\mathrm{PH}$ & $5,90^{\mathrm{d}}$ & $5,07^{\mathrm{b}}$ & $4,99^{a}$ & $5,32^{c}$ & $4,96^{\mathrm{b}}$ & $5,03^{d}$ & $5,21^{\mathrm{e}}$ & $4,92^{\mathrm{a}}$ & $5,01^{\mathrm{C}}$ & $4,86^{a}$ & $4,97^{\mathrm{C}}$ & $4,92^{\mathrm{b}}$ \\
\hline $\mathrm{H}+\mathrm{Al}$ & $24,59^{\mathrm{a}}$ & $53,04^{c}$ & $61,81^{\mathrm{d}}$ & $41,86^{\mathrm{b}}$ & $47,10^{\mathrm{e}}$ & $43,77^{\mathrm{b}}$ & $42,42^{\mathrm{a}}$ & $45,67^{\mathrm{d}}$ & $45,05^{\mathrm{c}}$ & $55,21^{\mathrm{b}}$ & $39,58^{\mathrm{a}}$ & $55,16^{\mathrm{b}}$ \\
\hline $\mathrm{Al}$ & $0,12^{\mathrm{a}}$ & $0,74^{\mathrm{c}}$ & $1,28^{\mathrm{d}}$ & $0,68^{\mathrm{b}}$ & $1,41^{\mathrm{d}}$ & $0,89^{b}$ & $0,21^{\mathrm{a}}$ & $1,46^{\mathrm{d}}$ & $1,00^{\mathrm{c}}$ & $2,01^{\mathrm{c}}$ & $1,02^{\mathrm{a}}$ & $1,61^{\mathrm{b}}$ \\
\hline K & $2,57^{\mathrm{b}}$ & $3,30^{c}$ & $2,34^{\mathrm{a}}$ & $2,37^{\mathrm{a}}$ & $3,08^{c}$ & $2,68^{a}$ & $3,56^{\mathrm{e}}$ & $2,73^{b}$ & $3,15^{\mathrm{d}}$ & $2,66^{\mathrm{b}}$ & $1,30^{\mathrm{a}}$ & $3,24^{c}$ \\
\hline $\mathrm{Ca}$ & $81,63^{d}$ & $55,72^{\mathrm{b}}$ & $50,91^{\mathrm{a}}$ & $57,53^{c}$ & $30,30^{c}$ & $24,12^{\mathrm{a}}$ & $38,35^{\mathrm{e}}$ & $27,21^{\mathrm{b}}$ & $33,05^{\mathrm{d}}$ & $29,59^{b}$ & $19,41^{\mathrm{a}}$ & $37,05^{\mathrm{c}}$ \\
\hline Mg & $43,70^{\mathrm{d}}$ & $21,65^{\mathrm{a}}$ & $23,67^{b}$ & $27,56^{c}$ & $12,01^{\mathrm{a}}$ & $12,21^{\mathrm{b}}$ & $13,01^{\mathrm{d}}$ & $12,21^{\mathrm{b}}$ & $12,50^{\mathrm{c}}$ & $15,04^{\mathrm{b}}$ & $9,63^{\mathrm{a}}$ & $20,17^{\mathrm{c}}$ \\
\hline SB & $127,93^{\mathrm{d}}$ & $80,78^{\mathrm{b}}$ & $76,83^{\mathrm{a}}$ & $87,39^{c}$ & $45,31^{\mathrm{c}}$ & $39,40^{\mathrm{a}}$ & $56,80^{\mathrm{e}}$ & $42,28^{\mathrm{b}}$ & $48,82^{\mathrm{d}}$ & $47,07^{\mathrm{b}}$ & $29,55^{\mathrm{a}}$ & $61,74^{\mathrm{c}}$ \\
\hline CTC & $148,08^{\mathrm{d}}$ & $133,62^{b}$ & $138,44^{c}$ & $130,34^{\mathrm{a}}$ & $92,87^{C}$ & $82,69^{a}$ & $99,97^{\mathrm{d}}$ & $87,55^{\mathrm{b}}$ & $92,85^{c}$ & $102,90^{\mathrm{b}}$ & $68,44^{\mathrm{a}}$ & $115,15^{c}$ \\
\hline V\% & $83,60^{\mathrm{d}}$ & $60,34^{\mathrm{b}}$ & $55,47^{\mathrm{a}}$ & $66,94^{\mathrm{C}}$ & $48,57^{\mathrm{C}}$ & $46,59^{\mathrm{a}}$ & $52,04^{e}$ & $47,99^{\mathrm{b}}$ & $50,44^{\mathrm{d}}$ & $46,37^{\mathrm{b}}$ & $41,50^{\mathrm{a}}$ & $51,72^{\mathrm{C}}$ \\
\hline M\% & $0,07^{\mathrm{a}}$ & $1,35^{\mathrm{c}}$ & $1,67^{\mathrm{d}}$ & $1,01^{\mathrm{b}}$ & $3,24^{d}$ & $2,95^{\mathrm{c}}$ & $0,50^{\mathrm{a}}$ & $4,28^{\mathrm{e}}$ & $2,25^{\mathrm{b}}$ & $4,06^{\mathrm{b}}$ & $4,06^{\mathrm{b}}$ & $3,26^{a}$ \\
\hline Argila & $37,70^{\mathrm{a}}$ & $42,46^{c}$ & $44,29^{d}$ & $39,37^{\mathrm{b}}$ & $26,19^{\mathrm{e}}$ & $15,14^{\mathrm{a}}$ & $20,76^{\mathrm{b}}$ & $21,57^{\mathrm{C}}$ & $22,29^{\mathrm{d}}$ & $29,79^{b}$ & $13,10^{\mathrm{a}}$ & $37,54^{\mathrm{c}}$ \\
\hline Areia & $33,28^{b, c}$ & $27,05^{\mathrm{a}}$ & $32,97^{b}$ & $33,29^{c}$ & $63,74^{\mathrm{a}}$ & $79,00^{\mathrm{e}}$ & $64,84^{\mathrm{b}}$ & $70,95^{d}$ & $69,27^{\mathrm{c}}$ & $57,87^{\mathrm{b}}$ & $83,95^{\mathrm{c}}$ & $43,71^{\mathrm{a}}$ \\
\hline
\end{tabular}

* Para cada área, dentro de uma mesma linha, médias das variáveis seguidas por letras distintas são significativamente diferentes entre as unidades de gerenciamento de acordo com o teste HSD de Tukey para amostras de tamanho diferentes $(P=0,05)$. 
Tabela 22. Média da produtividade nas diferentes safras nas áreas Fabc, CR e RB

\begin{tabular}{|c|c|c|c|c|c|c|c|c|c|c|c|c|c|}
\hline \multirow[t]{3}{*}{ Área } & \multirow[t]{3}{*}{ Variáveis * } & \multicolumn{12}{|c|}{ Área* } \\
\hline & & \multicolumn{4}{|c|}{ Fabc } & \multicolumn{5}{|c|}{ CR } & \multicolumn{3}{|c|}{$\mathrm{RB}$} \\
\hline & & 1 & 2 & 3 & 4 & 1 & 2 & 3 & 4 & 5 & 1 & 2 & 3 \\
\hline \multirow{5}{*}{ Fabc } & Soja 1998/ 1999 & $2,84^{\mathrm{a}}$ & $3,26^{\mathrm{c}}$ & $3,31^{d}$ & $2,95^{b}$ & - & - & - & - & - & - & - & - \\
\hline & Milho 1999/ 2000 & $9,19^{a}$ & $9,87^{\mathrm{c}}$ & $10,47^{\mathrm{d}}$ & $9,72^{\mathrm{b}}$ & - & - & - & - & - & - & - & - \\
\hline & Soja 2000/ 2001 & $3,40^{\mathrm{a}}$ & $3,46^{\mathrm{b}}$ & $3,67^{c}$ & $3,72^{d}$ & - & - & - & - & - & - & - & - \\
\hline & Soja 2001/ 2002 & $4,17^{\mathrm{d}}$ & $3,26^{\mathrm{a}}$ & $3,56^{\mathrm{b}}$ & $3,88^{\mathrm{c}}$ & - & - & - & - & - & - & - & - \\
\hline & Milho 2002/ 2003 & $10,36^{\mathrm{a}}$ & $10,34^{\mathrm{a}}$ & $10,46^{\mathrm{b}}$ & $10,63^{c}$ & - & - & - & - & - & - & - & - \\
\hline \multirow{4}{*}{ CR } & Soja 1999/ 2000 & - & - & - & - & $3,50^{\mathrm{d}}$ & $3,11^{\mathrm{a}}$ & $3,21^{\mathrm{b}}$ & $3,39^{c}$ & $3,60^{\mathrm{e}}$ & - & - & - \\
\hline & Milho 2000/ 2001 & - & - & - & - & $11,99^{\mathrm{d}}$ & $11,91^{\mathrm{c}}$ & $11,43^{\mathrm{a}}$ & $11,83^{\mathrm{b}}$ & $12,03^{\mathrm{d}}$ & - & - & - \\
\hline & Soja 2001/ 2002 & - & - & - & - & $4,30^{\mathrm{b}}$ & $4,19^{\mathrm{a}}$ & $4,60^{\mathrm{C}}$ & $4,57^{\mathrm{c}}$ & $4,88^{\mathrm{d}}$ & - & - & - \\
\hline & Milho 2002/ 2003 & - & - & - & - & $8,64^{\mathrm{d}}$ & $7,91^{\mathrm{a}}$ & $8,33^{\mathrm{c}}$ & $8,11^{\mathrm{b}}$ & $8,36^{c}$ & - & - & - \\
\hline \multirow{4}{*}{ RB } & Soja 1998/ 1999 & - & - & - & - & - & - & - & - & - & $3,70^{\mathrm{c}}$ & $3,42^{\mathrm{b}}$ & $3,35^{\mathrm{a}}$ \\
\hline & Soja 2000/ 2001 & - & - & - & - & - & - & - & - & - & $3,96^{\mathrm{c}}$ & $3,33^{\mathrm{a}}$ & $3,76^{\mathrm{b}}$ \\
\hline & Soja 2001/ 2002 & - & - & - & - & - & - & - & - & - & $3,87^{\mathrm{c}}$ & $2,97^{\mathrm{a}}$ & $3,59^{b}$ \\
\hline & Milho 2002/ 2003 & - & - & - & - & - & - & - & - & - & $7,89^{b}$ & $7,97^{\mathrm{c}}$ & $7,83^{\mathrm{a}}$ \\
\hline
\end{tabular}

* Para cada área, dentro de uma mesma linha, médias das variáveis seguidas por letras distintas são significativamente diferentes entre as unidades de gerenciamento de acordo com o teste HSD de Tukey para amostras de tamanho diferentes $(P=0,05)$. 
Na área Fabc, apenas para a CEa rasa (1 e 2), K (3 e 4) e teor de areia (1 e 3; 1 e 4) ocorreram médias semelhantes entre algumas unidades de gerenciamento, notadamente no caso do teor de areia. Mesmo assim o bom resultado da classificação do uso do solo é evidente.

Quanto à produtividade, apenas no caso do milho para a safra 2002/2003 (1 e 2), duas unidades obtiveram médias semelhantes, mas no geral (conforme pode ser visto para as outras quatro safras monitoradas), a divisão da área dessa forma gera sub-regiões que apresentam tendência de possuírem médias de produtividade diferentes.

O destaque nessa área é que a CEa rasa não possui relação nítida com a textura do solo, contrariando o que foi observado por tantos autores (Banton et al. 1997; Lund et al., 1998; Dalgaard et al. 2001; Durlesser ${ }^{7}$ citado por Dalgaard et al., 2001).

Esse fato foi indicado na etapa de análise de correlação (seção 4.4.1, anexo A1) a partir da baixa correlação obtida entre essas duas variáveis, e é agora reforçado pela verificação das médias nas diferentes unidades de gerenciamento para ambas (Tabela 21). Se observa que nos dois monitoramentos realizados para a CEa rasa, os teores médios da mesma, em ordem crescente entre as quatro unidades de gerenciamento, foi $4<3<2<1$, bastante diferente do comportamento médio do teor de argila, que em ordem crescente foi igual a $1<4<2<3$.

Essa constatação de forma nenhuma descarta o que muitas outras pesquisas mostraram (o que pelo contrário os resultados na área RB comprovaram), desmerecendo a utilização prática dessa informação. No entanto, apenas sugerem cautela nessa utilização devido à complexidade da interação dos inúmeros fatores que influenciam a leitura da CEa.

O que foi exposto na seção 4.5, de que se esperava que a unidade 1 na área Fabc seria aquela com as condições mais favoráveis quanto à fertilidade do solo, parece se confirmar através da observação das médias obtidas (Tabela 22) para os teores de P, pH, Ca, Mg, SB, CTC e V\% terem sido, dentre todas as unidades, as mais altas, além dos teores médios do $\mathrm{H}+\mathrm{Al}$; $\mathrm{Al}$ e M\% terem sido os mais baixos. Com relação a essa unidade a CEa, tanto na leitura rasa quanto na profunda, foram as mais altas, mas, no geral, no que se refere às outras três unidades de gerenciamento, não é possível se verificar uma tendência clara de relação das médias da CEa com as demais variáveis.

Na área CR as únicas variáveis para as quais não foram identificadas diferenças significativas entre as unidades de gerenciamento foram o Al (1 e 4); o Mg (2 e 4); a CTC (1 e 5), além da produtividade de milho nas safras de 2000/2001 (1 e 5); 2002/2003 (3 e 5) e de soja na safra 2001/2002 (3 e 4). 
O fato da ocorrência de uma tendência de semelhança entre as unidades (com exceção da 2) para a produtividade das culturas pode ser um indicador ou de que a fertilidade do solo não é um fator importante a influenciar a produtividade agrícola nessa área, nos níveis atuais na qual ela se encontra, ou então determinadas unidades estariam com níveis de fertilidade aquém do requerido para plena manifestação do potencial produtivo dos cultivares plantados nessa área. Como não se observam, nos resultados das médias das variáveis entre as unidades dessa área, uma relação nítida entre o comportamento das variáveis físico-químicas do solo (Anexo C1)(CEa incluso) e de produtividade das culturas (Tabela 22), isso parece confirmar a primeira hipótese.

Novamente, as distinções feitas na seção 4.5, relativas às condições físico-químicas do solo entre as cinco unidades de gerenciamento da área CR, são confirmadas pelos resultados das médias dessas variáveis (Tabela 21). A unidade 3 é aquela com as melhores condições e, possivelmente, a unidade 2 com as piores. A CEa rasa segue essa tendência com fidelidade relativamente boa entre as unidades propostas, apesar das baixas correlações obtidas entre essa com as demais variáveis físico-químicas do solo (Anexo B2).

A terceira, e última, área analisada (RB) foi aquela aonde os resultados obtidos em relação à utilização da CEa na avaliação e definição de unidades de gerenciamento do solo foram os mais favoráveis a esta camada de informação. Ao contrário do que ocorreu na área Fabc, aonde nenhuma relação da CEa e conteúdo de argila foi evidenciada, nessa, conforme já havia sido destacado antes, a relação da CEa rasa e profunda com o teor de argila do solo é considerável (ver ordem crescente das médias dessas variáveis na Tabela 22).

Além disso, a maior parte dos atributos do solo analisados nesse estudo acompanham essa tendência nessa área, com a unidade 3 sendo aquela com os maiores índices de fertilidade do solo, conforme foi afirmado em função dos resultados apresentados na Tabela 17.

Também nessa área poucas situações de semelhança entre unidades de gerenciamento puderam ser verificadas, exceções feitas apenas no caso do $\mathrm{H}+\mathrm{Al}$ (1 e 3) e do M\% (1 e 2).

O fato de em certas unidades de gerenciamento não terem sido constatadas diferenças para o M\% na área $\mathrm{RB}$ e para o $\mathrm{Al}$ na área $\mathrm{CR}$, pode ser explicado pelo fato de que ambas foram retiradas da análise de componentes principais na seção 4.4.2, e por isso não tiveram nenhuma influência sobre as novas variáveis geradas por aquele processo e que, após classificação pela técnica fuzzy k-means, resultaram no delineamento das unidades de gerenciamento propostas para essas áreas (Figuras 22C e 22B, respectivamente). 
Como regra geral dessa análise de variância, entre as unidades de gerenciamento nas três áreas, não se encontrou um padrão de relação do comportamento da produtividade em função dos atributos da fertilidade do solo. Isso por um lado não fornece nenhum indício sobre possíveis oportunidades de gerenciamento localizado para determinadas características do solo, por outro também não pode ser visto como argumento contra as divisões propostas.

Além dessas variáveis físico-químicas do solo amostradas e analisadas nesse trabalho, inúmeras outras como clima, capacidade de armazenamento de água do solo, plantas daninhas, somente para citar algumas, tem influência sobre o complexo processo fisiológico de desenvolvimento das plantas cultivadas. Assim, para cada safra agrícola uma diferente variável desse complexo sistema pode ser o fator limitante, o elo mais fraco do complexo, que limita, ou condiciona, a produtividade final resultante em determinada região de uma lavoura. Mesmo porque, as unidades de gerenciamento propostas utilizando a CEa e demais atributos do solo forneceram algum discernimento sobre a variação dos mesmos, como pôde ser observado nos resultados apresentados. 


\section{CONCLUSÕES}

Para as condições desta pesquisa não foi possível se observar correlação elevada entre a CEa e a produtividade em nenhuma das áreas experimentais. Com relação à correlação da CEa com as variáveis físico-químicas do solo, os resultados verificados nesse estudo, especificamente na área RB, são promissores pois indicam elevada relação da CEa, em ambas as profundidades de leitura, com a textura do solo para as condições desta área.

O procedimento para definição de unidades de gerenciamento do solo a partir das suas variáveis físico-químicas foi realizado com sucesso, como pôde ser comprovado em função do: decréscimo da variância da produtividade nas diferentes safras e das variáveis físico-químicas do solo em função da divisão das áreas em unidades de gerenciamento; pela contiguidade espacial das unidades de gerenciamento criadas e devido à análise de variância (ANOVA), realizada para os atributos do solo, entre as unidades criadas, ter indicado, na maioria dos casos, diferenças significativas entre as médias desses atributos nessas unidades, indicando que essas divisões conseguiram captar regiões distintas do solo dentro das áreas. A influência da CEa sobre as novas variáveis (criadas pela análise de componentes principais) na área $\mathrm{RB}$, novamente, sugere sua validade na definição das unidades de gerenciamento.

Por tudo isso, a utilização da CEa, visando auxiliar na definição das unidades de gerenciamento, é uma técnica de mapeamento que apresenta boas perspectivas. Ela se apresenta como uma forma de complementação da informação obtida com a análise de amostras do solo em laboratório, entretanto não apresenta a limitação da baixa densidade amostral dessas. 
ANEXOS 
ANEXO A1 - Parâmetros dos semivariogramas dos valores de condutividade elétrica aparente do solo $(\mathrm{CEa})(\mathrm{mS} / \mathrm{m})$ nas leituras rasa $(0-0,3 \mathrm{~m})$ e profunda $(0-0,9 \mathrm{~m})$ obtidos na áreas experimentais Fabc, CR e RB nos meses de outubro de 2002 e março de 2003

\begin{tabular}{|c|c|c|c|c|c|c|c|}
\hline Área & Variável & $\begin{array}{c}\text { Efeito } \\
\text { pepita } \\
\text { (C0) }\end{array}$ & $\begin{array}{l}\text { Patamar } \\
(\mathrm{C} 0+\mathrm{C} 1)\end{array}$ & $\begin{array}{c}\text { Alcance } \\
\text { (a) }\end{array}$ & SSE & $\frac{C 1}{C 0+C 1}$ & Modelo \\
\hline \multirow[t]{4}{*}{ Fabc } & CEa rasa & 0,47 & 5,57 & 9,24 & 0,55 & 0,91 & Exponencial \\
\hline & CEa prof. & 0,29 & 1,64 & 11,89 & 0,14 & 0,82 & Exponencial \\
\hline & CEa rasa & 5,17 & 8,02 & 11,10 & 6,79 & 0,36 & Esférico \\
\hline & CEa prof. & 0,27 & 1,34 & 20,55 & 0,12 & 0,80 & Esférico \\
\hline \multirow[t]{2}{*}{$\mathrm{CR}$} & CEa rasa & 1,01 & 2,72 & 14,27 & 0,32 & 0,63 & Exponencial \\
\hline & CEa prof. & 0,23 & 0,96 & 10,18 & 0,02 & 0,76 & Exponencial \\
\hline \multirow[t]{2}{*}{$\mathrm{RB}$} & CEa rasa & 0,30 & 1,09 & 15,85 & 0,05 & 0,72 & Exponencial \\
\hline & CEa prof. & 0,08 & 0,31 & 11,65 & $3 * 10^{-3}$ & 0,74 & Exponencial \\
\hline
\end{tabular}

ANEXO A2 - Parâmetros dos semivariogramas dos valores de produtividade nas safras de 1998/1999 até 2002/2003 nas áreas experimentais Fabc, CR e RB

\begin{tabular}{|c|c|c|c|c|c|c|c|}
\hline Área & Variável & $\begin{array}{c}\text { Efeito } \\
\text { pepita } \\
\text { (C0) }\end{array}$ & $\begin{array}{l}\text { Patamar } \\
(\mathrm{C} 0+\mathrm{C} 1)\end{array}$ & $\begin{array}{c}\text { Alcance } \\
\text { (a) }\end{array}$ & SSE & $\frac{C 1}{C 0+C 1}$ & Modelo \\
\hline \multirow[t]{5}{*}{ Fabc } & Soja 1998/1999 & 0,08 & 0,35 & 6,34 & $5 * 10^{-3}$ & 0,77 & Esférico \\
\hline & Milho 1999/2000 & 0,64 & 2,11 & 5,49 & 0,12 & 0,70 & Exponencial \\
\hline & Soja 2000/2001 & 0,15 & 0,53 & 6,52 & 0,02 & 0,72 & Exponencial \\
\hline & Soja 2001/2002 & 0,09 & 0,47 & 5,83 & 0,03 & 0,81 & Exponencial \\
\hline & Milho 2002/2003 & 3,23 & 3,90 & 9,16 & 0,20 & 0,17 & Esférico \\
\hline \multirow[t]{4}{*}{ CR } & Soja 1999/2000 & 0,01 & 0,15 & 11,64 & $8 * 10^{-4}$ & 0,93 & Exponencial \\
\hline & Milho 2000/2001 & 0,04 & 0,43 & 5,97 & 0,02 & 0,91 & Exponencial \\
\hline & Soja 2001/2002 & 0,00 & 0,29 & 10,24 & $7 * 10^{-3}$ & 1,00 & Exponencial \\
\hline & Milho 2002/2003 & 0,36 & 0,87 & 29,61 & $8 * 10^{-3}$ & 0,59 & Exponencial \\
\hline \multirow[t]{4}{*}{$\mathrm{RB}$} & Soja 1998/1999 & 0,04 & 0,42 & 8,17 & $7 * 10^{-3}$ & 0,90 & Esférico \\
\hline & Soja 2000/2001 & 0,13 & 0,41 & 11,85 & 0,01 & 0,68 & Esférico \\
\hline & Soja 2001/2002 & 0,04 & 0,36 & 9,54 & $6 * 10^{-3}$ & 0,89 & Esférico \\
\hline & Milho 2002/2003 & - & - & - & - & - & Ef. Pe. Pur* \\
\hline
\end{tabular}

* Ef. Pe. Pur= Efeito pepita puro. 
ANEXO A3 - Parâmetros dos semivariogramas dos valores das variáveis físico-químicas do solo amostradas em laboratório no ano de 2001 nas áreas Fabc, CR e RB

\begin{tabular}{|c|c|c|c|c|c|c|c|}
\hline Área & Variável & $\begin{array}{c}\text { Efeito } \\
\text { pepita } \\
\text { (C0) }\end{array}$ & $\begin{array}{l}\text { Patamar } \\
(\mathrm{C} 0+\mathrm{C} 1)\end{array}$ & $\begin{array}{c}\text { Alcance } \\
\text { (a) }\end{array}$ & SSE & $\frac{C 1}{C 0+C 1}$ & Modelo \\
\hline \multirow[t]{14}{*}{ Fabc } & $\mathrm{P}$ & 979,2 & 3680,0 & 440 & $2 * 10^{-6}$ & 0,73 & L. c/ pat.* \\
\hline & MO & 11,78 & 23,22 & 250,2 & 0,01 & 0,49 & Esférico \\
\hline & $\mathrm{pH}$ & $1 * 10^{-3}$ & 0,13 & 241,6 & $2 * 10^{-4}$ & 0,99 & Esférico \\
\hline & $\mathrm{H}+\mathrm{AL}$ & 34,74 & 250,84 & 262,0 & $2 * 10^{-4}$ & 0,86 & Esférico \\
\hline & $\mathrm{Al}$ & 0,26 & 1,43 & 80,65 & 0,13 & 0,82 & Exponencial \\
\hline & $\mathrm{K}$ & 0,38 & 0,96 & 390,0 & 22,78 & 0,60 & L. c/ pat.* \\
\hline & $\mathrm{Ca}$ & 52,22 & 180,72 & 97,96 & $7 * 10^{-5}$ & 0,71 & Exponencial \\
\hline & $\mathrm{Mg}$ & 11,30 & 82,30 & 123,3 & $8 * 10^{-4}$ & 0,86 & Exponencial \\
\hline & SB & 106,5 & 466,9 & 103,4 & $1 * 10^{-5}$ & 0,77 & Exponencial \\
\hline & CTC & 92,0 & 141,0 & 178,2 & $3 * 10^{-5}$ & 0,35 & Esférico \\
\hline & V\% & 19,03 & 180,63 & 151,0 & $3 * 10^{-4}$ & 0,89 & Exponencial \\
\hline & M\% & 1,25 & 3,64 & 162,1 & 0,10 & 0,66 & Esférico \\
\hline & Argila (\%) & 10,59 & 52,83 & 175,5 & 21,29 & 0,80 & Esférico \\
\hline & Areia (\%) & 1,94 & 43,05 & 473,1 & 51,07 & 0,95 & L. c/ pat.* \\
\hline \multirow[t]{14}{*}{$\mathrm{CR}$} & $\mathrm{P}$ & 388,2 & 706,6 & 556,5 & 1033,0 & 0,45 & Esférico \\
\hline & MO & 5,45 & 32,72 & 670,9 & 25,35 & 0,83 & Esférico \\
\hline & $\mathrm{pH}$ & $8 * 10^{-3}$ & 0,02 & 403,0 & $1 * 10^{-3}$ & 0,64 & Esférico \\
\hline & $\mathrm{H}+\mathrm{AL}$ & 23,62 & 35,93 & 358,7 & 38,78 & 0,34 & Gaussiano \\
\hline & $\mathrm{Al}$ & 0,60 & 1,21 & 292,6 & 0,04 & 0,50 & Esférico \\
\hline & K & 0,12 & 0,29 & 460,5 & $3 * 10^{-3}$ & 0,59 & Esférico \\
\hline & $\mathrm{Ca}$ & 50,33 & 106,23 & 497,2 & 183,5 & 0,52 & Gaussiano \\
\hline & $\mathrm{Mg}$ & - & - & - & - & - & Ef. Pe. Pur. $\dagger$ \\
\hline & SB & 106,6 & 207,9 & 471,0 & 702,4 & 0,49 & Gaussiano \\
\hline & CTC & 84,52 & 167,3 & 386,8 & 782,8 & 0,49 & Gaussiano \\
\hline & V\% & - & - & - & - & - & Ef. Pe. Pur. $†$ \\
\hline & M\% & 6,2 & 12,0 & 331,3 & 5,3 & 0,52 & Esférico \\
\hline & Argila (\%) & 2,2 & 35,6 & 630,0 & 25,5 & 0,94 & Esférico \\
\hline & Areia (\%) & 5,2 & 55,5 & 489,9 & 211,5 & 0,91 & Esférico \\
\hline \multirow[t]{14}{*}{$\mathrm{RB}$} & $\mathrm{P}$ & 223,2 & 542,7 & 253,5 & 9045,6 & 0,59 & Esférico \\
\hline & MO & 4,9 & 63,0 & 375,8 & 123,3 & 0,92 & L. c/ pat.* \\
\hline & $\mathrm{pH}$ & 0,01 & 0,03 & 579,6 & $1 * 10^{-5}$ & 0,67 & Gaussiano \\
\hline & $\mathrm{H}+\mathrm{AL}$ & 34,35 & 84,07 & 249,7 & 26,72 & 0,59 & Esférico \\
\hline & $\mathrm{Al}$ & 1,62 & 2,35 & 361,6 & 0,11 & 0,31 & Esférico \\
\hline & K & 0,41 & 0,68 & 352,2 & $8 * 10^{-3}$ & 0,40 & Esférico \\
\hline & $\mathrm{Ca}$ & 16,13 & 83,32 & 340,6 & 57,40 & 0,81 & Exponencial \\
\hline & $\mathrm{Mg}$ & 3.51 & 30,51 & 198,2 & 8,00 & 0,88 & Exponencial \\
\hline & SB & 35,42 & 173,52 & 393,8 & 363,8 & 0,80 & Esférico \\
\hline & CTC & 1,73 & 149,83 & 253,6 & 849,5 & 0,99 & Esférico \\
\hline & V\% & 40,59 & 67,53 & 375,8 & 87,42 & 0,40 & Esférico \\
\hline & M\% & - & - & - & - & - & Ef. Pe. Pur. $\dagger$ \\
\hline & Argila (\%) & 15,46 & - & - & $7 * 10^{-3}$ & - & Fun. pot.†† \\
\hline & Areia (\%) & 18,55 & - & - & 774,9 & - & Fun. pot. $\dagger^{\circ}$ \\
\hline
\end{tabular}

* L. c/ pat.= Linear com patamar; † Ef. Pe. Pur.= Efeito pepita puro; $\dagger \dagger=$ Função potência. 
Anexo B1 - Coeficientes de correlação entre a CEa do solo nas leituras rasa (0-0,3m) e profunda (0-0,9m) medida nos anos de 2002 e 2003, produtividade das culturas de soja e milho nas safras de 1998/ 1999 até 2002/ 2003 e atributos físico-químicos do solo na área Fabc

\begin{tabular}{|c|c|c|c|c|c|c|c|c|c|c|c|c|c|c|c|c|c|c|c|c|c|}
\hline Variáveis * & 1 & 2 & 3 & 4 & 5 & 6 & 7 & 8 & 9 & 10 & 11 & 12 & 13 & 14 & 15 & 16 & 17 & 18 & 19 & 20 & 21 \\
\hline 1. CEa r. 2002 & - & & & & & & & & & & & & & & & & & & & & \\
\hline 2. CEa p. 2002 & 0,47 & - & & & & & & & & & & & & & & & & & & & \\
\hline 3. CEa r. 2003 & 0,86 & 0,52 & - & & & & & & & & & & & & & & & & & & \\
\hline 4. CEa p. 2003 & 0,48 & 0,83 & 0,59 & - & & & & & & & & & & & & & & & & & \\
\hline 5. S. 1998/ 99 & 0,07 & $-0,07$ & $-0,05$ & $-0,06$ & - & & & & & & & & & & & & & & & & \\
\hline 6. M. 1999/ 00 & $0,02 \dagger$ & $-0,14$ & $-0,04$ & $0,02 \dagger$ & 0,43 & - & & & & & & & & & & & & & & & \\
\hline 7. S. 2000/ 01 & $-0,24$ & $-0,18$ & $-0,22$ & $-0,11$ & 0,37 & 0,38 & - & & & & & & & & & & & & & & \\
\hline 8. S. 2001/ 02 & $-0,14$ & 0,05 & $-0,03$ & 0,09 & $-0,13$ & $0,01 \dagger$ & 0,33 & - & & & & & & & & & & & & & \\
\hline 9. M. 2002/ 03 & $-0,20$ & $-0,10$ & $-0,18$ & $-0,09$ & 0,07 & 0,14 & 0,21 & 0,17 & - & & & & & & & & & & & & \\
\hline 10. P & 0,38 & 0,64 & 0,42 & 0,51 & $-0,11$ & $-0,34$ & $-0,30$ & $-0,16$ & $-0,18$ & - & & & & & & & & & & & \\
\hline 11. MO & $0,00 \dagger$ & $-0,38$ & $-0,14$ & $-0,35$ & 0,36 & 0,31 & 0,02 & $-0,37$ & $-0,08$ & $-0,50$ & - & & & & & & & & & & \\
\hline 12. $\mathrm{pH}$ & 0,04 & 0,48 & 0,20 & 0,41 & $-0,42$ & $-0,37$ & $-0,08$ & 0,47 & $0,02 \dagger$ & 0,39 & $-0,65$ & - & & & & & & & & & \\
\hline 13. $\mathrm{H}+\mathrm{Al}$ & $-0,04$ & $-0,51$ & $-0,20$ & $-0,44$ & 0,41 & 0,32 & 0,03 & $-0,47$ & $-0,06$ & $-0,42$ & 0,76 & $-0,96$ & - & & & & & & & & \\
\hline 14. K & 0,41 & 0,50 & 0,34 & 0,31 & 0,21 & $-0,13$ & $-0,29$ & $-0,50$ & $-0,24$ & 0,69 & $0,00 \dagger$ & $-0,18$ & 0,13 & - & & & & & & & \\
\hline 15. Ca & 0,21 & 0,61 & 0,36 & 0,53 & $-0,37$ & $-0,38$ & $-0,21$ & 0,34 & $-0,05$ & 0,53 & $-0,56$ & 0,92 & $-0,88$ & $0,00 \dagger$ & - & & & & & & \\
\hline 16. Mg & 0,06 & 0,43 & 0,23 & 0,39 & $-0,43$ & $-0,31$ & $-0,10$ & 0,49 & $0,01 \dagger$ & 0,25 & $-0,53$ & 0,94 & $-0,86$ & $-0,29$ & 0,92 & - & & & & & \\
\hline 17. SB & 0,17 & 0,57 & 0,32 & 0,49 & $-0,40$ & $-0,36$ & $-0,18$ & 0,39 & $-0,03$ & 0,45 & $-0,56$ & 0,94 & $-0,89$ & $-0,09$ & 0,99 & 0,97 & - & & & & \\
\hline 18. СТC & 0,25 & 0,35 & 0,29 & 0,28 & $-0,12$ & $-0,25$ & $-0,29$ & 0,07 & $-0,17$ & 0,24 & 0,07 & 0,45 & $-0,25$ & 0,03 & 0,65 & 0,62 & 0,65 & - & & & \\
\hline 19. V\% & 0,10 & 0,54 & 0,25 & 0,46 & $-0,40$ & $-0,34$ & $-0,09$ & 0,45 & 0,03 & 0,42 & $-0,68$ & 0,98 & $-0,98$ & $-0,11$ & 0,94 & 0,92 & 0,95 & 0,40 & - & & \\
\hline 20. Argila & 0,03 & $-0,42$ & $-0,11$ & $-0,35$ & 0,49 & 0,30 & 0,03 & $-0,44$ & $-0,07$ & $-0,36$ & 0,81 & $-0,72$ & 0,79 & 0,10 & $-0,65$ & $-0,67$ & $-0,67$ & $-0,11$ & $-0,74$ & - & \\
\hline 21. Areia & $-0,28$ & $-0,18$ & $-0,21$ & $-0,14$ & $-0,14$ & 0,14 & 0,18 & 0,41 & 0,23 & $-0,56$ & $-0,09$ & 0,20 & $-0,17$ & $-0,67$ & 0,11 & 0,34 & 0,19 & 0,14 & 0,16 & $-0,27$ & - \\
\hline
\end{tabular}

- Todas as correlações são significantes com p<0,05 com exceção das marcadas por †.* CEa r. = Condutividade elétrica aparente rasa ( 0 0,3m); CEa p. = Condutividade elétrica aparente profunda (0-0,9m); Variáveis 5-9: S = Soja, M = Milho. 
Anexo B2 - Coeficientes de correlação entre a CEa do solo nas leituras rasa (0-0,3m) e profunda (0-0,9m), produtividade das culturas de soja e milho nas safras de 1999/ 2000 até 2002/ 2003 e atributos físico-químicos do solo na área CR

\begin{tabular}{lccccccccccccccccc}
\hline \multicolumn{1}{c}{ Variáveis * } & 1 & 2 & 3 & 4 & 5 & 6 & 7 & 8 & 9 & 10 & 11 & 12 & 13 & 14 & 15 & 16 & 17 \\
\hline 1. CEa r. 2002 & - & & & & & & & & & & & & & & & \\
2. CEa p. 2002 & 0,84 & - & & & & & & & & & & & & & & \\
3. S. 1999/ 00 & $-0,14$ & $-0,13$ & - & & & & & & & & & & & & & \\
4. M. 2000/ 01 & $-0,19$ & $-0,24$ & 0,28 & - & & & & & & & & & & & & \\
5. S. 2001/ 02 & 0,18 & 0,03 & 0,13 & $-0,09$ & - & & & & & & & & & & & \\
6. M. 2002/03 & $-0,11$ & 0,04 & 0,14 & 0,25 & $-0,23$ & - & & & & & & & & & & \\
7. P & 0,30 & 0,47 & 0,03 & $-0,21$ & 0,19 & 0,13 & - & & & & & & & & & \\
8. MO & 0,34 & 0,52 & 0,23 & $-0,09$ & 0,05 & 0,37 & 0,59 & - & & & & & & & & \\
9. pH & 0,25 & 0,36 & $-0,25$ & $-0,27$ & 0,10 & $-0,04$ & 0,83 & 0,29 & - & & & & & & & \\
10. H+Al & $-0,13$ & $-0,16$ & 0,35 & 0,33 & $-0,22$ & 0,30 & $-0,50$ & 0,25 & $-0,72$ & - & & & & & & & \\
11. K & 0,41 & 0,54 & 0,04 & $-0,21$ & 0,22 & 0,22 & 0,85 & 0,80 & 0,67 & $-0,22$ & - & & & & & & \\
12. Ca & 0,34 & 0,52 & 0,19 & $-0,14$ & 0,16 & 0,26 & 0,88 & 0,80 & 0,58 & $-0,19$ & 0,83 & - & & & & & \\
13. Mg & 0,28 & 0,34 & $-0,08$ & $-0,28$ & 0,21 & $-0,09$ & 0,71 & 0,24 & 0,71 & $-0,74$ & 0,53 & 0,61 & - & & & & \\
14. SB & 0,34 & 0,53 & 0,12 & $-0,20$ & 0,18 & 0,21 & 0,91 & 0,74 & 0,66 & $-0,32$ & 0,84 & 0,99 & 0,69 & - & & & \\
15. CTC & 0,31 & 0,52 & 0,22 & $-0,10$ & 0,07 & 0,35 & 0,77 & 0,91 & 0,45 & 0,05 & 0,83 & 0,96 & 0,43 & 0,92 & - & & \\
16. V\% & 0,39 & 0,50 & 0,22 & $-0,14$ & 0,28 & 0,14 & 0,85 & 0,69 & 0,56 & $-0,29$ & 0,78 & 0,94 & 0,75 & 0,95 & 0,85 & - \\
17. Argila & 0,23 & 0,28 & 0,34 & 0,05 & 0,09 & 0,31 & 0,04 & 0,77 & $-0,27$ & 0,69 & 0,42 & 0,31 & $-0,28$ & 0,21 & 0,51 & 0,24 & - \\
18. Areia & $-0,31$ & $-0,46$ & $-0,24$ & 0,07 & $-0,04$ & $-0,37$ & $-0,36$ & $-0,94$ & $-0,09$ & $-0,45$ & $-0,67$ & $-0,60$ & $0,00 \dagger$ & $-0,53$ & $-0,76$ & $-0,49$ & $-0,91$ \\
\hline
\end{tabular}

- Todas as correlações são significantes com $\mathrm{p}<0,05$ com exceção das marcadas por $\dagger . *$ CEa r. = Condutividade elétrica aparente rasa $(0-0,3 \mathrm{~m})$; CEa p. = Condutividade elétrica aparente profunda (0-0,9m); Variáveis 5-9: S = Soja, $\mathrm{M}=$ Milho. 
Anexo B3 - Coeficientes de correlação entre a CEa do solo nas leituras rasa (0-0,3m) e profunda (0-0,9m), produtividade das culturas de soja e milho nas safras de 1999/ 2000 até 2002/ 2003 e atributos físico-químicos do solo na área RB

\begin{tabular}{|c|c|c|c|c|c|c|c|c|c|c|c|c|c|c|c|c|c|c|}
\hline & 1 & 2 & 3 & 4 & 5 & 6 & 7 & 8 & 9 & 10 & 11 & 12 & 13 & 14 & 15 & 16 & 17 & 18 \\
\hline 1. CEa r. 2002 & - & & & & & & & & & & & & & & & & & \\
\hline 2. CEa p. 2002 & 0,96 & - & & & & & & & & & & & & & & & & \\
\hline 3. S. 1998/ 99 & $0,00 \dagger$ & $-0,01 \dagger$ & - & & & & & & & & & & & & & & & \\
\hline 4. S. 2000/ 01 & 0,29 & 0,25 & 0,55 & - & & & & & & & & & & & & & & \\
\hline 5. S. 2001/ 02 & 0,37 & 0,33 & 0,52 & 0,72 & - & & & & & & & & & & & & & \\
\hline 6. M. 2002/ 03 & $-0,18$ & $-0,16$ & $-0,01 \dagger$ & $-0,08$ & $-0,09$ & - & & & & & & & & & & & & \\
\hline 7. $\mathrm{P}$ & $-0,68$ & $-0,64$ & $-0,14$ & $-0,40$ & $-0,55$ & 0,23 & - & & & & & & & & & & & \\
\hline 8. MO & 0,86 & 0,82 & 0,10 & 0,35 & 0,49 & $-0,22$ & $-0,84$ & - & & & & & & & & & & \\
\hline 9. $\mathrm{pH}$ & $-0,41$ & $-0,42$ & $-0,38$ & $-0,45$ & $-0,58$ & 0,11 & 0,62 & $-0,57$ & - & & & & & & & & & \\
\hline 10. $\mathrm{H}+\mathrm{Al}$ & 0,66 & 0,62 & 0,02 & 0,24 & 0,35 & $-0,22$ & $-0,80$ & 0,76 & $-0,47$ & - & & & & & & & & \\
\hline 11. K & 0,87 & 0,81 & 0,13 & 0,40 & 0,53 & $-0,28$ & $-0,80$ & 0,95 & $-0,52$ & 0,71 & - & & & & & & & \\
\hline 12. Ca & 0,84 & 0,81 & $0,00 \dagger$ & 0,30 & 0,40 & $-0,23$ & $-0,68$ & 0,88 & $-0,41$ & 0,60 & 0,92 & - & & & & & & \\
\hline 13. Mg & 0,63 & 0,60 & $-0,10$ & 0,18 & 0,25 & $-0,17$ & $-0,62$ & 0,67 & $-0,25$ & 0,57 & 0,69 & 0,72 & - & & & & & \\
\hline 14. SB & 0,84 & 0,81 & $-0,05$ & 0,25 & 0,34 & $-0,22$ & $-0,67$ & 0,88 & $-0,36$ & 0,61 & 0,91 & 0,99 & 0,73 & - & & & & \\
\hline 15. CTC & 0,77 & 0,74 & $-0,03$ & 0,24 & 0,38 & $-0,21$ & $-0,83$ & 0,85 & $-0,44$ & 0,83 & 0,84 & 0,83 & 0,75 & 0,84 & - & & & \\
\hline 16. V\% & 0,76 & 0,73 & 0,04 & 0,34 & 0,41 & $-0,25$ & $-0,57$ & 0,76 & $-0,27$ & 0,45 & 0,86 & 0,95 & 0,66 & 0,94 & 0,72 & - & & \\
\hline 17. Argila & 0,75 & 0,66 & 0,16 & 0,43 & 0,49 & $-0,20$ & $-0,68$ & 0,84 & $-0,36$ & 0,59 & 0,87 & 0,76 & 0,58 & 0,76 & 0,70 & 0,72 & - & \\
\hline 18. Areia & $-0,86$ & $-0,79$ & $-0,07$ & $-0,35$ & $-0,45$ & 0,25 & 0,79 & $-0,95$ & 0,39 & $-0,74$ & $-0,96$ & $-0,87$ & $-0,69$ & $-0,88$ & $-0,82$ & $-0,79$ & $-0,90$ & - \\
\hline
\end{tabular}

- Todas as correlações são significantes com $\mathrm{p}<0,05$ com exceção das marcadas por $+{ }^{*}$ CEa $\mathrm{r}$. = Condutividade elétrica aparente rasa $(0-0,3 \mathrm{~m})$; CEa p. = Condutividade elétrica aparente profunda (0-0,9m); Variáveis 5-9: $\mathrm{S}=$ Soja, $\mathrm{M}=$ Milho. 
Anexo C1 - Redução na variância da produtividade nas diferentes safras, da CEa rasa e profunda e dos atributos físico-químicos do solo na área Fabc devido a divisão da área em unidades de gerenciamento

\begin{tabular}{|c|c|c|c|c|c|c|c|c|}
\hline \multirow[t]{2}{*}{ Variável } & \multicolumn{8}{|c|}{ Número de unidades de gerenciamento } \\
\hline & 1 & 2 & 3 & 4 & 5 & 6 & 7 & 8 \\
\hline CEa r. 2002 & 100,00 & 93,51 & 95,22 & 74,69 & 65,99 & 65,76 & 57,12 & 54,46 \\
\hline CEa p. 2002 & 100,00 & 97,73 & 83,57 & 62,20 & 53,77 & 44,42 & 44,32 & 41,22 \\
\hline CEa r. 2003 & 100,00 & 96,59 & 97,97 & 77,22 & 66,01 & 64,42 & 58,44 & 56,36 \\
\hline CEa p. 2003 & 100,00 & 97,88 & 89,32 & 70,47 & 62,82 & 57,95 & 57,50 & 54,48 \\
\hline Soja 98/ 99 & 100,00 & 94,33 & 82,21 & 77,52 & 77,17 & 74,69 & 75,01 & 72,54 \\
\hline Milho 99/ 00 & 100,00 & 99,05 & 88,05 & 88,00 & 85,09 & 85,60 & 85,49 & 83,62 \\
\hline Soja 00/ 01 & 100,00 & 97,84 & 99,40 & 94,38 & 93,60 & 92,27 & 88,93 & 88,18 \\
\hline Soja 01/ 02 & 100,00 & 75,70 & 69,55 & 67,69 & 68,74 & 66,12 & 64,78 & 64,18 \\
\hline Milho 02/ 03 & 100,00 & 97,25 & 98,09 & 92,22 & 94,35 & 93,51 & 93,61 & 92,66 \\
\hline $\mathrm{P}$ & 100,00 & 72,11 & 51,02 & 33,31 & 34,04 & 25,58 & 38,40 & 23,76 \\
\hline MO & 100,00 & 99,06 & 30,55 & 30,84 & 30,95 & 25,95 & 31,95 & 21,78 \\
\hline $\mathrm{pH}$ & 100,00 & 82,71 & 44,79 & 36,05 & 29,68 & 24,83 & 23,86 & 23,04 \\
\hline $\mathrm{H}+\mathrm{Al}$ & 100,00 & 88,92 & 40,33 & 37,85 & 34,24 & 24,79 & 23,89 & 22,27 \\
\hline $\mathrm{Al}$ & 100,00 & 98,17 & 79,20 & 77,47 & 71,53 & 58,13 & 56,71 & 54,53 \\
\hline K & 100,00 & 51,41 & 56,58 & 45,10 & 43,09 & 37,79 & 47,60 & 35,15 \\
\hline $\mathrm{Ca}$ & 100,00 & 90,36 & 59,44 & 36,92 & 28,13 & 24,75 & 23,54 & 22,15 \\
\hline $\mathrm{Mg}$ & 100,00 & 69,85 & 46,47 & 29,99 & 24,65 & 21,66 & 20,33 & 19,40 \\
\hline SB & 100,00 & 84,42 & 54,92 & 33,79 & 25,89 & 22,71 & 21,23 & 20,20 \\
\hline CTC & 100,00 & 89,01 & 87,53 & 46,59 & 39,31 & 35,07 & 34,88 & 34,48 \\
\hline V\% & 100,00 & 86,52 & 45,74 & 39,95 & 32,23 & 25,97 & 24,68 & 22,92 \\
\hline M\% & 100,00 & 91,07 & 76,61 & 79,99 & 70,35 & 56,94 & 53,43 & 47,91 \\
\hline Argila & 100,00 & 92,59 & 33,03 & 30,74 & 33,88 & 26,07 & 29,72 & 25,56 \\
\hline Areia & 100,00 & 45,10 & 49,92 & 50,74 & 52,91 & 50,57 & 55,62 & 44,63 \\
\hline
\end{tabular}


Anexo C2 - Redução na variância da produtividade nas diferentes safras, da CEa rasa e profunda e dos atributos físico-químicos do solo na área CR devido a divisão da área em unidades de gerenciamento

\begin{tabular}{|c|c|c|c|c|c|c|c|c|}
\hline \multirow[t]{2}{*}{ Variável } & \multicolumn{8}{|c|}{ Número de unidades de gerenciamento } \\
\hline & 1 & 2 & 3 & 4 & 5 & 6 & 7 & 8 \\
\hline CEa r. 2002 & 100,00 & 90,41 & 86,87 & 81,48 & 78,67 & 79,14 & 77,29 & 74,66 \\
\hline CEa p. 2002 & 100,00 & 78,30 & 74,72 & 63,13 & 60,20 & 60,66 & 59,39 & 57,98 \\
\hline Soja 99/ 00 & 100,00 & 99,03 & 84,77 & 83,61 & 78,41 & 78,65 & 77,44 & 77,86 \\
\hline Milho 00/ 01 & 100,00 & 87,85 & 89,84 & 85,17 & 84,26 & 81,64 & 81,71 & 80,79 \\
\hline Soja 01/ 02 & 100,00 & 97,13 & 95,08 & 86,99 & 83,68 & 82,13 & 81,91 & 83,01 \\
\hline Milho 02/ 03 & 100,00 & 99,94 & 84,66 & 81,11 & 80,50 & 80,20 & 74,40 & 69,15 \\
\hline $\mathrm{P}$ & 100,00 & 32,96 & 28,55 & 33,22 & 9,61 & 7,25 & 7,16 & 6,83 \\
\hline MO & 100,00 & 82,77 & 30,87 & 17,06 & 12,42 & 12,05 & 10,62 & 7,63 \\
\hline $\mathrm{pH}$ & 100,00 & 43,35 & 44,25 & 35,84 & 26,88 & 24,47 & 23,43 & 20,88 \\
\hline $\mathrm{H}+\mathrm{Al}$ & 100,00 & 55,74 & 21,46 & 14,00 & 14,93 & 11,15 & 8,50 & 8,91 \\
\hline $\mathrm{Al}$ & 100,00 & 66,80 & 58,09 & 56,09 & 53,74 & 52,79 & 49,30 & 49,30 \\
\hline K & 100,00 & 61,13 & 42,54 & 41,61 & 23,76 & 22,58 & 22,12 & 16,68 \\
\hline $\mathrm{Ca}$ & 100,00 & 49,07 & 19,25 & 23,90 & 8,50 & 6,63 & 5,21 & 5,29 \\
\hline Mg & 100,00 & 40,91 & 38,61 & 27,72 & 24,17 & 21,24 & 21,21 & 19,33 \\
\hline SB & 100,00 & 39,51 & 20,58 & 21,90 & 7,63 & 5,56 & 4,56 & 4,36 \\
\hline CTC & 100,00 & 68,10 & 24,16 & 23,08 & 11,13 & 9,30 & 6,60 & 6,11 \\
\hline V\% & 100,00 & 46,88 & 25,40 & 27,69 & 12,61 & 10,38 & 9,60 & 9,73 \\
\hline M\% & 100,00 & 62,51 & 61,37 & 61,47 & 51,41 & 49,06 & 47,59 & 45,63 \\
\hline Argila & 100,00 & 98,38 & 37,43 & 17,19 & 16,58 & 15,87 & 13,66 & 9,59 \\
\hline Areia & 100,00 & 96,27 & 37,99 & 15,83 & 15,11 & 14,83 & 12,76 & 8,65 \\
\hline
\end{tabular}


Anexo C3 - Redução na variância da produtividade nas diferentes safras, da CEa rasa e profunda e dos atributos físico-químicos do solo na área RB devido a divisão da área em unidades de gerenciamento

\begin{tabular}{|c|c|c|c|c|c|c|c|c|}
\hline \multirow[t]{2}{*}{ Variável } & \multicolumn{8}{|c|}{ Número de unidades de gerenciamento } \\
\hline & 1 & 2 & 3 & 4 & 5 & 6 & 7 & 8 \\
\hline CEa r. 2002 & 100,00 & 74,98 & 33,77 & 31,15 & 29,96 & 28,49 & 26,59 & 24,81 \\
\hline CEa p. 2002 & 100,00 & 77,22 & 44,66 & 41,46 & 26,69 & 38,72 & 34,49 & 35,02 \\
\hline Soja 98/ 99 & 100,00 & 98,07 & 91,90 & 89,61 & 63,19 & 84,10 & 80,91 & 80,98 \\
\hline Soja 00/ 01 & 100,00 & 99,89 & 79,94 & 76,91 & 56,88 & 79,41 & 74,59 & 73,19 \\
\hline Soja 01/ 02 & 100,00 & 99,81 & 63,86 & 59,42 & 42,65 & 60,09 & 53,05 & 54,32 \\
\hline Milho 02/ 03 & 100,00 & 95,73 & 93,91 & 93,97 & 65,33 & 94,25 & 92,78 & 93,38 \\
\hline $\mathrm{P}$ & 100,00 & 93,25 & 17,06 & 23,95 & 16,37 & 14,52 & 12,86 & 15,69 \\
\hline MO & 100,00 & 80,27 & 24,68 & 17,80 & 14,10 & 15,09 & 14,14 & 15,78 \\
\hline $\mathrm{pH}$ & 100,00 & 97,07 & 40,25 & 32,47 & 17,17 & 28,22 & 28,87 & 26,62 \\
\hline $\mathrm{H}+\mathrm{Al}$ & 100,00 & 96,36 & 35,71 & 41,46 & 29,51 & 29,14 & 24,50 & 25,88 \\
\hline $\mathrm{Al}$ & 100,00 & 99,08 & 56,70 & 52,48 & 34,96 & 40,79 & 36,78 & 37,99 \\
\hline K & 100,00 & 70,63 & 20,49 & 14,74 & 9,86 & 11,63 & 10,45 & 8,37 \\
\hline $\mathrm{Ca}$ & 100,00 & 61,66 & 30,13 & 21,73 & 14,32 & 21,50 & 15,56 & 15,93 \\
\hline Mg & 100,00 & 68,01 & 49,93 & 51,20 & 38,48 & 46,22 & 42,02 & 44,42 \\
\hline SB & 100,00 & 58,83 & 29,32 & 21,73 & 13,81 & 19,50 & 14,55 & 15,12 \\
\hline СТC & 100,00 & 78,72 & 28,35 & 33,32 & 23,52 & 22,19 & 18,21 & 22,48 \\
\hline V\% & 100,00 & 54,51 & 38,77 & 27,51 & 17,56 & 26,21 & 18,50 & 16,60 \\
\hline M\% & 100,00 & 79,47 & 84,31 & 82,58 & 54,26 & 77,95 & 73,61 & 74,52 \\
\hline Argila & 100,00 & 77,87 & 40,27 & 34,80 & 22,27 & 24,40 & 24,53 & 21,50 \\
\hline Areia & 100,00 & 68,64 & 22,96 & 18,13 & 10,89 & 10,44 & 10,12 & 10,27 \\
\hline
\end{tabular}




\section{REFERÊNCIAS BIBLIOGRÁFICAS}

AFIFI, A.A.; CLARK, V. Computer-aided multivariate analysis. New York: Chapman \& Hall, 1996. 455 p.

ANDERSON-COOK, C.M.; ALLEY, M.M.; ROYGARD, J.K.F.; KHOSLA,R.; NOBLE,R.B.;

DOOLITLLE, J.A. Differentiating soil types using electromagnetic conductivity and crop yield maps. Soil Science Society of America Journal, v. 66, p. 1562-1570, 2002.

AUESRWALD, K.; SIMON, S.; STANJEK, H. Influence of soil properties on electrical conductivity under humid water regimes. Soil Science, v. 166, n. 6, p. 382-390, 2001.

AUSTIN, R.S.; RHOADES, J.D. Four-electrode, current generator and resistance meter circuits. Soil Science Society of America Journal, v. 43, p. 808-810, 1979.

BALASTREIRE, L.A. Agricultura de precisão. Piracicaba: O autor, 2001. 1v.

BANTON, O.; SEGUIN, M.K.; CIMON, M.A. Mapping field-scale physical properties of soil with electrical resistivity. Soil Science Society of America Journal, v. 61, p. 1010-1017, 1997.

BLACKMORE, A.V. Interpretation of electrical conductivity in a clay soil contaning salts. Australian Journal of Soil Research, v. 16, p. 311-318, 1978.

BOBERT, J.; SCHIMIDT, F.; GEBBERS, R.; SELIGE, T.; SCHIMDHALTER, U. Estimating soil moisture distribution for crop managment with capacitance probes, EM-38 and digital terrain analysis (compact disc). In: EUROPEAN CONFERENCE ON PRECISION AGriCUlture, 3., Montpellier, 2001. Proceedings. Montpellier: Ecole Nationale Supériure Agronomique, 2001.

BOHN, H.L.; BEM-ASHER, J.; TABBARA, H.S.; MARWA, M. Theories and tests of electrical conductivity in soils. Soil Science Society of America Journal, v. 46, p. 1143-1146, 1982. 
BREVIK, E.C; FENTON, T.E. Soil sensing techniques as soil survey tools in lacustrine-derived soils, central Iowa (compact disc). In: INTERNATIONAL CONFERENCE ON PRECISION AGRICULTURE, 5., Bloomington, 2000. Proceedings. Bloomington: ASA;CSSA;SSSA, 2000.

BUCHLEITER, G.W.; FARAHANI, H. Comparison of electrical conductivity measurements from two different sensing technologies. Artigo 021056 apresentado em encontro da American Society of Agricultural Engineering. 9 p. 2002.

BURROUGH, P.A. Fuzzy mathematical methods for soil survey and land evaluation. Journal of Soil Science, v. 40, p. 477-492, 1989.

BURROUGH, P.A.; VAN GAANS, P.F.M.; HOOTSMANS, R. Continuos classification in soil survey: spatial correlation, confusion and boundaries. Geoderma, v. 77, p. 115-135, 1997.

CAMBARDELLA, C. A.; MOORMAN, T. B.; NOVAK, J. M.; PARKIN, T. B.; KARLEN, D. L.; TURCO, R. F.; KONOPKA, A. E. Field-scale variability of soil properties in central Iowa soils. Soil Science Society of America Journal, v. 58, n. 5, p. 1501-1511, 1994.

CAMPOS, H. Estatística experimental não-paramétrica. Piracicaba: Fealq,1983. 1v.

CLARK, R.L.; CHEN, F.; KISSEL, D.E.; ADKINS, W. Mapping soil hardpans with the penetrometer and electrical conductivity (compact disc). In: INTERNATIONAL CONFERENCE ON PRECISION AGRICUlTURE, 5., Bloomington, 2000. Proceedings. Bloomington: ASA;CSSA;SSSA, 2000.

COOK, P.G.; WALKER, G.R.; BUSELLI, G.; POTTS, I.; DODDS, A.R. The application of electromagnetic techniques to groundwater recharge investigations. Journal of Hydrology, v. 30, p. 201-229, 1992.

CUPITT, J.; WHELAN, B. M. Determining within-field crop management zones (compact disc). In: EUROPEAN CONFERENCE ON PRECISION AGRICULTURE, 3., Montpellier, 2001. Proceedings. Montpellier: Ecole Nationale Supériure Agronomique, 2001.

DABAS, M.; TABBAGH, J.; BOISGONTIER, D. Multi-depth continuos electrical profiling (MuCEP) for characterization of in-field variability (compact disc). In: EUROPEAN CONFERENCE ON PRECISION AGRICULTURE, 3., Montpellier, 2001. Proceedings. Montpellier: Ecole Nationale Supériure Agronomique, 2001.

DALGAARD, M.; HAVE, H.; NEHMDAHL, H. Soil clay mapping by measurement of electromagnetic conductivity (compact disc). In: EUROPEAN CONFERENCE ON PRECISION AGRICUlTURE, 3., Montpellier, 2001. Proceedings. Montpellier: Ecole Nationale Supériure Agronomique, 2001. 
DAVIS, J.G; KIETCHEN, N.R; SUDDUTH, K.A; DRUMMOND, S.T. Using electromagnetic induction to characterize soils. Better crops with plant food, n. 4. 1997.

DEUTSCH, C. V.; JOURNEL, A.G. GSLIB - Geostatistical Software Library and User's Guide. Oxford: Oxford University Press, 1992. 340 p.

DOBERMANN, A.; OBERTHUR, T. Fuzzy mapping of soil fertility: a case study on irrigated riceland in the Philippines. Geoderma, v. 77, p. 317-339, 1997.

DOMSCH, H.; GIEBEL, A. Electrical conductivity of soils typical for the state of Bradenburg in Germany (compact disc). In: EUROPEAN CONFERENCE ON PRECISION AGriCUlturE, 3., Montpellier, 2001. Proceedings. Montpellier: Ecole Nationale Supériure Agronomique, 2001.

DOOLITTLE, J.A.; MURPHY, R.; PARKS, G.; WARNER, J. Electromagnetic induction investigations of a soil delineation in Reno County, Kansas. Soil Survey Horizone, v. 37, p.11-20, 1996.

DOOLITTLE, J.A.; SUDDUTH, K.A.; KIETCHEN, N.R.; INDORANTE, S.J. Estimating depth to claypans using electromagnetic induction methods. Journal of Soil and Water Conservation, v. 49, n. 6, p. 572-575, 1994.

EDLEFSEN, N.E.; ANDERSON, A.B.C. The four-electrode resistance method for measuring soil-moisture content under field conditions. Soil Science, v. 51, p. 367-376, 1941.

ELLSBURY, M.M.; MAIO, D.D.; CLAY, D.E.; CLAY, S.A.; CARLSON, C.G. Spatial distribution of soil-dwelling stages of northern corn rootworm in relation to measurable soil and crop characteristics (compact disc). In: INTERNATIONAL CONFERENCE ON PRECISION AGRICULTURE, 5., Bllomington, 2000. Proceedings. Bloomington: ASA;CSSA;SSSA, 2000.

EMPRESA BRASILEIRA DE PESQUISA AGROPECUÁRIA. Sistema brasileiro de classificação de solos. Brasília, 1999. 412 p.

FLEMING, K.L.; WESTPHALL, D.G.; WIENS, D.W.; ROTHE, L.E.; CIPRA, J.E.; HEERMAN, D.F. Evaluating farmer developed management zone map for precision farming. In: INTERNATIONAL CONFERENCE ON PRECISION AGRICULTURE, 4., St. Paul, 1998. Proceedings. St. Paul: ASA;CSSA;SSSA, 1998. p. 335-343.

FNP consultoria e comércio. Agrianual 2001: anuário estatístico da agricultura brasileira. São Paulo, 2001. 536 p. 
FRAISSE, C.W.; SUDDUTH, K.A.; KITCHEN, N.R. Delineation of site-specific management zones by unsupervised classification of topographic attributes and soil electrical condutctivity. Transactions of the ASAE, v. 44, n. 1, p. 155-166, 2001.

FRANSSEN, H.J.W.M.H.; VAN EIJNSBERGEN, A.C.; STEIN, A. Use of spatial prediction techniques and fuzzy classification for mapping soil pollutants. Geoderma, v. 77, p. 243262, 1997.

FRANZEN, D.W.; HALVORSON, A.D.; KRUPINSKY, J.; HOFMAN, V.L.; CIHACEK, L.J. Directed sampling using topography as a logical basis. In: INTERNATIONAL CONFERENCE ON PRECISION AGRICUltURE, 4., St. Paul, 1998. Proceedings. St. Paul: ASA;CSSA;SSSA, 1998. p. 1559-1568.

FREELAND, R.S. Review of soil moisture sensing using soil electrical conductivity. Transaction of the ASAE, v. 32, n. 6, p. 2190-2194, 1989.

FRIDGEN, J.J.; KITCHEN, N.R.; SUDDUTH, K.A. Variability of soil and landscape attributes within sub-field management zones (compact disc). In: INTERNATIONAL CONFERENCE ON PRECISION AGRICUltURE, 5., Bloomington, 2000. Proceedings. Bloomington: ASA;CSSA;SSSA, 2000.

FRITZ, R.M.; MAIO, D.D.; SCHUMACHER, T.E.; CLAY, D.E.; CARLSON, C.G.; ELLSBURY, M.M.; DALSTED, K.J. Field comparison of two soil electrical conductivity measurment systems. In: INTERNATIONAL CONFERENCE ON PRECISION AGriCUlture, 4., St. Paul, 1998. Proceedings. St. Paul: ASA;CSSA;SSSA, 1998. p. 1211-1217.

FUKS, S.D. Novos modelos para mapas derivados de informações de solos. In: ASSAD, E.D.; SANO, E.E. Sistemas de informações geográficas: aplicações na agricultura. Brasília: EMBRAPA, 1998. Cap. 19, p. 373-410.

GIMENEZ, L.M.; MOLIN, J.P. Desenvolvimento de um algoritmo para redução de erros em mapas de rendimento obtidos em agricultura de precisão (compact disc). In: CONGRESSO E MOSTRA DE AGROINFORMÁtICA, 1., Ponta Grossa, 2000. Mostra de agroinformática. Ponta Grossa: s. ed.. 2000.

GOLDEN SOFTWARE. Surfer (Win 32) version 6.01: surface mapping system. Golden, 1995. GOMES, F.P. A estatística moderna na pesquisa agropecuária. Piracicaba: Associação Brasileira para Pesquisa da Potassa e do Fosfato, 1984. 160 p. 
GONÇALVES, A.C.A. Variabilidade espacial de propriedades físicas do solo para fins de manejo da irrigação. Piracicaba, 1997. 118 p. Tese (Doutorado) - Escola Superior de Agricultura “Luiz de Queiroz”, Universidade de São Paulo.

GONÇALVES, A.C.A; FOLEGATTI, M.V.; da. MATA, J.,D.,V. Análises exploratória e geoestatística da variabilidade de propriedades físicas de um argissolo vermelho. Acta Scientiarum, v. 23, n. 5, p. 1149-1157, 2001.

HALVORSON, A. D.; RHOADES, J. D. Field mapping soil conductivity to delineate dryland saline seeps with four electrode techniques. Soil Science Society of America Journal, v. 40, p. 571-575, 1976.

HALVORSON, A.D. RHOADES, J.D.; REULE, C.A. Soil salinity-Four-electrode conductivity relationships for soils of the Northern Great Plains. Soil Science Society of America Journal, v. 41, p. 966-971, 1977.

HAMLETT, J.M; HORTON, R.; CRESSIE, N.A.C. Resistant and exploratory techniques for use in the semivariogram analyses. Soil Science Society of America Journal, v. 50, p. 868-875, 1986.

HARSTOCK, N.J.; MUELLER, T.G.; THOMAS, G.W.; BARNHISEL, R.I.; WELLS, K.L. Soil electrical conductivity variability (compact disc). In: INTERNATIONAL CONFERENCE ON PRECISION AGRICUltURE, 5., Bloomington, 2000. Proceedings. Bloomington: ASA;CSSA;SSSA, 2000.

HENDRICKX, J.M.H; WIERENGA, P.J. Variability of soil water tension in a trickle irrigated chile pepper field. Irrigation Science, v. 11, p. 23-30, 1990.

HENDRICKX, J.M.H.; BAERENDS, B.; RAZA, Z.I.; SADIG, M.; CHAUDHRY, M.A. Soil salinity assesmente by electromagnetic induction of irrigated land. Soil Science Society of America Journal, v. 56, n. 6, p. 1933-1941, 1992.

HOSKINSON, R.L.; HESS, J.R.; ALESSI, R.S. Temporal changes in the spatial variability of soil nutrients. In: EUROPEAN CONFERENCE ON PRECISION AGRICULTURE, 2., Odense, 1999. Proceedings. Odense: s. ed., 1999. P. 61-70.

INMAN, D.J.; FREELAND, R.S.; AMMONS, J.T.; YODER, R. E. Soil investigations using Electromagnetic Induction and Ground-Penetrating Radar in Southwest Tennesse. Soil Science Society of America Journal, v. 66, p. 206-211, 2002.

ISAAKS, E.H; SRIVASTAVA, R.M. Applied geostatistics. New York: Oxford University Press, 1989. $561 \mathrm{p}$. 
JAYNES, D.B. Improved soil mapping using electromagnetic induction surveys. In: INTERNATIONAL CONFERENCE ON PRECISION AGRICULTURE, 3., Minneapolis, 1996. Proceedigs. Minneapolis: s. ed., 1996. p. 169-179.

JAYNES, D.B; COLVIN, T.S; AMBUEL, J. Yield mapping by electromagnetic induction. In: INTERNATIONAL CONFERENCE ON SITE-SPECIFIC MANAGEMENT FOR AGRICULTURAL SYSTEMS, 2., 1995. Proceedings. p. 383-394, 1995.

JOHANSEN, C.J.; CARTER, P.G.; MORRIS, D.K.; ERICKSON, B.; ROSS, K. Potential applications of remote sensing: site specific Management Guidelines 22 Net, Nov. 1999. 4 p. 1999. http://www.ppi-far.org. (18 dez. 2002).

JOHNSON, C.K.; DORAN, J.W.; DUKE, H.R.; WIENHOLD, B.J.; ESKRIDGE, K.M.; SHANAHAN, B.J. Field-scale electrical conductivity mapping for delineating soil condition. Soil Science Society of America Journal, v. 65, p. 1829-1837, 2001.

JOURNEL, A.G.; HUIJBREGTS, C.H. Mining geostatistics. New York: Academic Press, 1978.

KACHANOSKI, R.G.; GREGORICH, E.G.; VAN WESENBEECK, I.J. Estimating spatial variations of soil water content using non-contacting electromagnetic inductive methods. Canadian Journal of Soil Science, v. 68, p. 715-722, 1988.

KING, J.A; DAMPNEY, P.M.R.; LARK, M.; MAYR, T. R.; BRADLEY, R. I. Sensing soil spatial variability by electromagnetic induction (EMI): it's potencial in precision farming (compact disc). In: EUROPEAN CONFERENCE ON PRECISION AGRICULTURE, 3., Montpellier, 2001. Proceedings. Montpellier: Ecole Nationale Supériure Agronomique, 2001.

KIRKHAM, D.; TAYLOR, G. S. Some tests of a four-electrode probe for soil moisture measurement. Soil Science Society of America Proceedings, v. 14, p. 42-46. 1949.

KITCHEN, N.R.; SUDDUTH, K.A.; DRUMMOND, S.T. Mapping of sand deposition from 1993 midwest floods with electromagnetic induction measurments. Journal of Soil and Water Conservation, v. 51, n. 4, p. 336-340, 1996.

KITCHEN, N.R.; SUDDUTH, K.A.; FRIDGEN, J.J. Influence of claypan soil topsoil thickness and fertility factors on corn and soybean yield (compact disc). In: INTERNATIONAL CONFERENCE ON PRECISION AGRICUlTURE, 5., Bloomington, 2000. Proceedings. Bloomington: ASA;CSSA;SSSA, 2000. 
KRAVCHENKO, A.N.; BOLLERO, D.G.; BULLOCK, D.G.; OMONODE, R. Multivariate and geostatistical techniques for predicting soil drainage classes (compact disc). In: EUROPEAN CONFERENCE ON PRECISION AGRICULTURE, 3., Montpellier, 2001. Proceedings. Montpellier: Ecole Nationale Supériure Agronomique, 2001.

KRAVCHENCKO, A.; BULLOCK, D.G. Correlation of corn and soybean grain yield with topography and soil properties. Agronomy Journal, v. 92, n. 1, p. 75-83, 2000.

LARK, R.M.; BOLAM, H.C.; MAYR, T.; BRADLEY, R.I.; BURON, R.G.O.; DAMPNEY, P.M.R. Analysis of yield maps in support of field investigation. In: STAFFORD, J. Precision agriculture 99. Sheffield: Sheffield Academic Press, 1999. p. 151-162.

LESCH, S.M.; RHOADES, J.D.; LUND, L.J.; CORWIN, D.L. Mapping soil salinity using calibrated electromagnetic measurements. Soil Science Society of America Journal, v. 56, p. 540-548, 1992.

LI, C.B. Electric conductance. In: YU, T.R. Chemistry of variable charge soils. New York: Oxford University Press, 1997. p. 272-308.

LIBARDI, P.L.; MANFRON, P.A.; MORAES, S.O.; TUON, R.L. Variabilidade da umidade gravimétrica de um solo hidromórfico. Revista Brasileira de Ciência do Solo, v. 20, p. 1-12, 1996.

LUCHIARI JR., A.; SHANAHAN, J.; FRANCIS, D.; SCHLEMMER, M.; SCHEPERS, J; LIEBIG, M.; SCHEPERS A.; PAYTON, S. Strategies for establishing management zones for site specific nutrient management (compact disc). In: INTERNATIONAL CONFERENCE ON PRECISION AGRICUltURE, 5., Bloomington, 2000. Proceedings. Bloomington: ASA;CSSA;SSSA, 2000.

LÜCK, E.; EISENREICH, M. Eletrical conductivity mapping for precision agriculture (compact disc). In: EUROPEAN CONFERENCE ON PRECISION AGRICULTURE, 3., Montpellier, 2001. Proceedings. Montpellier: Ecole Nationale Supériure Agronomique, 2001.

LUND, E.D.; CHRISTY, C.D.; DRUMMOND, P.E. Practical applications of soil electrical conductivity mapping. In: EUROPEAN CONFERENCE ON PRECISION AGRICULTURE, 2., Odense: Elsevier, 1999. Proceedings. Odense: s. ed., p. 771-780, 1999. 
LUND, E.D.; CHRISTY, C.D.; DRUMMOND, P.E. Using yield and soil electrical conductivity (EC) maps to derive crop production perfomance information (compact disc). In: INTERNATIONAL CONFERENCE ON PRECISION AGRICULTURE, 5., Bloomington, 2000. Proceedings. Bloomington: ASA;CSSA;SSSA, 2000.

LUND, E.D.; COLIN, P.E.; CHRISTY, D.; DRUMMOND, P.E. Applying soil electrical conductivity technology to precision agriculture. In: INTERNATIONAL CONFERENCE ON PRECISION AgRICUltURE, 4., St. Paul, 1998. Proceedings. St. Paul: ASA;CSSA;SSSA, 1998. p. 1089-1100.

LUTTICKEN, R.E. Implementation of precision fertilizing concepts on practical farms in western Germany. In: INTERNATIONAL CONFERENCE ON PRECISION AGRICULTURE, 4., St. Paul, 1998. Proceedings. St. Paul: ASA;CSSA;SSSA, 1998. p. 859867.

MALLANTS, D.; MOHANTY, B.P.; JACQUES, D.; FEYEN, J. Spatial variability of hydraulic properties in a multi-layered soil profile. Soil Science, v. 161, n. 3, p. 167-181, 1996.

MANKIN, K.R; EWING, K.L; SCHROCK, M.D. Field measurment and mapping of soil salinity in saline seeps: annual international meeting, Minneapolis: ASAE, 1997. 12 p.

MANLY, B.F.J. Multivariate statistical methods: a primer. London: Chapman \& Hall, 1997. $215 \mathrm{p}$.

MARDIA, K.V.; KENT, J.T.; BIBBY, J.M. Multivariate analysis. London: Academic Press, 1989. $521 \mathrm{p}$.

MARTINHO, P.R.R. Amostragem e análise geoestatística das propriedades do solo em dois latossolos vermelhos sob plantio direto para a aplicação em agricultura de precisão. Campinas, 2001. 175 p. Dissertação (Mestrado) - Instituto Agronômico.

MCBRATNEY, A.B.; ODEH, I.O.A. Application of fuzzy sets in soil science: fuzzy logic, fuzzy measurements and fuzzy decisions. Geoderma, v. 77, p. 85-113, 1997.

MCBRATNEY, A.B.; WEBSTER, R. Choosing functions for semi-variograms of soil properties and fitting them to sampling estimates. Journal of Soil Science, v. 37, p. 617-639, 1986.

MCBRIDE, R.A.; GORDON, A.M.; SHRIVE, S.C. Estimating Forest Soil Quality from Terrain Measurments of Apparent Electrical Conductivity. Soil Science Society of America Journal, v.54, p. 255-260, 1990.

MCKENZIE, R.C.; CHOMISTEK, W; CLARK, N.F. Conversion of electromagnetic inductance readings to saturated paste extract values in soils for diferent temperature, texture and moisture conditions. Canadian Journal of Soil Science, v. 69, p. 25-32, 1989. 
MCKENZIE, R.C.; GEORGE, R.J.; WOODS, S.A.; CANNON, M.E.; BENNET, D.L. Use of the electromagnetic induction meter as a tool in managing salinisation. Hydrogeology Journal $_{2}$ v. 5, n. 1, p. 37-50, 1997.

MINASNY, B.; MCBRATNEY, A.B. FuzME version 2.1. Australian Centre for Precision Agriculture, The University of Sydney. 2002. http://www.usyd.edu.au/su/agri/acpa. (23 fev. 2002).

MINASNY, B.; MCBRATNEY, A.B.; WHELAN, B.M. Vesper version 1.5. Australian Centre for Precision Agriculture, The University of Sydney. 2002. http://www.usyd.edu.au/su/agri/acpa. (28 jan. 2002).

MOLIN, J.P. Agricultura de precisão: o gerenciamento da variabilidade. Piracicaba: O autor, 2001. 83 p.

MOLIN, J.P. Definição de unidades de manejo a partir de mapas de produtividade. Engenharia Agrícola, v. 22, n. 1, p. 83-92, 2002.

MOLIN, J.P.; GIMENEZ, L.M. Use of GPS without differential correction on yield mapping (compact disc). In: INTERNATIONAL CONFERENCE ON PRECISION AGRICULTURE, 6., Minneapolis, 2002. Proceedings. Minneapolis: ASA;CSSA;SSSA, 2002.

MORGAN, C.L.S.; NORMAN, J.M. WOLKOWSKI, R.P.; LOWERY, B; MORGAN, G.D.; SCHULER, R. Two approaches to mapping plant available water: EM-38 measurements and inverse yield modeling (compact disc). In: INTERNATIONAL CONFERENCE ON PRECISION AGRICUlTURE, 5., Bloomington, 2000. Proceedings. Bloomington: ASA;CSSA;SSSA, 2000.

MULLA, D.J.; SCHEPERS, J.S. Key processes and proporties for site-specific soil and crop management. IN: PIERCE, F.J.; SADLER, E.J. The state of site-specific mangement for agriculture. Madison: ASA;CSSA;SSSA, 1997. p. 1-18.

MUZILLI, O. Análise de solos: Interpretação e recomendação de calagem e adubação para o estado do Paraná. Londrina: Fundação Instituto Agronômico do Paraná, 1978. 49 p. (Circular, IAPAR., 9).

MYERS, D.B.; KITCHEN, N.R.; SUDDUTH, K.A.; MILES, R.J. Estimation of a soil productivity index on claypan soils using soil electrical conductivity (compact disc). In: INTERNATIONAL CONFERENCE ON PRECISION AGRICULTURE, 5., Bloomington, 2000. Proceedings. Bloomington: ASA;CSSA;SSSA, 2000. 
NADLER, A; FRENKEL, H. Determination of soil solution electrical conductivity from bulk soil electrical conductivity measurments by the four electrode method. Soil Science Society of America Journal, v.44, n.5, p. 1216-1221, 1980.

NEHMDAHL, H.; GREVE, M.H. Using soil electrical conductivity measurements for delineating management zones on highly variable soils in Denmark (compact disc). In: EUROPEAN CONFERENCE ON PRECISION AGRICULTURE, 3., Montpellier, 2001Proceedings. Montpellier: Ecole Nationale Supériure Agronomique, 2001.

NIELSEN, D.R.; ALEMI, M.H. Statistical opportunities for analyzing spatial and temporal heterogeneity of field soils. Plant and Soil, v. 115, p. 285-296, 1989.

ODEH, I.O.A.; MCBRATNEY, A.B.; CHITTLEBOROUGH, D.J. Soil pattern recognition with fuzzy-c-means: Application to classification and soil-landform interrelationships. Soil Science Society of America Journal, v. 56, p. 505-516, 1992.

OLIVER, M.A. Exploring soil spatial variation geostatistically. In: EUROPEAN CONFERENCE ON PRECISION AGRICULTURE, 2., Odense, 1999. Proceedings. Odense: s. ed., 1999. p. 19-34.

OLIVER, M. A.; WEBSTER, R. How can geoestatistics help you. Soil Use and Management, v. 7, n. 4, p. 206-217, 1991.

POZDNYAKOVA, L.; ZHANG, R. Estimating spatial variability of soil salinity using geoestatistical methods. In: INTERNATIONAL CONFERENCE ON PRECISION AGRICUlTURE, 4., St. Paul, 1998. Proceedings. St. Paul: ASA;CSSA;SSSA, 1998. p. 7989.

PRECISION agriculture in the $21^{\text {st }}$ century: geospatial and information technologies in crop management. Washington: National Academy Press, 1997. 149 p.

QUEIROZ, D. M.; GUTEMBERG, P. D.; MANTOVANI, E. C. Agricultura de precisão na produção de grãos. In: SIMPÓSIO INTERNACIONAL DE AGRICULTURA DE PRECISÃO, 1., Viçosa, 2000. Anais. Viçosa: s. ed., 2000. p. 1-42.

RAIJ, B. van. Fertilidade do solo e adubação. Piracicaba: Potafos, 1991. 343 p.

RAIJ, B. van; CANTARELLA, H.; QUAGGIO, J.A.; FURLANI, A.M.C. Recomendações de adubação e calagem para o estado de São Paulo. Campinas: Instituto Agronômico e Fundação IAC, 1996. 285 p. (IAC. Boletim Técnico, 100).

RAIJ, B. van; QUAGGIO, J.A.; CANTARELLA, H.; FERREIRA, M.E.; LOPES, A.S. BATAGLIA, O.C. Análise química do solo para fins de fertilidade. Campinas: Fundação Cargill, 1987. 170p. 
RHOADES, J.D. Inexpensive four-electrode probe for monitoring soil salinity. Soil Science Society of America Journal, v. 43, p. 817-818, 1979.

RHOADES, J.D. Predicting bulk soil electrical conductivity versus saturation paste extract electrical conductivity from soil properties. Soil Science Society of America Journal, v. 45, p. 42-44, 1981.

RHOADES, J.D. Electrical conductivity methods for measuring and mapping soil salinity. Advances in Agronomy, v. 49, p. 232-242, 1993.

RHOADES, J.D.; CORWIN, D.L. Determining soil electrical conductivity-depth relations using and inductive electromagnetic soil conductivity meter. Soil Science Society of America Journal, v. 45, p. 255-260, 1981.

RHOADES, J.D.; CORWIN, D.L. Measurment of inverted electrical conductivity profiles using electromagnetic induction. Soil Science Society of America Journal, v. 44, p.288-291, 1984.

RHOADES, J.D.; CORWIN, D.L. Soil electrical conductivity: effects of soil properties and application to soil salinity appraisal. Commun. Soil Sci. Plant. Anal., v. 21, p.837-860, 1990 .

RHOADES, J.D.; INGVALSON, R.D. Determining salinity in field soils with soil resistance measurements. Soil Science Society of America Journal, v. 35, p. 54-60, 1971.

RHOADES, J.D.; VAN SCHILGAARDE, J. An electrical conductivity probe for determining soil salinity. Soil Science Society America Journal, v.40, n. 5, p. 647-651, 1976.

RHOADES, J.D.; MANTEGHI, N.A.; SHOUSE, P.J.; ALVES, W.J. Soil electrical conductivity and soil salinity: New formulations and calibrations. Soil Science Society of America Journal, v. 53, p. 433-439, 1989a.

RHOADES, J.D.; RAATS, P.A.C.; PRATHER, R.J. Effects of liquid-phase electrical conductivity, water content and surface conductivity on bulk soil electrical conductivity. Soil Science Society of America Journal, v. 40, p. 651-655, 1976.

RHOADES, J.D.; WAGGONER, B.L.; SHOUSE, P.J.; ALVES, W.J. Determining soil salinity from soil and soil-paste electrical conductivities: Sensitivity analysis of models. Soil Science Society of America Journal, v. 53, p. 1368-1374, 1989b.

ROBERT, P. C. Precision agriculture: research needs and status in the USA. In: EUROPEAN CONFERENCE ON PRECISION AGRICULTURE, 2., Odense, 1999. Proceedings. Odense: s. ed., 1999. P. 19-33. 
SÁ, J.C.M. Fósforo: frações, formas de ocorrência e distribuição no perfil do solo, In: SÁ, J.C.M. (Coord.). Curso sobre manejo do solo no sistema plantio direto. Castro: Fundação ABC, 1995. P. 228-241.

SA, M.F.M. Abordagem quantitativa na predição espacial de atributos do solo e geração de zonas de manejo agrícola. Piracicaba, 2001. 117 p. Tese (Doutorado) - Escola Superior de Agricultura “Luiz de Queiroz”, Universidade de São Paulo.

SCHAINBERG, I.; RHOADES, J.D.; PRATHER, R.J. Effect of exchangeable sodium percentage, cation exchange capacity, and soil solution concentration on soil electrical condutivity. Soil Science Society of America Journal, v. 44, p. 469-473, 1980.

SHEA, P.F.; LUTHIN, J.N. An investigation of the use of the four-electrode probe for measuring soil salinity in situ. Soil Science, v. 92, p. 331-339, 1961.

SHEETS, K.R; HENDRICKX, J.M.H. Noninvasive soil water content measurment using electromagnetic induction. Water Resources Research, v. 31, n. 10, p. 2401-2409, 1995.

SHEETS, K.R; TAYLOR, J.P.; HENDRICKX, J.M.H. Rapid salinity mapping by electromagnetic induction for determining riparian restoration potencial. Restoration Ecology, v. 2, n. 4, p. 242-246, 1994.

STATSOFT. Statistica. Tulsa, 1999.

TRAINTAFILIS, J.; ODEH, I.O.A.; MCBRATNEY, A.B. Five geostatistical models to predict soil salinity from electromagnetic induction data across irrigated corn. Soil Science Society of America Journal, v. 65, p. 869-878, 2001.

TRANGMAR, B.B; YOST, R.S; UEHARA, G. Application of geostatistics to spatial studies of soil properties. Advances In Agronomy, v. 38, p. 45-94, 1985.

TUKEY, J. W. Exploratory data analysis. Reading: Addison-Wesley, 1977. 1v.

VERIS TECHNOLOGIES. Frequently asked questions about soil electrical conductivity Net, Maio. 2001. 2 p. 2001. http://www.veristech.com. (18 set. 2002).

VIEIRA, S.R. Uso da geoestatística em estudos de variabilidade espacial. In: Curso de Atualização em Conservação do Solo. Campinas: IAC, 1995. 61p.

VIEIRA, S.R. Geoestatística aplicada a agricultura de precisão In: BORÉM, A.; GIÚDICE, M.P.D.; QUEIROZ, D.M.; MANTOVANI, E.C.; FERREIRA, L.R.; VALLE, F.X.R.; GOMIDE, R.L. (Org.). Agricultura de precisão. Viçosa: s. ed., 2000. p. 93-108. 
VIEIRA, S.R.; MOLIN, J.P. Spatial variability of soil fertility for precision agriculture (compact disc). In: EUROPEAN CONFERENCE ON PRECISION AGRICULTURE, 3., Montpellier, 2001. Proceedings. Montpellier: Ecole Nationale Supériure Agronomique, 2001.

VIEIRA, S.R; NIELSEN, D.R; BIGGAR, J.W. Spatial variability of field-measured infiltration rate. Soil Science Society of America Journal, v. 45, p. 1040-1048, 1981.

WEBSTER, R; BURGESS, T.M. Spatial variation in soil and the role of kriging. Agricultural and Water Management, v. 6, p. 111-122, 1983.

WEBSTER, R.; MCBRATNEY, A.B. On the akaike information criterion for choosing models for variograms of soil properties. Journal of Soil Science, v. 40, p. 493-496, 1989.

WEBSTER, R; OLIVER, M.A. Statistical methods in soil and land resource survey. New York: Oxford University Press, 1990. 316p.

WILDIN, L.P.; DREES, L.R. Pedogenesis and soil taxonomy: concepts and interactions. Amsterdam: Elsevier, 1983. p. 83-116.

WILLIAMS, B.G; HOEY, D. The use of electromagnetic induction to detect the spatial variability of the salt and clay contents of soils. Australian Journal of Soil Research, v. 25, n.1, p. 21-27, 1987.

YOST, R.S.; UEHARA, G.; FOX, R.L. Geostatistical analysis of soil chemical properties of large land areas. II. Kriging. Soil Science Society of America Journal, v. 46, p. 10331037, 1982.

ZADEH, L. A. Fuzzy sets Information Control, v. 8, p. 338-353, 1965. 